\title{
THE ANALYSIS OF REFLECTION TYPE COILS FOR EDDY-CURRENT TESTING
}
C. V. Dodd
C. C. Cheng
W. A. Simpson
D. A. Deeds
J. H. Smith

\section{OAK RIDGE NATIONAL LABORATORY}




\section{DISCLAIMER}

This report was prepared as an account of work sponsored by an agency of the United States Government. Neither the United States Government nor any agency Thereof, nor any of their employees, makes any warranty, express or implied, or assumes any legal liability or responsibility for the accuracy, completeness, or usefulness of any information, apparatus, product, or process disclosed, or represents that its use would not infringe privately owned rights. Reference herein to any specific commercial product, process, or service by trade name, trademark, manufacturer, or otherwise does not necessarily constitute or imply its endorsement, recommendation, or favoring by the United States Government or any agency thereof. The views and opinions of authors expressed herein do not necessarily state or reflect those of the United States Government or any agency thereof. 


\section{DISCLAIMER}

Portions of this document may be illegible in electronic image products. Images are produced from the best available original document. 
This report was prepared as an account of work sponsored by the United States Government. Neither the United States nor the United States Atomic Energy Commission, nor any of their employees, nor any of their contractors, subcontractors, or their employees, makes any warranty, express or implied, or assumes any legal liability or responsibility for the accuracy, completeness or usefulness of any information, apparatus, product or process disclosed, or represents that its use would not infringe privately owned rights. 
Contract No. W-7405-eng-26

METALS AND CERAMICS DIVISION

THE ANALYSIS OF REFLECTION TYPE COILS FOR EDDY-CURRENT TESTING

C. V. Dodd, C. C. Cheng, W. A. Simpson, D. A. Deeds, and J. H. Smith

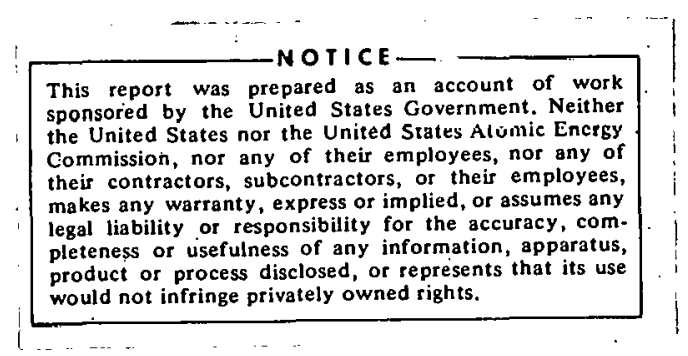

APRIL 1973

OAK RIDGE NATIONAL LABORATORY

Oak Ri.dge, Tennessee 37830

operated by

UNION CARBIDE CORPORATION

for the

U.S. ATOMIC ENERGY COMMISSION

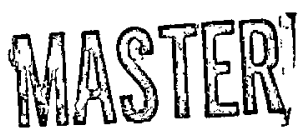




\section{THIS PAGE}

\section{WAS INTENTIONALLY \\ LEFT BLANK}




\begin{tabular}{|c|c|c|c|c|c|c|c|c|c|c|c|c|}
\hline bstract $\cdot \cdot \cdot \cdot \cdot \cdot \cdot \cdot \cdot \cdot \cdot \cdot$ & . & • & & & & - & & • & • & • & • & \\
\hline ntroduction $\cdot \cdot \cdot \cdot \cdot \cdot \cdot \cdot \cdot \cdot \cdot \cdot$ & - & $\cdot \cdot$ & & - & & - $\cdot$ & & - & . & - & - & \\
\hline heoretical Analysis. & . & - . & & & & - $\cdot$ & & • & . & • & • & \\
\hline onsiderations for Test Design . . . & - & - $\cdot$ & & - & - & - . & & - & • & •. & . & I \\
\hline Maximize Sensitivity & - & - $\cdot$ & & & - & - $\cdot$ & & - & - & $\cdot$ & - & \\
\hline Minimize the Undesired Effects & & - & & & . & - $\cdot$ & & . & • & • & - & \\
\hline Lift-off Variations . . & & - . & & & • & - $\cdot$ & & • & - & - & - & 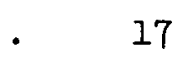 \\
\hline Coil Geometry . . . & - & - $\cdot$ & & & - & - $\cdot$ & & - & • & • & - & • \\
\hline Lift-Off Range $\cdot \cdot$ & & - $\cdot$ & & & . & - $\cdot$ & & - & • & - & . & 18 \\
\hline Range of Measurements & & - . & & & • & - $\cdot$ & & • & - & • & • & - \\
\hline Attenuator Parameters & & and & & & & of & & urn & & - & - & - \\
\hline flection Coil Above a Single Condu & & ting & & & & - & & - & - & • & - & \\
\hline Sample Calculation of RFCON . . & & - $\cdot$ & • & & - & - $\cdot$ & & - & - & • & . & • \\
\hline RFCON, FORTRAN Version $\cdot \cdot \cdot$ & & • & • & & & - & & . & • & & • & \\
\hline Sample Calculation of RFCON.F4 & & - & • & & • & - $\cdot$ & & - & - & • & • & \\
\hline eflection Coil Above a Clad Conduct & & . & • & & & . & & - & • & . & • & \\
\hline Sample Calculation of RFCLAD & & - & & & . & $\cdot$ & & - & - & - & - & \\
\hline RFCLAD, FORTRAN Version . . • & & • & • & & & - $\cdot$ & & - & - & & - & \\
\hline Sample Calculation of RFCLAD.F4 & & • & & & & - & & . & & & • & \\
\hline ection Coil Above Multiple Condu & & ors & & & & & & ity & & & & \\
\hline Variation . . . . . . . . . & & 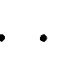 & & & & - & & . & & & • & \\
\hline Sanple Calculation of MULTIC & & - & & & & - & & - & • & - & - & \\
\hline MULTIC, FORTRAN Version $\cdot \cdot \cdot \cdot$ & & • & & & - & - · & & $\cdot$ & • & & - & • \\
\hline Sample Calculation of MULTIC.F4 & & 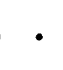 & & & & : & & • & - & & - & 77 \\
\hline eflection Coil Above Multiple Condu & & & & & & knes & & & & & & \\
\hline Variation $\cdot \cdot \cdot \cdot \cdot \cdot \cdot \cdot \cdot \cdot \cdot \cdot \cdot$ & & • & & & & - & & - & - & & - & 127 \\
\hline Sample Calculation of MULTIT & & - & & & - & - & & $\cdot$ & - & & - & נטلו \\
\hline MULTIT, FORTRAN Version . • • • & & - & & . & . & - & & $\cdot$ & · & & - & 15 \\
\hline Sample Calculation of MULTIT.F4 & & & & & & & & & & & 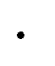 & \\
\hline
\end{tabular}




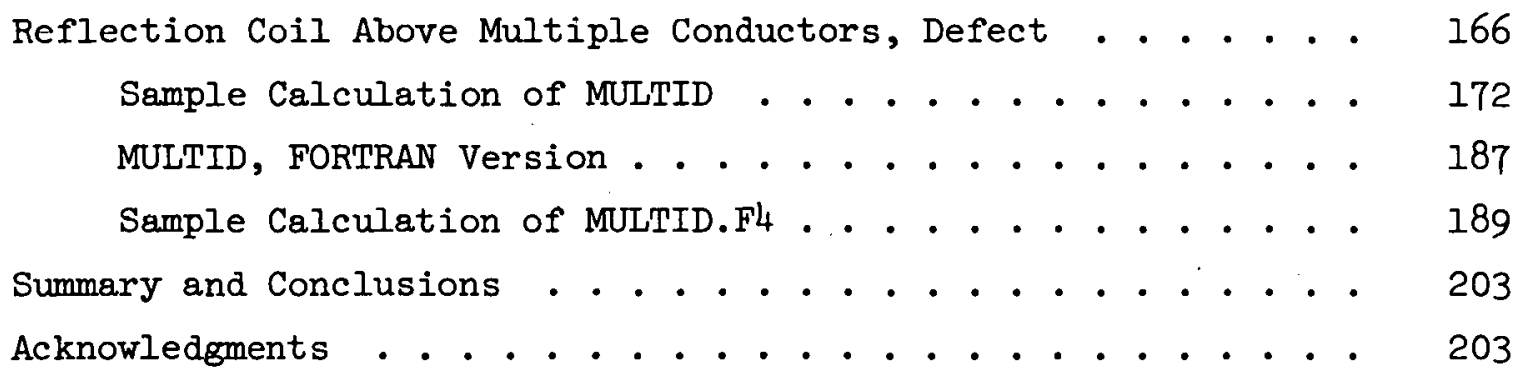


THE ANALYSIS OF REFLECTION TYPE COILS FOR EDDY-CURRENT TESTING

C. V. Dodd, C. C. Cheng, ${ }^{1}$ W. A. Simpson, D. A. Deeds, ${ }^{2}$ and J. H. Smith

\author{
ABSTRACT
}

This report contains the theoretical analysis and computer programs for reflection type coils above multiple layered conductors. The performance of the coils when connected to phase-sensitive eddy-current instrumentation can be evaluated. The programs are written in both BAS.TC and FORTRAN for timesharing on the PDP-10 to calculate the effects of defects or variations in either conductivity or thickness for multiple conductors, all in the presence of lift-off variations. In addition, program options are included that allow the study of the design of the coil, the effects of small variations or drifts of all the coil, conductor and instrument parameters, and the effects of the instrument output and input impedance on the problem. Examples are given of the use of the programs for the design of eddy-current tests with reflection type coils. Application of these techniques allow optimum design of eddycurrent tests using probe coils without the necessity of expensive trial and error experiments and fabrication. These programs can be applied to the solution of many inspection problems involving reactor fuels and materials.

\title{
INTRODUCTION
}

Eddy-current tests have been successfully used for many years in industry to measure the thickness of conductors, to measure the electrical conductivity or magnetic permeability of metals, to detect defects in metals and to measure the distance between conducting components. Early eddy-current instruments used simple bridge circuits operated in a balanced mode and measured the magnitude of the signal as the balance changed. Later instruments used bridges with a test coil and a reference coil operated in an unbalanced mode lo measure the effect of one variable and eliminate the effects of all the other variables. These instruments may measure either magnitude or phase of the bridge unbalance

\footnotetext{
${ }^{1}$ Consultant from the University of Tennessee.

${ }^{2}$ summer student from the University of Tennessee.
} 
voltage. ${ }^{3},{ }^{4}$ Still later instruments use briages with transformer coupling from a primary into a secondary which is connected to the test and reference coils. Instruments developed at Oak Ridge National Laboratory ${ }^{5}, 6$ utilize a reflection type probe, as shown in Fig. 1. This probe consists of a large ariver coil to generate the electromagnetic field and two pickup coils, connected in a differential arrangement to measure differences in this field. In air, the signals developed across the pickup coils cancel due to the symmetry of the field, but when a conductor is present lie field io unbalanced and a signal results. The total fleld in the prosence of a metil can be considered as the sum of the original field of the coll $1 \mathrm{n}$ uls, plus a rofleatud field. The original field of the coil in air is still symmetrical with respect to the pickups and cancels, but the reflected field is much larger at the front pickup (nearest the metal) than at the rear pickup coil and does not cancel. Thus, the signal produced by the pickup coils is approximately equal to the reflected field. 'l'his arrangement is approximately equivalent to a bridge circuit with a test and reference coil having transformer coupling directly from the primary (driver) coil to the test and reference (front and rear piclup) soils:

The magnitude of the' reflected signal is a function of lift-off (coil to conductor spacing), electrical conductivity, magnetic permeability, the thickness of the conductor and the presence of discontinuities in the conductor. The phase of the reflected signal is also a function of the same parameters but does not vary nearly as much with Iift-off as the magnitude.

Thic report is devoted to the analysis, computer calculation and design of reflection coils and their associated circuitry. The programs

${ }^{3}$ R. Hochschild, "Bleclumagnet1c Melhuds of Trating Metals," Progress in Nondestructive Testing, Vol. I, The Macmillan Company, New York, 1959.

${ }^{4}$ R. C. McMaster, Nondestructive Testing Handbook, Vol. II, The Ronald Fress Cu., 1959.

${ }^{5}$ C. V. Dodd, "Applications of a Phase-Sensitive Eddy-Current Instrument," Mater. Eval. 22(6): 260-63 (June 1964).

${ }^{6}$ C. V. Dodd, "A Portable Phase-Sensitive Eddy-Current Instrument," Mater. Eval. 26(3): 33-36 (March 1968). 


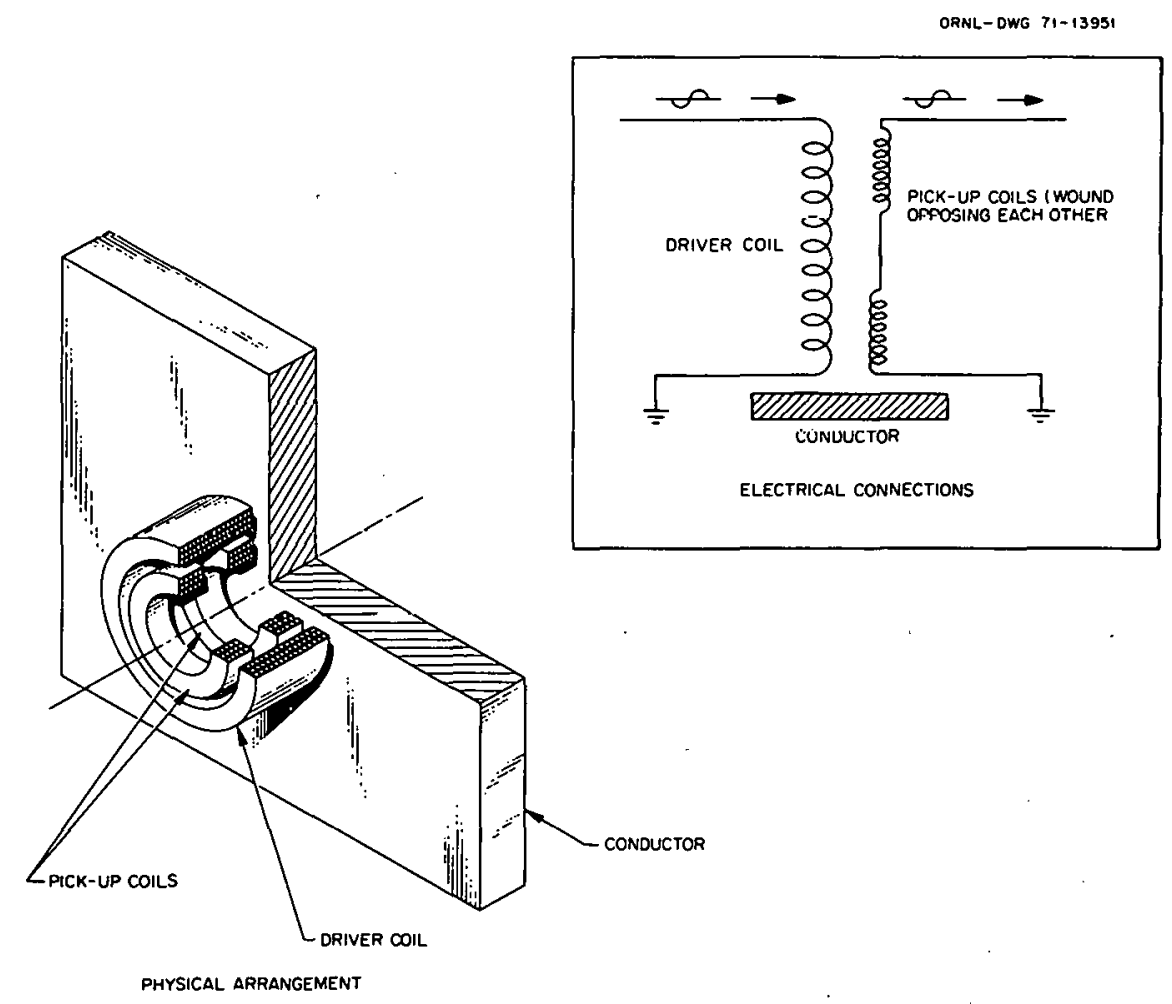

Fig. 1. A Reflection-Type Probe in the Presence of a Conductor.

will calculate the actual phase and magnitude of the reflected signals when the probes are connected to phase-sensitive eddy-current instrumentation developed at Oak Ridge National Laboratory. Each program is self-contained and will allow the complete design of an entire system for conductivity measurements, thickness measurements etc., including the coil, attenuation, and operating parameters.

\section{THEORETICAL ANALYSIS}

The equivalent circuit of a reflection type probe is shown in Fig. 2. We cun write the tollowing set of equations for the arops in voltage around each of the lonps in the circuit: 


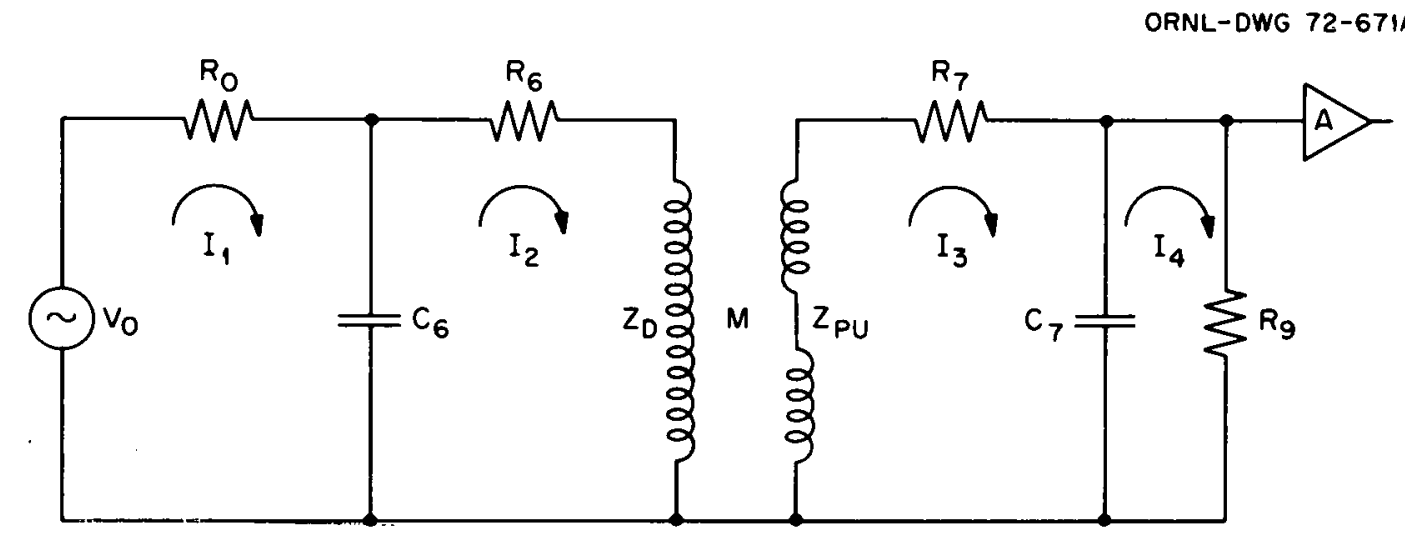

VO DRIVING VOLTAGE

RO SERIES RESISTANCE IN THE DRIVING CIRCUIT

$C_{6}$ SHUNT CARACITANCE OF THE DRIVING CIRCUIT

$R_{6}$ D.C. RESISTANCE OF THE DRIVER COIL

$Z_{D}$ IMPEDANCE OF THE DRIVER COIL

$M$ MUTUAL IMPEDANCE BETWEEN THE ORIVER AND PICK-UP COILS

$Z_{\text {PU IMPEDANCE OF THE PICK-UP COILS }}$

$R_{7}$ D.C. RESISTANCE OF THE PICK-UP COILS

$C_{7}^{7}$ SHUNT CAPACITANCE OF THE PICK-UP CIRCUIT

$R_{9}$ AMPLIFIER INPUT. IMPEDANCE

I LOOP CURRENT

Fig. 2. Simplified Circuit Diagram for an Eddy-Current Reflection Type Probe.

$I_{1}\left(R_{0}-\frac{j}{\omega C_{6}}\right)-I_{2}\left(-\frac{j}{\omega C_{6}}\right)$

$=\mathrm{v}_{0}$

$-I_{1}\left(-\frac{j}{\omega C_{6}}\right)+I_{2}\left(-\frac{j}{\omega C_{6}}+R_{6}+Z_{D}\right)-I_{3}(j \omega M)$

$=0$

$$
\begin{aligned}
-I_{2}(j \omega M) & +I_{3}\left(I_{P U}+\bar{K}_{7}-\frac{j}{\omega C_{7}}\right)-I_{4}\left(-\frac{j}{\omega C_{7}}\right)=0 \\
& -I_{3}\left(-\frac{j}{\omega C_{7}}\right)+I_{4}\left(-\frac{j}{\omega C_{7}}+R_{9}\right)=0
\end{aligned}
$$

where $j$ is the square root of -1 and $\omega$ is the angular operating frequency.

We can use determinants and solve for the current in the final loop, $I_{4}$, produced by an applied voltage $V_{0}$ : 


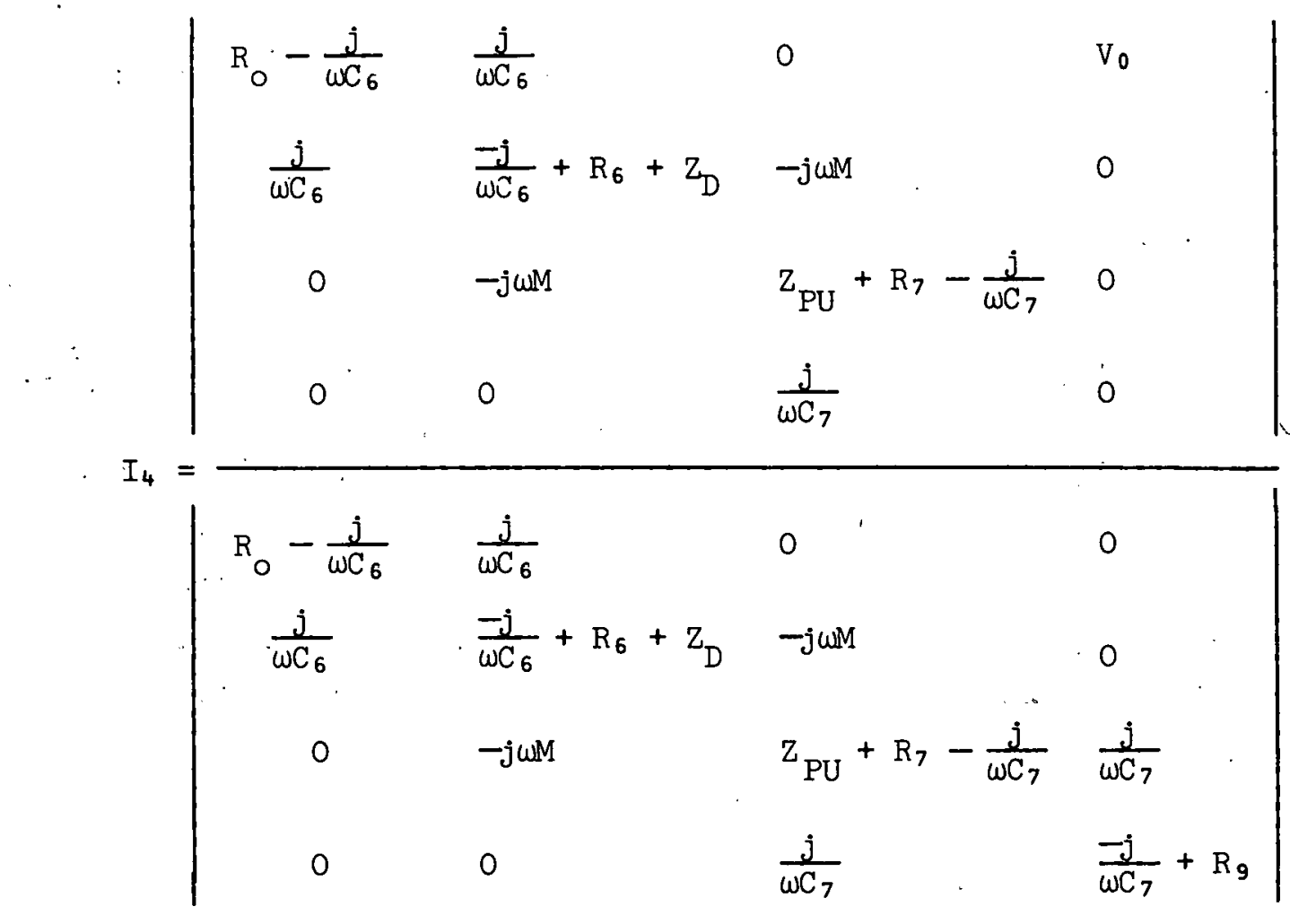

We shall solve for the current, $I_{4}$, multiply it by the resistance $R_{9}$ to determine the input voltage to the amplifier and then multiply by the amplifier gain $G$ to determine the voltage output.

$$
\begin{aligned}
& V_{\text {out }}=-j \frac{M V_{0} R_{9} G}{\omega C_{6} C_{7}} \div\left\{\left(R_{0}-\frac{j}{\omega C_{6}}\right) \omega^{2} M^{2}\left(R_{9}-\frac{j}{\omega C_{7}}\right)\right. \\
& \left.+\left[\left(R_{0}-\frac{j}{\omega C_{6}}\right)\left(Z_{D}+R_{6}-\frac{j}{\omega C_{6}}\right)+\frac{1}{\omega^{2} C_{6}^{2}}\right]\left[\left(R_{9}-\frac{j}{\omega C_{7}}\right)\left(Z_{P U}+R_{7}-\frac{j}{\omega C_{7}}\right)+\frac{1}{\omega^{2} C_{7}}\right]\right\}
\end{aligned}
$$

From Eq. (6) we can calculate the phase shift between the voltage driving the eddy-current probe and the amplified voltage received at the phase shift detector. All the terms in Eq. (6) can easily be determined except for the mutual impedance between the driver and pickup coils, $M$, the ariver coil impedance, $Z_{D}$, and the pickup coil impedance, $\mathrm{Z}_{\mathrm{PU}}$ 
We can derive the following expression ${ }^{7}$ for the voltage induced in a pickup coil by a current $I_{1}$ flowing in a driver coil, as shown in Fig. 3.

$$
\begin{aligned}
& V=j \omega I_{1} \pi n n^{-} \mu_{0} \int_{0}^{\infty} \frac{1}{\alpha^{6}} J\left(r_{2}, r_{1}\right) J\left(r_{4}, r_{3}\right)\left\{2 \alpha\left(l_{2}^{\prime}-l_{1}^{\prime}\right)+\right. \\
& \left.\left[1-e^{-\alpha\left(l_{2}^{\prime}-l_{1}^{\prime}\right)}\right] \cdot\left[\gamma\left(e^{-\alpha\left(l_{1}+l_{1}^{\prime}\right)}-e^{-\alpha\left(l_{2}+l_{1}^{\prime}\right)}\right)-e^{-\alpha\left(l_{2}-l_{2}^{\prime}\right)}-e^{-\alpha\left(l_{1}^{\prime}-l_{1}\right)}\right]\right\} d \alpha
\end{aligned}
$$

The driver coil has in lurns per unit eross-sectional area; the pickup

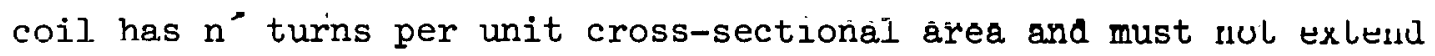
beyond the driver in the axial direction ( $\ell_{2}^{\prime}$ must not be greater than $\ell_{2}$ and $\ell_{1}$ must not be less than $\ell_{1}$ ). The $\gamma$ factor is a furction of the metal alone and is more fully explained in ref. 7 . The function $J\left(r_{2}, r_{1}\right)$ is

$$
\int_{\alpha r_{1}}^{\alpha r_{2}} x J_{1}(x) d x \text {, }
$$

where $J_{1}(x)$ is a first order Bessel function.

We shall now add a second pickup coil to the probe in Fig. 3, but with the turns reversed, as shown in Fig. 4. The equation for the second pickup will be the same as Eq. (7), except the sign will be reversed. This is equivalent to integrating the vector potential in the positive $\theta$ direction for one coil and the negative $\theta$ direction for the other coil. We shail take the directlun of the turns in the front pickup coil (nearest the metal) to be the same as the driver, and the turns of the rear pickup coil to be in a direction opposite the driver. This reversal of turns in the rear pickup will give a negative sign when the integration around the coil is performed. We will then have for the total mutual coupling between the driver and both pickups

${ }^{7}$ C. C. Cheng, C. V. Dodd, and W. E. Deeds, "General Analysis of Probe Coils Near Stratified Conductors," Int. J. Nondestruct. Test. 3: $109-30(1971)$. 
ORNL-DWG 72-10907

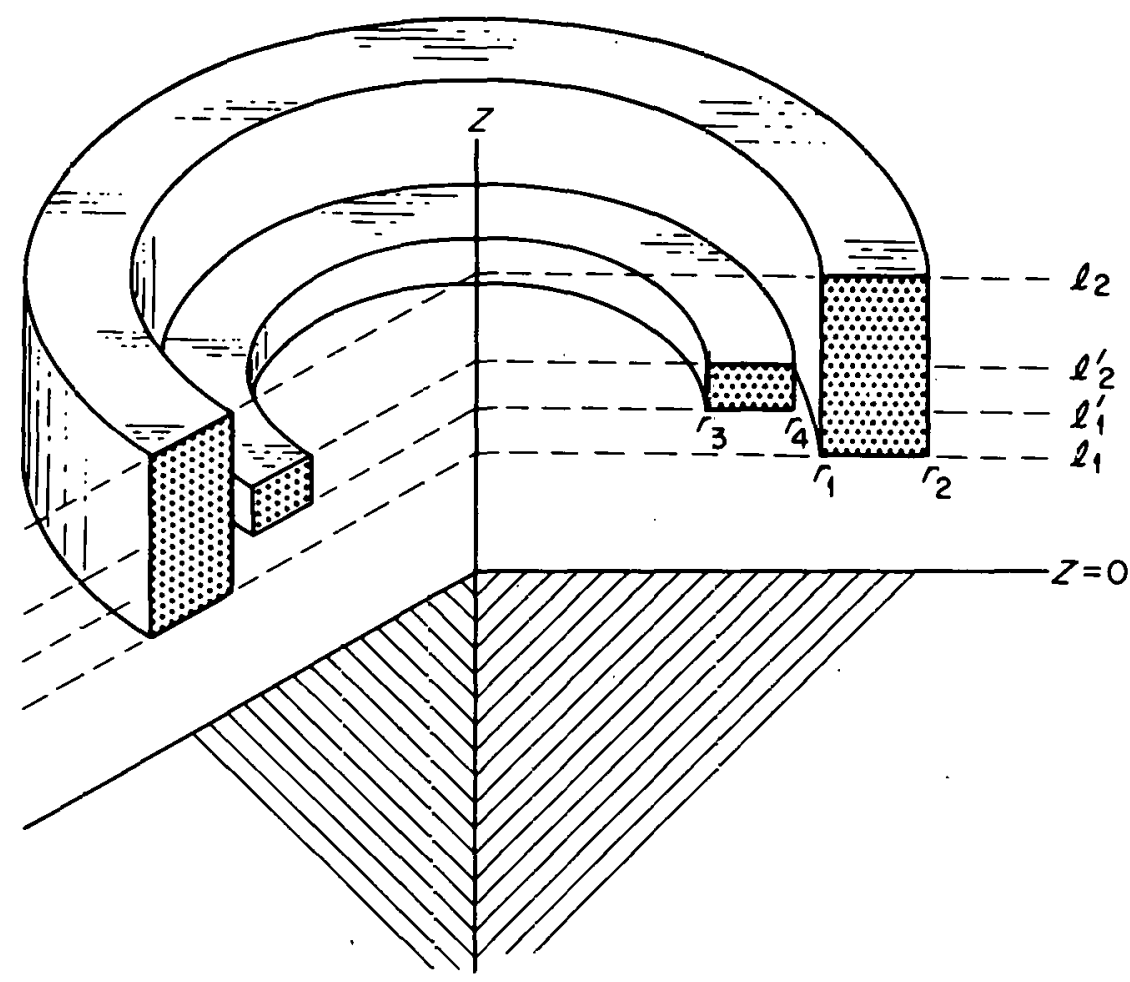

Fig. 3. Driver Coil Encircling a Pickup Coil.

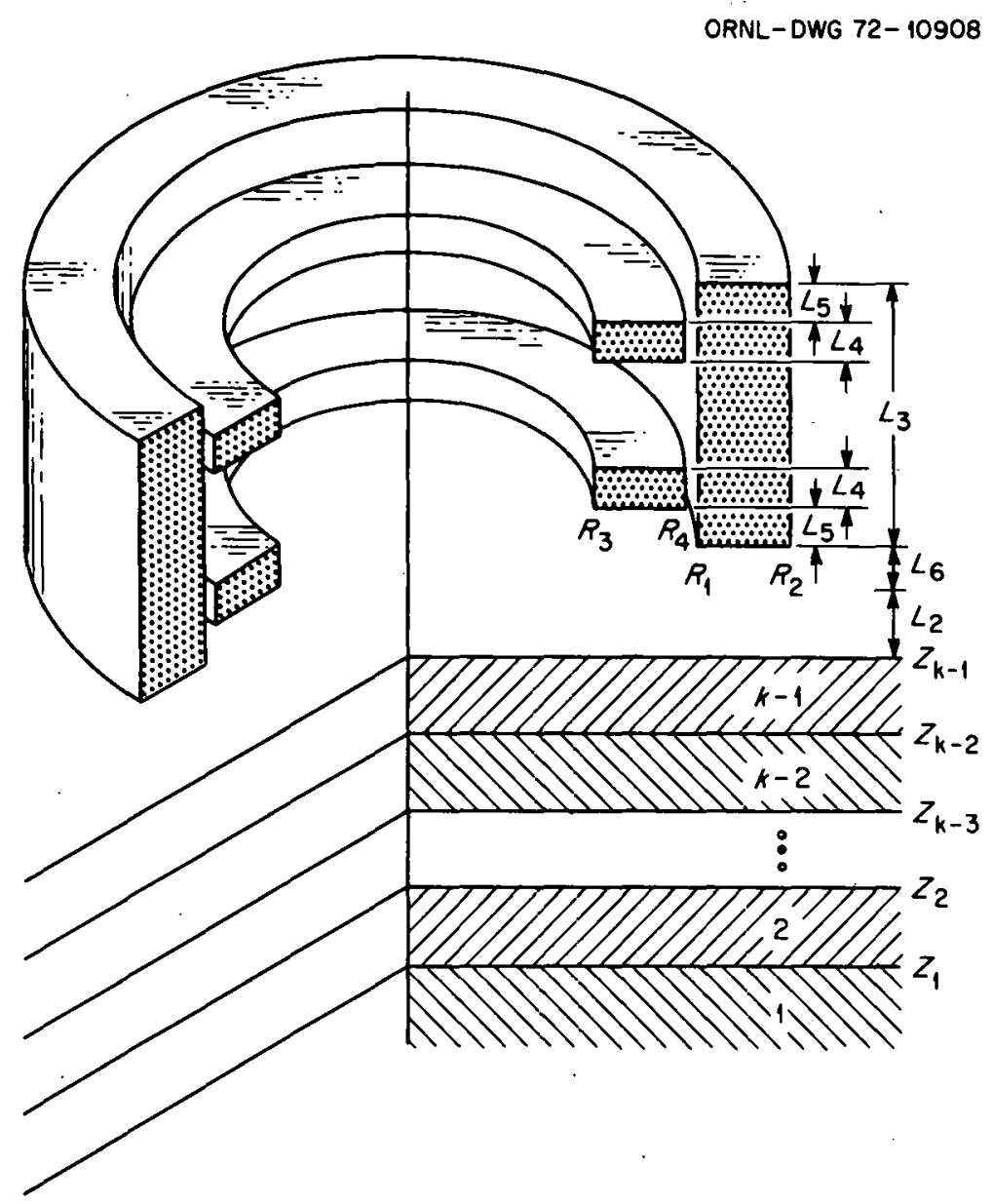

Fig. 4. Reflection Probe Above Multiple Conductors. 


$$
M=\frac{I}{j \omega I}\{V(\text { driver, front pickup })+V(\text { driver, réar pickup })\}
$$

where $\mathrm{V}$ is given by substituting the proper dimensions in Fig. 4 into Eq. (7), with a negative sign for the rear pickup. The results are

$$
\begin{gathered}
M=\frac{\pi N_{3} N_{4} \mu_{0} R_{5}}{L_{3}\left(R_{2}-R_{1}\right) L_{4}\left(R_{4}-R_{3}\right)} \int_{0}^{\infty} \frac{1}{\alpha^{6}} J\left(R_{2}, R_{1}\right) J\left(R_{4}, R_{3}\right) e^{-\alpha L_{5}} e^{-2 \alpha L_{2}} e^{-2 \alpha L_{6}} \\
\left(1-e^{-\alpha L_{4}}\right)\left[1-e^{-\alpha I_{3}}\right)\left(1-e^{-\alpha\left(L_{3}-L_{4}-2 L_{5}\right)}\right) \gamma d \alpha
\end{gathered}
$$

where

$\mathrm{L}_{6}=$ the minimum amount of lift-off of the driver coil,

$\mathrm{L}_{2}=$ the increase in lift-off,

$\mathrm{L}_{3}=$ the length of the driver coll,

$\mathrm{L}_{4}=$ the length of each pickup coil,

$\mathrm{L}_{5}=$ the distance each pickup is recessed from each end of the הrivnr noid,

$\mathrm{N}_{3}=$ the number of turns on the driver coil,

$N_{4_{4}}=$ the number of turns on each pickup coil,

$R_{1}=$ the driver coil inner radius,

$R_{2}=$ the driver coil outer radius,

$\mathrm{R}_{3}=$ the pickup coil inner radius,

$\mathrm{R}_{4}=$ the pickup coil outer radius, and

$R_{5}=$ the mean radius of the driver coil.

All dimensions have been normalized in Eq. (8) by dividing by the mean radius of the driver coil, and all the $\alpha$ 's have been multiplied by the same mean radius.

The impedance of the driver coil, $z_{D}$, can be calculated from Eq. (7) by making both coils the same and dividing by $I_{1}$. The results are 


$$
\begin{gathered}
\dot{z}_{D}=\frac{j \omega \pi \mu_{0} N_{3}{ }^{2} R_{5}}{\left(R_{2}-R_{1}\right)^{2} L_{3}^{2}} \int_{0}^{\infty} \frac{1}{\alpha^{5}} j^{2}\left(R_{2}, R_{1}\right)\left\{2\left(\alpha L_{3}+e^{-\alpha L_{3}}-I\right)\right. \\
\left.+\left(1-e^{-\alpha L_{3}}\right)^{2} e^{-2 \alpha L_{2}} e^{-2 \alpha L_{6}} \gamma\right\} d \alpha .
\end{gathered}
$$

We shall now calculate the total coil impedance of the two pickup coils. The total vector potential produced by a current flowing in the pickup coils is

$$
\overrightarrow{\mathrm{A}}_{\mathrm{PU}}=\overrightarrow{\mathrm{A}}_{\mathrm{PU}_{1}}-\overrightarrow{\mathrm{A}}_{\mathrm{PU}_{2}}
$$

We have made the vector potential from the front pickup coil $\left(\mathrm{PU}_{1}\right)$ in Fig. 4 positive and therefore the second pickup $\left(\mathrm{PU}_{2}\right)$ negative due to its current flowing in the opposite direction. If we open the driver circuit (make $R_{0}$ infinite and $V_{0}$ and $C_{6}$ zero), we will have no current flow in the driver coil and no contribution to the vector potential from the driver coil. In the actual clrcuit, the entire interaction between the driver and pickup coils is contained in the mutual impedance term.

The total self-induced voltage in the pickups is

$$
\begin{aligned}
\mathrm{V}_{\mathrm{PU}}=j \omega \phi \overrightarrow{\mathrm{A}}_{\mathrm{PU}} \cdot \mathrm{d} \vec{l}_{\mathrm{PU}} & =j \omega \oint\left\{\overrightarrow{\mathrm{A}}_{\mathrm{PU}_{1}} \cdot \mathrm{d}_{1}-\overrightarrow{\mathrm{A}}_{\mathrm{PU}_{2}} \cdot \mathrm{d} \vec{l}_{1}\right. \\
& \left.+\overrightarrow{\mathrm{A}}_{\mathrm{PU}_{1}} \cdot \mathrm{d} \vec{l}_{2}-\vec{A}_{\mathrm{PU}_{2}} \cdot \overrightarrow{\mathrm{d}}_{2}\right\} .
\end{aligned}
$$

However $\vec{l}_{2}$ is in the opposite direction from our normal direction of integration. Performing the dot product and integrating in the $+\theta$ direction gives:

$$
\mathrm{v}_{\mathrm{PU}}=j \omega \oint\left\{\mathrm{A}_{\mathrm{PU}_{1}} \mathrm{~d} l_{1}+\mathrm{A}_{\mathrm{PU}_{2}} \mathrm{~d} l_{2}-\mathrm{A}_{\mathrm{PU}_{2}} \mathrm{~d} l_{1}-\mathrm{A}_{\mathrm{PU}_{1}} \mathrm{~d} l_{2}\right\} .
$$

Calculating the impedance of both coils gives 


$$
\begin{aligned}
Z_{P U}=\frac{V_{P U}}{I}=\frac{j \omega}{I} \oint_{A_{P U_{1}}} d l_{1}+\frac{j \omega}{I} \oint_{A_{P U_{2}} d l_{2}}-\frac{j \omega}{I} \oint_{A_{P U_{2}} d l_{1}} \\
-\frac{j \omega}{I} \oint_{A_{P_{1}} d \ell_{2}}
\end{aligned}
$$

This equation is the same as

$$
\mathrm{z}_{\mathrm{PU}}=\mathrm{z}_{\mathrm{PU}_{1}}+\mathrm{z}_{\mathrm{PU}_{2}}-2 j \omega \mathrm{M}_{12}
$$

which can be obtained by considering the coils separately. From ref. 7 , Eq. (57), we can write the following relationship for the voltage induced in the upper pickup coil by a current in the lower pickup coll,

$$
\begin{aligned}
j \omega M_{12}=\frac{j \omega \pi N_{4}^{2} R_{5} \mu_{0}}{\left(R_{1}-R_{3}\right)^{2} L_{4}^{2}} \int_{0}^{\infty} \frac{1}{\alpha^{6}} J^{2}\left(R_{4}, R_{3}\right)\left[\gamma e^{-\alpha\left(2 L_{2}+2 L_{6}+L_{3}-L_{4}\right)}\right. \\
\left.+e^{-\alpha\left(L_{3}-2 L_{4}-2 L_{5}\right)}\right]\left(1-e^{-\alpha L_{4}}\right)^{2} d \alpha .
\end{aligned}
$$

From ref. 7, Eq. (58), we can write the same expression for the voltage induced in the lower pickup coil by a unit current in the upper pickup coil.

Using Eq. (7) for the impedance of the front pickup coil gives

$$
\begin{aligned}
& \mathrm{Z}_{\mathrm{PU}_{1}}=\frac{j \omega \pi \mathrm{N}_{4}{ }^{2} \mu_{0} \mathrm{R}_{5}}{\left(\mathrm{R}_{4}-\mathrm{R}_{3}\right)^{2} \mathrm{~L}_{4}{ }^{2}} \int_{0}^{\infty} \frac{1}{\alpha^{6}} \mathrm{~J}^{2}\left(\mathrm{R}_{4}, \mathrm{R}_{3}\right)\left\{2\left(\alpha \mathrm{L}_{4}+\mathrm{e}^{-\alpha \mathrm{L}_{4}}-1\right\}\right. \\
& \left.+\left(1-e^{-\alpha L_{4}}\right)^{2} \gamma e^{-\alpha\left(2 L_{5}+2 L_{6}+2 L_{2}\right)}\right\} d \alpha .
\end{aligned}
$$

For the rear pickup we have 


$$
\begin{aligned}
\mathrm{Z}_{\mathrm{PU}_{2}}= & \frac{j \omega \pi N_{4}{ }^{2} \mu_{0} \mathrm{R}_{5}}{\left(\mathrm{R}_{4}-\mathrm{R}_{3}\right)^{2} \mathrm{~L}_{4}{ }^{2}} \cdot \int_{0}^{\infty} \frac{1}{\alpha^{6}} J^{2}\left(\mathrm{R}_{4}, \mathrm{R}_{3}\right)\left\{2\left(\alpha \mathrm{L}_{4}+\mathrm{e}^{-\alpha L_{4}}-1\right) .\right. \\
& \left.+\left(1-\mathrm{e}^{-\alpha \mathrm{L}_{4}}\right)^{2} \gamma \mathrm{e}^{-\alpha\left(2 \mathrm{~L}_{6}+2 \mathrm{~L}_{2}+2 \mathrm{~L}_{3}-2 \mathrm{~L}_{5}-2 \mathrm{~L}_{4}\right)}\right\} \mathrm{d} \alpha .
\end{aligned}
$$

From Eq. (13) the total pickup coil impedance is the sum of Eqs. (15) and (16) minus twice Eq. (14). The result is

$$
\begin{aligned}
& Z_{P U}=\frac{j \omega \pi N_{4}^{2} \mu_{0} R_{5}}{\left(R_{4}-R_{3}\right)^{2} L_{4}^{2}} \int_{0}^{\infty} \frac{1}{\alpha^{6}} J^{2}\left(R_{4}, R_{3}\right)\left\{4\left(\alpha L_{4}+e^{-\alpha L_{4}}-1\right)\right. \\
& \left.+\left(1-e^{-\alpha L_{4}}\right)^{2}\left[e^{-\alpha\left(2 L_{2}+2 L_{6}+2 L_{5}\right)}\left(1-e^{-\alpha\left(L_{3}-L_{4}-2 L_{5}\right)}\right)^{2} \gamma-2 e^{-\alpha\left(L_{3}-2 L_{4}-2 L_{5}\right)}\right]\right\} d \alpha .
\end{aligned}
$$

We have now derived equations for the mutual impedance between the driver and pickup coils, $M$, the driver coil impedance, $\mathrm{Z}_{D}$, and the pickup coil impedance, $\mathrm{Z}_{\mathrm{PU}}$, and only these factors are needed for thickness, cladding thickness, and conductivity calculations. However, if we wish to calculate the effect of discontinuities, we must go still further. The quantities that we have already calculated will be modified slightly due to the presence of a flaw in the material.

The voltage change in the driver $\operatorname{coil}^{8}$ per unit current in a pickup coil due to the presence of a flaw is:

$$
\frac{V_{d}}{I_{D}}=\left[\frac{3}{2} \sigma \omega^{2}\left(\frac{A_{P U}}{I_{P U}}\right)\left(\frac{A_{D}}{I_{D}}\right)\right] \times\left[\operatorname{Vol} \alpha_{22}\right]=j \omega M^{\prime},
$$

where $A_{F U}$ and $A_{D}$ are the vector potentials of the driver and pickup coils, respectively. The factor $\left[\operatorname{Vol} \alpha_{22}\right]$ is a size, shape, and

${ }^{8}$ C. V. Dodd, W. E. Deeds, J. W. Luquire, and W. G. Spoeri, Some Eddy-Current Problems and Their Integral Solutions, ORNL-4384 (April 1969). 
orientation factor and will be discussed later. The vector potential for any region, $n$, below the coil, from ref. 7 , Eq. (55) is

$$
\begin{aligned}
A^{(n)}(r, z)=\frac{1}{2} & \frac{N I \mu_{0}}{\left(r_{2}-r_{1}\right)\left(l_{2}-l_{1}\right)} \int_{0}^{\infty} \frac{e^{-\alpha l_{1}}}{\alpha^{3}} \cdot\left(r_{2}, r_{1}\right)\left[1-e^{-\alpha\left(l_{2}-\ell_{1}\right)}\right] \\
& \times J_{1}(\alpha r)\left\{\frac{V_{12}(n, I)}{V_{22}(k, I)} e^{-\alpha n^{z}}+\frac{V_{22}(n, I)}{V_{22}(k, I)} e^{\alpha n^{2}}\right\} d \alpha .
\end{aligned}
$$

Substituting for the vector potential of the driver and pickup coils in Eq. (18) gives

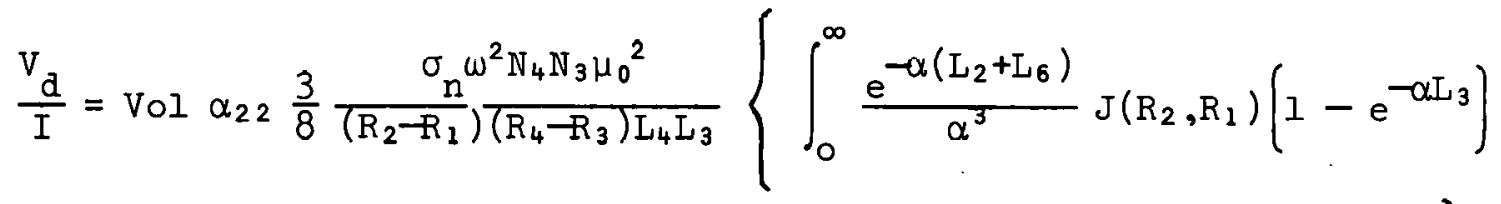

$$
\begin{aligned}
& \left.\times J_{1}(\alpha r)\left[\frac{V_{12}(n, I)}{V_{22}(k, I)} e^{-\alpha_{n} z}+\frac{V_{22}(n, I)}{V_{22}(k, I)} e^{\alpha_{n} z}\right] d \alpha\right\} \\
& x\left\{\int_{0}^{\infty} \frac{e^{-\alpha\left(L_{2}+L_{6}+L_{5}\right)}}{\alpha^{3}}\left(1-c^{-\alpha\left(L_{3}-L_{4}-2 L_{5}\right)}\right) J\left(R_{4}, R_{5}\right)\left(1-c^{-\alpha L_{4}}\right)\right. \\
& \left.\times J_{1}(\alpha r)\left[\frac{V_{12}(n, I)}{V_{22}(k, I)} e^{-\alpha_{n} z}+\frac{V_{22}(n, I)}{V_{22}(k, I)} e^{\alpha_{n} z}\right] d \alpha\right\} \text {. }
\end{aligned}
$$

We shall now normalize all dimensions by the mean radius of the coil and separate the terms.

$$
\begin{aligned}
\frac{V_{d}}{I}=\operatorname{Voi} \alpha_{22}\left(\omega \mu \sigma_{n} R_{5}{ }^{2}\right) \frac{3}{8} \omega \mu_{0} R_{5}\left\{\frac{N_{3}}{\left(R_{2}-R_{1}\right) L_{3}} \int_{0}^{\infty} \frac{e^{-\alpha\left(L_{2}+L_{6}\right)}}{\alpha^{3}} J\left(R_{2}, R_{1}\right)\left(I-e^{-\alpha L_{3}}\right)\right. \\
\left.\times\left[J_{1}(\alpha r)\left(\frac{V_{12}(n, I)}{V_{22}(k, I)} e^{-\alpha_{n} z}+\frac{V_{22}(n, I)}{V_{22}(k, I)} e^{\alpha n^{2}}\right] \cdot\right] d \alpha\right\}
\end{aligned}
$$




$$
\begin{gathered}
\times\left\{\frac{N_{4}}{\left(R_{4}-R_{3}\right) L_{3}} \int_{0}^{\infty} \frac{e^{-\alpha\left(L_{2}+L_{6}+L_{5}\right)}}{\alpha^{3}}\left(1-e^{-\alpha\left(L_{3}-L_{4}-2 L_{5}\right)}\right) J\left(R_{4}, R_{3}\right)\left(1-e^{-\alpha L_{4}}\right)\right. \\
\left.\times\left[J_{1}(\alpha r)\left(\frac{V_{12}(n, I)}{V_{22}(k, I)} e^{-\alpha n^{z}}+\frac{V_{22}(n, I)}{V_{22}(k, I)} e^{\alpha n^{2}}\right)\right] d \alpha\right\}=j \omega M^{-} .
\end{gathered}
$$

Equation (2l) represents the change in the mutual coupling due to the presence of the discontinuity. If we wish to calculate the change in impedance of the driver coil, $Z_{D}^{\prime}$, due to the flaw, we simply square the term in the first set of curly brackets and omit the term in the second set of curly brackets. Likewise, the change in impedance of the pickup coil is the square of the term in the second set of curly brackets with the first set omitted. Also the term in the square brackets is identical in both sets of curly brackets and needs to be calculated for only one.

We shall now discuss the calculation of the terms $v_{12}(n, I)$ and $\mathrm{V}_{22}(\mathrm{n}, 1)$. In our actual computer programs we will be concerned only with the quotient of these terms, and we shall use a simple iterative method described in ref. 7 . We shall redefine the terms as

$$
\frac{V_{\ell 2}(n, 1)}{V_{22}(k, 1)}=2^{k-n} e^{-(-1)^{l_{\alpha} z}{ }_{n-1}} \frac{v_{\ell 2}^{\prime}(n, 1)}{V_{22}^{\prime}(k, 1)}\left(\beta_{n+1} \beta_{n+2} \cdot \cdots \beta_{k}\right)
$$

The letter $\mathrm{n}$ represents any arbitrary region under the coil and the letter $\mathrm{k}$ that of the region directly under the coil.

For the special case of $n$ equal to one, we have

$$
V_{\ell^{2}}(I, I)=V_{\ell^{2}}(I, I)=\left\{\begin{array}{l}
0 \text { if } \ell=1 \\
I \text { if } \ell=2 .
\end{array}\right.
$$

Therefore,

$$
\frac{V_{22}(1,1)}{V_{22}(k, I)}=\frac{2^{k-1} e^{-\alpha_{12} z_{1}}}{V_{22}^{\prime}(k, 1)}\left(\beta_{2} \beta_{3} \cdot \cdot \cdot \beta_{k}\right)
$$


(1) We calculate the numerical value of the first transformation matrix as

$$
v_{i .2}^{\prime}(2,1) \equiv\left[B_{2}+(-1)^{i} B_{1}\right]=t_{i 2}(2,1) \text { for } i=1,2 \text {, }
$$

where

$$
\beta_{n}=\frac{1}{\mu_{n}} \sqrt{\alpha^{2}+j \omega \mu_{0} \mu_{n} \sigma_{n} R_{5}^{2}}=\frac{\alpha_{n}}{\mu_{n}}
$$

and is dimensionless. The $\mu_{n}$ is the relative permeability of the layer with index $n$. (2) Then we determine the numerical value for the four elements of the transformation to the next layer. They are

$$
t_{i j}(n, n-1)=\left[\beta_{n}+(-1)^{i+j_{B}} \beta_{n-1}\right] \exp \left[(-1)^{j_{\alpha_{n-1}}}\left(z_{n-1}-z_{n-2}\right)\right] \text {. }
$$

(3) From this we shall numerically calculate:

$$
\begin{aligned}
& V_{12}^{\prime}(n, I)=t_{11}(n, n-1) V_{12}^{\prime}(n-1,1)+t_{12}(n, n-1) V_{22}^{\prime}(n-1,1) . \\
& V_{22}^{\prime}(n, 1)=t_{21}(n, n-1) V_{12}^{\prime}(n-1,1)+t_{22}(n, n-1) V_{22}^{\prime}(n-1,1) .
\end{aligned}
$$

Step 1 is performed for the first region. Steps 2 and 3 are repeated for $\mathrm{n}=3,4 \ldots ., \mathrm{k}$.

The gamma factor, $\gamma$, used for all cascs except defect calculations, is

$$
\gamma=\frac{V_{12}(k, 1)}{V_{22}(k, 1)}=\frac{v_{12}^{*}(k, 1)}{V_{22}^{\prime}(k, 1)}
$$

For the case of defects the term in the square brackets in Eq. (2l) becomes 


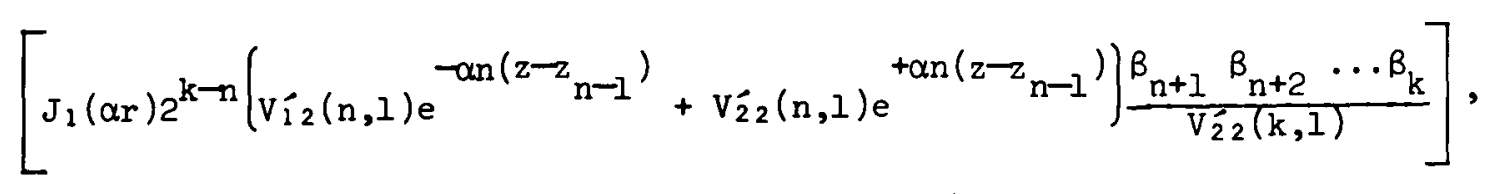

and for the epecial case of defects in region 1 it becomes

$$
\left[J_{1}(\alpha r) 2^{k-1}\left(e^{-\alpha_{1}\left(z_{1}-z\right)}\right) \frac{\beta_{2} \beta_{3} \cdots \beta_{k}}{V_{22}^{\prime}(k, 1)}\right]
$$

We shall now consider a few examples. The $\gamma$ factor for a single, semi-infinite conductor is:

$$
\frac{V_{1.2}(2,1)}{V_{22}(2,1)}=\frac{\beta_{2}-\beta_{1}}{\beta_{2}+\beta_{1}}=\frac{\alpha-\beta_{1}}{\alpha+\beta_{1}}
$$

The term in square brackets in Eq. (20) for a defect in region 1 is:

$$
\frac{2 \alpha e^{\alpha_{1} z} e^{-\alpha_{1} z_{1}}}{\left(\alpha+\beta_{1}\right)}
$$

If we have two conductors, the $\gamma$ factor becomes:

$$
\begin{gathered}
\frac{V_{12}^{\prime}(3,1)}{V_{22}^{\prime}(3,1)}=\frac{t_{11}(3,2) V_{12}^{\prime}(2,1)+t_{12}(3,2) V_{22}^{\prime}(2,1)}{t_{21}(3,2) V_{12}^{\prime}(2,1)+t_{22}(3,2) V_{22}^{\prime}(2,1)} \\
=\frac{\left(\beta_{3}+\beta_{2}\right)\left(\beta_{2}-\beta_{1}\right) e^{-\alpha_{2}\left(z_{2}-z_{1}\right)}+\left(\beta_{3}-\beta_{2}\right)\left(\beta_{2}+\beta_{1}\right) e^{+\alpha_{2}\left(z_{2}-z_{1}\right)}}{\left(\beta_{3}-\beta_{2}\right)\left(\beta_{2}-\beta_{1}\right) e^{-\alpha_{2}\left(z_{2}-z_{1}\right)}+\left(\beta_{3}+\beta_{2}\right)\left(\beta_{2}+\beta_{1}\right) e^{+\alpha_{2}\left(z_{2}-z_{1}\right)}} .
\end{gathered}
$$

The term in square brackets in $\mathrm{Eq}$. (20) for a defect in region 2 is

$$
\left[\frac{2 \alpha\left(\beta_{2}-\beta_{1}\right) e^{\alpha_{2} z_{1}-\alpha_{2} z}+2 \alpha\left(\beta_{2}+\beta_{1}\right) e^{-\alpha_{2} z_{1}+\alpha_{2} z}}{\left(\beta_{3}-\beta_{2}\right)\left(\beta_{2}-\beta_{1}\right) e^{-\alpha_{2}\left(z_{2}-z_{1}\right)}+\left(\beta_{3}+\beta_{2}\right)\left(\beta_{2}+\beta_{1}\right) e^{+\alpha_{2}\left(z_{2}-z_{1}\right)}}\right] .
$$


The term in square brackets in Eq. (20) for a defect in region 1 is

$$
\left[\frac{4 \beta_{2} \beta_{3} e^{\alpha_{1} z}-\alpha_{1} z_{1}}{\left(\beta_{3}-\beta_{2}\right)\left(\beta_{2}-\beta_{1}\right) e^{-\alpha_{2}\left(z_{2}-z_{1}\right)}+\left(\beta_{3}+\beta_{2}\right)\left(\beta_{2}+\beta_{1}\right) e^{\alpha_{2}\left(z_{2}-z_{1}\right)}}\right] .
$$

Thus, in principle, we can analyze the response of a reflection coil above any number of layers.

\section{CONSIDERATTONS FOR TEST DESIGN}

We shall now consider some practical aspects in the design of eddycurrent tests using reflection type colls.

The design of the eddy-current test is not automatic. The user must take the conductor parameters given in the problem, choose the coil and operating parameters, and mun these in the computer program. The computer program will calculate the output of the coil and circuit which shows how well the measurements can be made using the selected parameters. Other parameters must be selected and run to determine which choice is optimum. The choice of the parameters used in the examples in each section is near optimum. Other reports referenced in the individual sections may be used to ensure that lhe initial trial is near optimum. Reference 9 gives a good overall description of the lift-off interactions in design.

We shall attempt to present an outline to follow in optimizing these tests, although due to the complex interactions between the many test variables it will become apparent that the outline cannot be followed exactly in every situation. Because of the interactions among the various parameters, this entire section on considerations for test design should be read before starting a design.

${ }^{9} \mathrm{C}$. V. Dodd and W. A. Simpson, Jr., Thickness Measurements Using Eddy-Current Techniques, ORNL-TM-3712 (March 19'T'2). 
Maximize Sensitivity

The sensitivity to the desired test variable should be maximized. This is usually done with very large impedances of the driving and pickup circuits. Under these conditions, only the mutual coupling between the driver and pickup coils is affecting the tests. The sensitivity curves usually have very broad peaks so that it is not really necessary to operate at conditions necessary for the absolute maximum sensitivity.

\section{Minimize the Undesired Effects}

The sensitivity to variations in variables that we do not wish to measure should be minimized while keeping the sensitivity to the variables of interest as high as possible. We shall discuss these undesired variables in their general order of consideration in coil design problems.

\section{Lift-Off Variations}

Lift-off, or variations in the distance between the coil and conductor, is the largest source of error in most eddy-current tests. However, in many tests using phase sensing, the lift-off error can be reduced to insignificant proportions. The controllable factors influencing the phase variation due to lift-off are as follows.

Coil Geometry. - The shorter the driver coil, the smaller is the value of $\bar{r}^{2} \omega \mu \sigma$ at which the minimum lift-off effect occurs. In general, in order to make the value of $\bar{r}^{2} \omega \mu \sigma$ for minimum lift-off effect be the same as that for maximum sensitivity, the normalized length of the driver coil must be from 0.4 to 0.6 . Most other effects tend to increase the value of $\bar{r}^{2} \omega \mu \sigma$ for minimum lift-off, and usually there is a problem getting this value low enough (or the coils short enough).

By "zero lift-off" we really mean the minimum value of lift-off, which is not actually zero, but some finite value of lift-off because of the thickness of the insulation and the bearing surface on the face of the probe. The "zero lift-off" is a normalized thickness, and should not be confused with the minimum lift-off effect, which is a phase shift 
due to a lift-off variation. The larger the "zero lift-of $f$ ", the larger is the value of $\bar{r}^{2} \omega \mu \sigma$ at which the minimum lift-off effect occurs. Therefore, we try to make the "zero lift-off" as small as practical. For a coil with Teflon tape over the face, the normalized "zero liftoff" ranges from about 0.3 for a mean radius of 0.020 in. to about 0.025 for a mean radius of $0.40 \mathrm{in.}$. For the same coils without the Teflon tape over the face, the normalized "zero lift-off" would range from about 0.1 to 0.015 , respectively.

The normalized values of the inner and outer radii of the driver coil and pickup coils have only a small effect on the value of $\bar{r}^{2} \omega \mu \sigma$ at which the minimum lift-off effect occurs. 'l'he values of R1, R2, R3, and $R 4$ used in this report $(0.75,1.25,0.35$, and 0.7 , respectively) represent a compromise between those producing a minimum value of $\bar{r}^{2} \omega \mu \sigma$ for the minimum lift-off effect and those producing maximum voltage from a reflection-type coil system.

Lift-Off Range. - This is the range of variation of the lift-off, or coil to conductor spacing and usually represents a compromise between what is easily obtainable and the amount of error introduced. If the lift-off is increased from "zero lift-off" (the minimum) to a maximum value, this produces a phase shift known as the lift-off effect. The smaller the lift-off range, the smaller is the lift-off effect and the value of $\vec{r}^{2} \omega \mu \sigma$ at which the minimum lift-off effect occurs.

Range of Measurements. - The range of measurements is the range of the variable such as thickness, cladding thickness, or conductivity that we desire to measure. The smaller the range of measurements, the smaller is the lift-of $f^{\prime}$ ef'ect. In most cases the value of $\tilde{r}^{2} \omega \mu \sigma$ for minimum lift-off effect tends to increase slightly as the range increases. Attenuator Parameters and Number of Turns. - The attenuator parameters, unlike the previous parameters, do not require any adiitional numerical integrations and, therefore, require very little additional computation time. Since these parameters will tend to increase the value of $\bar{r}^{2} \omega \mu \sigma$ for minimum lift-off effect, the coil must be made shorter than the optimum indicated in the previous paragraphs. The attenuator parameters consist of the resistance and capacitance in the instrument 
driving and pickup circuits. The attenuator parameters, together with the turns on the coil, play an important part in the total instrument response. Selection of the values of these parameters should proceed with the following steps.

1. Determine the desired ratio of $\omega$ to $\omega_{0}$ (the resonant frequency). The coil inductance and the shunt capacitance (including cable, coil interwinding, and amplifier input capacitance) in both the driving and pickup circuits form a resonant circuit that limits the high frequency response of the probe and, therefore, the noise. With no capacitance in the circuit, the signal with the probe on a conductor will increase continuously with frequency, at a rate somewhat greater than $\omega$ to the first power. The ratio of the resonant frequency to the operating frequency is given by

$$
\frac{\omega_{0}}{\omega}=\frac{1}{\omega \sqrt{\mathrm{CI} \mathrm{Im}}}
$$

where $\mathrm{C}$ is the shunt capacitance, $\mathrm{L}$ is the coil inductance, and Im represents the normalized imaginary part of the coil impedance. Both the ratio $\omega_{0} / \omega$ and $I m$ are calculated in the programs. The normal value of the ratio ranges from 2 to 20 , with 10 being the most used. For a ratio greater than 20 , the noise becomes troublesome. With smaller ratios, the coils cannot be made short enough to achieve good lift-off compensation, and component variation causes larger phase shifts.

2. Determine approximate coil inductance. The minimum coil inductance, determined by the system's low frequency operation and the minimum output resistance, $R_{0}$, can be approximated by:

$$
\text { Min Inductance } \approx \frac{\mathrm{RO}_{\min }}{1.5 \mathrm{Im}\left[\omega_{\min }\left(\frac{\omega_{0}}{\omega_{\min }}\right)\right]} \text {. }
$$

Substituting approximate values for the minimum driving resistance and the normalized imaginary part of the impedance gives 
Min Inductance $\approx \frac{42}{\left[\omega_{\min }\left(\frac{\omega_{0}}{\omega_{\min }}\right)\right]}, \quad$ (henries)

where $\omega$ is the minimum operating frequency under consideration and $\omega_{0} / \omega_{\min }$ is the ratio of the resonance frequency to the minimium frequency.

The maximum inductance will be limited by the high frequency response of the system and is approximated by:

$$
\operatorname{Max} \text { Inductance } \approx \frac{1}{\mathrm{C} \operatorname{Im}\left[\omega_{\max } \frac{\omega_{0}}{\omega_{\max }}\right]} \text { ? }
$$

The minimum capacitance in the leads, coils, and amplifiers will usually be approximately $100 \mathrm{pF}$. Thus, we have

$$
\text { Max Inductance } \approx \frac{1}{8 \times 10^{-11}\left[\omega_{\max } \frac{\omega_{0}}{\omega_{\max }}\right]^{2}} .
$$

The probe may be designed to operate over a very wide frequency range or for a single frequency, where $\omega_{\min }=\omega_{\max }$. A wire gage must be chosen (using the coil design option) to give an inductance somewhere between the maximum and minimum values. For coils with the greatest range of operating frequency, the inductance of the driver and pickup coils should be approximately the same, since the lead capacitances will usually be similar.

3. Once the exact inductance has been determined, the capacitance necessary to give the desired ratio of $\omega_{0} / \omega$ must be selected (for each value of operating frequency). This is given by

$$
C=\frac{1}{\operatorname{LIm}\left[\omega\left(\frac{\omega_{0}}{\omega}\right)\right]^{2}}
$$


and the ratio $\omega_{0} / \omega$ is calculated by the attenuator design option in the programs.

4. Next, the value of driver series or pickup shunt resistance needed to give a minimum temperature orift (due to variations in the coil dc resistance) must be determined. A rough approximation for this resistance is

$$
\mathrm{RO} \approx 1.25 \omega_{\mathrm{D}}\left(\frac{\omega_{0}}{\omega}\right)
$$

for the driver series resistance (RO), and

$$
\mathrm{R} 9 \approx 1.75 \omega \mathrm{L}_{\mathrm{PU}}\left(\frac{\omega_{0}}{\omega}\right)
$$

for the pickup shunt resistance (R9). It should be emphasized here that these values may be in error by a factor of 2 . The only way to get an accurate value of the resistance for minimum drift will be to vary $R O$ and $R 9$ and calculate the drift. Positive values of the drift indicate that the resistance should be increased, negative values of the drift indicate the resistance should be decreased. The drifts will not become exactly zero, and there is an interaction between RO and R9 so that several calculations on each may be necessary. Drifts on the order of $0.005^{\circ} /{ }^{\circ} \mathrm{C}$ are practical, both analytically and experimentally.

5. Once the proper attenuator has been obtained, it is necessary to reexamine the lift-off error since this is affected by the attenuator parameters. It may be necessary to vary the coil length, the zero lift-off, and the lift-off range in order to minimize the lift-off error. This unfortunately requires that the coil and attenuator be redesigned. Therefore, since it is known that the addition of the attenuator will increase the value of $\bar{r}^{2} \omega \mu \sigma$ at which the minimum liftoff error occurs, it is desirable to design the coil without an attenuator so that the value of $\vec{r}^{2} \omega \mu \sigma$ for minimum lift-off error is less than that for maximum sensitivity. In Fig. 5 we show how the fractional increase in the value of $\overrightarrow{\mathrm{r}}^{2} \omega \mu \sigma$ for minimum lift-off error increases as the ratio $\omega_{0} / \omega$ decreases for a particular coil. The value of $\vec{r}^{2} \omega \mu \sigma$ 


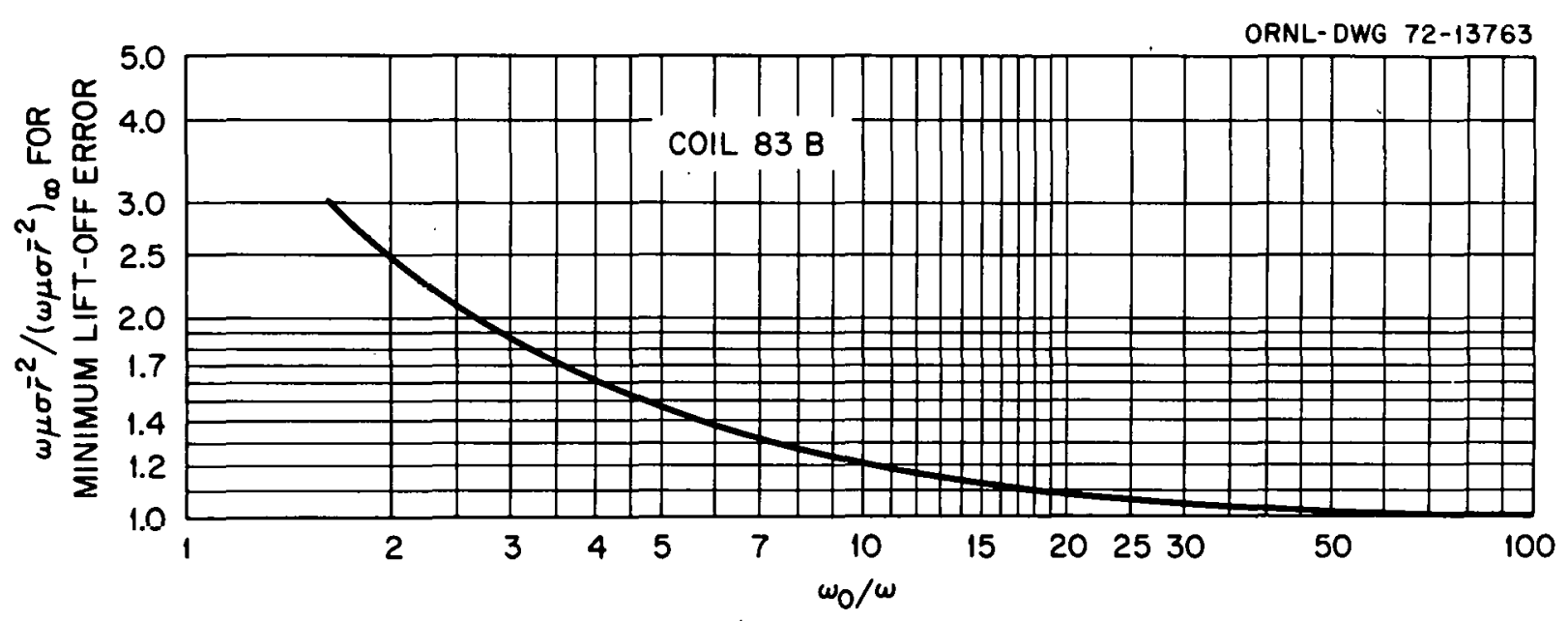

Fig. 5. Ratio of the Value of $\bar{r}^{2} \omega \mu \sigma$ for Minimum Lift-off Error for an Attenuator Having a Resonant to Operating Frequency of $\omega_{0} / \omega$ to the value of $\vec{r}^{2} \omega \mu \sigma_{\infty}$ for Minimum Lift-Off Error with an Infinite Ratio of $\omega_{0} / \omega$, Plotted Against $\omega_{0} / \omega$.

for minimum lift-off error with an infinite ratio of $\omega_{0} / \omega$ has been taken as unity. This should give at least an estimate of how much the value of $\vec{r}^{2} \omega \mu \sigma$ will be increased and should be taken into account in the original selection of the coil parameters.

The series of steps outlined in this section should serve as a rough guide to good coil design.

\section{REFLECTION COIL ABÖVE $\Lambda$ SINGLE CONDUCTING PLANE}

We shall now consider the case of a reflection coil above a single conductor. This computer program calculates the magnitude and phase of the voltage that is fed to the phase measuring circuits of the phasesensitive eddy-current instruments and is designed to help analyze eddy-current measurements of conductivity.

The program calculates the magnitude and phase of the induced voltage at 5 different values of lift-off for each of 3 different conductivity values, making a total of 15 calculations. This allows one to examine the sensitivity to lift-off variations as well as conductivity variations. In addition, the program also calculates the phase shift with the discriminator adjusted to give the same phase on the nominal conductivity sample with maximum and minimum lift-off. The 
phase on the nominal conductivity sample with minimum lift-off is taken as zero, and all other phase shifts are measured relative to it.

The equations that are evaluated are Eq. (8) for the mutual coupling, Eq. (9) for the driver coil impedance, and Eq. (17) for the pickup coil impedance. The gamma factor for the single, semi-infinite conductor is given in Eq. (31).

The programs are written in both BASIC and. FORTRAN for use on the PDP-10. The BASIC program follows.

To use this program, one must first divide all dimensions by the mean radius of the driver coil. Then the following lines must be typed into the program.

\begin{tabular}{|c|c|}
\hline 250 & $\mathrm{R} 5=$ (numerical value of driver coil mean radius in inches) \\
\hline 260 & $\mathrm{RI}=$ (numerical value of normalized driver coil inner radius) \\
\hline 70 & $\mathrm{R} 2$ = (numerical value of normalized driver coil outer radius) \\
\hline 280 & L3 = (numerical value of normalized driver coil length) \\
\hline & $\mathrm{R} 3=$ (numerical value of normalized pickup coil inner radius) \\
\hline 00 & $\mathrm{R} 4$ = (numerical value of normalized pickup coil outer radius) \\
\hline & L4 = (numerical value of normalized pickup coil length) \\
\hline & $\begin{aligned} \text { L5 }= & \text { (numerical value of normalized pickup coil recess from } \\
& \text { face of driver) }\end{aligned}$ \\
\hline 330 & L6 = (numerical value of normalized driver coil minimum lift-off) \\
\hline & $\mathrm{R} 6=$ (numerical value of resistance of driver coil in ohms) \\
\hline & $\begin{aligned} \mathrm{R} 7= & \text { (numerical value of total resistance of both pickup coils } \\
& \text { in ohms) }\end{aligned}$ \\
\hline 60 & N3 = (number of turns on driver coil) \\
\hline 7 & N4 = (number of turns on each pickup coil) \\
\hline & RO $=$ (output series resistance of driving amplifier in ohms) \\
\hline & $\mathrm{R} 9=$ (input shunt resistance of pickup amplifier in ohms) \\
\hline & C6 $=$ (total shunt capacitance in driving circuit in farads) \\
\hline & $C 7=$ (total shunt capacitance in pickup circuit in farads) \\
\hline & vo $=$ (output voltage of driving amplifier in volts) \\
\hline & $G 5=$ (gain of pickup amplifier) \\
\hline & $F=$ (operating frequency in Hertz) \\
\hline
\end{tabular}


$450 \quad$ L2 $=$ (numerical value of normalized driver coil lift-off increment)

$510 \mathrm{Kl}=$ (numerical value of resistivity of conductor in microhm centimeter)

$515 \mathrm{Ul}=$ (numerical value of relative permeability of conductor)

$750 \quad$ MO $=$ (numerical value of fractional conductivity change)

The program may now be run. The print-out by the computer will have the following format.

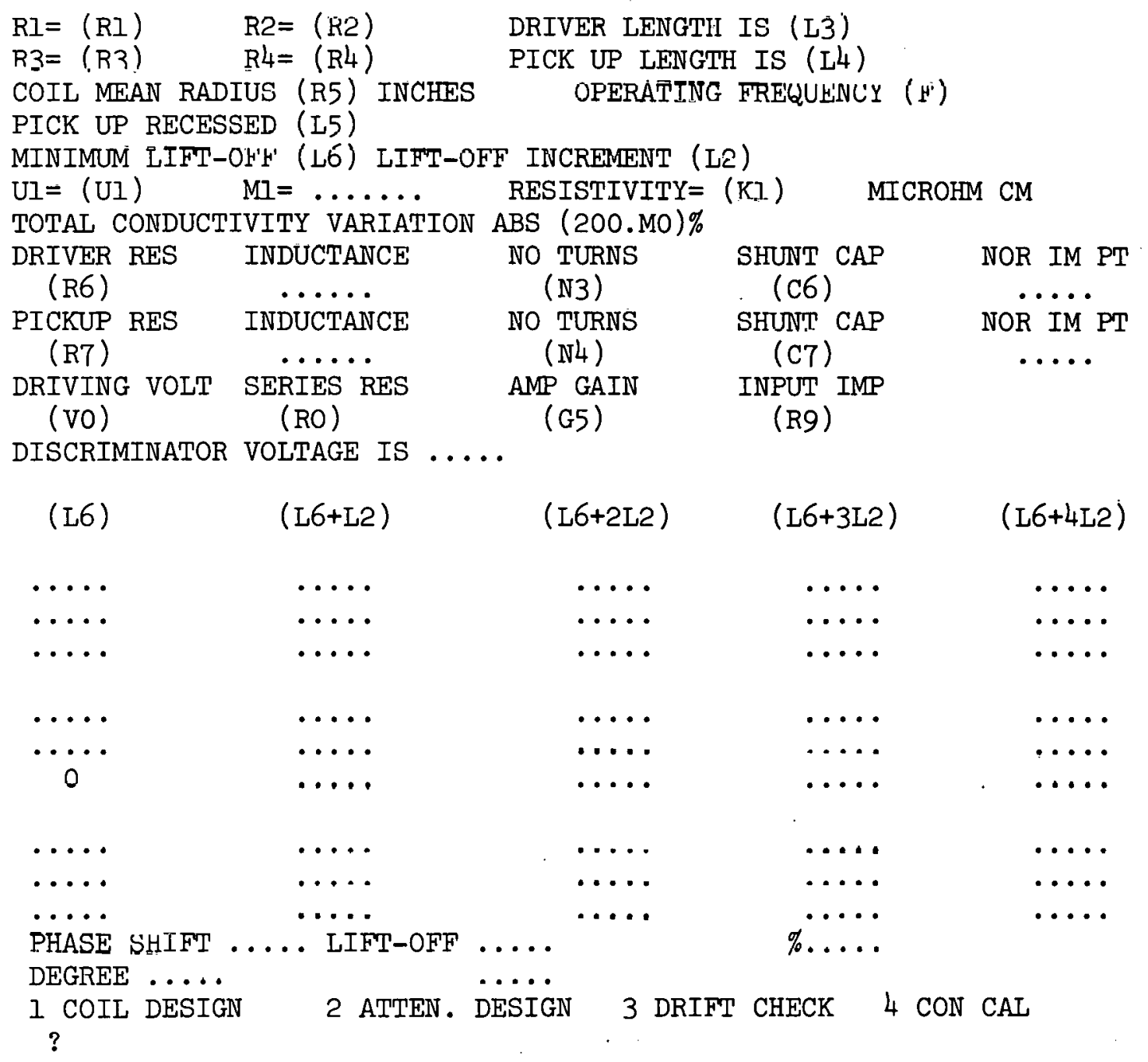

The various symbols enclosed in parentheses are used to indicate that the numerical value of the symbol will be printed.

There are five columns of data, one under each value of lift-off. Each column is divided into three sections of three lines each. These 
sections correspond, from top to bottom, to the three values (-100*MO, 0 , and $+100 * \mathrm{M} 0 \%$ ) of variations from the nominal conductivity. The three lines in each section are, from top to bottom, the magnitude of the voltage out of the pickup amplifier, the phase shift between the voltage out of the pickup amplifier and the driving voltage, and the phase shift between the voltage out of the pickup amplifier with the discriminator set to give the same phase shift with minimum lift-off and maximum lift-off on the nominal conductivity sample. The phase shift in the third line is always measured from the nominal conductivity sample with minimum lift-off. The voltage out of the pickup amplifier will be in volts and be either peak-to-peak or RMS, whichever is used for vo, the output voltage of the driving amplifier. The value of the dimensionless product $R_{5}{ }^{2} \omega \mu_{1} \sigma_{1}$ is also calculated and printed out as $\mathrm{MI}=\left(R_{5}{ }^{2} \omega \mu_{1} \sigma_{1}\right)$. The inductance in henries of the driving coil in air and the normalized imaginary part of the driving coil impedance, with nominal conductivity and nominal lift-off (L6+2L2), is also printed. Likewise the inductance in henries of both pickup coils in air and the normalized imaginary part of the pickup coils' impedance with nominal conductivity and lift-off is also printed. The total phase shift for the 200*MO \% conductivity variation, the maximum phase shift due to lift-off, and the maximum percent of range error in conductivity measurements due to lift-off are given. The phase shifts are given first in radians and then in degrees.

The program then enters a branching loop that allows the following options, depending on which of $1,2,3$, or 4 is typed as input after the question mark.

1. Coil Design

If a 1 is typed by the operator after the question mark, the program will enter the Coil Design Loop. This loop will allow the number of turns on the driver and pickup coils to be varied. The loop will allow the wire gage to be given and then calculate the number of turns and coil resistance, or it will allow the number of turns to be entered and calculate the gage and coil resistance, or both turns and gage can 
be entered. If zeros are entered for both the gage and turns of either the driver or pickup coils, the present value of these will be retained. The program then starts with the label

DRIVER RES INDUCTANCE NO TURNS SHUNT CAP NOR IM PT, and the remainder of the program is recalculated and printed, with the "new" coil in the circuit. However, the numerical integrations to calculate $\mathrm{M}, \mathrm{Z}_{\mathrm{DR}}$, and $\mathrm{Z}_{\mathrm{PU}}$ do not have to be repeated.

2. Attenuator Design

This loop will allow the driver series resistance, RO, the driver shunt capacitance, $\mathrm{C6}$, the amplifier input impedance, $\mathrm{K} 9$, and the shunt capacitance in the pickup circuit, $\mathrm{C} 7$, to be varied. If a 2 is typed after the question mark, the computer will respond with

DRIVER SERIES RES, SHUNT CAP, PICK-UP SHUNT RES, SHUNT CAP . The resistance is to be given in ohms, and the capacitance in farads. If zero is typed in for any value, the present value in the computer will be retained. After the input data and a carriage return are typed, the computer will calculate the ratio of resonant frequency to operating frequency for the particular I-C circuit, a very rough value of resistance for minimum temperature drift, and the ratio between the resistance and reactance in the circuit for both the driver and pickup circuits. The program then starts with the label

DRIVER RES INDUCTANCE NO TURNS SHUNT CAP NOR IM PT, and the remainder of the program is recalculated and printed with the "new" attenuator in the circuit. Again, the numerical integrations to calculate $M, Z_{D R}$, and $z_{P U}$ do not have to be repeated.

3. Drift Check

This loop calculates the effect of the drift of any of the circuit or sample parameters after the instrument has been calibrated and adjusted. If a 3 is typed as input, the program will respond with the percent variation, the parameter varied, the maximum change in phase (both radians and degrees) of any of the 15 different phases calculated ( 5 lift-off values for each of 3 different conductivity values) and the percent of the range the drift represents. The percent variation of 
each parameter may be varied independently. The following table gives the parameter, the line number, and the constant to be varied:

\section{Parameter}

Driver Resistance

Pickup Resistance

Driver Shunt Cap.

Pickup Shunt Cap.

Series Resistance

Amplifier Input Resistance

Applied Voltage

Frequency

Mean Radius

Resistivity
Line Number

8610

8620

8630

8640

8650

8660

8670

8680

8690

8700
Constant.

EI

E2

E3

E4

E7

E8

E9

AI

A2

A8

For example, to put in a $2 \%$ variation in the driver coil resistance, one would type:

$$
8610 \mathrm{El}=.02
$$

The amount that each parameter is varied must be set before the program is run. All of the variations are 0.01 or $1 \%$ in the current version of the program. Since the phase shift produced by the parameter variation is quite linear over a range of about $10 \%$, a linear interpolation or extrapolation may be used from the $1 \%$ parameter variation. If zero is typed in for any parameter variation, that parameter will not he varied nor will it be typed out in the list of parameter variations. When the calculation is completed and the drifts printed, the program returns to the branch point and repeats the question

1 Coil Design 2 Atten. Design 3 Drift Check 4 Con Cal .

The first seven drifts do not require that the numerical integrations to calculate $\mathrm{M}, \mathrm{Z}_{\mathrm{DR}}$, and $\mathrm{Z}_{\mathrm{PU}}$ be repeated, but they must be repeated to calculate the drifts due to frequency, mean radius, and resistivity changes. Therefore, the calculation of these last. three drifts requires a considerable amount of computer time. 
4. Con Cal

This loop is to continue calculations. If a series of calculations is to be made, a loop may be established at this point. However, in the present version of the program, if a 4 is typed as input, the program will end.

\section{Sample Calculation of RFCON}

Let us suppose we wish to design a reflection-type soil to measure electrical conductivity ot a thick metal plate. The coil values below were chosen by trial and error to give good results. 'I'he driver coll has a mean radius of $0.300 \mathrm{in.}$. Inner and outer radii of 0.225 in. and $0.375 \mathrm{in.}$, and a length of $0.180 \mathrm{in.}$ The pickup coils have inner and outer radii of 0.105 and $0.210 \mathrm{in.,} \mathrm{a} \mathrm{length} \mathrm{of} 0.060 \mathrm{in.,}$ and are mounted flush with the ends of the driver coil. The driver coil has 810 turns of No. 36 wire with a resistance of $57.555 \Omega$, and the pickup coils have 2925 turns each of No. 48 wire, with a resistance of 3443.01 $\Omega$ for both coils. The input resistances of both the driver series and the pickup amplifier are chosen to be 1 MR. The shunt capacitances in both circuits are chosed to be $1 \mathrm{pF}$. This corresponds to practically infinite source and detector impedances, so that only the mutual cnupl.ing. M. affects the phases. The minimum lift-off is taken to be $0.030 \mathrm{in}$. with a lift-off increment of $0.0075 \mathrm{in}$. The nominal resistivity of the material is $2.95 \mu \Omega \mathrm{cm}$, the variation in conductivity is $\pm 5 \%$, and the relative magnetic permeability is 1 . The frequency is $500 \mathrm{~Hz}$; the output voltage of the driving amplifier is $10 \mathrm{~V}$, and the gain of the pickup amplifier is unity (a unity gain allows the actual gain needed in the amplifier to be culculated by dividing the maximum output voltage with unity gain into 10).

The program RFCON is assumed to be in the active core, and the following information is typed into the computer. All linear dimensions are normalized by dividing by the coll meun radius, cxcept for the coil mean radius, which is in inches. 


$\begin{array}{ll}250 & \text { R5 }=.300 \\ 260 & \text { R1 }=.75 \\ 270 & \text { R2 }=1.25 \\ 280 & \text { L3 }=.6 \\ 290 & \text { R3 }=.35 \\ 300 & \text { R4 }=.70 \\ 310 & \text { L4 }=.2 \\ 320 & \text { L5 }=0 \\ 330 & \text { L6 }=.1 \\ 340 & \text { R6 }=57.555 \\ 350 & \text { R7 }=3443.01 \\ 360 & \text { N3 }=810 \\ 370 & \text { N4 }=2925 \\ 380 & \text { RO }=1 E 6 \\ 390 & \text { R9 }=1 E 6 \\ 400 & \text { C6 }=1 E-12 \\ 410 & \text { C7 }=1 E-12 \\ 420 & \text { VO }=10 \\ 430 & \text { G5 }=1 \\ 440 & \text { F }=500 \\ 450 . & \text { L2 }=.025 \\ 510 & \text { K1 }=2.95 \\ 515 & \text { U1 }=1 \\ 750 & \text { MO }=-0.05\end{array}$

The program may now be run with the following results. The data inputed from the terminal by the user are underlined. A carriage return must be typed by the user at the end of each input line. 
RFCON(BASIC)

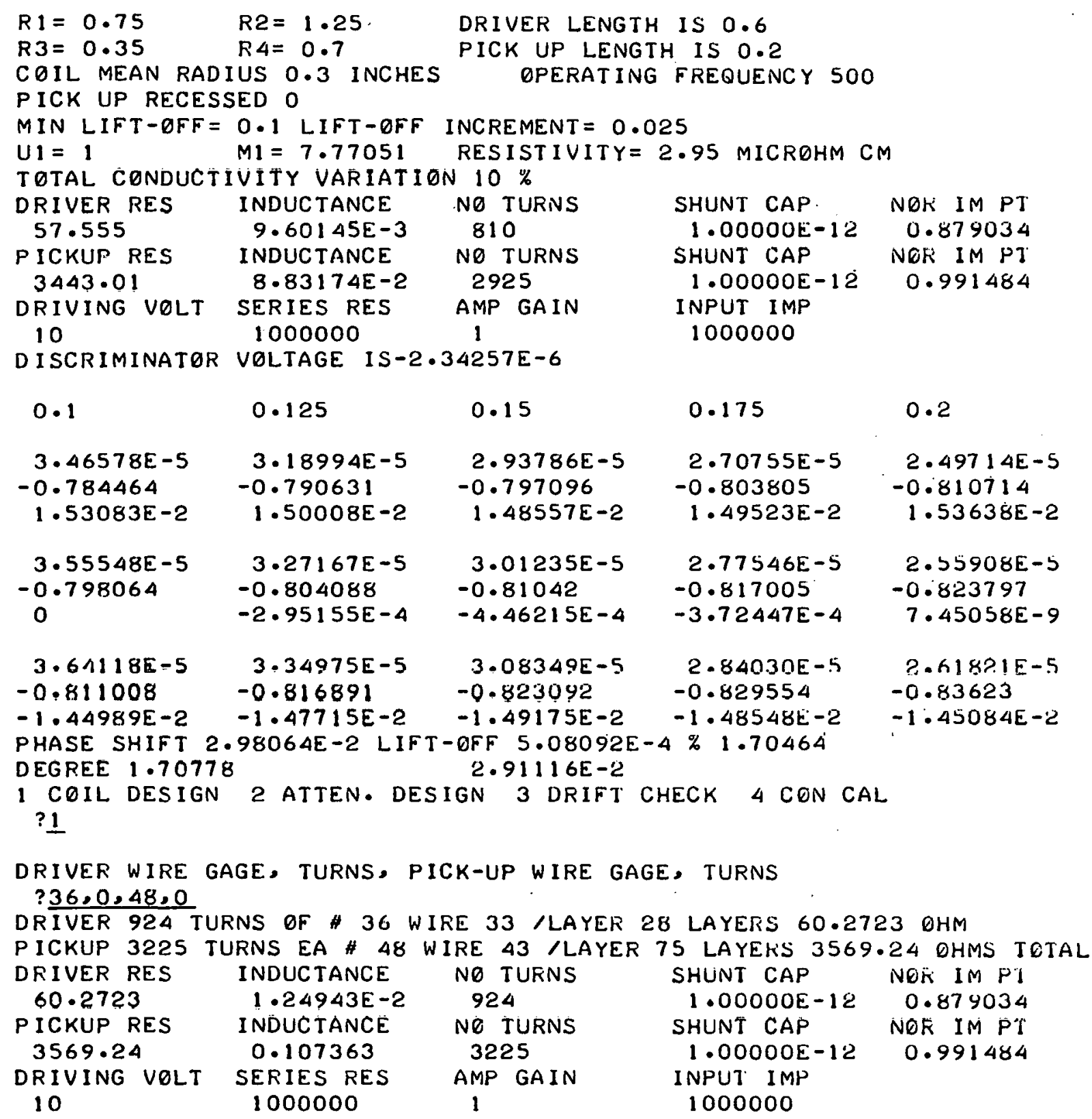


DISCRIMINATER VELTAGE IS-2.94602E-6

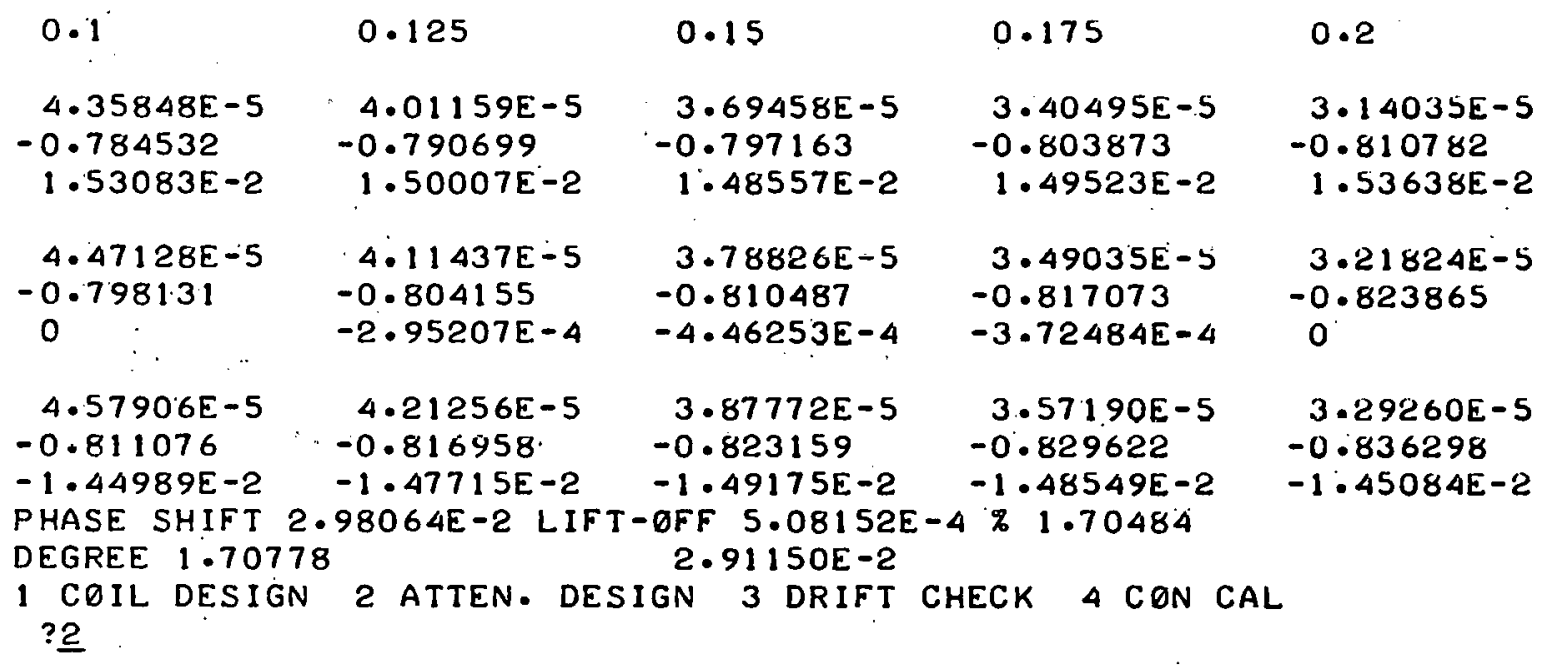

DRIVER SERIES RES, SHUNT CAP, PICK-UP SHUNT RES, SHUNT CAP $? 4 \cdot 1 E 2,1 \cdot 2 E-7,5 \cdot 4 E 3,1 \cdot 1 E-8$

DVR CT 8.76802 BELOW RES 302.529 OPT RES 11.8828 RES/REACTANCE P-U CT 9.30217 BELOW RES 3110.81 OPT RES 16.1475 RES/REACTANCE

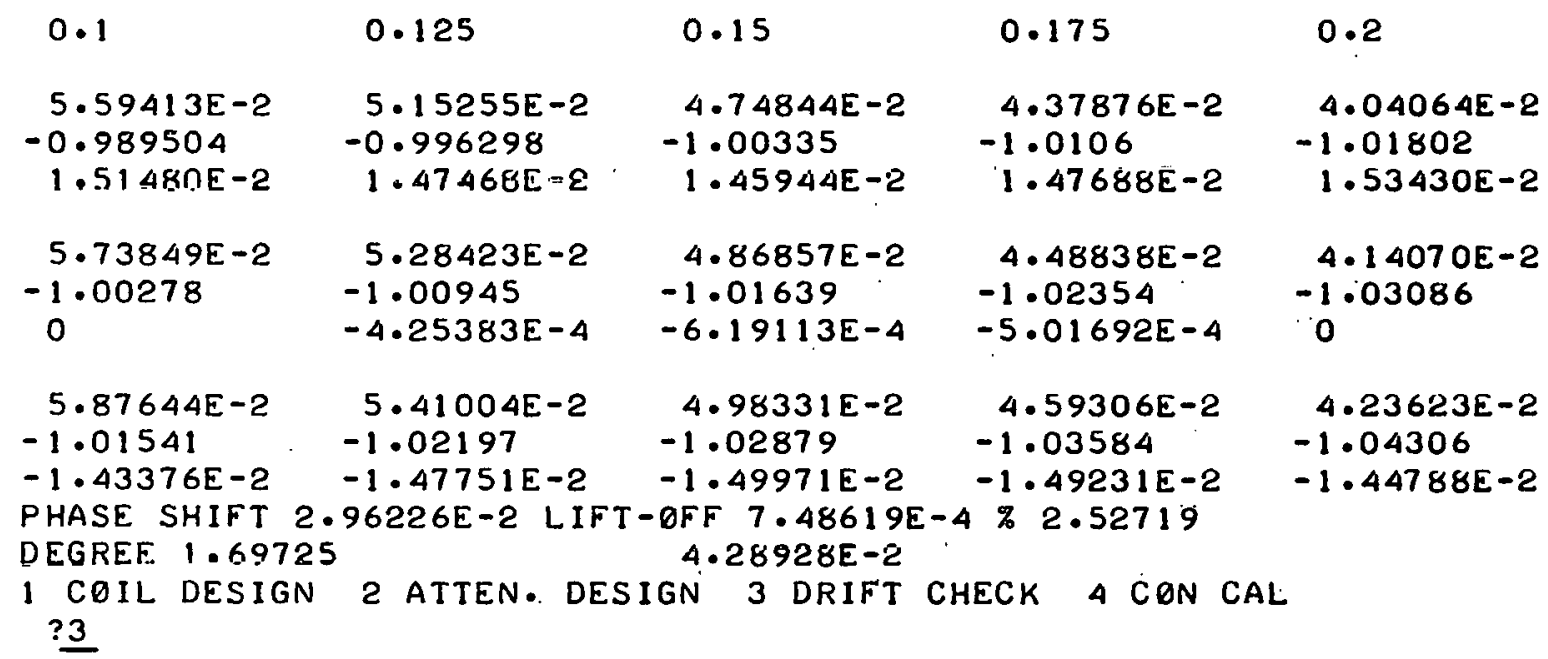




\begin{tabular}{|c|c|c|c|c|}
\hline $\begin{array}{l}\text { SYSTEM DRIFT } \\
\% \text { VARIATN }\end{array}$ & $\begin{array}{l}\text { VAR I ATIONS } \\
\text { PARAMETER }\end{array}$ & RAD IAN & DEGREE & $\%$ OF RANGE \\
\hline 1 & DRIVER RES & $5.94109 E-5$ & 0.003404 & 0.20056 \\
\hline 1 & PICKUP RES & $1 \cdot 25870 E-4$ & $7.21183 E-3$ & 0.424913 \\
\hline $\mathbf{1}$ & DUR SHUNT CAP & $-2 \cdot 27377 E-4$ & $-1 \cdot 30277 E-2$ & -0.76758 \\
\hline $\mathbf{1}$ & $P-U$ SHUNT & $-7 \cdot 46027 E-4$ & $-4 \cdot 27442 E-2$ & $-2 \cdot 51844$ \\
\hline 1 & SERIES RES & $1 \cdot 50037 \mathrm{E}-3$ & $8.59648 E-2$ & 5.06495 \\
\hline 1 & AMP INPUT RES & $-4.83483 E-4$ & $-2.77016 E-2$ & -1.63215 \\
\hline 1 & APPLIED VOLT & $-1 \cdot 02489 E-3$ & $-5.87217 E-2$ & $-3 \cdot 45982$ \\
\hline 1 & FREQUENCY & $-6.11736 E-3$ & -0.350499 & -20.651 \\
\hline 1 & MEAN RADIUS & $-8 \cdot 12030 E-3$ & -0.465259 & $-27 \cdot 4126$ \\
\hline 1 & RES IST I VITY & $2.99047 E-3$ & 0.171341 & 10.0952 \\
\hline $1 \mathrm{COIL}$ & 2 ATTEN DES & GN 3 DRIFT & ECK 4 CON & \\
\hline
\end{tabular}
34

The user has exercised all the design options available, and these options may be repeated, omitted, or taken in any order. The BASIC version of the program RFCON follows. 


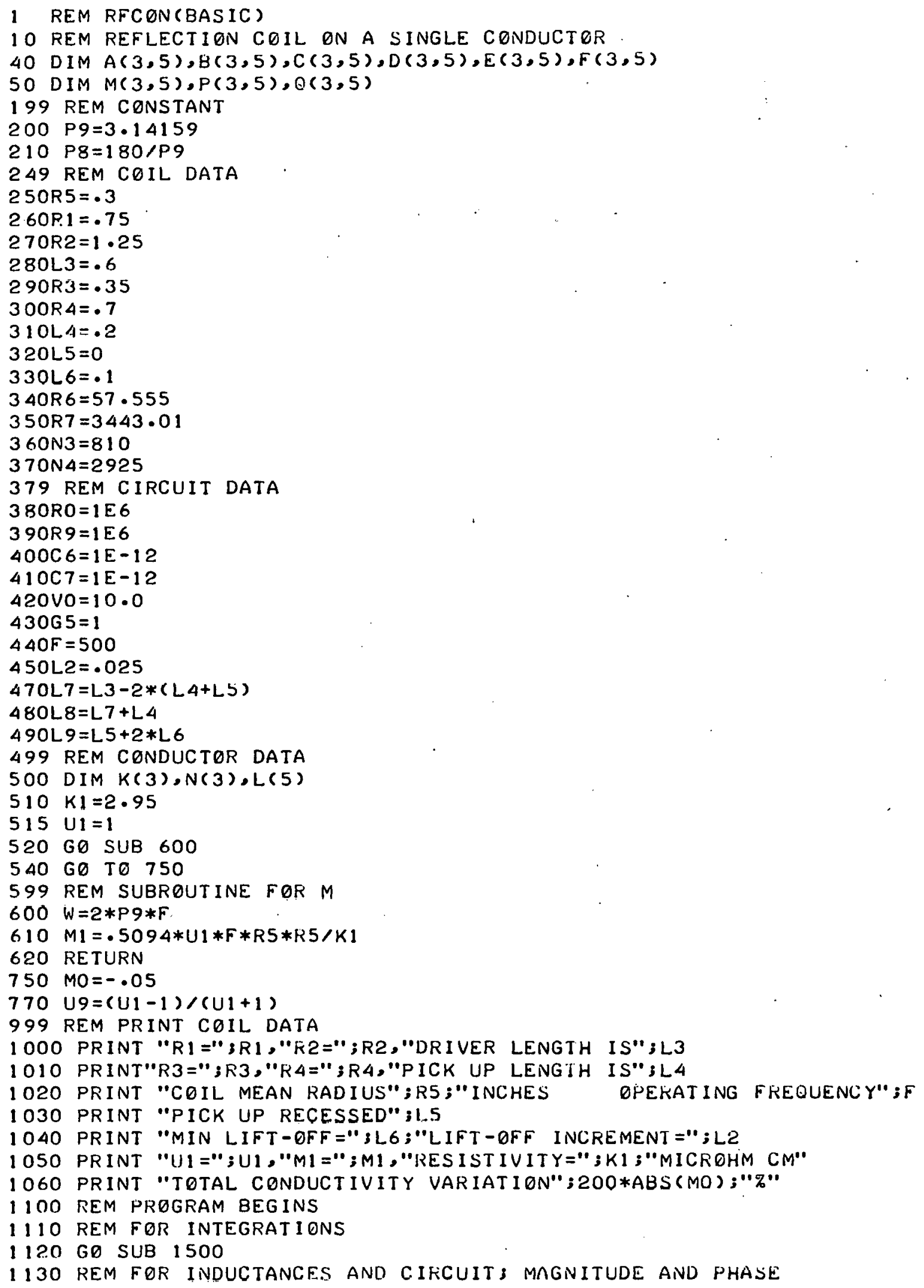




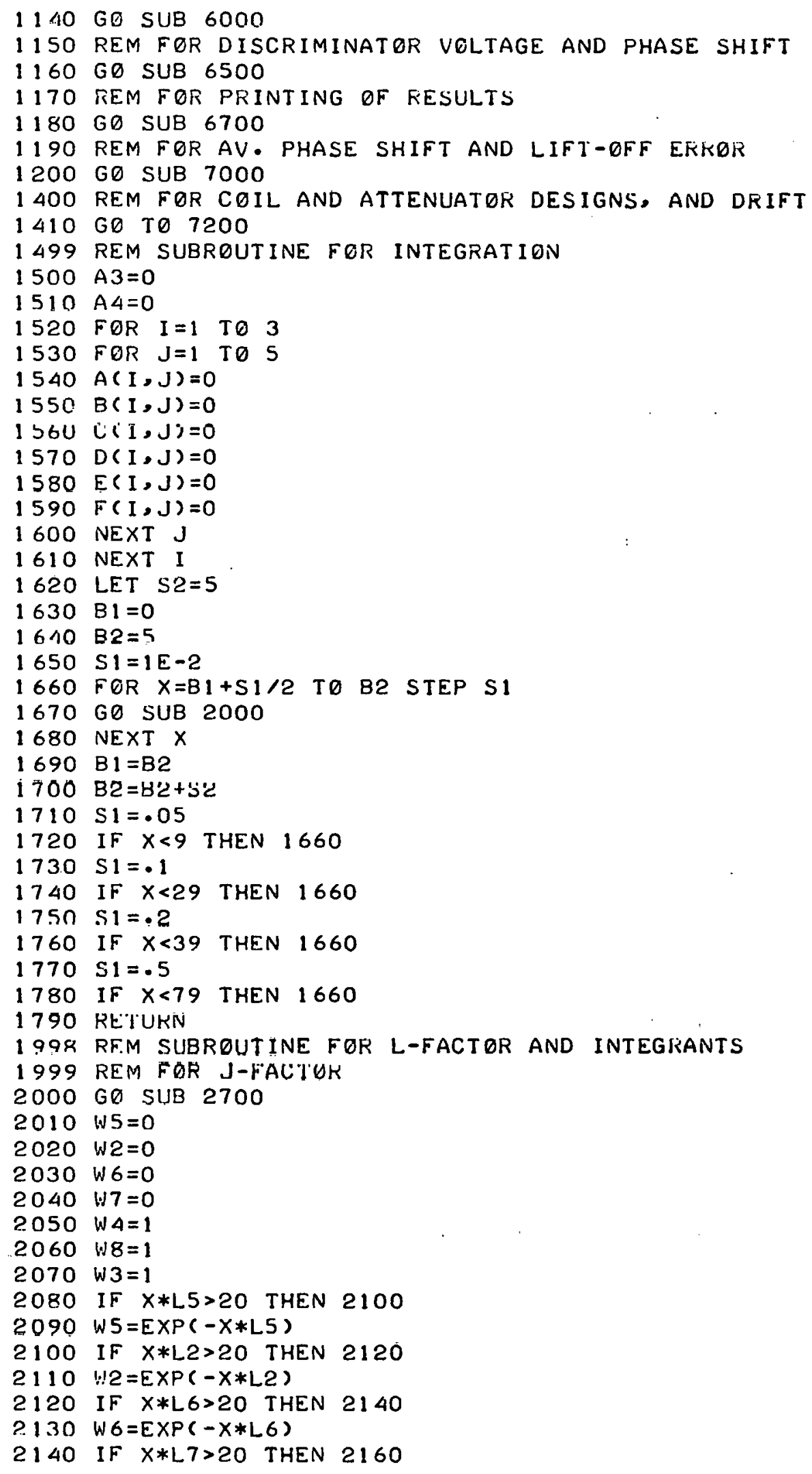




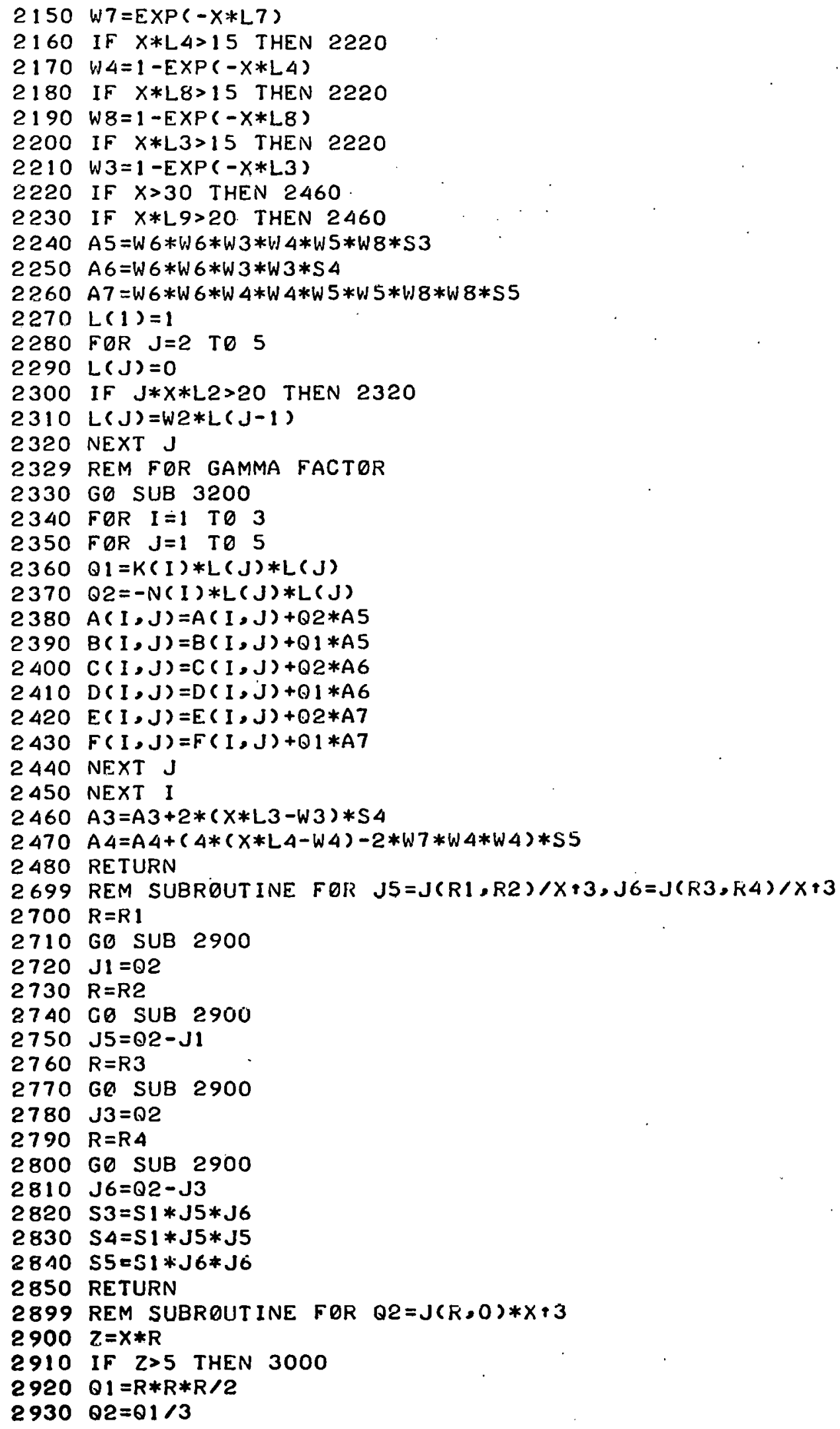




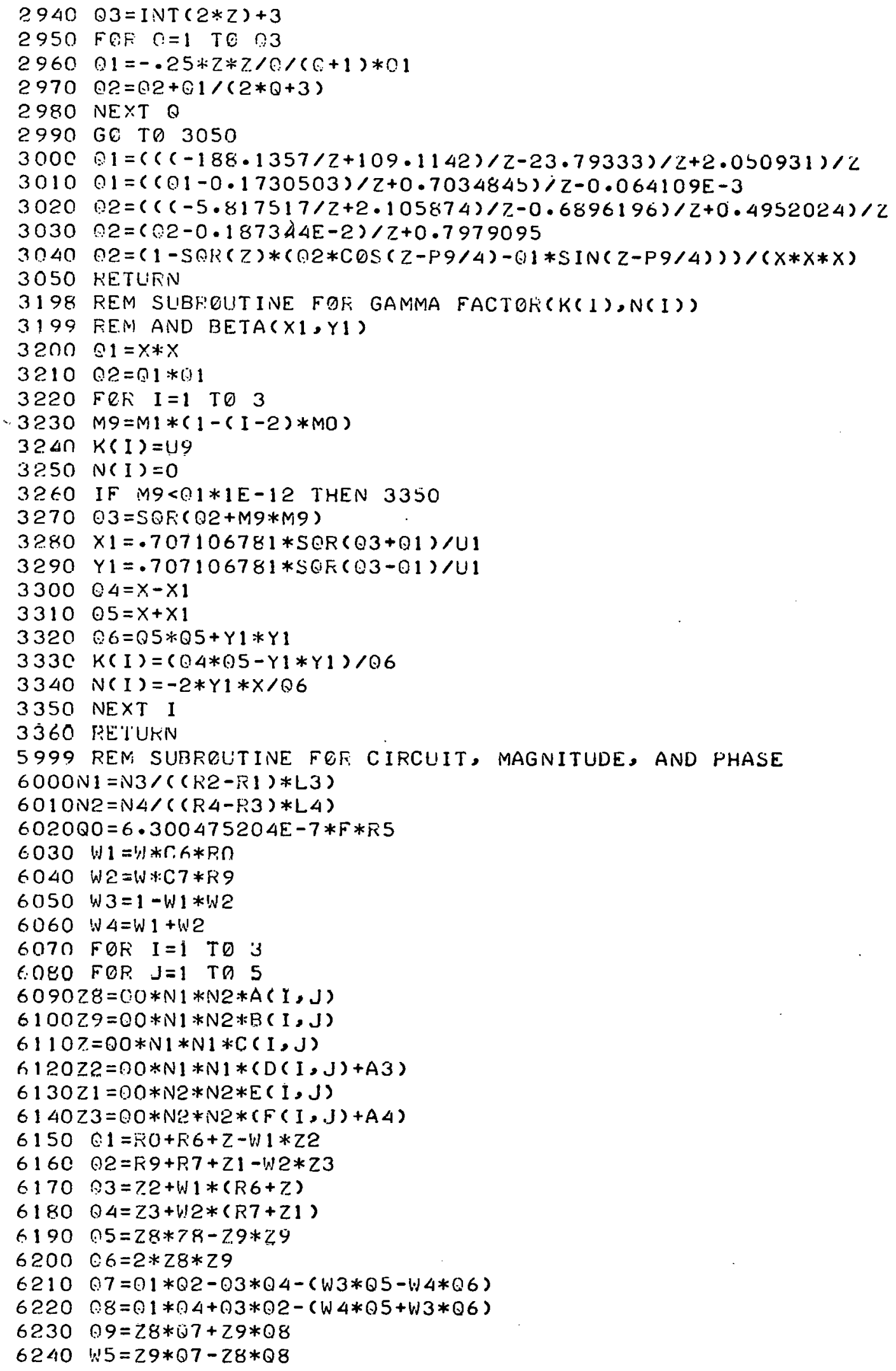




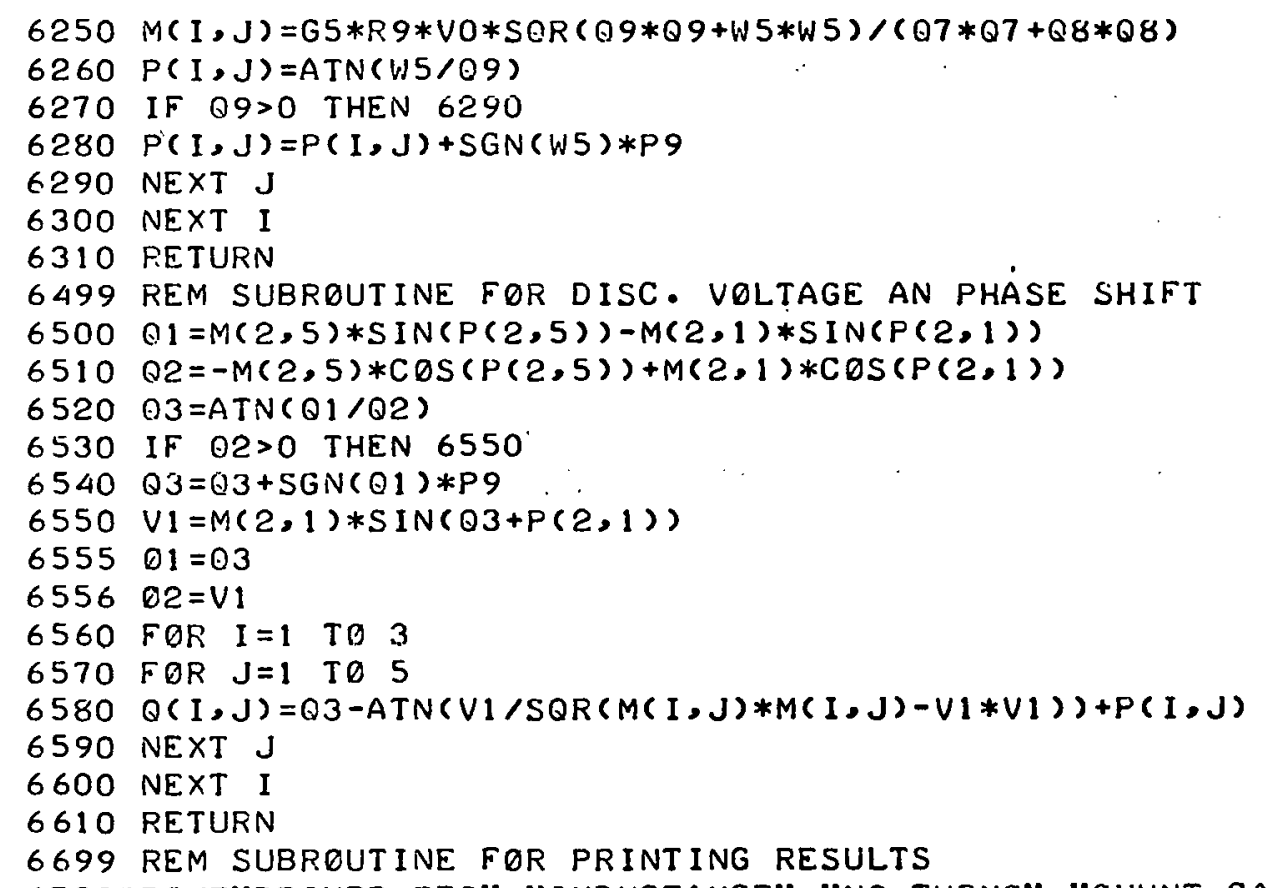

6700PRINT"DRIVER RES","INDUCTANCE","NO TURNS","SHUNT CAP","NOR IM PT" 6710 PRINTR $6,00 * N 1 * N 1 * A 3 / W, N 3, C 6,(D(2,3)+A 3) / A 3$

6720PRINT"PICKUP RES","INDUCTANCE","NO TURNS","SHUNT CAP","NOR IM PT" $6730 P R I N T R 7, Q 0 * N 2 * N 2 * A 4 / W, N 4, C 7,(F(2,3)+A 4) / A 4$

$6740 P R I N T$ "DRIVING VOLT","SERIES RES","AMP GAIN","INPUT IMP."

675OPRINTVO, RO, G5, R9

$6760 P R I N T$ "DISCRIMINATOR VOLTAGE IS";VI

6770 PRINT

6780 PRINT L6,L6+L2,L6+2*L2,L6+3*L2,L6+4*L2

6790 FOR $\quad I=1 \quad T 03$

6800 PRINT

6810 PRINT $M(I, 1), M(I, 2), M(I, 3), M(I, 4), M(I, 5)$

6820 PRINT $P(I, 1), P(I, 2), P(I, 3), P(I, 4), P(I, 5)$

6830 PRINT $Q(I, 1), Q(I, 2), Q(I, 3), Q(I, 4), Q(I, 5)$

6840 NEXT I

6850 RETURN

6999 REM SUBROUTINE FØR AV. PHASE SHIFT AND LIFT-QFF ERRQR

$7000 \quad 01=Q(1,1)$

$7010 \quad 02=Q(1,1)$

7020 FOR $J=2$ TO 5

7030 IF $Q(1, J)<Q 1$ THEN 7050

$7040 \quad Q 1=Q(1, J)$

7050 IF $Q(1, J)>Q 2$ THEN 7070

$7060 \quad 02=0(1, \mathrm{~J})$

7070 NEXT J

$7080 \quad \theta=(\theta(1,1)+\theta(1,2)+\theta(1,3)+\theta(1,4)+\theta(1,5)) / 5$

$7090 \quad \theta=\theta-(\theta(3,1)+\theta(3,2)+\theta(3,3)+\theta(3,4)+\theta(3,5)) / 5$

$70920=0$

7100 PRINT"PHASE SHIFT";Q;"LIFT-QFF";Q1-Q2;"\%";100*(Q1-Q2)/Q

7110 PRINT "DEGREE" $\$ Q * P 8,(Q 1-Q 2) * P 8$

7120 RETURN

7199 REM FOR COIL DESIGN, ATTENUATOR, DRIFT, AND EXIT

$7200 P R I N T " 1$ COIL DESIGN 2 ATTEN. DESIGN 3 DRIFT CHECK 4 CON CAL"

7210 INPUT N5 
7 2ROPPINT

$72300 N$ NS GO TO $7300,8200,8600,9900$

7299 REM FER COIL DESIGN

7300 PRINT "DRIVER HIRE GAGE, TURNS, PICK-UP WIRE GAGE, TUKNS"

7310 INPUT $01,02,03,04$

7319 REM FER DRIVER

7320 : $1=R 1$

$7330 W 2=R 2$

7340 W $3=$ L 3

7350 G0 SUB 7510

7360 N3 $=02$

7370 R6 $=09$

7380 PRINT "DRIVER";N3 3"TURNS OF \#";G;"WIRE";

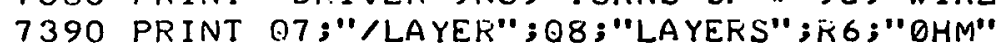

7399 REM FOR PICKUP

$7400 \quad Q 1=03$

1 100 192

$7420 \quad W_{1}=\mathrm{R} 3$

7430 W2-R4

$7440 \quad W 3=L 4$

7450 GO SUB 7510

7460 N4 $=$. 2

$7470 \mathrm{R} 7=2 * 199$

7480 PRINT "PICKUP";N4;"TURNS EA \#";G;"WIRE";

7490 PRINT 07;"/LAYER"; Q8;"LAYERS";R7;"QHMS TOTAL"

7500 GO TO 1140

7509 REM SUBROUTINE FER GAGE AND TURN NUMBER

$7510 W 1=W 1 * R 5$

7520 W2 $=W 2 * R 5$

$7530 W 3=W 3 * R 5$

7539 REM FOR GABE

$7540 \quad G=01$

7550 IF $G>.5$ THEN 7640

$7560 \quad Q 5=.95 * S \theta R((W 2-W 1) * W 3 / U 2)$

$7570 \quad 06=1.0371 E-5 / 05 / 05$

$7.580 \quad \mathrm{G} O=40$

$7590 \mathrm{G}=40+10 *(\operatorname{LOG}(06)-\operatorname{LOG}(.9989+.017 *(G \overline{0} / 10-1) 3) / 2 \cdot 30234$

7600 IF $A B S(G-G O)<1 E-4$ THEN 7630

$7610 \quad \mathrm{GO}=\mathrm{G}$

7620 GO TO 7590

$76.30 \quad G=I N T(G)$

7639 REM FGR TURN NUMBER ANU K6

$7640 \quad 0.6=(.9989+.017 *(G / 10-1)) * 10+(G / 10-4)$

7650 กS $=\operatorname{SOR}(1.0371 \mathrm{E}-5 / 06)$

7660 IF G> 40 THEN 7690

7670 OS $=(.460655 * \operatorname{LQG}(Q 5 * 1 E 3)-.43444) * 1 E-3+05$

7680 G0 TO 7700

$7690 \quad 05=(98.02228 * 05+2.56791 E-2) * 1 E-3+05$

$7700 \quad 67=I N T(W 3 / 05)$

$7710 \quad 08=I N T((W 2-W 1) / 05)$

7720 IF $Q 2>.5$ THEN 7740

$77.30 \quad 02=07 * 08$

7740 Q9 $=$ (N) $26 *(W 2+W 1) * P 9 / 12$

7750 RETLIRN

8199 REM FOR ATTENUATGR.DESIGN

R2OO PRINT "DRIVEF SERIES KES, SHUNT CAP, PICK-UP SHUNI KES, SHUIVI C̈HP" 8210 INPIT $B 1,02,03,04$

8220 IF $Q 1=0$ THEN 8240 


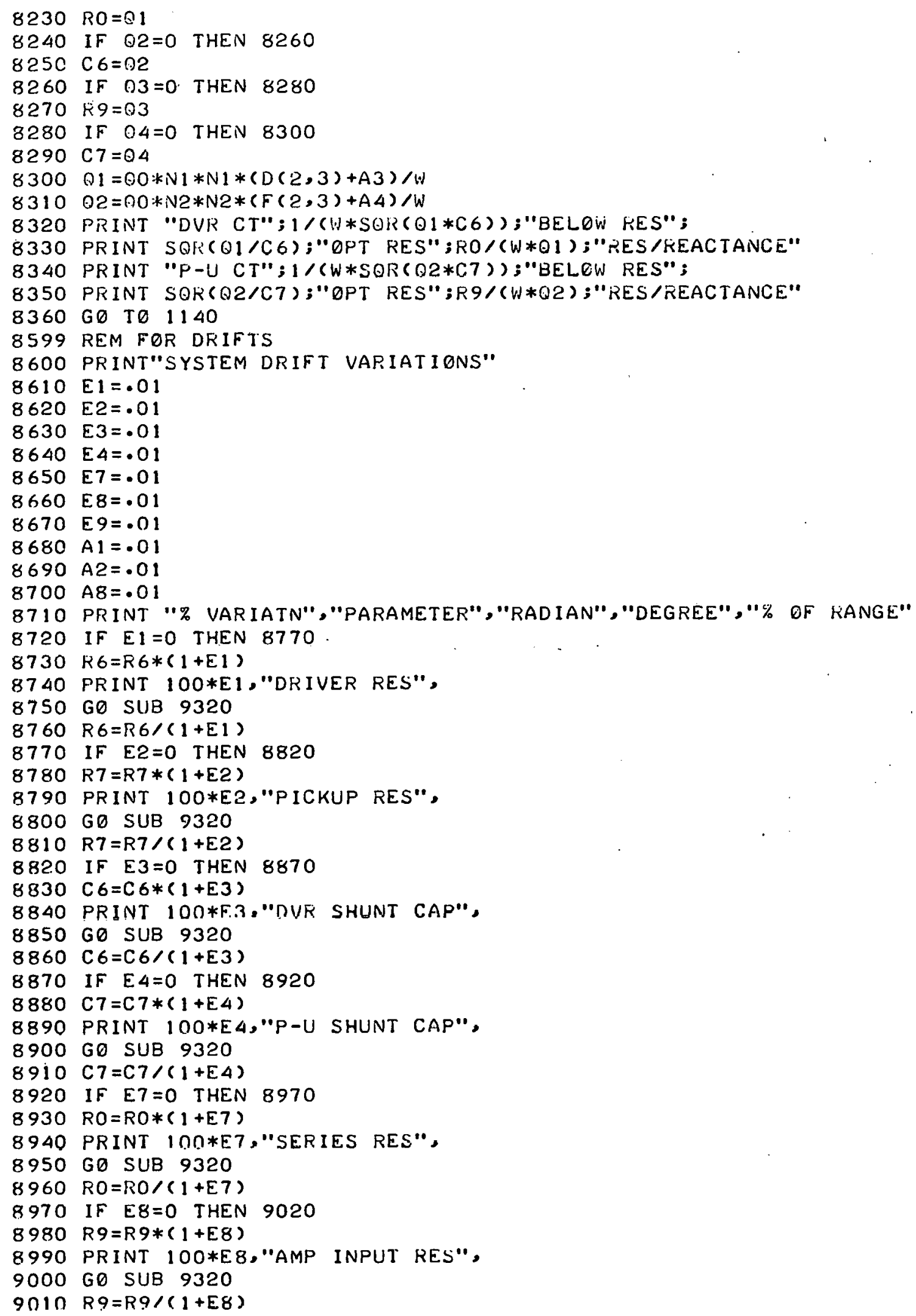




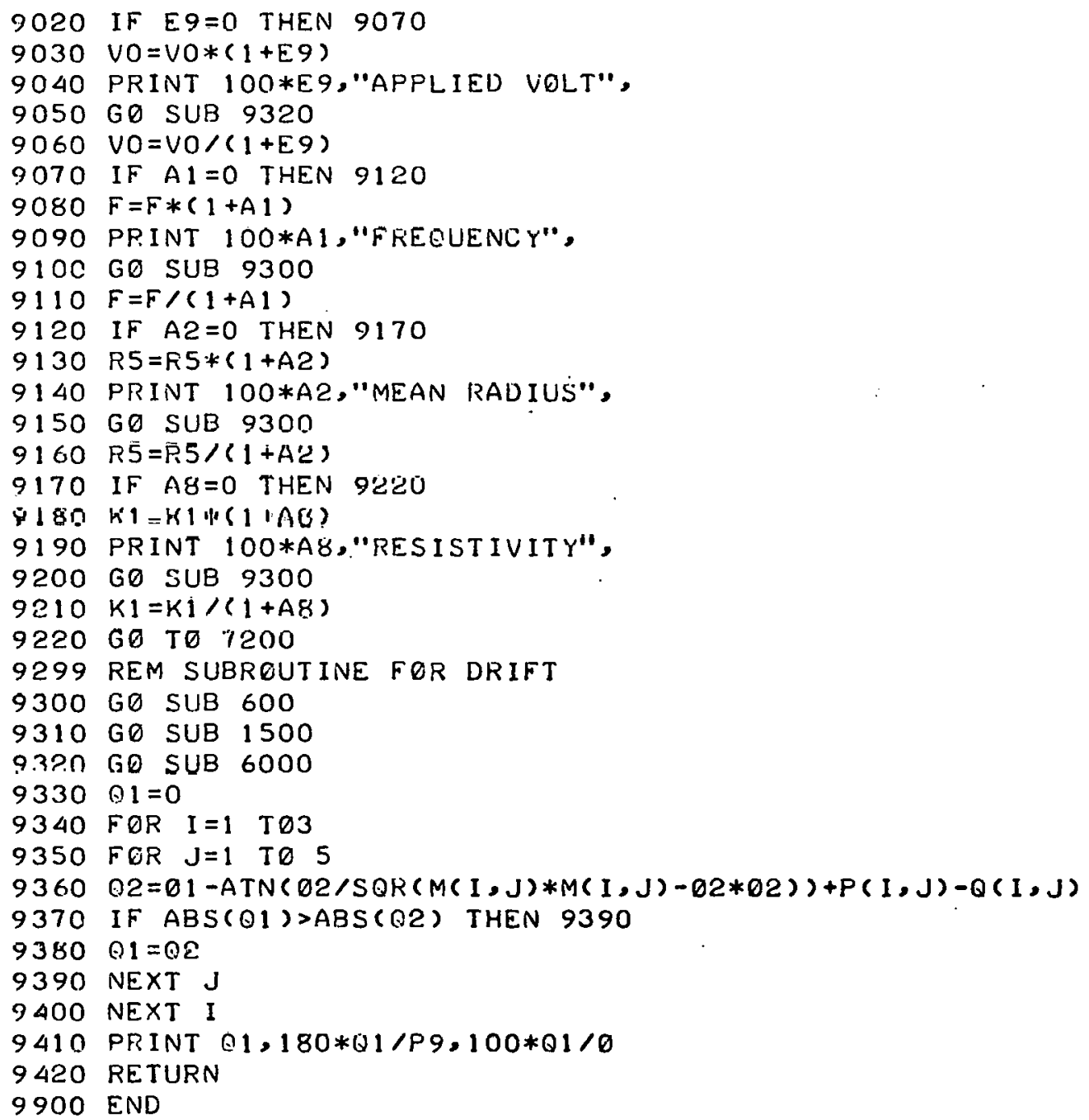


RFCON, FORTRAN Version

The FORTRAN version of RFCON is very similar to the BASIC version. The line numbers given are only for identification and editing purposes and have no effect on the actual execution of the FORTRAN program. The input data for the program is contained in lines 250 through 480 . The data must be typed in the seventh column, or six spaces must first be. typed. The data are inputed as follows:

\begin{tabular}{|c|c|}
\hline 00250 & $\mathrm{R} 5 \cdot=($ coil mean radius in inches $)$ \\
\hline 00260 & $\mathrm{Rl}=$ (normalized inner radius of driver coil) \\
\hline 00270 & $\mathrm{R} 2=$ (normalized outer radius of driver coil) \\
\hline 00280 & L3 = (normalized length of driver coil) \\
\hline 00290 & $R 3=$ (normalized inner radius of pickup coil) \\
\hline 00300 & R4 = (normalized outer radius of pickup coil) \\
\hline 00310 & L4 = (normalized length of pickup coil) \\
\hline 00320 & $\begin{aligned} \text { L5 }= & \text { (normalized length of recess of each pickup coil from } \\
& \text { the face of the driver coil). }\end{aligned}$ \\
\hline 00330 & L6 = (normalized minimum lift-off of the driver coil) \\
\hline 00340 & $\mathrm{R} 6=$ (resistance of driver coil in ohms) \\
\hline 00350 & $R 7=$ (resistance of both pickup coils in ohms) \\
\hline 00360 & N3 $=$ (number of turns on the driver coil) \\
\hline 00370 & $N_{4}=$ (number of turns on each pickup coil) \\
\hline 00380 & $R O=$ (driver amplifier series resistance in ohms) \\
\hline 00390 & $\mathrm{R} 9=$ (pickup amplifier shunt resistance in ohms) \\
\hline 00400. & C6 - (shunt capacitance of driver circuit in farads) \\
\hline 00410 & $\mathrm{C} 7=$ ( shunt capacitance of pickup circuit in farads) \\
\hline 00420 & vo $=$ (output voltage in volts) \\
\hline $00430^{\circ}$ & GAIN = (amplifier gain) \\
\hline 00440 & $\mathrm{FREQ}=$ (operating frequency in Hert. $\mathrm{z}$ ) \\
\hline 00450 & L2 $=$ (normalized lift-off increment of the driver coil) \\
\hline 00460 & RIOL $=$ (nominal electrical resistivity in microhm-cm) \\
\hline 00470 & $\mathrm{Ul}=$ (relative magnetic permeability) \\
\hline & M9 $=$ (fractional variation of conductivity) \\
\hline
\end{tabular}


The print-out of the FORIRAN version of RFCON is practically identical to the BASIC version and will not be repeated. The main difference is that the question mark is not printed out when the program is ready to accept data. The Coil Design, Attenuator Design, Drift Check, and Continue Calculations options are the same. The line numbers, constant names, and parameter varied in the drift calculations are as follows :

\begin{tabular}{|c|c|c|}
\hline Line Number & Constant & Parameter Varied \\
\hline 03120 & DRI & Driver Resistance \\
\hline 03130 & DR2 & F1ckup Résistanco \\
\hline 03140 & DR3 & Driver Shunt Capacitance \\
\hline 03150 & DR4 & Pickup Shunt Capacitance \\
\hline 03160 & DR5 & Series Resistance \\
\hline 03170 & DR6 & Amplifier Input Resistance \\
\hline 03180 & DR7 & Applied Voltage \\
\hline 03190 & DR8 & Frequency \\
\hline 03200 & DR9 & Mean Radius \\
\hline 03210 & DRIO & Resistivity \\
\hline
\end{tabular}

For example, to vary the driver resistance by $2 \%$, one would type: 03120 DRI $=0.02$

As in the BASIC version, the last three drifts require that the entire numerical integration be repeated and are relatively long running. If any of the drifts is set equal to zero, it wlll ve omittcd from the drift calculations.

\section{Semple Calculation of RFCON.F4}

Let us suppose that we wish to design a reflection type coil, identical to the one designed by the BASIC version. We put the following data in the program (generally by using the EDIT RECON.F4 command on the PDP-10 and inserting the statements). All linear dimenslons are normalized by dividing by the coil mean radius, except the coil mean radius, which is in inches. 


\begin{tabular}{|c|c|}
\hline 00250 & $\mathrm{R} 5=.300$ \\
\hline 00260 & $\mathrm{RI}=.75$ \\
\hline 00270 & $\mathrm{R} 2=1.25$ \\
\hline 00280 & $\mathrm{I} 3=.6$ \\
\hline 00290 & $\mathrm{R} 3=.35$ \\
\hline 00300 & $\mathrm{R} 4=.70$ \\
\hline 00310 & $\mathrm{LL}_{4}=.2$ \\
\hline 00320 & $\mathrm{I.} 5=0.0$ \\
\hline 00330 & $\mathrm{~L} 6=.1$ \\
\hline 00340 & $\mathrm{R} 6=57.555$ \\
\hline 00350 & $\mathrm{R} 7=3443.01$ \\
\hline 00360 & $\mathrm{~N} 3=810.0$ \\
\hline 00370 & $\mathrm{~N} 4=2925.0$ \\
\hline 00380 & $\mathrm{RO}=1 . \mathrm{E} 6$ \\
\hline 00390 & $\mathrm{R} 9=1 . \mathrm{E} 6$ \\
\hline 00400 & $\mathrm{C} 6=1 . \mathrm{E}-12$ \\
\hline 00410 & $\mathrm{C} 7=1 \cdot \mathrm{E}-12$ \\
\hline 00420 & $\mathrm{VO}=10$ \\
\hline 00430 & GAIN $=1$ \\
\hline 00440 & $F R E Q=500$ \\
\hline 00450 & $\mathrm{~L} 2=.025$ \\
\hline 00460 & $\mathrm{RHOI}=2.95$ \\
\hline 00470 & $\mathrm{UI}=1.0$ \\
\hline 00480 & $\mathrm{~N} 9=.05$ \\
\hline
\end{tabular}

The FORTRAN program may now be executed. The print-out will be essentially identical to the BASIC print-out and will not be repeated. The FORTRAN version of RFCON follows. 
OOOIOC IN THIS PROGRAM, RHOI IS THE RESISTIVITY

OOO20C SIGMA IS THE GAMMA FACTOR

00030

00040

00050

00060

00070

00080

00090

00100

00110 COMPLEX BETA1, BETA2, EX1, RNUM, DEN, SIGMA COMPLEX TMUT,DRIVER,PICKUP

REAL L3,L4,L5,L6,L2,N3,N4,M9,M9A,KI

COMMON $X, Z, Q 1, P I / B 1 / R 1, R 2, R 3, R 4, L 3, L 4, R 0, R 6, R 7$

COMMON /B1/R9,C6,C7,VO,GAIN,W,FREQ,R5,N3,N4

COMMON /B2/TMUT, DRIVER,PICKUP,AIR1, AIR2/B3/GAGE, XIN

COMMON /B3/XOUT, XLEN, TURNS, NIA,JI,PERLAY, XLAY

DIMENSION RL(5),SIGMA(3), TMUT $(3,5), \operatorname{DRIVER}(3,5)$

00120

00130

00140

$00150 \mathrm{C}$

DIMENSI ON PICKUP $(3,5), \operatorname{TMAG}(3,5), \operatorname{PHASE}(3,5), \operatorname{SHIFT}(3,5)$

EQUIVALENCE (RHO1,KI), (GAIN,G5), (FREQ,F)

$P I=3.14159265$

$R A D=180 \cdot 0 / P I$

$00160 \mathrm{C}$

$0.17 n$.

$00180 \mathrm{C}$

$00130 \mathrm{C}$

$00200 \mathrm{C}$

$00210 \mathrm{C}$

00220

$00230 \mathrm{C}$

$J K L=0$

$00240 \mathrm{C}$

00250

00260

00270

00280

00290

00300

00310

00320

00330

00340

00350

00360

00370

00380

00390

00400

00410

00420

00430

00440

00450

00460

00470

00480

00490

00500

00510

$00520 \mathrm{C}$
00530

00540

00550

00560

00570

HE FOLLOWING ARE INPUT DATA FOR THE PARAMETERS OF

THE COILS, MATERIAL, AND CIRCUIT

$\mathrm{R} 5=.3$

$\mathrm{R} I=.75$

$\mathrm{R} 2=1 \cdot 25$

$L 3=.6$

$R 3=.35$

$R 4=.7$

$L A=.2$

$L 5=0 \cdot 0$

L $6=.1$

$R 6=57.555$

$R 7=3443.01$

N3 $=810 \cdot 0$

$N 4=2925 \cdot 0$

$R O=1 \cdot 0 E 6$

$R 9=1 \cdot 0 E 6$

$\mathrm{C} 6=1 \cdot \mathrm{OE}-12$

$\mathrm{C} 7=1 \cdot \mathrm{OE}-12$

$V O=10.0$

$G A I N=1 \cdot 0$.

FREQ $=500 \cdot 0$

LR $=0.025$

RHOL $=2.95$

$U 1=1 \cdot 0$

$M 9=.05$

$M 9 A=200 \cdot 0 * M 9$

$5 W=2 \cdot 0 * P I * F R E Q$

$R M 1=0.5094 * U 1 * F R E Q * R 5 * R 5 / R H 01$

THE SYSTEM PARAMETERS ARE PRINTED OUT

IF (JKL.NE.U) GO TO 105

TYPE $30, R 1, R 2, L 3$

30 FORMAT 1 IH , 3HRI $=, F 8,5,3 X, 3 H R 2=, F 8.5,3 X, 14 H D R I V E R$ LENGTH=, (F8.5)

TYPE $40, R 3, R 4, L 4$ 
00580

00590

00600

00610

00620

00630

00640

00650

00660

00670

00680

00690

00700

00710

00720

$00730 \mathrm{C}$

$00740 \mathrm{C}$

$00750 \mathrm{C}$

$00760 \mathrm{C}$

0077 OC

$00780 \mathrm{C}$

00790

00800

00810

00820

00830

00840

00850

00860

00870

00880

00890

00900

00910

00920

00930

00940

00950

00960

0097 OC ก. $980 \mathrm{C}$

$00990 \mathrm{C}$

01000

01010

01020

01030

01040

01050

01060

01070

01080

01090

01100

01110

01120

01130

01140

01150
40 FORMAT $(1 H, 3 H R 3=, F 8 \cdot 5,3 X, 3 H R 4=, F 8,5,3 X, 14 H P I C K U P$ LENGTH $=$, (F8.5) TYPE $50, R 5, F R E Q$

50 FORMAT $(1 \mathrm{H}, 17 \mathrm{HC} \oslash I L$ MEAN RADIUS $=, F 8.5,7 \mathrm{H}$ INCHES, $3 \mathrm{X}$, $120 H O P E R A T$ ING FREQUENCY $=, 1 P E 12.5$ ) TYPE 60.25

60 FORMAT (1H, 15 HPICKUP RECESSED,F8.5) TYPE $70, L 6, L 2$

70 FORMAT $(1 \mathrm{H}, 13 \mathrm{HMIN}$ LIFT-OFF $=, F 8 \cdot 5,3 \mathrm{X}, 19 \mathrm{HL}$ IFT-OFF INCREMENT = $(F 8.5)$ TYPE $80, U 1, R M 1, R H O 1$

80 FORMAT $(1 \mathrm{H}, 3 \mathrm{HU1}=, F 6.2,5 X, 3 \mathrm{HMI}=, F 9.5,2 X, 12 \mathrm{HRES}$ IST IVITY $=$, 1 (PE12.5, 11H MICROHM CM) TYPE $90, M 9 A$

90 FORMAT ( $1 \mathrm{H}, 23 \mathrm{HCONDUCTIVITY} \mathrm{VARIATION=,F8.2,1} \mathrm{HZ)}$

THE INTEGRATION IS PERF ORMED BY THE TRAPEZOIDAL METHOD,

EVALUATING AT THE CENTER OF THE INTERVAL, FOR X LAKGE

THE INTEGRAL CONVERGES RAPIDLY,SO LARGER INTERVALS ARE TAKEN

IN THE INTEGRATION TMUT, DRIVER, PICKUP, AIRI, AND AIR2 ARE CALCULATED

$105 \mathrm{~S} 1=0.01$

$\mathrm{S} 2=5 \cdot 0$

$B 1=0.0$

$\mathrm{B} 2=\mathrm{S} 2$

$A I R 1=0.0$

$A$ IR2 $=0.0$

DQ $108 \quad \mathrm{~J}=1,3$

DO $108 \quad K=1,5$

$\operatorname{DRIVER}(J, K)=(0.0,0.0)$

$P I C K U P(J, K)=(0.0,0.0)$

$\operatorname{TMUT}(J, K)=(0.0,0.0)$

108 CONT INUE

$110 \quad I 1=(B 2-B 1) / S 1$

$X=B 1-S 1 / 2.0$

DO $170 \quad M=1,11$

$X=X+S 1$

$\mathrm{Z}=\mathrm{R} 2 * \mathrm{X}$

$Q 1=R 2$

SUBREUTINE BESSEL EVALUATES THE. INTEGRAL OF

THE PRODUCT. OF THE BESSEL FUNCTION AND ITS

ARGUMENT

CALL BESSEL(VAL2)

$\mathrm{Z}=\mathrm{R} 1 * \mathrm{X}$

Q.1 $=\mathrm{R} 1$

CALL BESSEL(VAL1)

$Z=R A * X$

$Q 1=R 4$

CALL BESSEL(VALA)

$\mathrm{Z}=\mathrm{R} 3 * \mathrm{X}$

Q1 $=R 3$

CALL. BESSEL (VAL3)

$S 3=S 1 *(V A L 4-V A L 3) *(V A L 2-V A L 1)$

$S 4=S 1 *(V A L 2-V A L 1) *(V A L 2-V A L 1)$

$S 5=S 1 *(V A L 4-V A L 3) *(V A L 4-V A L 3)$

$E \times 3=E \times P(-X * L 3)$

$W 1=1 \cdot 0-E \times 3$

$\operatorname{EXA}=\operatorname{EXP}(-X * L 4)$ 


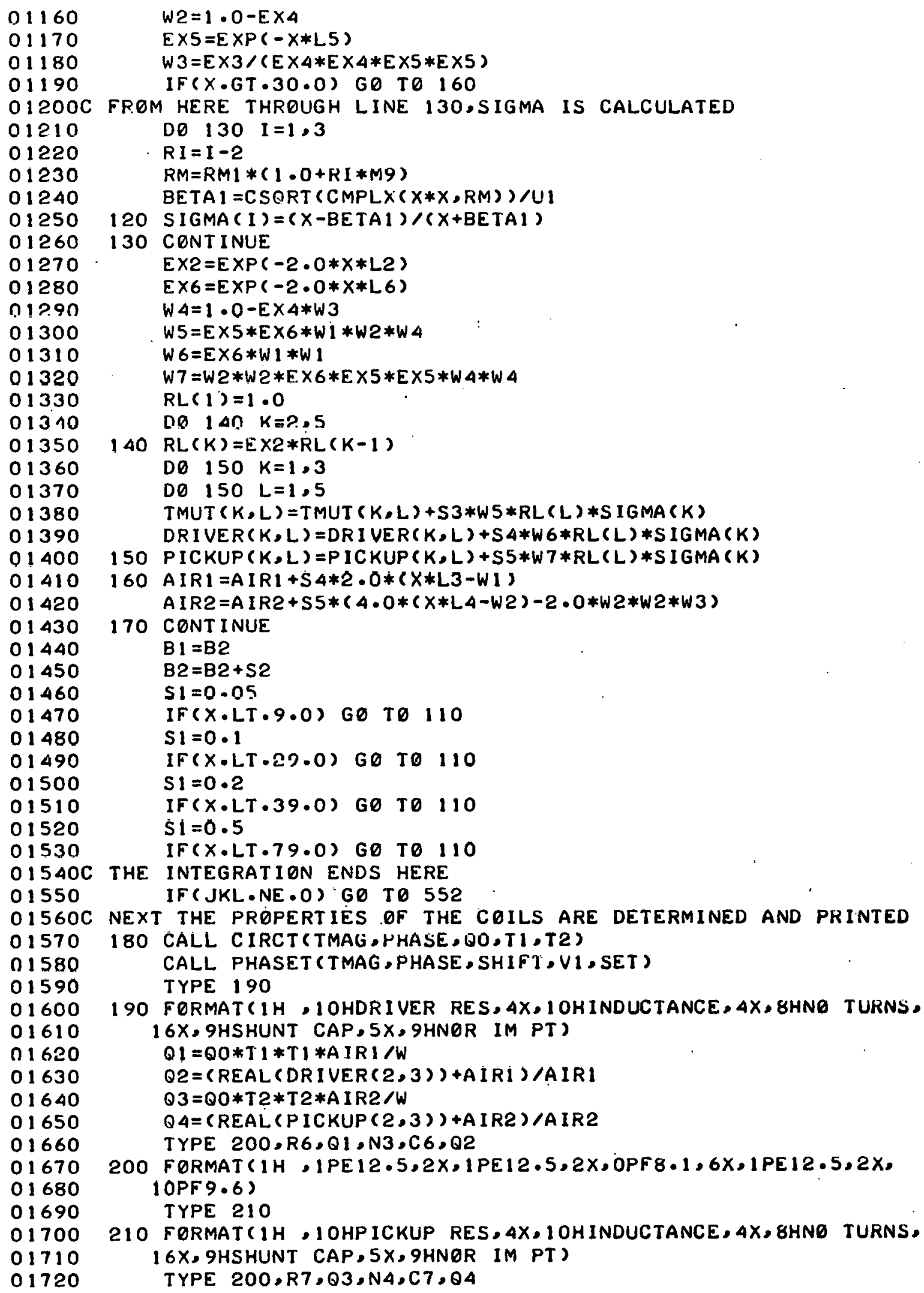




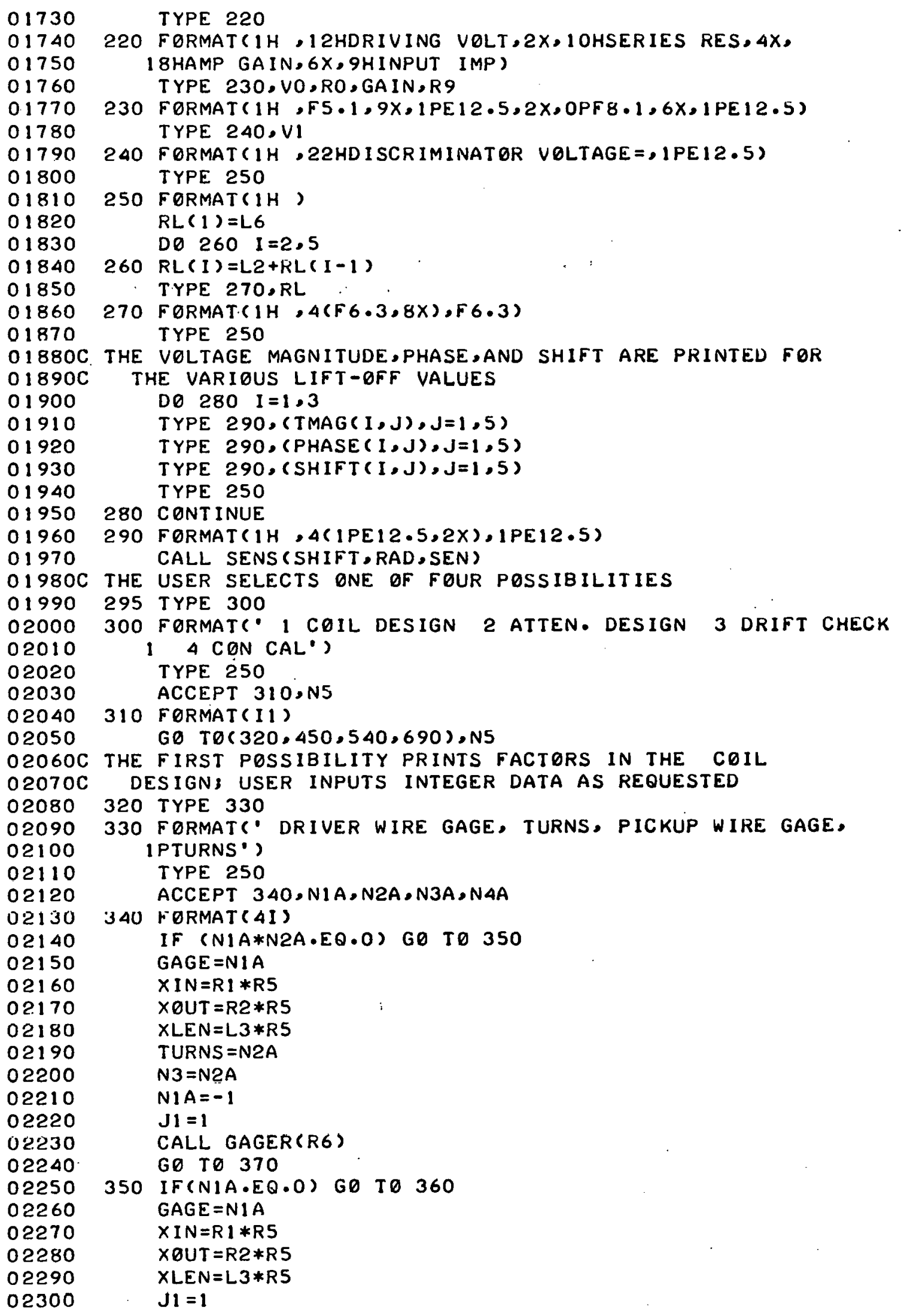




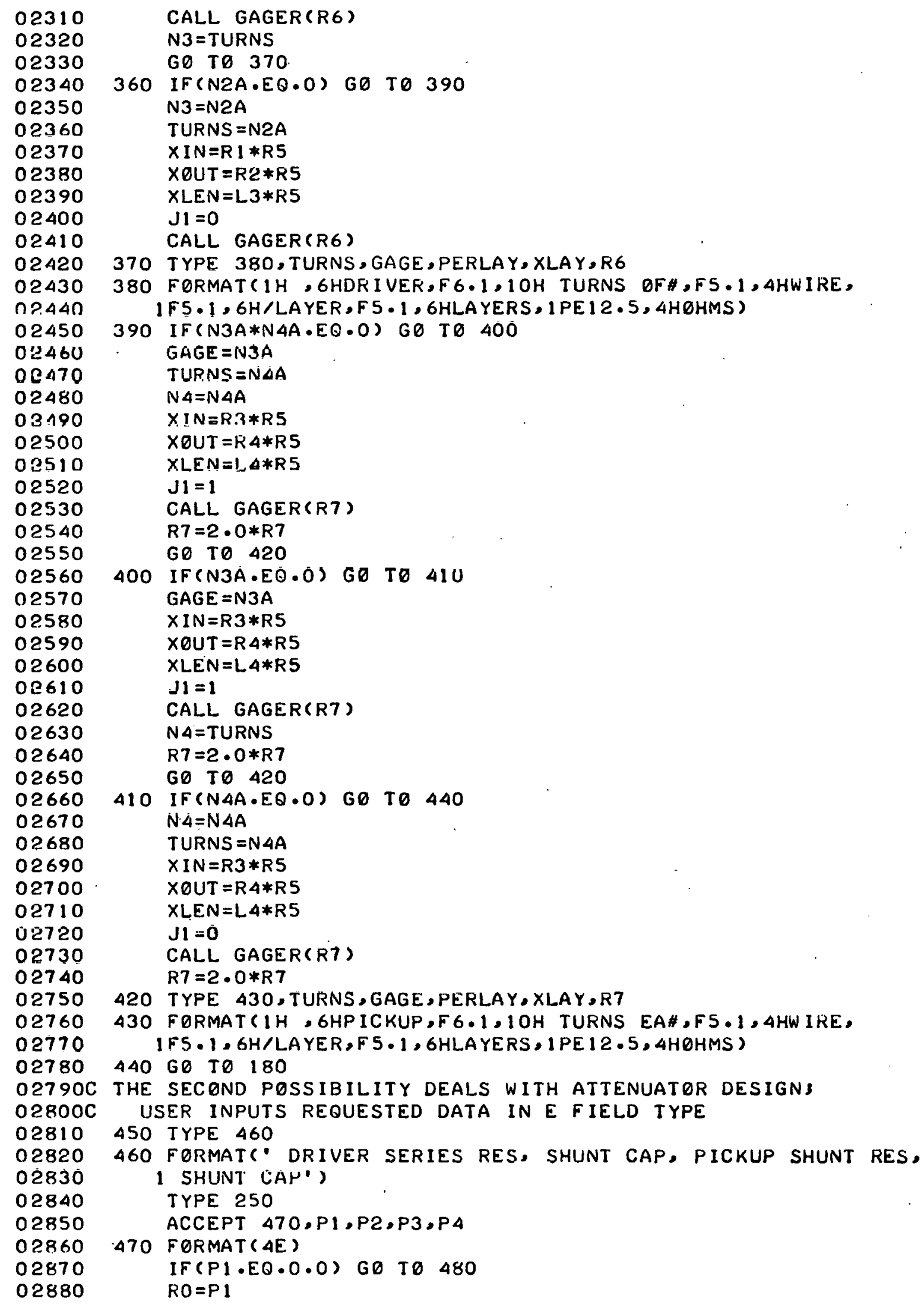




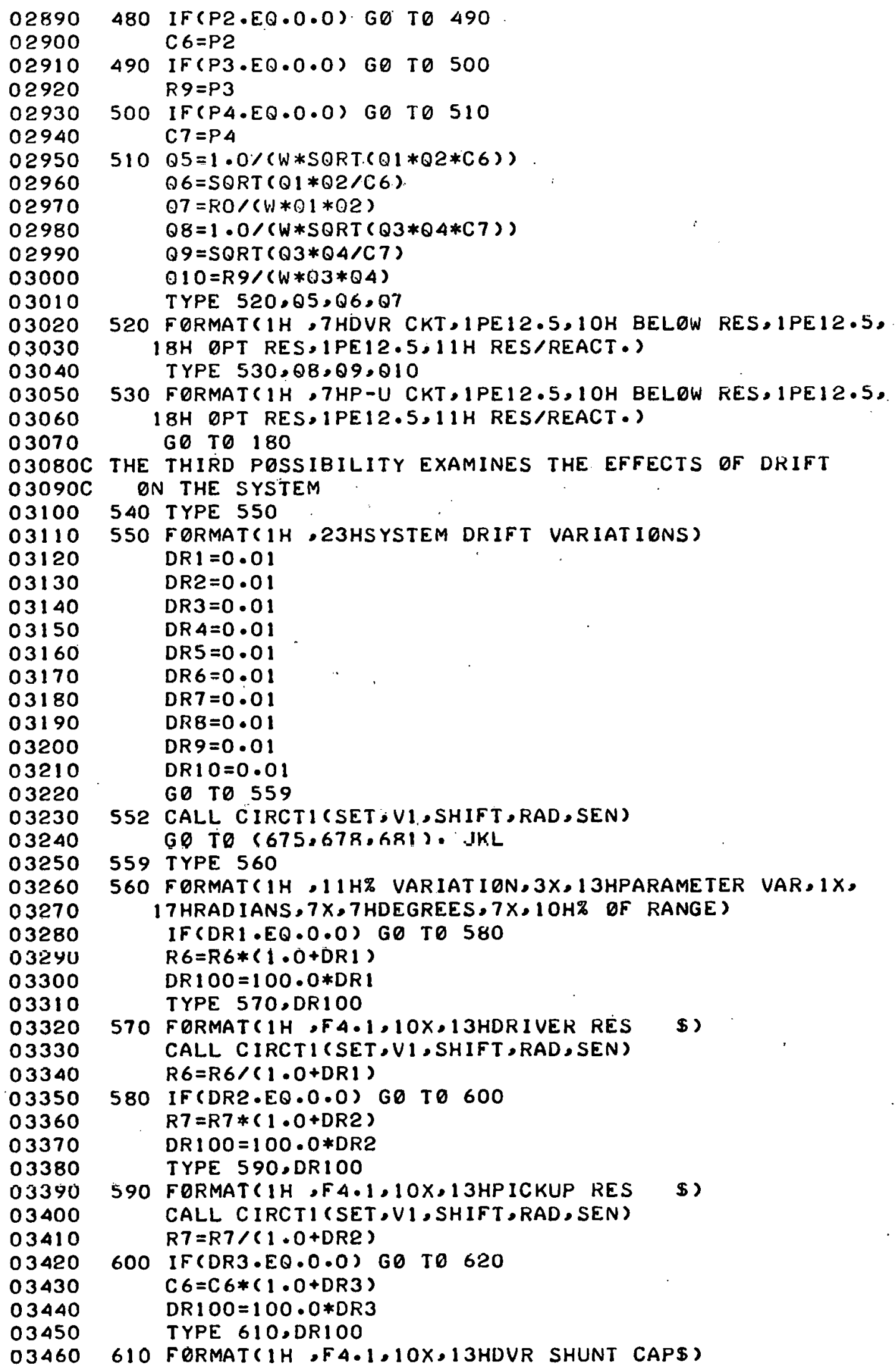


03470

03480

03490

03500

03510

03520

03530

03540

03550

03560

03570

03580

03590

$0.3 \mathrm{k} n \mathrm{n}$

03610

03680

ก.36.30

03640

03650

03660

03670

03680

03690

03700

03710

03720

03730

03740

03750

03760

03770

03780

03790

03800

03810

03820

03830

03840

03850

03860

03870

03880

03890

03900

03910

03920

039.30

03940

03950

03960

03970

03980

03990

04000

04010

04020

04030

04040
CALL CIRCT 1 (SET, V1, SHIFT,RAD,SEN)

$C 6=C 6 /(1.0+D R 3)$

620 IF (DRA.EQ.0.0) GO TO 640

$C 7=C 7 *(1 \cdot 0+D R 4)$

$D R 100=100 \cdot 0 * D R 4$

TYPE $630, D R 100$

630 FORMAT ( $1 \mathrm{H}, \mathrm{F} 4,1,10 \mathrm{X}, 13 \mathrm{HP}-\mathrm{U}$ SHUNT CAPS)

CALL CIRCTI (SET, V1, SHIFT, RAD, SEN)

$C 7=C 7 /(1 \cdot 0+D R 4)$

640 IF (DRS.EQ.0.0) GO TO 660

$R O=R O *(1 \cdot 0+D R S)$

DR $100=100 \cdot 0 *$ DR5

TYPE 650, DR 100

650 FORMAT ( $1 \mathrm{H}, \mathrm{F} 4,1,10 \mathrm{X}, 13$ 3HSERIES RES S)

CALL CIRCTI (SET,VI, SHIFT, RAD, SEN)

$R O=R O /(1 \cdot 0+D R 5)$

660 IF (DR6.EQ.0.0) GD TU $67 \mathrm{i}$

$R 9=R 9 *(1 \cdot 0+D R 6)$

$D R 100=100 \cdot 0 * D R 6$

TYPE $6 \%$ O DR 100

670 FORMAT ( $1 \mathrm{H}, \mathrm{F} 4,1,10 \mathrm{X}, 13$ HAMP INPUT RESS)

CALL CIRCTI (SET,VI,SHIFT,RAD,SEN)

$R 9=R 9 /(1 \cdot 0+D R 6)$

671 IF (DR7 •EQ.0.0) GO TO 673

$\mathrm{VO}=\mathrm{VO} *(1 \cdot 0+\mathrm{DR7})$

$D R 100=100 \cdot 0 * \bar{R} \overline{7} 7$

TYPE $672, D R 100$

672 FORMAT ( $1 \mathrm{H}$, F4.1,10X,13HAPPLIED VOLT .\$)

CALL CIRCTI (SET, VI, SHIFT,RAD, SEN)

$\mathrm{VO}=\mathrm{VO} /(1 \cdot 0+\mathrm{DR7})$

673 IF (DR8.EQ.0.0) GO TO 676

FRE $Q=F R E Q *(1 \cdot 0+D R 8)$

DR1 $00=100 \cdot 0 * D R 8$

TYPE $674, D R 100$

674 FORMAT ( $1 \mathrm{H}$, F4.1,10X,13HFREQUENCY S)

JKL $=1$

GO TO 5

675 FRE $Q=F R E Q /(1 \cdot 0+D R 8)$

$J K L=0$

676 IF(DR9.EQ.0.0) G0 TO 679

$R 5=R 5 *(1 \cdot 0+D R 9)$

DR $100=100.0 *$ URY

TYPE $677, D R 100$

677 FORMAT (1H,F4.1,10X,13HMEAN KAOIUS 5$)$

$J K L=2$

GO TO 5

$678 R 5=R 5 /(1 \cdot 0+D R 9)$

$J K L=0$

679 IF (DRIO.EQ.0.0) GO TO 295

$R H \otimes 1=R H O 1 *(1.0+D R 10)$

DR $100=100 \cdot 0 * D R 10$

TYPE $680.0 R 100$

680 FURMAT ( $1 \mathrm{H}, \mathrm{H} 4 \cdot 1,10 \mathrm{x}, 13$ HRESISTIVITY \$)

$J K L=3$

GO TO 5

$681 R H 01=R H O 1 /(1 \cdot 0+D R 10)$

$\mathrm{JKL}=0$

GO TO 295 


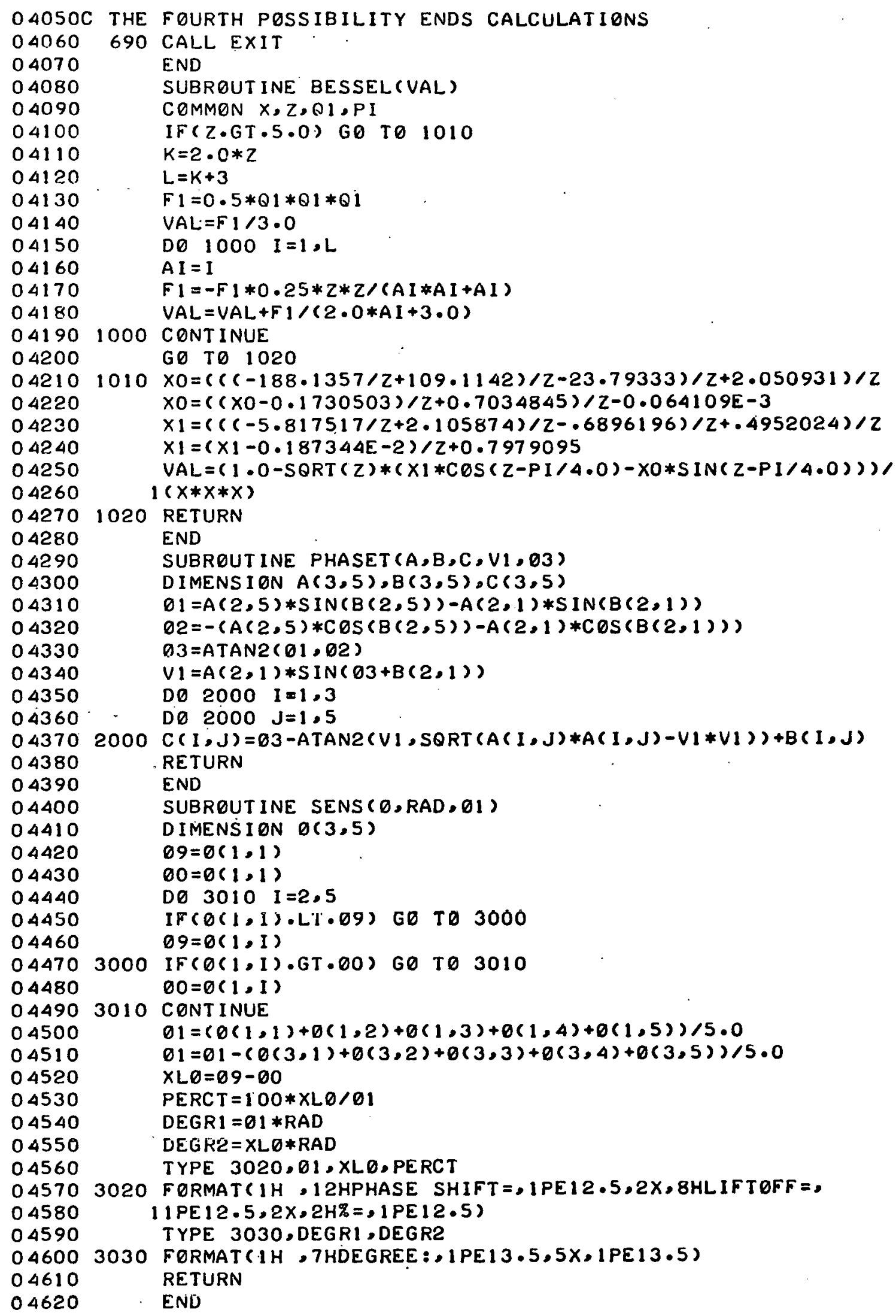




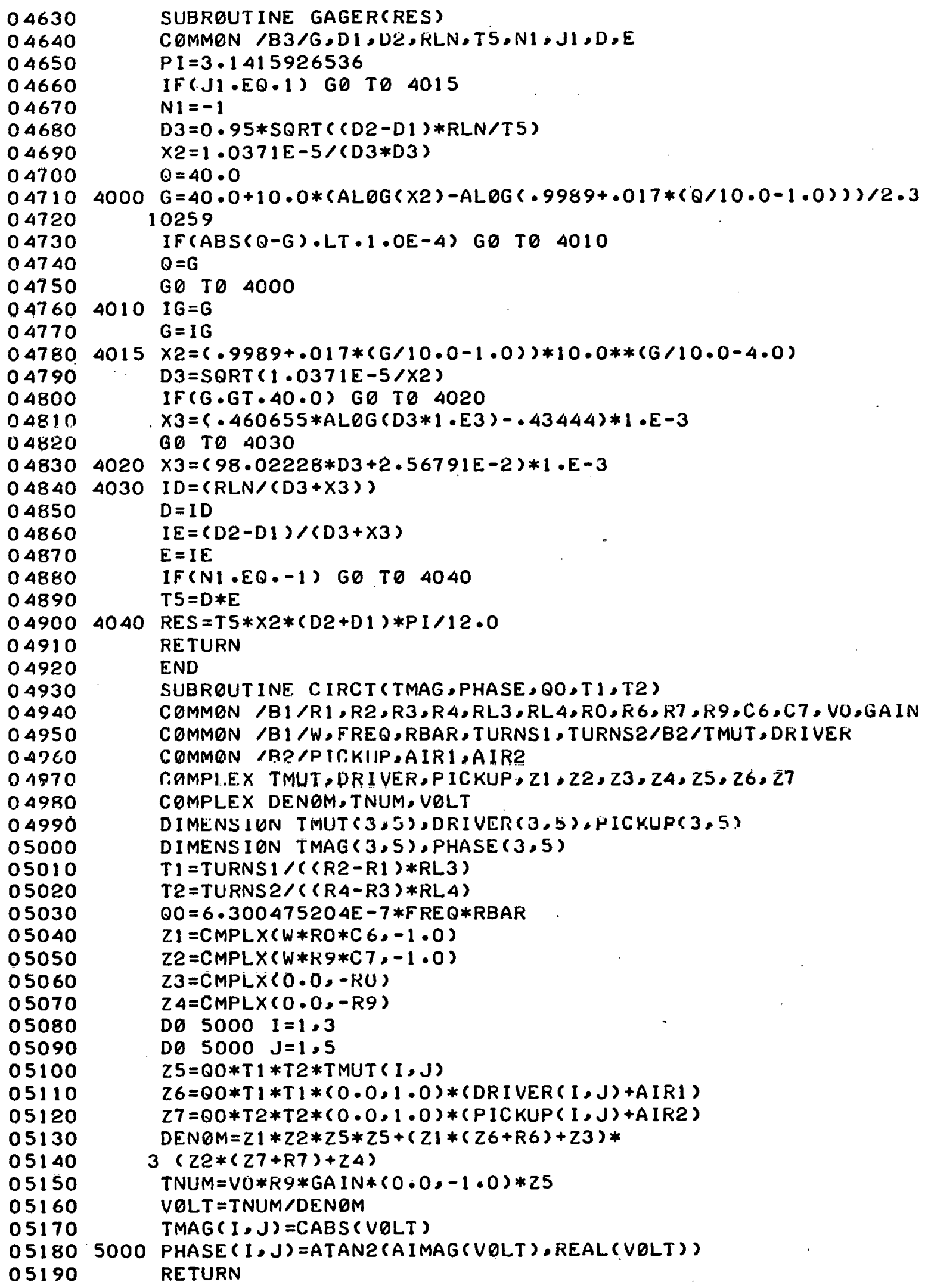




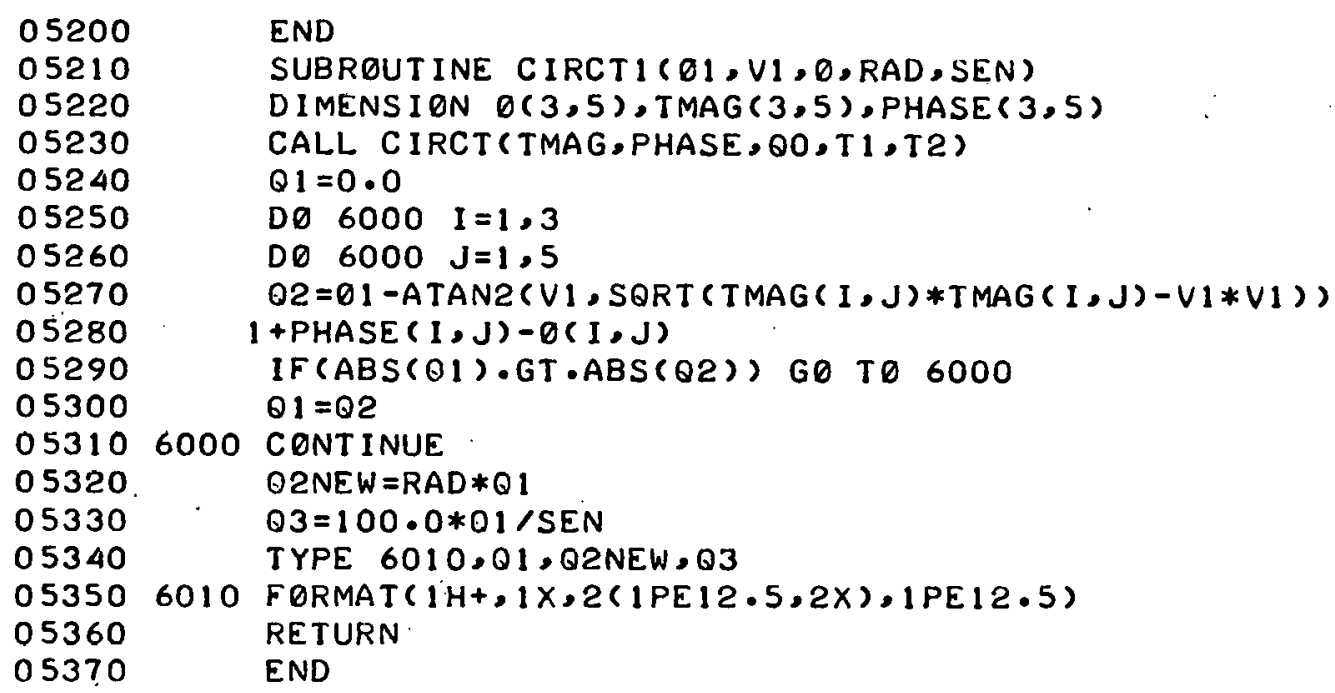


REFLECTION COIL ABOVE A CLAD CONDUCTOR

We shall now consider the case of a reflection coil above a clad conductor. This program calculates the magnitude and phase of the voltage that is fed to the phase measuring circuits of the phasesensitive eddy-current instrument and is designed to help analyze eddycurrent measurements of cladding thickness.

The program calculates the magnitude and phase of the induced voltage for five different values of lift-off with each of three different cladiing thickness values, for a total of fifteen calculations. This allows one to examine the seusllivity to lift off variations as well as cladding thickness variations. In addition, the program also calculates the phase shift with the discriminator adjusted to give the same phase on the nominal cladding thickness sample with maximum and minimum lift-off. The phase on the nominal sample with minimum liftoff is taken as zero, and all uller phase shifts are measured relative to it. The equations that are evaluated are Eq. (8) for the mutual coupling, Eq. (9) for the driver coil impedance, and Eq. (17) for the pickup coil impedance. The gamma factor for the clad conductor is given in Eq. (33). The programs are written in both BASIC and FORTRAN for use on a PDP-10. The BASIC program follows.

To use this program, one must first divide all coil and lift-off dimensions by the mean radius of the driver coil. Then the following lines must be typed into the program:

$250 \quad \mathrm{R} 5=$ (numerical value of driver coil mean radius in inches)

$260 \mathrm{Rl}=$ (numerical value of normalized driver coll inner radius)

$270 \quad R 2=$ (numerical value of normalized driver coil outer radius)

$280 \mathrm{~L} 3=$ (numerical value of normalized driver coll lenglh)

$290 \mathrm{R} 3=$ (numerical value of normalized pickup coil inner radius)

$300 \quad R 4=$ (numerical value of normalized pickup coil outer radius)

$310 \quad L 4=$ (numerical value of normalized pickup coil length)

$320 \quad \mathrm{~L} 5=$ (numerical value of normalized pickup recess from face of driver)

$330 \mathrm{~L} 6=$ (numerical value of normalized driver, coil minimum lift-off) 


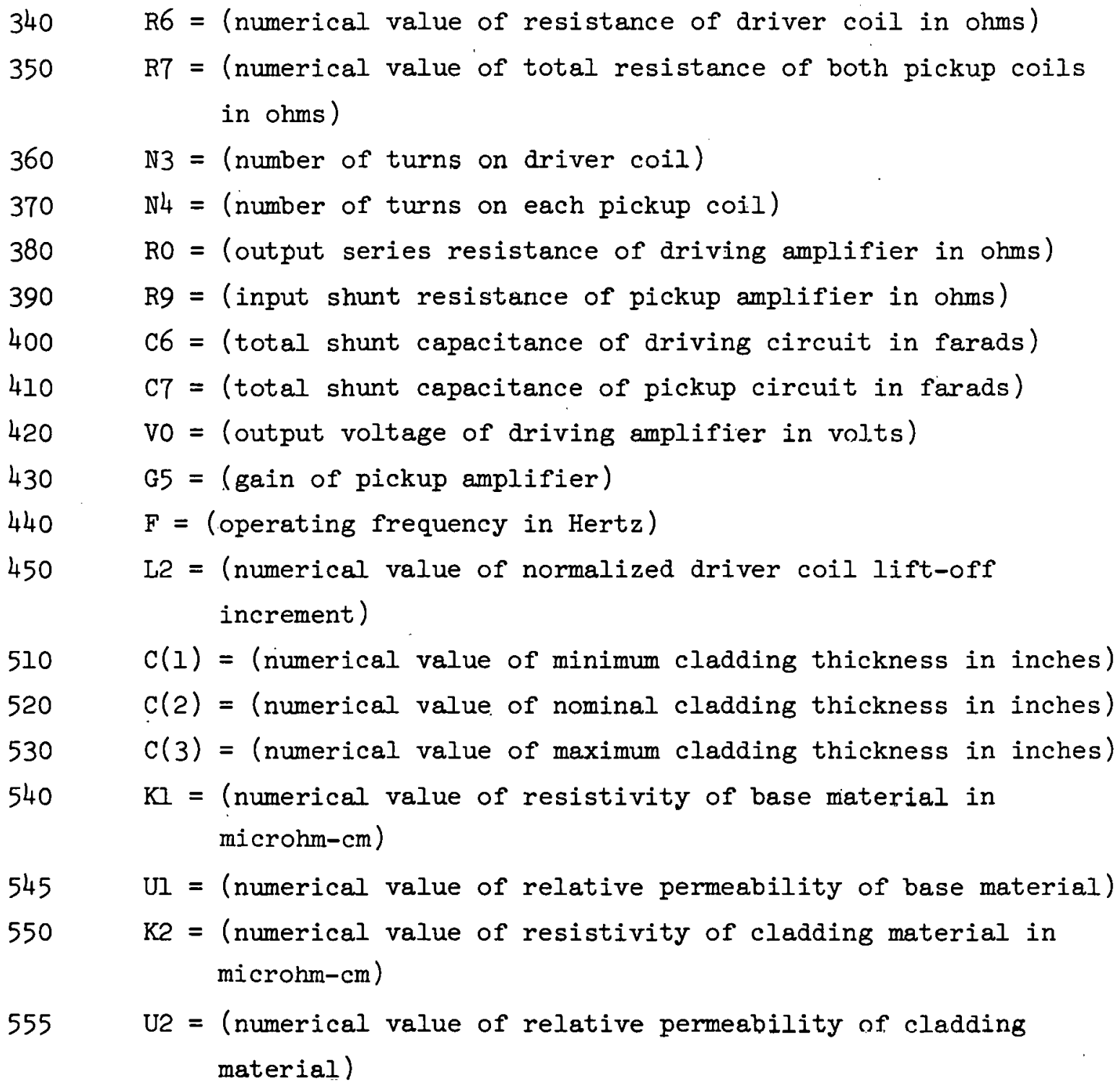

The program may now be run. The print-out by the computer will have the following format: 


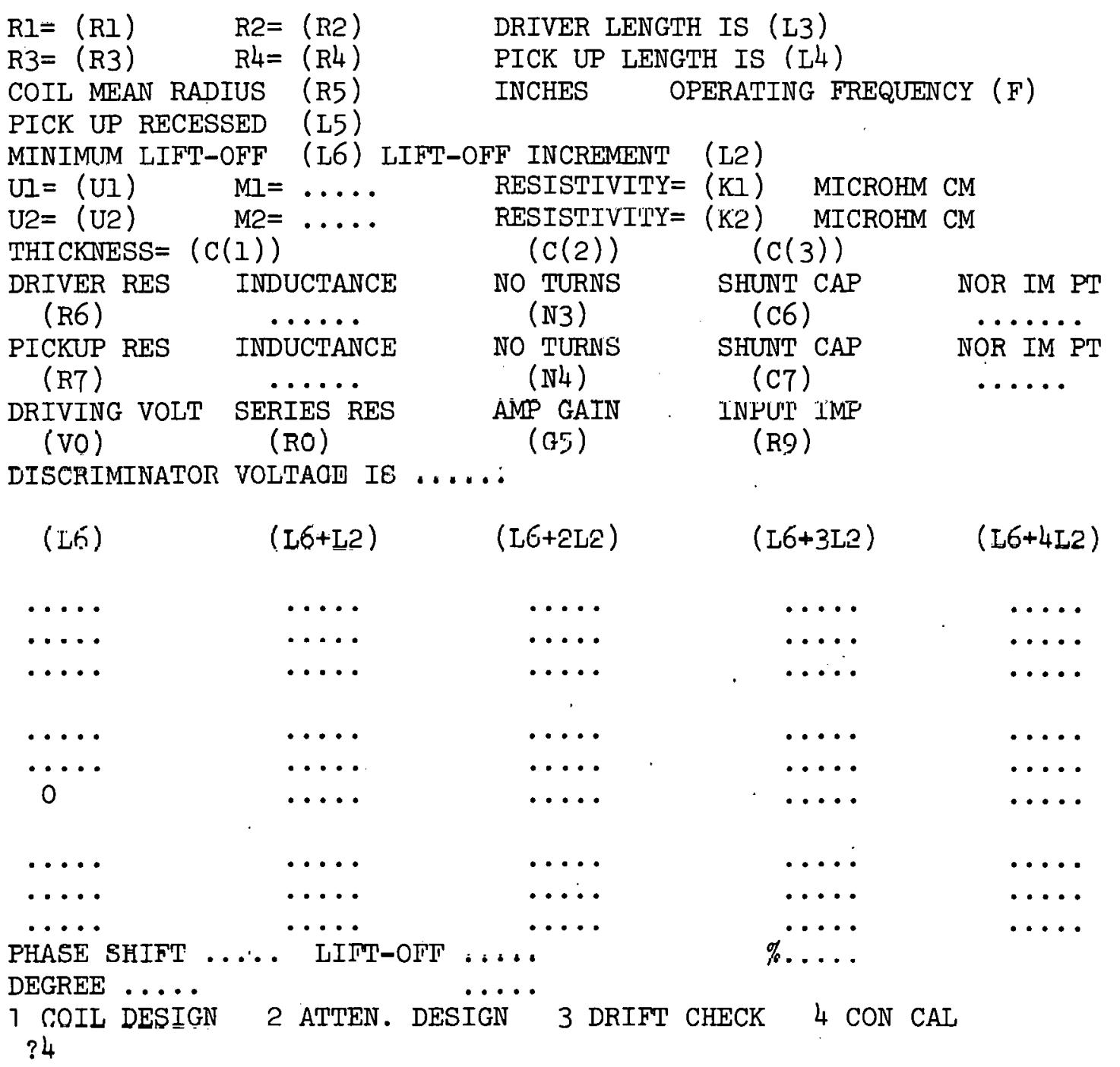

The various symbols enclosed in parentheses are used to indicate tha.t. the numerical value of the symbol will be printed.

There are five columns of data, one under each value of lift-off. Each column is divided into three sections of three lines each. These sections correspond, from top to bottom, to the triree values of cladding thickness. The three lines in each section are, from top to bottom, the magnitude of the voltage out of the pickup amplifier, the phase shift between the voltage out of the pickup amplifier and the driving voltage, and the phase shift between lue voltage out of the pickup amplifier with the discriminator set to give the same phase shift with minimum lift-off and maximum lift-off on the $C(2)$ cladding 
thickness sample. This sample is usually (but does not have to be) the nominal thickness. The phase shift in the third line is always measured from the $C(2)$ cladding thickness sample with minimum lift-off. The voltage out of the pickup amplifier will be in volts and be either peakto-peak or RMS, whichever is used for VO, the output voltage of the driving amplifier. The value of the dimensionless product $R_{5}{ }^{2} \omega \mu_{1} \sigma_{1}$ is also calculated and printed out as $M I=\left(R_{5}{ }^{2} \omega \mu_{1} \sigma_{1}\right)$ and likewise $M 2$ is calculated using $R_{5}{ }^{2} \omega \mu_{2} \sigma_{2}$. The inductance in henries of the driving coil in air and the normalized imaginary part of the driving coil impedance are also printed, with $\mathrm{C}(2)$ cladding thickness and nominal lift-off $(L 6+2 L 2)$. The inductance in henries of both pickup coils in air and the normalized imaginary part of the pickup coils' impedance with cladding thickness $C(2)$ and lift-off are also printed. The total phase shift for the cladding thickness variation between $C(3)$ and $C(1)$, the maximum phase shift due to lift-off, and the maximum percent of range error in cladding thickness measurements due to lift-off are given. The phase shifts are given first in radians and then in degrees.

The program then enters a branching loop that allows the following options, depending on which of $1,2,3$, or 4 is typed as input after the question mark.

1. Coil Design

If a 1 is typed by the operator after the question mark, the program will enter the Coil Design Loop. This loop will allow the number of turns on the driver and pickup coils to be varied. The loop will allow the wire gage to be given and then calculate the number of turns and coil resistance, or it will allow the number of turns to be entered and calculate the gage and coil resistance, or both turns and gage can be entered. If zeros are entered for both the gage and turns of either the driver or pickup coils, the present value of these will be retained. The program then starts with the label

DRIVER RES INDUCTANCE NO TURNS SHUNT CAP NOR IM PT,

and the remainder of the program is recalculated and printed, with the "new" coil in the circuit. However, the numerical integrations to calculate $M, Z_{D R}$, and $\underline{Z}_{\mathrm{PU}}$ do not have to he repeated. 


\section{Attenuator Design}

This loop will allow the driver series resistance, RO, the driver shunt capacitance, $\mathrm{C} 6$, the amplifier input impedance, $\mathrm{R} 9$, and the shunt capacitance in the pickup circuit, $\mathrm{C} 7$, to be varied. If a 2 is typed after the question mark, the computer will respond with

DRIVER SERIES RES, SHUNT CAP, PICK-UP SHUNT RES, CHUNT CAP . The resistance is to be given in ohms, and the capacitance in farads. If zero is typed in for any value, the present value in the computer will be retained. After the input data and a carriage return are typed, the computer.will calculate the ratio of resonant frequency to uprepting frequency for the particular L-C circuit, a very rough value of resistance for minimum temperature drift, and the ratio between the resistance and reactance in the circuit for both the driver and pickup circuits. The program then starts with the label

DRIVER RES INDUCTANCE NO TURNS SHUNT CAP NOR IM PT, and the remainder of the program is recalculated and printed with the "new" attenuator in the circuit. Again, the numerical integrations to calculate $\mathrm{M}, \mathrm{Z}_{\mathrm{DR}}$, and $\mathrm{Z}_{\mathrm{PU}}$ do not have to be repeated.

3. Drift Check

This lonp ralrulates the effect of the drift of any of the circuit or sample parameters arter the instrumenl has leein calibrated and adjusted. If a 3 is typed as input, the program will respond with the percent variation, the parameter varied, the maximum change in phase (both radians and degrees) of any of the 15 different phases calculated (5 lift-off values for each of 3 ditt'erent cladding liickness values) and the percent of the range represenled by the drift. The porsent. variation of each parameter may be varied independently. The following table gives the parameter, the Line number, and the constant to be varied: 


\begin{tabular}{lcc}
\multicolumn{1}{c}{ Parameter } & Line Number & Constant \\
\cline { 2 - 3 } Driver Resistance & 8610 & El \\
Pickup Resistance & 8620 & E2 \\
Driver Shunt Cap. & 8630 & E3 \\
Pickup Shunt Cap. & 8640 & E4 \\
Series Resistance & 8650 & E7 \\
Amp. Input Resistance & 8660 & E8 \\
Applied Voltage & 8670 & E9 \\
Frequency & 8680 & Al \\
Mean Radius & 8690 & A2 \\
Base Resistivity & 8700 & A8 \\
Cladding Resistivity & 8705 & A9
\end{tabular}

For example, to put in a $2 \%$ variation in the driver coil resistance, one would type:

$$
8610 \mathrm{EI}=.02
$$

The amount that each parameter is varied must be set before the program is run. All of the variations are 0.01 or $1 \%$ in the current version of the program. Since the phase shift produced by the parameter variation is quite linear over a range of about 10\%, a linear interpolation or extrapolation may be used from the $1 \%$ parameter variation. If zero is typed in for any parameter variation, that parameter will not be varied nor will it be typed out in the list of parameter variations. When the calculation is completed and the drifts printed, the program returns to the branch point and repeats the question

1 Coil Design 2 Atten. Design 3 Drift Check 4 Con Cal.

The first seven drifts do not require repetition of the numerical integrations to calculate $\mathrm{M}, \mathrm{Z}_{\mathrm{DR}}$, and $\mathrm{Z}_{\mathrm{PU}}$, but they must be repeated to calculate the drifts due to frequency, mean radius, and resistivity changes of the base and.cladding materials. 'Therefore, the calculation of these last four drifls requires a considerable amount of computer time.

4. Con Cal

This loop is to continue calculations. If a series of calculations is to be made, a loop may be established at this point. However, in 
the present version of the program, if a 4 is typed as input, the program will end.

\section{Sample Calculation of RFCLAD}

Let us suppose we wish to design a reflection-type coil to measure the thickness of aluminum with a resistivity of $3.632 \mu \Omega-\mathrm{cm}$ clad on aluminum with a resistivity of $5.393 \mu \Omega-\mathrm{cm}$. From another report ${ }^{10}$ we have determined that the following parameters give near optimum performance for a nominal cladding thickness of 0.028 in. The driver coil has a mean radius of $0.08325 \mathrm{in.}$, inner and outer ruili, uf 0.06 'L and $0.104 \mathrm{in.}$, and a length of $0.030 \mathrm{in}$. The pickup coils have inner and outer radii of 0.030 and $0.058 \mathrm{in.,} \mathrm{a} \mathrm{length} \mathrm{of} 0.008 \mathrm{in.,}$ and are mounted flush with the ends of the driver coil. The driver coil has 360 turns of No. 46 wire with a resistance of $79.36 \Omega$, and the pickup coils have 410 turns each of No. 54 wire, with a resistance of $530.5 \Omega$ for both coils. The ariver series and the pickup amplifier input resistances are both chosen to be $1 \mathrm{M} \Omega$. The shunt capacitances in both circuits are chosed to be $1 \mathrm{pF}$. This correspunds to practicnlly infinito source and detector impedances, so that only the mutual coupling, $M$, affects the phases. The minimum lift-off is taken to be $0.0083 \mathrm{in}$. with a lift-off increment of $0.002 \mathrm{in.}$ The nominal cladding thickness is 0.028 in., with the minimum and maximum thicknesses 0.0266 and 0.0294 in. The relative magnetic permeability is 1 for both cladding and base material. The frequency is $10 \mathrm{KHz}$; the output voltage of the driving amplifier is $10 \mathrm{~V}$, and the gain of the pickup amplifier is unity (a unity gain allows the actual gain needed in the amplifier to be calculated by dividing the maximum output voltage with unity gain Into 10).

The program RFCLAD is assumed to be in the active core, and the following information is typed into the computer. All linear dimensions are normalized by dividing by the coil mean radius, except for the coil mean radius, which is in inches.

${ }^{10} \mathrm{C}$. V. Dodd and W. A. Simpson, Thickness Measurements Using EddyCurrent Techniques, ORNL-TM-3712 (March 1972). 


\begin{tabular}{|c|c|}
\hline 250 & $\mathrm{R} 5=.08325$ \\
\hline 260 & $\mathrm{RI}=.75$ \\
\hline 270 & $\mathrm{R} 2=1.25$ \\
\hline 280 & $\mathrm{~L} 3=.36$ \\
\hline 290 & $\mathrm{R} 3=.36$ \\
\hline 300 & $\mathrm{R} 4=.696$ \\
\hline 310 & $\mathrm{~L} 4=.096$ \\
\hline 320 & $\mathrm{~L} 5=0$ \\
\hline 330 & $L 6=.1$ \\
\hline 340 & $\mathrm{R} 6=79.36$ \\
\hline 350 & $\mathrm{R} 7=530.5$ \\
\hline 360 & $\mathrm{~N} 3=360$ \\
\hline 370 & $\mathbb{N} 4=410$ \\
\hline 380 & $\mathrm{RO}=1 \mathrm{E} 6$ \\
\hline 390 & $\mathrm{R} 9=1 \mathrm{E} 6$ \\
\hline 400 & $C 6=1 E-12$ \\
\hline 410 & $C 7=1 E-12$ \\
\hline 420 & $\mathrm{VO}=10$ \\
\hline $430^{\circ}$ & $G 5=1$ \\
\hline 440 & $F=1 E 4$ \\
\hline 450 & $\mathrm{~L} 2=.025$ \\
\hline 510 & $c(1)=.0266$ \\
\hline 520 & $c(2)=.028$ \\
\hline 530 & $c(3)=.0294$ \\
\hline 540 & $\mathrm{Kl}=5.39261$ \\
\hline 545 & $\mathrm{Ul}=1$ \\
\hline 550 & $\mathrm{~K} 2=3.63204$ \\
\hline 555 & $\mathrm{U} 2=1$ \\
\hline
\end{tabular}

The program may now be run with the following results. The data inputed from the terminal by the user are underlined. A carriage return must be typed by the user at the end of each input line. 
RFCLAD (BAS IC)

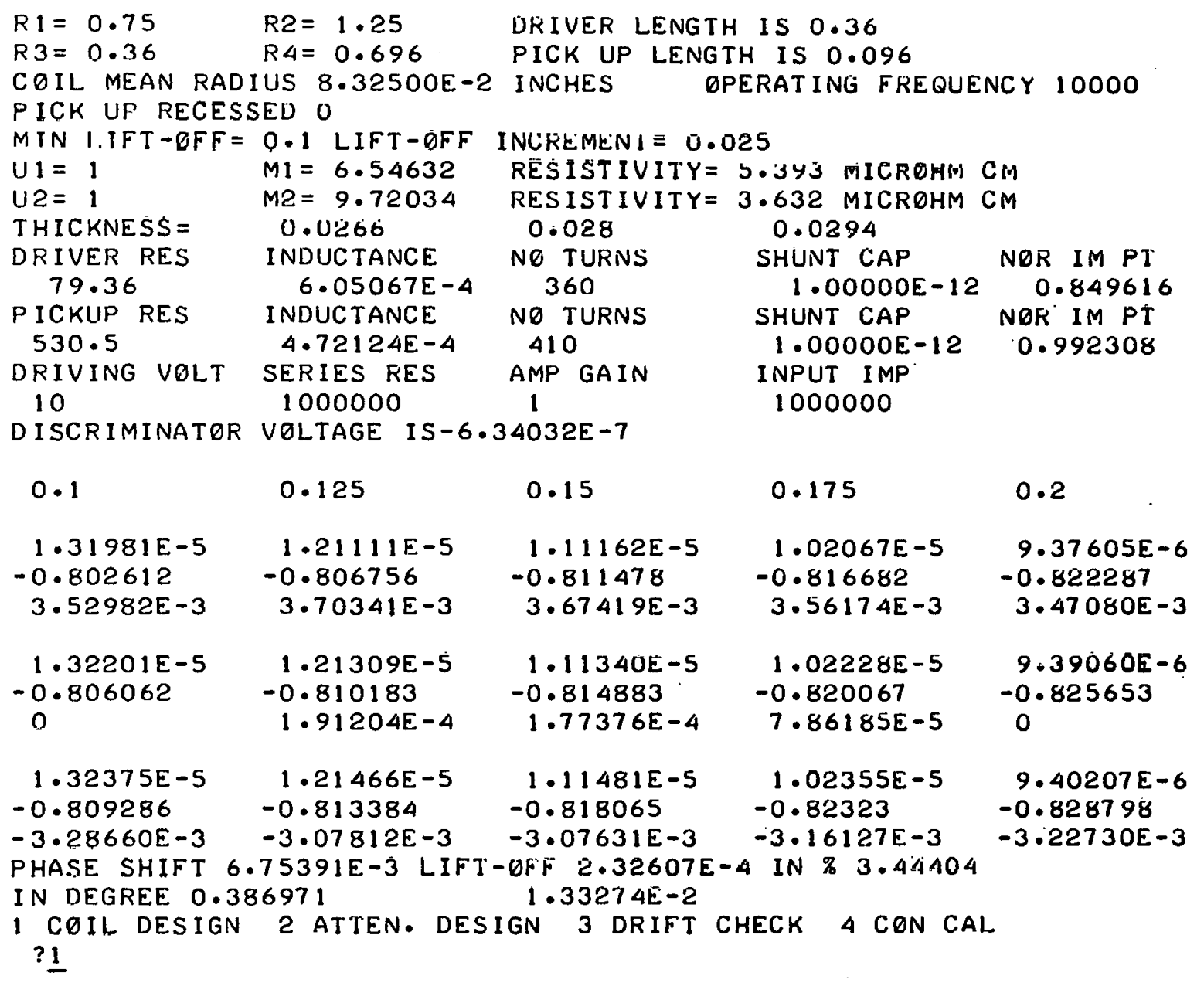


DRIVER WIRE GAGE, TURNS, PICK-UP WIRE GAGE, TURNS $? 46,0,54,0$

DRIVER 391 TURNS OF \# 46 WIRE 17 /LAYER 23 LAYERS 71.9293 OHM PICKUP 429 TURNS EA \# 54 WIRE 11 /LAYER 39 LAYERS 532.582 OHMS .TOTAL DRIVER . RES INDUCTANCE NO TURNS 71.9293. $7.13760 E-4 \quad 391$ 391
NO TURNS

PICKUP RES INDUC TANCE

532.582 $5.16896 E-4$ 429

DRIVING VOLT SERIES RES AMP GAIN 10 1000000 1 SHUNT CAP $1.00000 E-12$ NER IM PT SHUNT CAP 0.849616

DISCRIMINATOR VOLTAGE IS-7.20554E-7

$$
\begin{aligned}
& 1.00000 E-12 \\
& \text { INPUT IMP } \\
& 1000000
\end{aligned}
$$

$$
\begin{aligned}
& 0.1 \\
& 0.125 \\
& 0.15 \\
& 0.175 \\
& 0.2 \\
& 1.49990 E-5 \\
& -0.80262 \\
& 1.37637 \varepsilon-5 \\
& -0.806764 \\
& 1.26329 E-5 \\
& 3.52983 E-3 \\
& 3.70337 E-3 \\
& -0.811486 \\
& 1.15994 E-5 \\
& -0.81669 \\
& 1.06554 \mathrm{E}-5 \\
& 3.67417 E-3 \\
& 3.56171 \mathrm{E}-3 \\
& -0.822296 \\
& 3.47078 E-3 \\
& \text { 1.50239E-5 } \\
& 1.37861 E-5 \\
& -0.810191 \\
& 1.26532 E-5 \\
& -0.814891 \\
& 1 \cdot 16177 E-5 \\
& -0.820075 \\
& 1.77346 E-4 \\
& 7.85962 E-5 \\
& 1.06719 E-5 \\
& -0.825662 \\
& 0 \\
& 1.91189 E-4 \\
& 1.26693 E-5 \\
& -0.818073 \\
& 1.16321 \mathrm{E}-5 \\
& 1 \cdot 38040 E-5 \\
& -3.07633 \varepsilon-3 \\
& -0.823238 \\
& -3.16130 E-3
\end{aligned}
$$


DRIVER SERIES RES, SHUNT CAP, PICK-UP SHUNT RES, SHUNT CAP

?5.2E2, 4.7E-9,5.9E2,5.3E-9

DUR CT 9.42723 BELOW RES 359.202 OPT RES 13.6474 RES/REACTANCE P-U CT 9.6529 BELOW RES 311.091 DPT RES 18.3072 RES/REACIANCE

DRIVER RES INDUCTANCE ND TURNS

71.9293

PICKUP RES $532 \cdot 582$

DRIVING VOLT 10

$7.13760 \mathrm{E}-4$ INDUCTANCE $5 \cdot 16896 E-4$ SERIES RES 520 391 NO IURNS 429 AMP GAIN 1

$$
\begin{aligned}
& \text { SHUNT CAP } \\
& 4.7 \text { OOOE-9 } \\
& \text { SHUNT CAP } \\
& 5.30000 E-9 \\
& \text { INPUT IMP } \\
& 590
\end{aligned}
$$

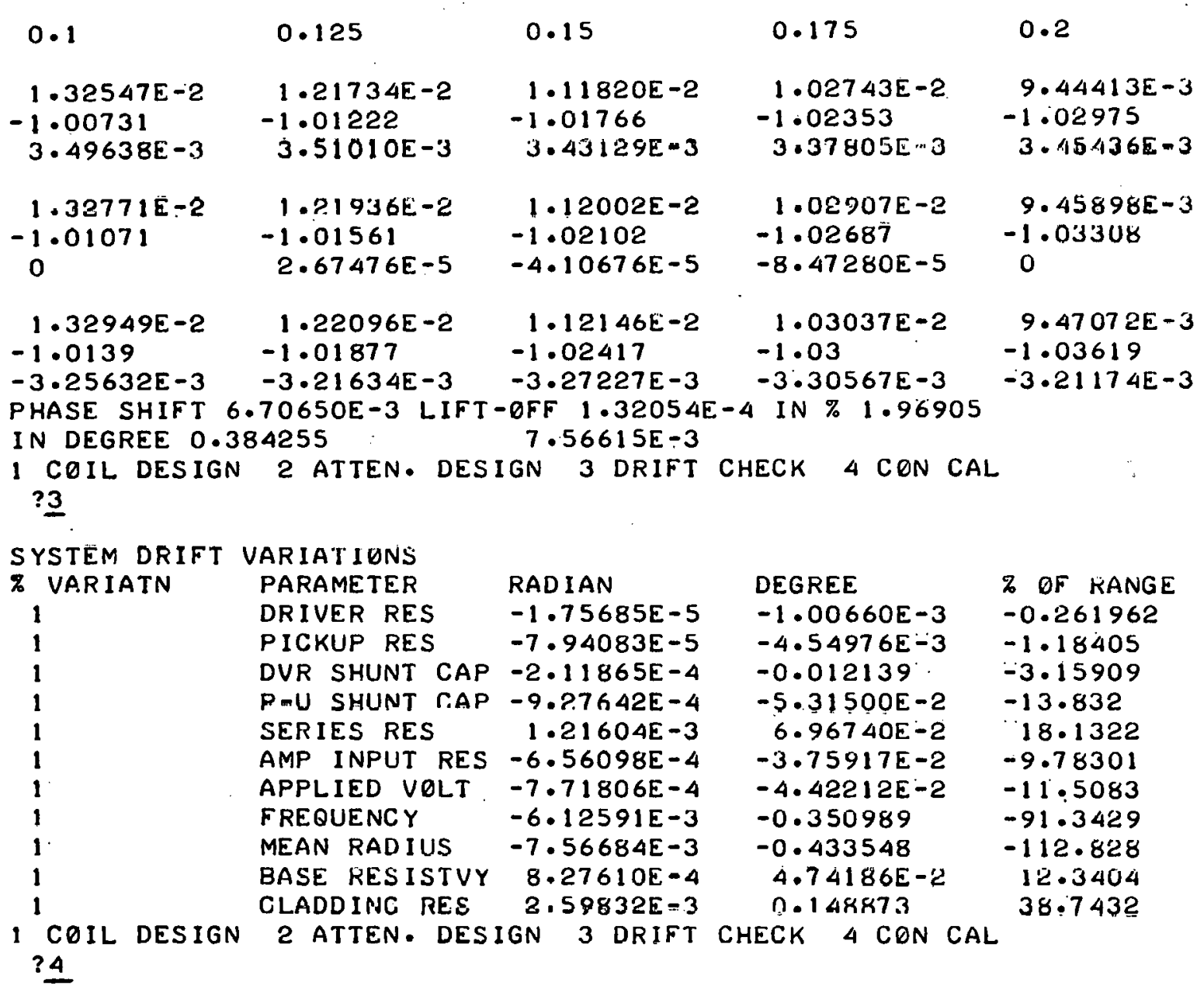

The user has exercised all he design uptions available, and thete upliuis may be repeated, omitted, or taken in any order. The BASIC version of the program RFCLAD follows. 


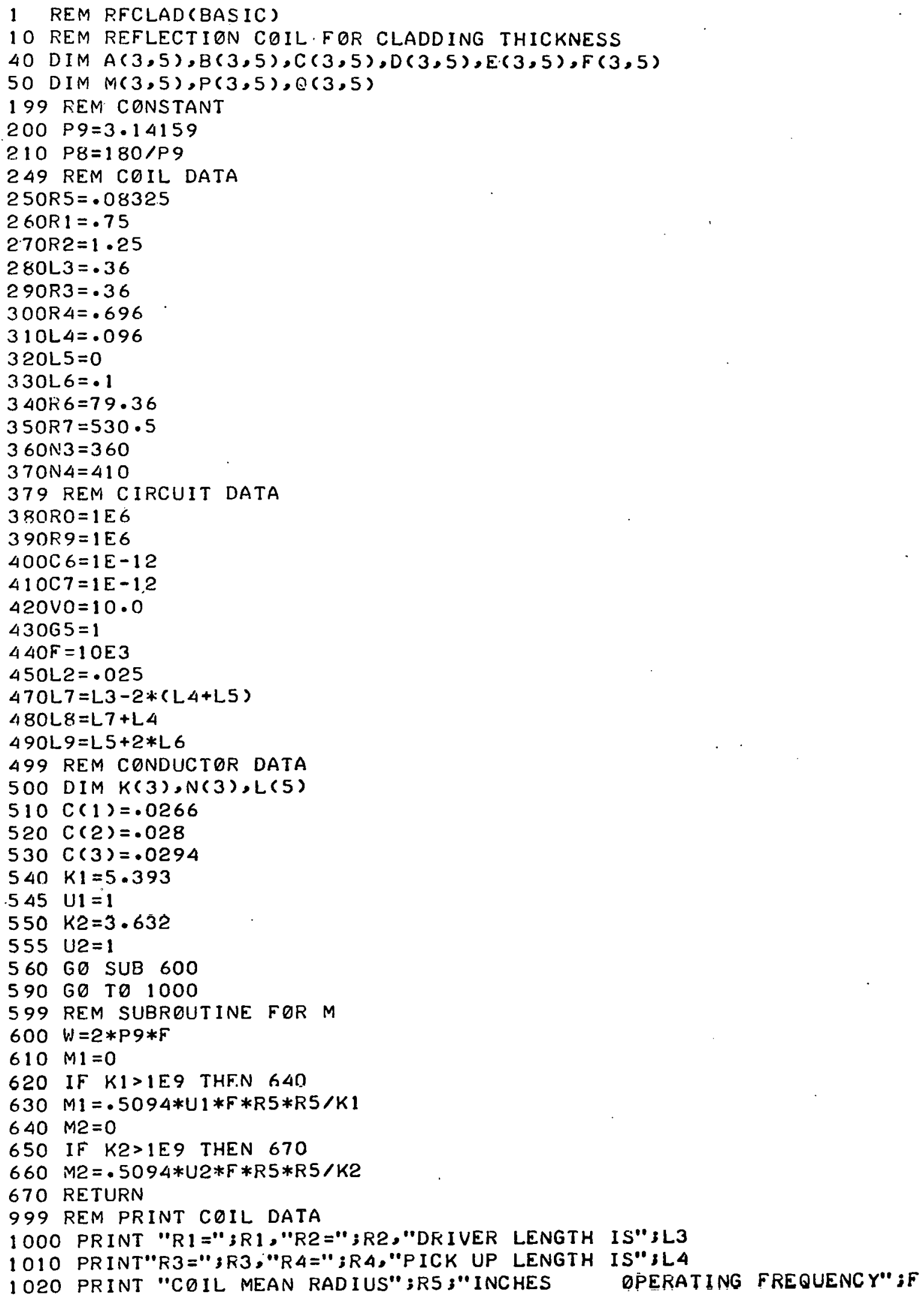




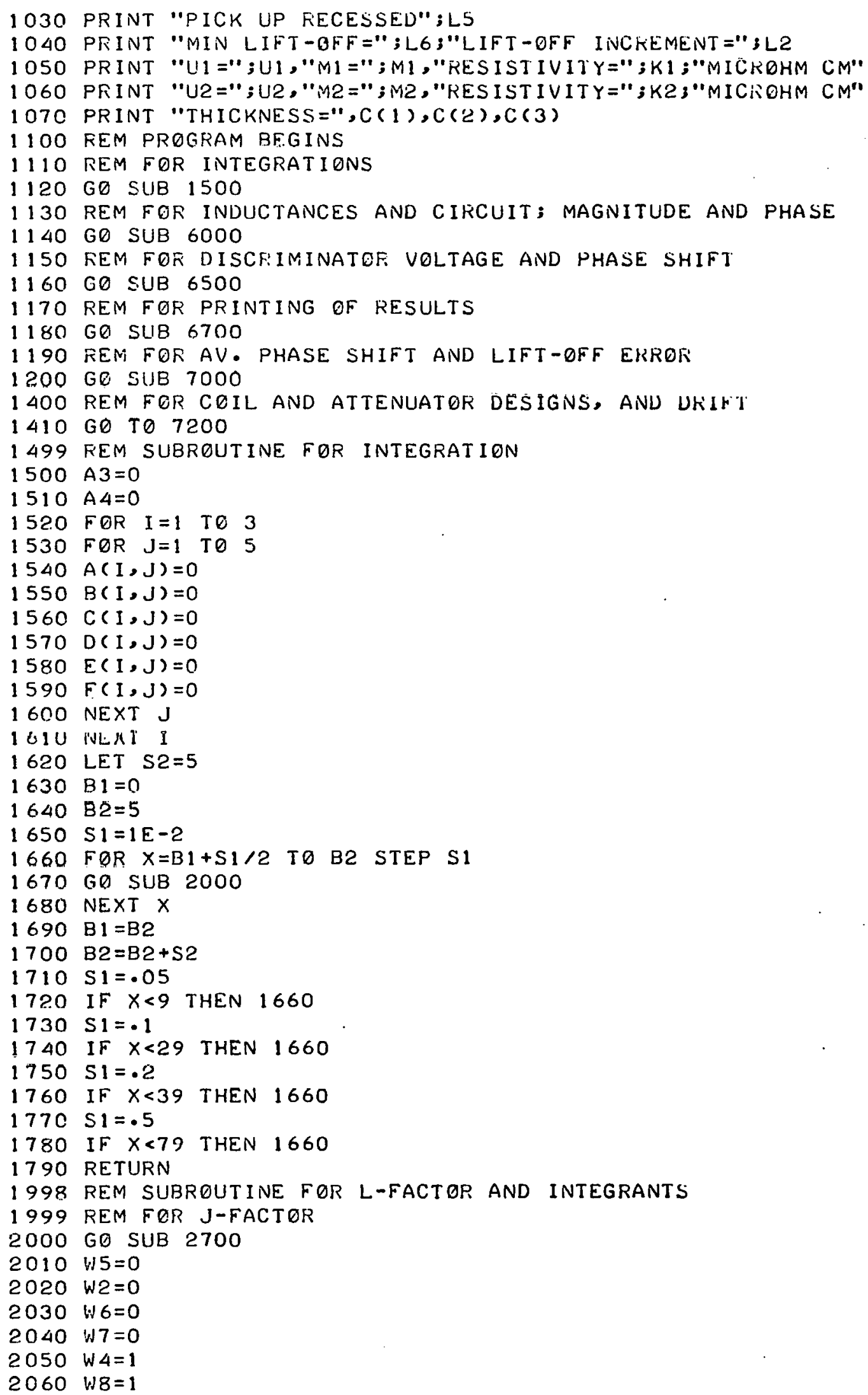




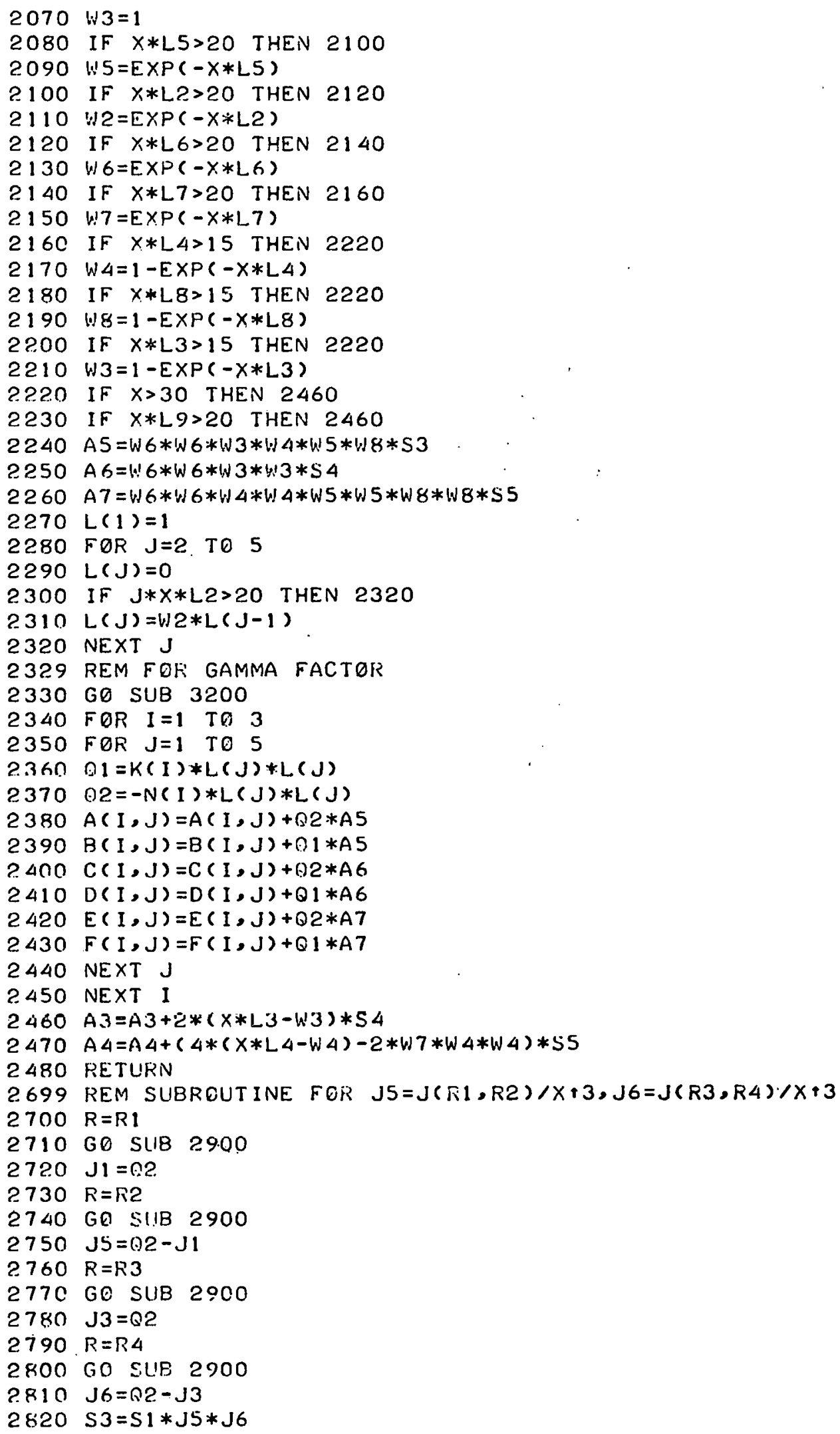




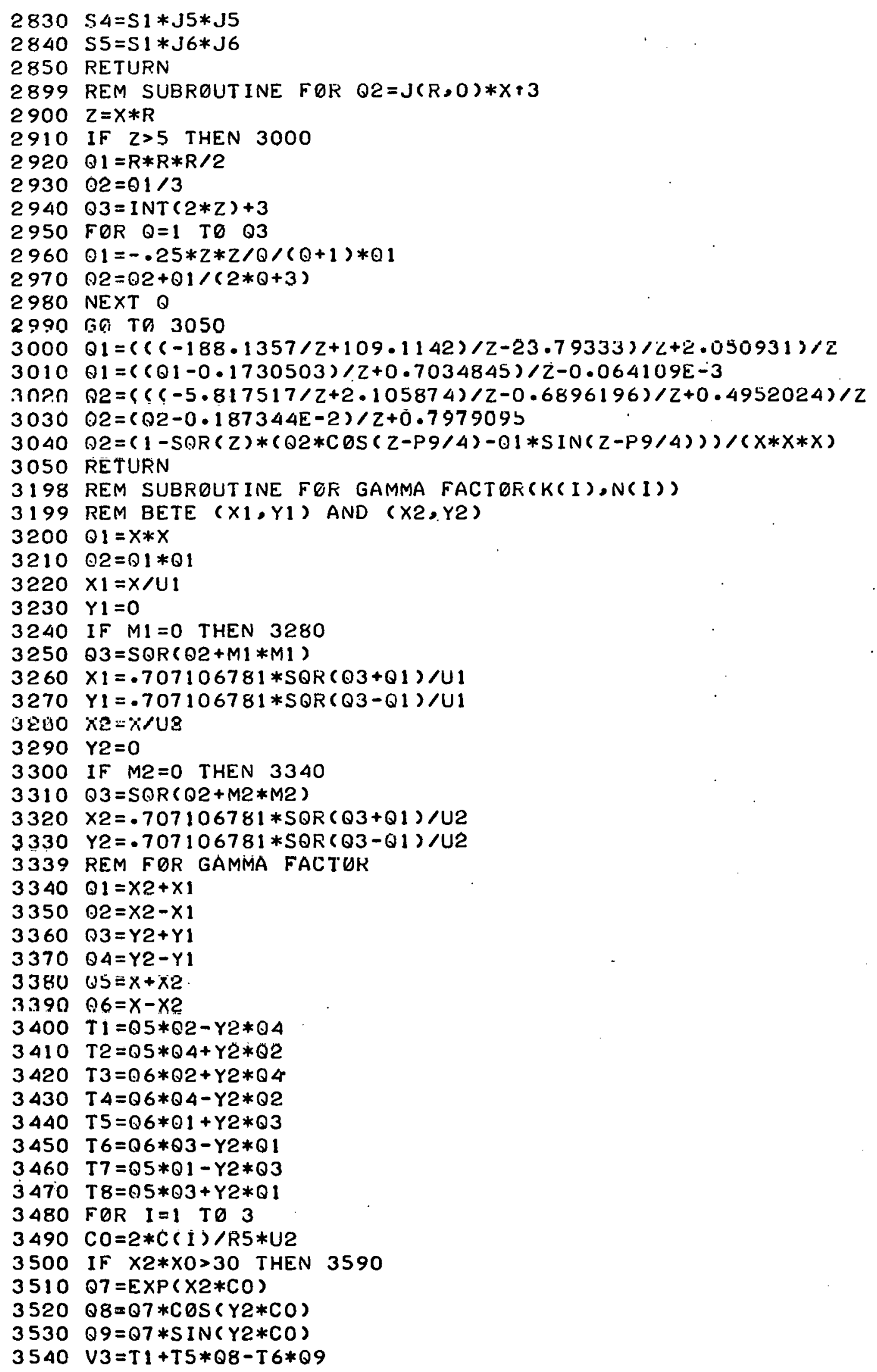




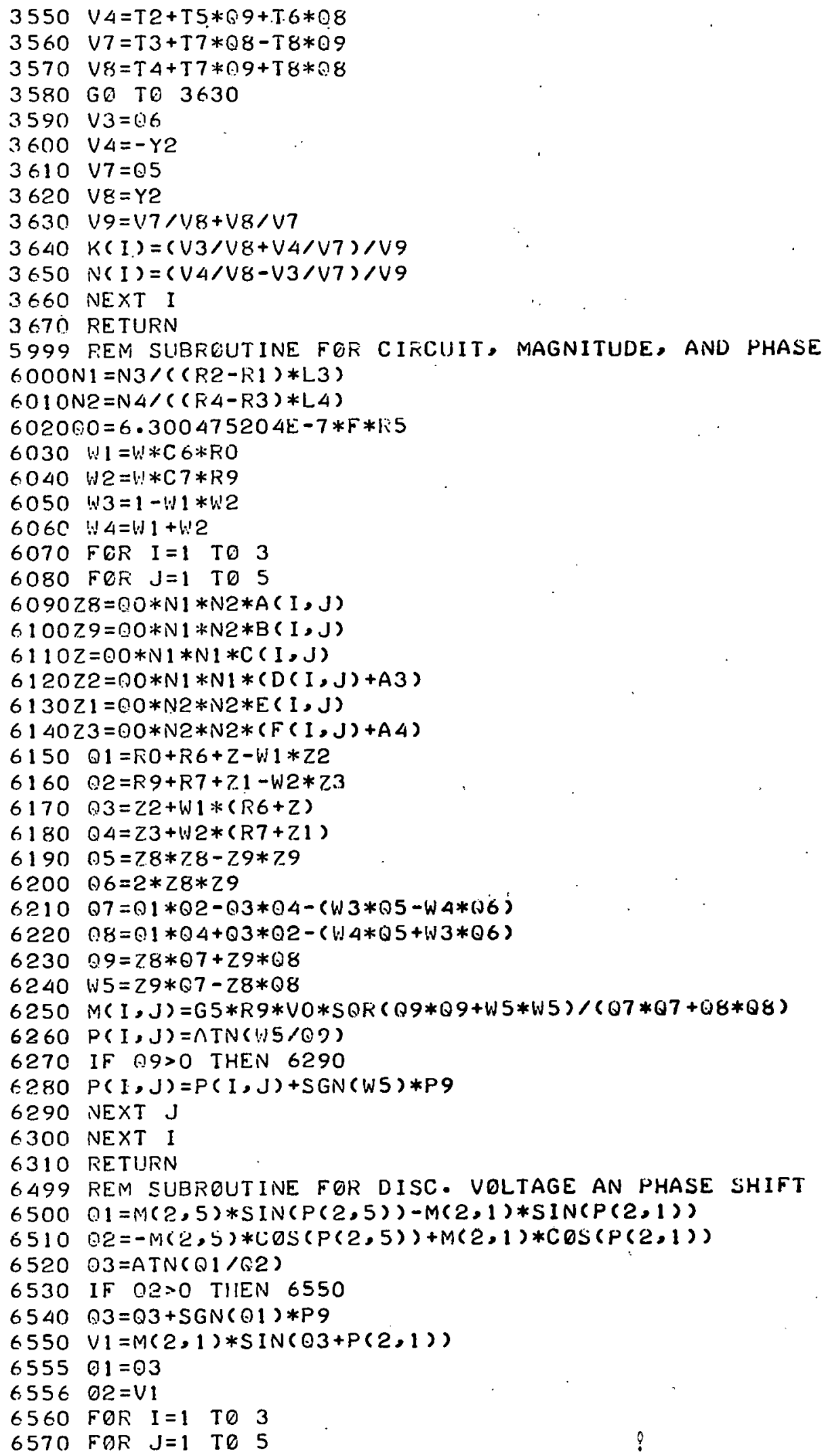




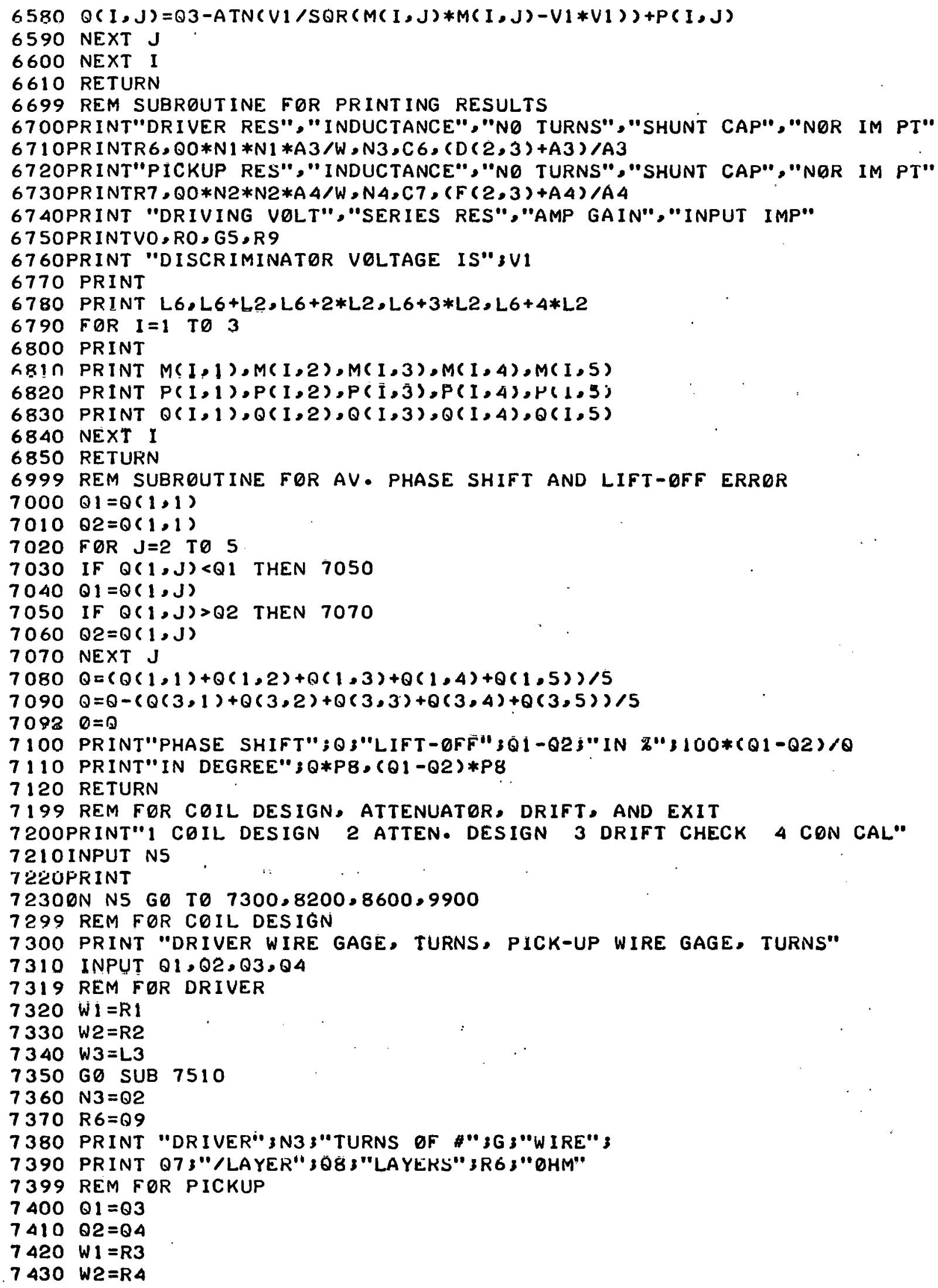




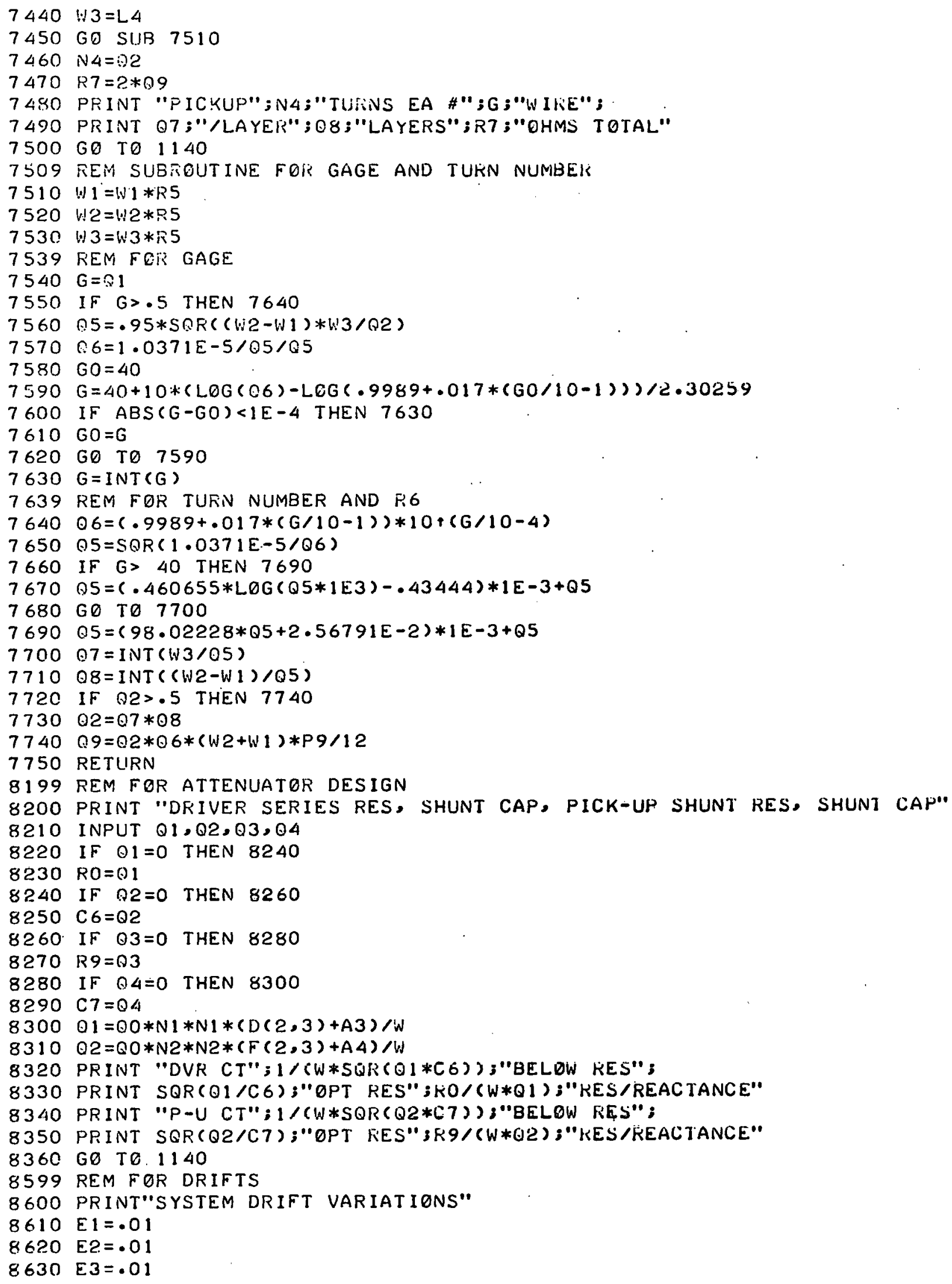




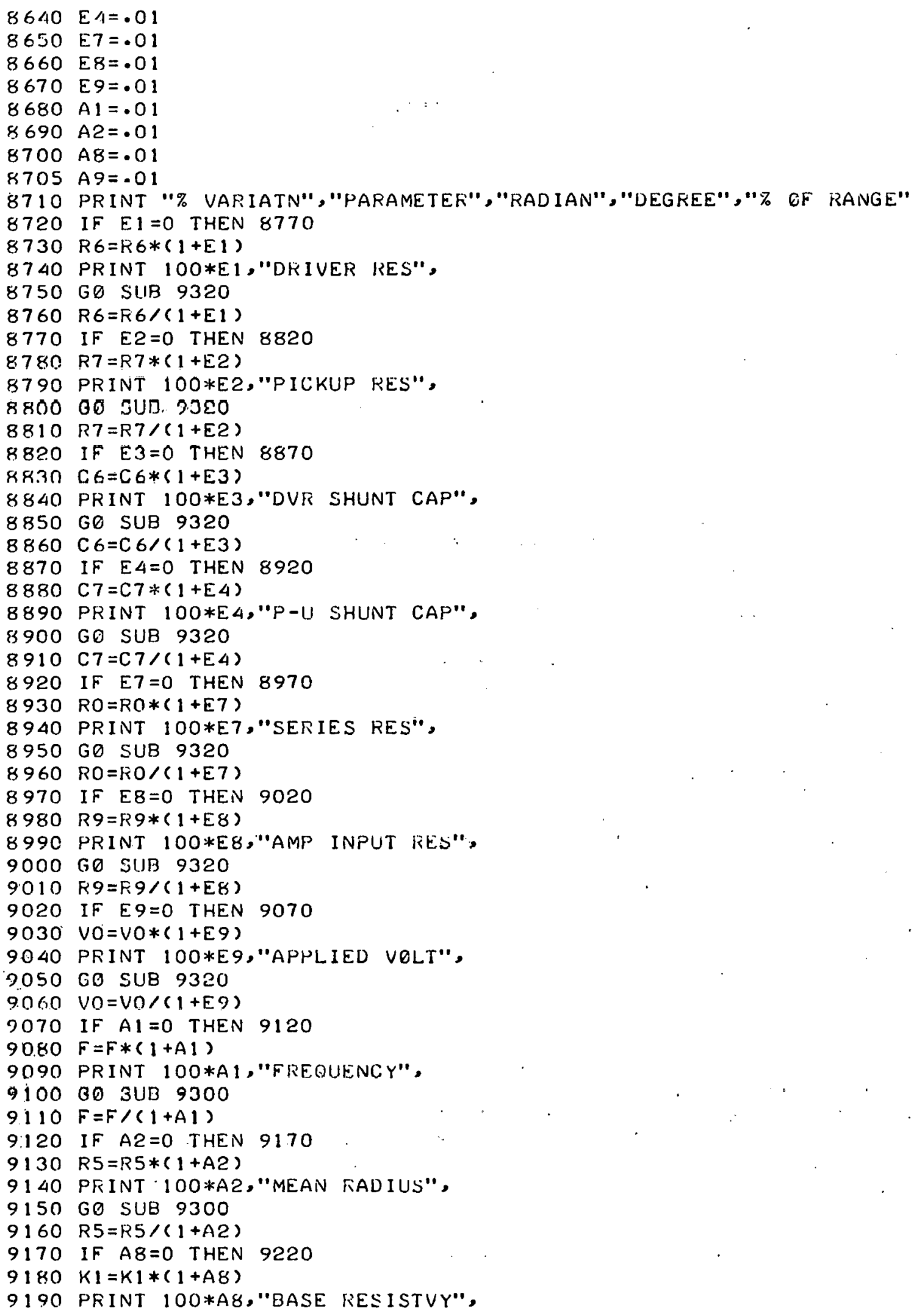




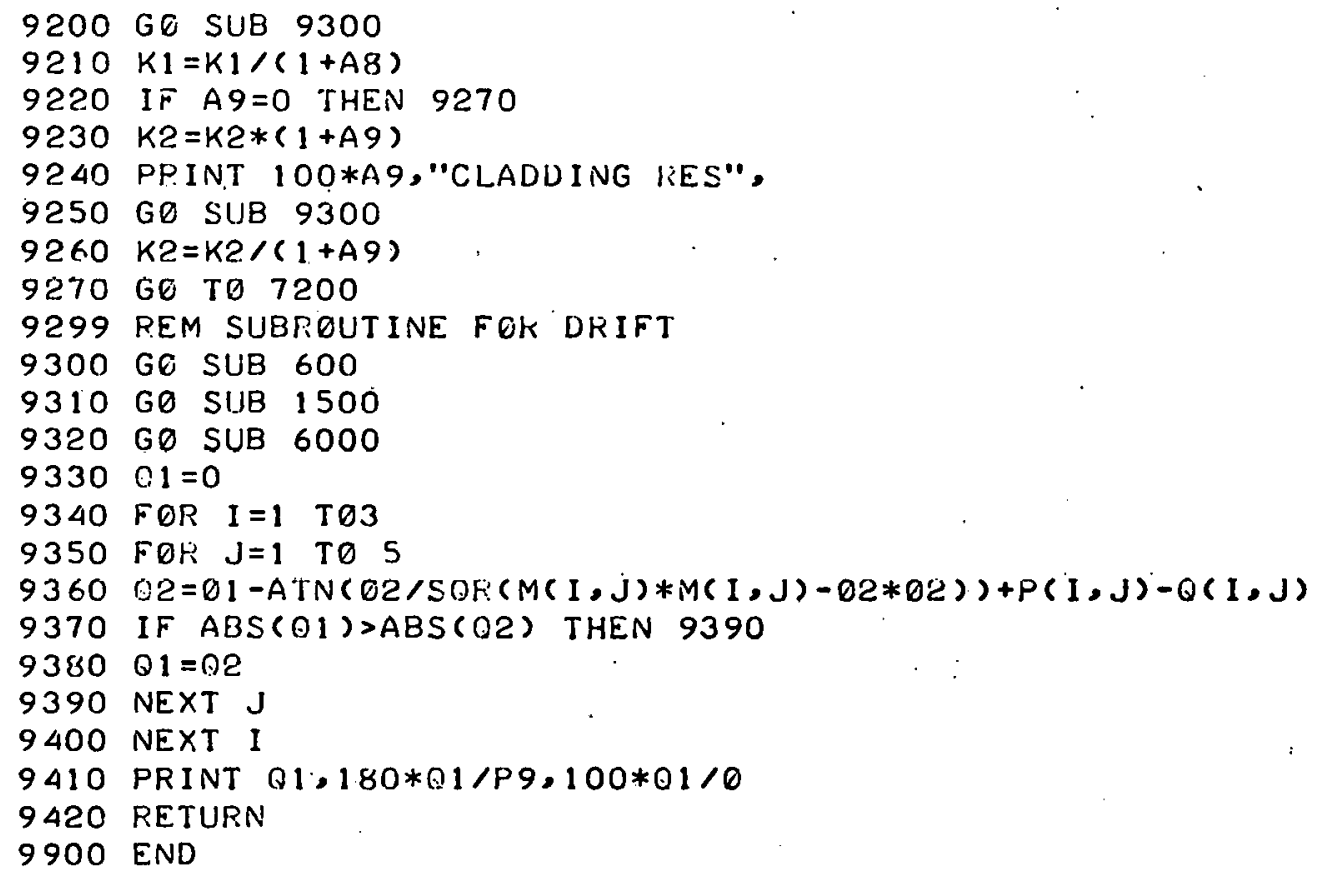


RFCLAD, FORTRAN Version

The FORTRAN version of RFCLAD is very similar to the BASIC version. The line numbers given are only for identification and editing purposes and have no effect on the actual execution of the FORTRAN program. The input data for the program is contained in lines 250 through 520. The data must be typed in the seventh column, or six spaces must first be typed. The data are inputed as follows:

\begin{tabular}{|c|c|}
\hline 00250 & $\mathrm{R} 5=$ (coil mean radius in inches) \\
\hline 00260 & $\mathrm{Rl}=$ (normalized inner radius of driver coil) \\
\hline 00270 & $\mathrm{R} 2=($ normalized outer radius of driver coil) \\
\hline 00280 & $\mathrm{~L} 3=$ (normalized length of driver coil) \\
\hline 00290 & $\mathrm{R} 3=$ (normalized inner radius of pickup coil) \\
\hline 00300 & $\mathrm{R} 4=$ (normalized outer radius of pickup coil) \\
\hline 00310 & LL = (normalized length of pickup coil) \\
\hline 00320 & $\begin{aligned} \mathrm{L} 5= & \text { (normalized length of recess of each pickup coil from } \\
& \text { the face of the driver coil) }\end{aligned}$ \\
\hline 00330 & L6 = (normalized minimum lift-off of the driver coil) \\
\hline 00340 & $\mathrm{R} 6=$ (resistance of driver coil in ohms) \\
\hline 00350 & $\mathrm{R} 7=$ (resistance of both pickup coils in ohms) \\
\hline 00360 & $\mathbb{N} 3=$ (number of turns on the driver coil) \\
\hline 00370 & N4 $=$ (number of turns on each pickup coil) \\
\hline 00380 & RO $=$ (driver amplifier series resistance in ohms) \\
\hline 00390 & $\mathrm{R} 9=$ (pickup amplifier shunt resistance in ohms) \\
\hline 00400 & C6 $=$ (shunt capacitance of driver circuit in farads) \\
\hline 00410 & $\mathrm{C} 7=$ (shunt capacitance of pickup circuit in farads) \\
\hline 00420 & $v 0=$ (output voltage in rolts) \\
\hline 00430 & GAIN $=($ amplifier gain $)$ \\
\hline 00440 & FREQ $=$ (operating frequency in Hertz) \\
\hline 00450 & $\mathrm{~L} 2=$ (normalized lift-off increment of the driver coil) \\
\hline 00460 & RHOl = (resistivity of base material in microhm-cm) \\
\hline 00470 & $\mathrm{Ul}=$ (relative magnetic permeability of base material) \\
\hline 00480 & RHO2 = (resistivity of cladding material in microhm-cm) \\
\hline 0045 & $\mathrm{U} 2$ = (relative magnetic permeability of cladding material) \\
\hline
\end{tabular}



$00500 \quad \operatorname{CLAD}(1)=$ (numerical value of minimum cladding thickness in inches)
$00510 \quad \operatorname{CLAD}(2)=$ (numerical value of nominal cladding thickness in inches)
$00520 \operatorname{CLAD}(3)=$ (numerical value of maximum cladding thickness in inches)

The print-out of the FORTRAN version of RFCLAD is practically identical to the BASIC version and will not be repeated. The main difference is that the question mark is not printed out when the program is ready to accept data. The Coil Design, Attenuator Design, Drift Check, and Continue Calculations options are the same. The line numbers, constant names, and parameter varied in the drift calculations are as follows:

\begin{tabular}{|c|c|c|}
\hline Line Number & Constant & Parameter Varied \\
\hline 03270 & DRI & Driver Resistance \\
\hline 03280 & DR2 & Pickup Resistance \\
\hline 03290 & DR3 & Driver Shunt Capacitance \\
\hline 03300 & DR4 & Pickup Shunt Capacitance \\
\hline 03310 & DR5 & Series Resistance \\
\hline 03320 & $\mathrm{DR} 6$ & Amplifier Input Resistance \\
\hline 03330 & $\mathrm{DR} 7$ & Applied Voltage. \\
\hline 03340 & DR8 & Frequency \\
\hline 03350 & DR9 & Mean Radius \\
\hline 03360 & DR10 & Base Resistivity \\
\hline 03370 & DRII & Cladding Resistivity \\
\hline
\end{tabular}

For example, to vary the driver resistance by $2 \%$ one would type:

$$
03270 \quad \mathrm{DRI}=0.02
$$

As in the BASIC version; the last four drifts require that the entire numerical integration be repeated and are relatively long running. If any of the drifts is set equal to zero, it will be omitted from the drift calculations. 


\section{Sample Calculation of RFCLAD.F4}

Let us suppose that we wish to design a reflection type coil, identical to the one designed by the BASIC version. We will put the following data in the program (generally by using the EDIT RFCLAD.F4 command on the PDP-10 and inserting the statements). All coil and liftoff dimensions are normalized by dividing by the coil mean radius, except the coil mean radius, which is in inches.

\begin{tabular}{|c|c|}
\hline 00250 & $\mathrm{R} 5=.08325$ \\
\hline nח & $\mathrm{RI}-.75$ \\
\hline 00270 & $\mathrm{R} 2=1.25$ \\
\hline 00280 & $\mathrm{~L} 3=.36$ \\
\hline 00290 & $\mathrm{R} 3=.36$ \\
\hline 00300 & $R 4=.696$ \\
\hline 00310 & $\mathrm{~L}_{4}=.096$ \\
\hline 00320 & $\mathrm{~L} 5=0.0$ \\
\hline 00330 & $L 6=.1$ \\
\hline 00340 & $\mathrm{R} 6=79.36$ \\
\hline 00350 & $\mathrm{R} 7=530.5$ \\
\hline 00360 & N3 $=36 n$, \\
\hline 00370 & $N 4=410$ \\
\hline 00380 & $\mathrm{RO}=1 . \mathrm{E} 6$ \\
\hline 00390 & $\mathrm{R} 9=1 . \mathrm{E} 6$ \\
\hline 00400 & $\mathrm{C} 6=1 \cdot E-12$ \\
\hline 00410 & $C 7=1 . L-12$ \\
\hline 00420 & $\mathrm{vo}=10$ \\
\hline 00430 & GAIN $=1$ \\
\hline 00440 & $\mathrm{FREQ}=1.0 \mathrm{E} 4$ \\
\hline 00450 & $\mathrm{~L} 2=.025$ \\
\hline 00460 & $\mathrm{RHOl}=5.39261$ \\
\hline 00470 & $\mathrm{UL}=1$ \\
\hline 00480 & $\mathrm{RHO2}=3.63204$ \\
\hline 00490 & $\mathrm{U} 2=1$. \\
\hline
\end{tabular}


500

$\operatorname{CLAD}(1)=.0266$

510

$\operatorname{CLAD}(2)=.028$

520

$\operatorname{CLAD}(3)=.0294$

The FORTRAN program may now be executed. The print-out will be essentially identical to the BASIC print-out and will not be repeated. The FORTRAN version of RFCLAD fOllows. 


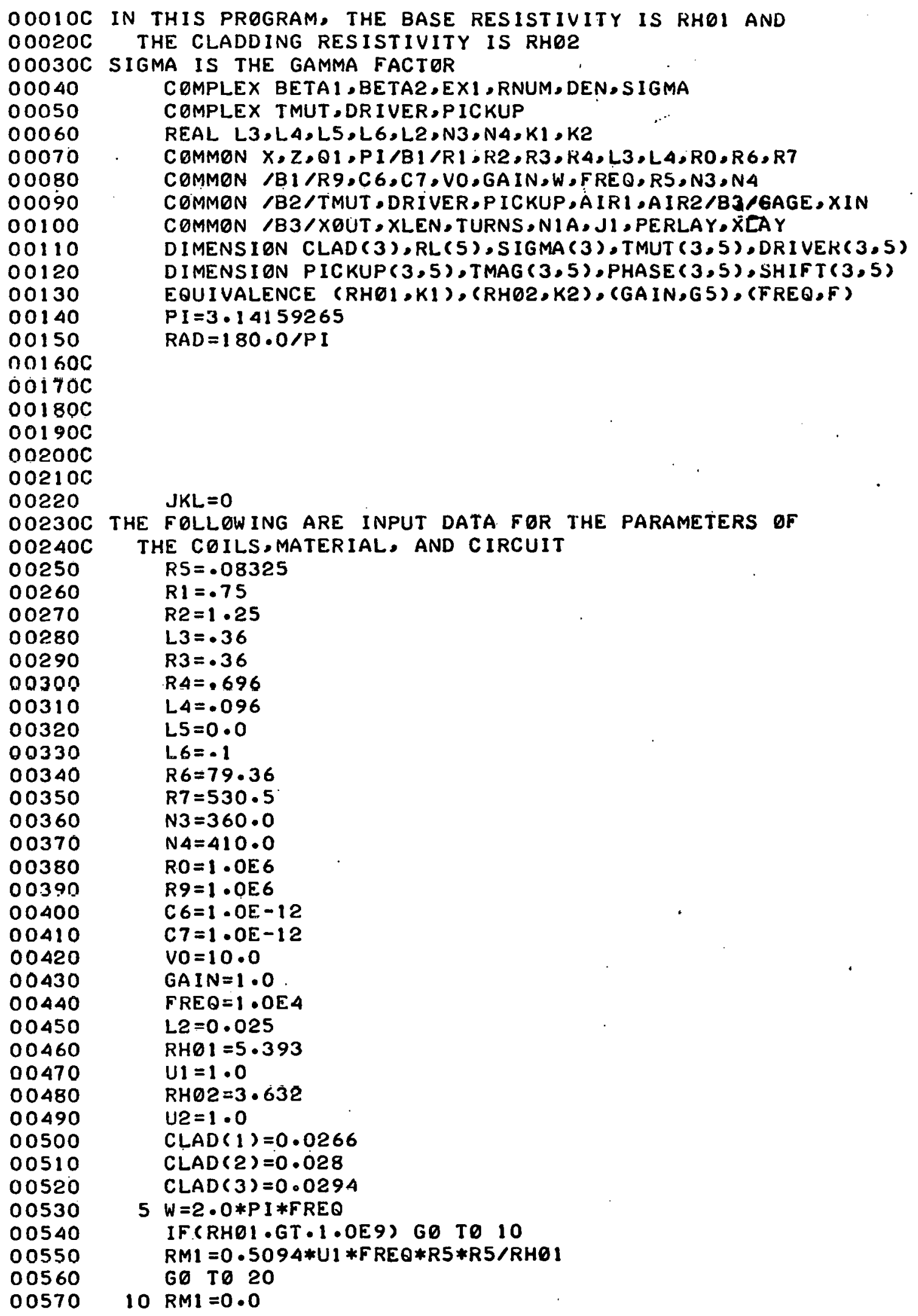


$0058020 \mathrm{RM2}=0.5094 * U 2 * F R E Q * R 5 * R 5 / R H 02$

O0590C THE SYSTEM PARAMETERS ARE PRINTED DUT

00600 IF (JKL.NE.0) GO TO 105

00610

00620

00630

00640

00650

00660

00670

00680

00690

00700

00710

00720

00730

00740

00750

00760

00770

00780

00790

00800

00810

00820

$00830 \mathrm{C}$

$00840 \mathrm{C}$

$00850 \mathrm{C}$

$00860 C$

$00870 \mathrm{C}$

$00880 \mathrm{C}$

00890

00900

00910

00920

00930

00940

00950

00960

00970

00980

00990

01000

01010

01020

01030

01040

01050

01060

$01070 \mathrm{C}$

$01080 \mathrm{C}$

$01090 \mathrm{C}$

01100

01110

01120

01130 TYPE $30, R 1, R 2, L 3$

30 FORMAT $(1 H, 3 H R 1=, F 8 \cdot 5,3 X, 3 H R 2=, F 8 \cdot 5,3 X, 14 H D R I V E R$ LENGTH=, (F8.5)

TYPE $40, R 3, R 4, L 4$

40 FORMAT $(1 \mathrm{H}, 3 \mathrm{HR} 3=, F 8,5,3 \mathrm{X}, 3 \mathrm{HR} 4=, F 8,5,3 \mathrm{X}, 14 \mathrm{HP}$ ICKUP LENG TH $=$, $1 F 8 \cdot 5)$ TYPE 50,R5,FREO

50 FORMAT $1 \mathrm{H}, 17 \mathrm{HCOIL}$ MEAN RADIUS $=, 58.5,7 \mathrm{H}$ INCHES, $3 \mathrm{X}$, 12OHOPERAT ING FREOUENC $Y=, 1 P E 12.5$ ) TYPE 60.25

60 FORMAT ( $1 \mathrm{H}, 15 \mathrm{HPICKUP}$ RECESSED,F8 .5) TYPE $70, L 6, L 2$

70 FORMAT $1 \mathrm{H}, 13 \mathrm{HMIN}$ LIFT-OFF $=, F 8 \cdot 5,3 \mathrm{X}, 1$ 9HLIFT$1 F 8 \cdot 5)$ TYPE $80, U 1, R M 1, R H 01$

80 FORMAT $(1 \mathrm{H}, 3 \mathrm{HU1}=, F 6.2,5 \mathrm{X}, 3 \mathrm{HMI}=, F 9.5,2 \mathrm{X}, 12 \mathrm{HRES}$ IST IVITY $=$, 11 PE $12.5,11 \mathrm{H}$ MICROHM (M) TYPE $90, \mathrm{U} 2, \mathrm{RM}, \mathrm{RH}$

90 FORMAT $(1 \mathrm{H}, 3$ HU2 $=, F 6.2,5 \mathrm{X}, 3 \mathrm{HM}=, F 9.5,2 \mathrm{X}, 12 \mathrm{HRESIST}$ IVITY $=$, 1 IPE:12.5,11H MICROHM (M) TYPE $100, C L A D(1), C L A D(2), C L A D(3)$

100 FORMAT $(1 \mathrm{H}, 1$ OHTHICKNESS $=, F 8.5,2(8 X, F 8.5))$

THE INTEGRATION IS PERFORMED BY THE TRAPEZOIDAL METHOD,

EVALUATING AT THE CENTER OF THE INTERVAL 3 FOR $X$ LARGE

THE INTEGRAL CONVERGES RAPIDLY,SO LARGER INTERVALS

ARE TAKEN

IN THE INTEGRATION TMUT, DRIVER, PICKUP, AIRI, AND

AIR2 ARE CALCULATED

$105 \mathrm{~S} 1=0.01$

$\mathrm{S} 2=5 \cdot 0$

$\mathrm{BI}=0.0$

$\mathrm{B} 2=52$

$A I R I=U \cdot U$

$A I R 2=0.0$

DO $108 \quad \mathrm{~J}=1.3$

DO $108 \quad K=1,5$

$\operatorname{DRIVER}(J ; K)=(0.0,0.0)$

PICKUP $(J, K)=(0.0,0.0)$

$\operatorname{TMUT}(J, K)=(0.0,0.0)$

108 CENT INUE

$110 I 1=(B 2-B 1) / S 1$

$X=B 1-51 / 2.0$

D0 $170 \quad I=1, I 1$

$x=x+51$

$\mathrm{z}=\mathrm{k} 2 * \mathrm{x}$

Q1 $=R 2$

SUBROUTINE BESSEL EVALUATES THE INTEGRAL OF

THE PRQDUCT OF THE BESSEL FUNCTION AND ITS

ARGUMENT

CALL BESSEL (VALZ)

$Z=R I * X$

$Q 1=R 1$

CALL BESSEL(VAL1) 


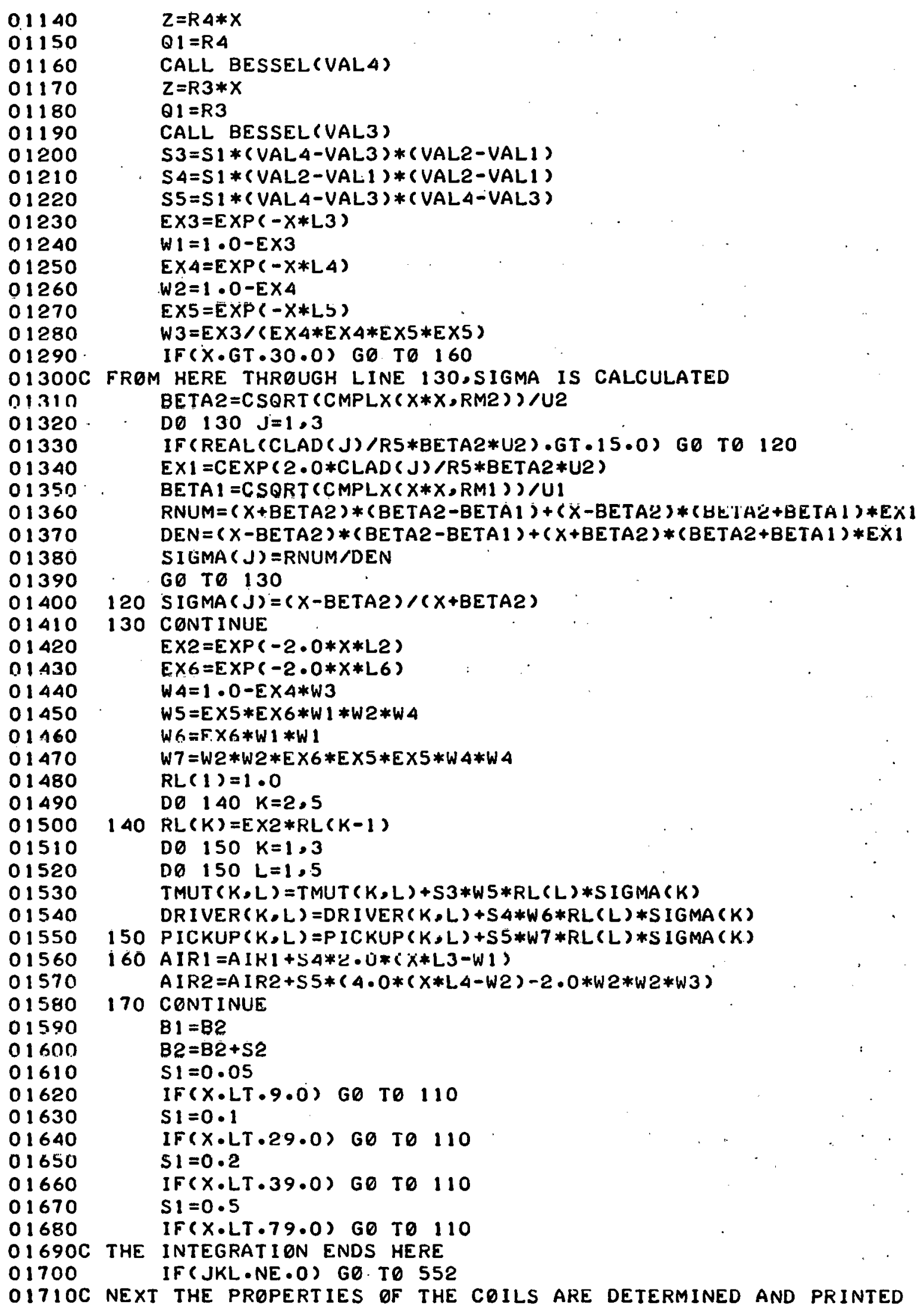


01720

01730

01740

01750

01760

01770

01780

01790

01800

01810

01820

01830

01840

01850

01860

01870

01880

01890

01900

01910

01920

01930

01940

01950

01960

01970

01980

01990

02000

02010

02020

$02030 \mathrm{C}$

$02040 \mathrm{C}$

02050

02060

08070

02080

02090

02100

02110

02120

$02130 \mathrm{C}$

02140

02150

02160

02170

02180

02190

02200

02 ? $10 \mathrm{C}$

$02220 \mathrm{C}$

02230

02240

02250

02260

02270

02280

02290
180 CALL CIRCT(TMAG,PHASE, Q0,T1,T2)

CALL PHASET (TMAG, PHASE, SHIFT, VI, SET)

TYPE 190

190 FERMAT ( $1 \mathrm{H}, 1$ OHDRIVER RES, 4X, 1 OHINDUCTANCE, 4X, 8HNO TURNS, $16 X, 9 H S H U N T$ CAP, $5 X, 9 H N O R$ IM PT)

$01=00 * T 1 * T 1 * A I R 1 / W$

$Q 2=(R E A L(D R I V E R(2,3))+A I R 1) / A I R 1$

$Q 3=00 * T 2 * T 2 * A I R 2 / W$

$\theta 4=(R E A L(P I C K U P(2,3))+A I R 2) / A I R 2$

TYPE $200, R 6, Q 1, N 3, C 6,82$

200 FERMAT $(1 \mathrm{H}, 1$ PE $12.5,2 \mathrm{X}, 1 \mathrm{PE} 12,5,2 \mathrm{X}, 0 \mathrm{PF} 8,1,6 \mathrm{X}, 1 \mathrm{PE} 12,5,2 \mathrm{X}$, 1OPF9.6)

TYPE 210

210 FORMAT $1 \mathrm{H}, 1$ OHPICKUP RES, 4X, 10HINDUCTANCE, 4X, 8HNO TURNS, $16 X, 9 H S H U N T$ CAP, 5X, 9HNOR IM PT)

TYPE $200, R 7,03, N 4, C 7,04$

TYPE 220

220 FORMAT 1 IH, 12 HDRIVING VOLT, 2X, 1OHSERIES RES, 4X,

18 HAMP GAIN, 6X, 9HINPUT IMP)

TYPE $230, V O, R O, G A I N, R 9$

230 FORMAT (1H,F5.1,9X,1PE12.5,2X,0PF $8,1,6 \mathrm{X}, 1 \mathrm{PE} 12.5)$

TYPE $240, V 1$

240 FORMAT $1 \mathrm{H}, 22 \mathrm{HDISCRIMINATOR}$ VOLTAGE $=, 1$ PE 12.5$)$

TYPE 250

250 FORMAT( $1 \mathrm{H})$

$R L(1)=L 6$

DO $260 \quad I=2,5$

$260 R L(I)=L 2+R L(I-1)$

- TYPE. $270, R L$

270 FORMAT $(1 H, 4(F 6.3,8 X), F 6.3)$

TYPE 250

THE VOLTAGE MAGNITUDE, PHASE, AND SHIFT ARE PRINTED FOR

THE VARIOUS LIFT-OFF VALUES

DO $280 \quad I=1.3$

TYPE $290,($ TMAG $(1, \mathrm{~J}), \mathrm{J}=1,5)$

TYPE $290,($ PHA3E $(1, J), J=1,5$ )

TYPE $290,($ SHIFT $(I, J), J=1,5)$

TYPE 250

280 CONTINUE

2.9ก FARMAT (1H . $\triangle(1 P E 12.5 .2 X) \cdot 1 P E 12.5)$

CALL SENS (SHIFT,RAD, SEN)

THE USER SELECTS ONE OF FOUR POSSIBILITIES

295 TYPE 300

300 FORMATC' 1 COIL DESIGN 2 ATTEN. DESIGN 3 DRIFT CHECK

$14 \mathrm{CON}^{\mathrm{C}} \mathrm{CAL}^{\prime}$ )

TYPE 250

ACCEPT $310, N 5$

310 FORMAT (11)

GO TO $(320,450,540,690), N 5$

THF FIRST POSSIBILITY PRINTS FACTORS IN THE COIL

DESIGN; USER INPUTS INTEGER DATA AS REQUESTED

320 TYPE 330

330 FORMATC' DRIVER WIRE GAGE, TURNS, PICKUP WIRE GAGE,

1 TURNS')

TYPE 250

ACCEPT $340, N 1 A, N 2 A, N 3 A, N 4 A$

340 FORMAT ( $4 I)$

IF $(N 1 A * N 2 A \cdot E Q \cdot 0)$ GO TO 350 


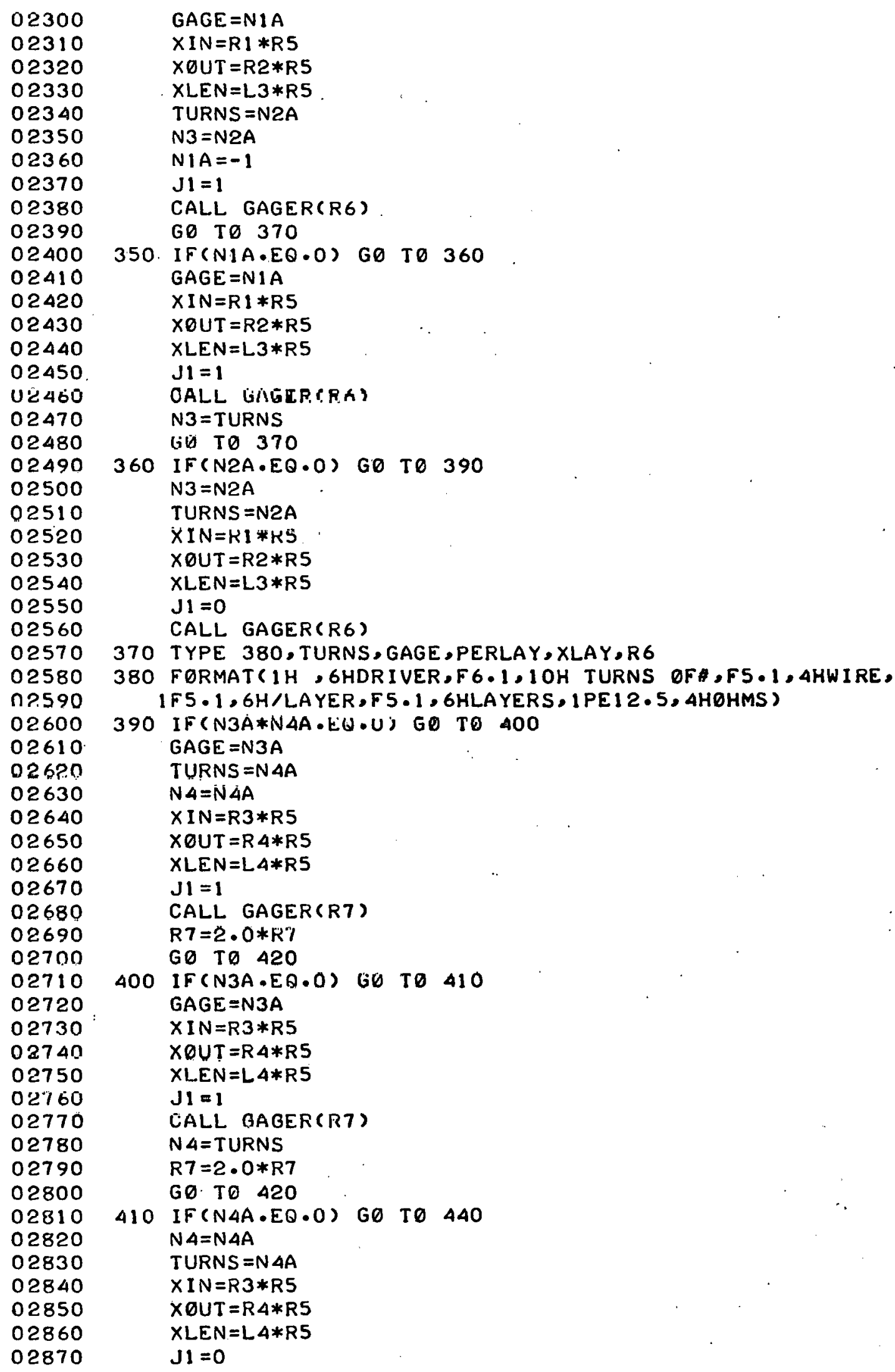

02300

02310

02320

02330

02340

02350

02360

02370

02380

02390

02400

02410

02420

02430

02440

02450

Uट 460

02470

02480

02490

02500

02510

02520

02530

02540

02550

02560

02570

02580

ก 2590

02600

02610

$026 ? 0$

02630

02640

02650

02660

02670

02680

02690

02700

02710

02720

02730

02740

02750

02760

02770

02780

02790

02800

02810

02820

02830

02840

02850

02860

02870

GAGE $=N \perp A$

$X I N=R I * R 5$

$X O U T=R 2 * R 5$

$X L E N=L 3 * R 5$.

TURNS = N2A

$N 3=N 2 A$

$N \mid A=-1$

$J 1=1$

CALL GAGER(R6)

GO TO 370

350. IF(NIA.EQ.O) GO TO 360

$G A G E=N 1 A$

$X I N=R I * R 5$

$X O U T=R 2 * R 5$

$X L E N=L 3 * R 5$

$J 1=1$

OALL GIGER(RA)

N3 = TURNS

GiU TO 370

360 IF (N2A.EQ.O) GO TO 390

N3 $=$ N2A

TURNS $=$ N2A

$X I N=K I * K S$

$X O U T=R 2 * R 5$

$X L E N=L 3 * R 5$

$J 1=0$

CALL GAGER(R6)

370 TYPE 380 , TURNS, GAGE,PERLAY, XLAY, R6

380 FORMAT $1 \mathrm{H}, 6 \mathrm{HDR}$ IVER,F6.1,10H TURNS OFE,F5.1,4HWIRE, IF5 . 1,6H/LAYER,F5 .1,6HLAYERS, IPE 12.5, 4HOHMS)

390 IFCN3Ä*NAA.EU.U' GO TO 400

GAGE $=N 3 A$

TURNS $=N 4 A$

$N 4=N 4 A$

$X I N=R 3 * R 5$

$X 0 U T=R 4 * R 5$

$X L E N=L A * R 5$

$J \mathbf{l}=\mathbf{1}$

CALL GAGER(R7)

$R T=2 \cdot 0 * R 7$

GO TO 420

400 IF (N3A.EQ.O) GO TO 410

GAGE $=N 3 A$

$X I N=R 3 * R 5$

XOUT $=R 4 * R 5$

$X$ L.EN $=L 4 * R 5$

$J 1=1$

CALL GAGER(R7)

NA $=$ TURNS

$R 7=2 \cdot 0 * R 7$

GO. TO 420

410 IF (N $4 A \cdot E Q \cdot 0)$ GO TO 440

$N 4=N 4 A$

TURNS $=N 4 A$

$X I N=R 3 * R 5$

$X$ OUT $=R 4 * R 5$

$X L E N=L 4 * R 5$

$J 1=0$ 


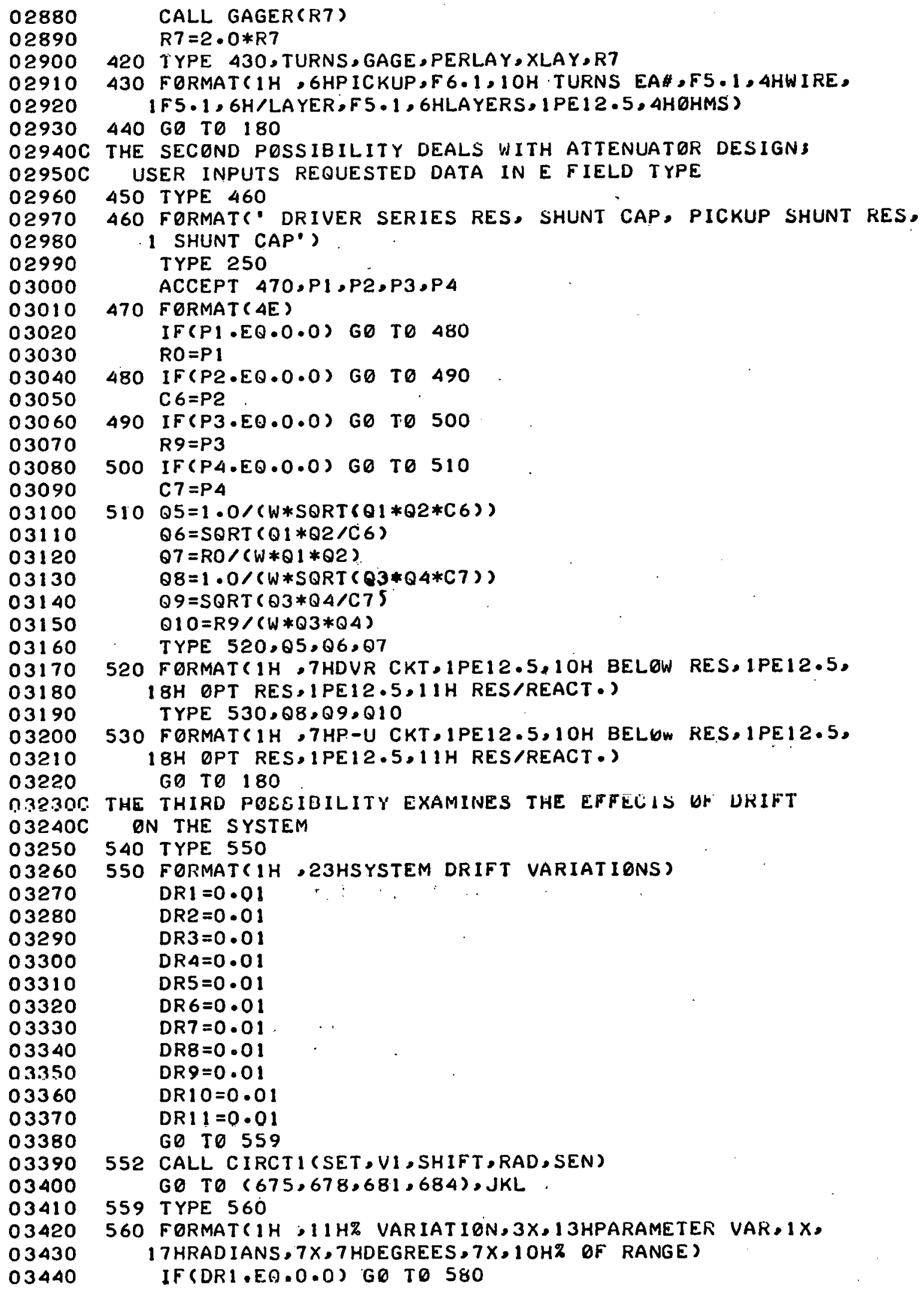




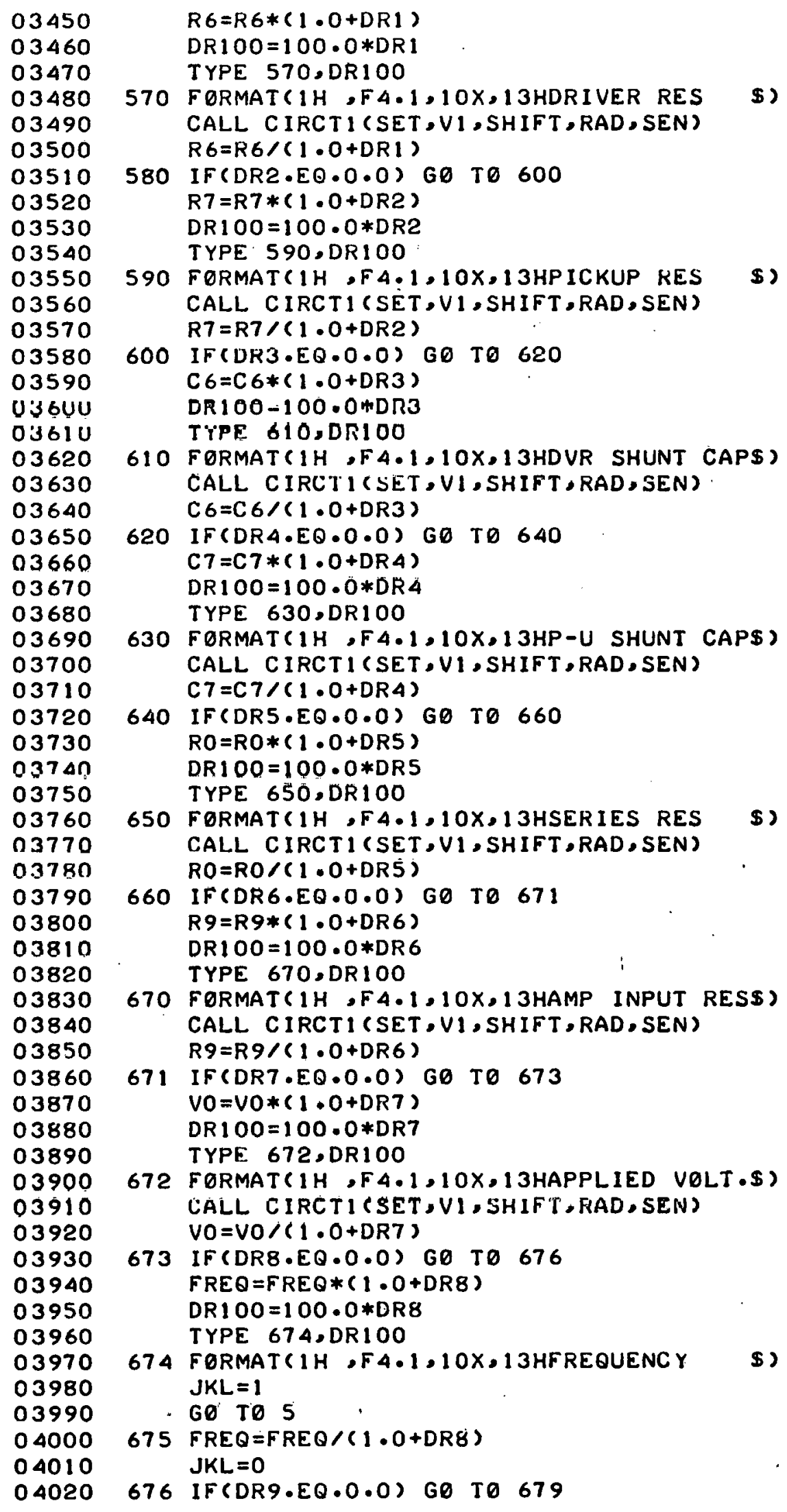




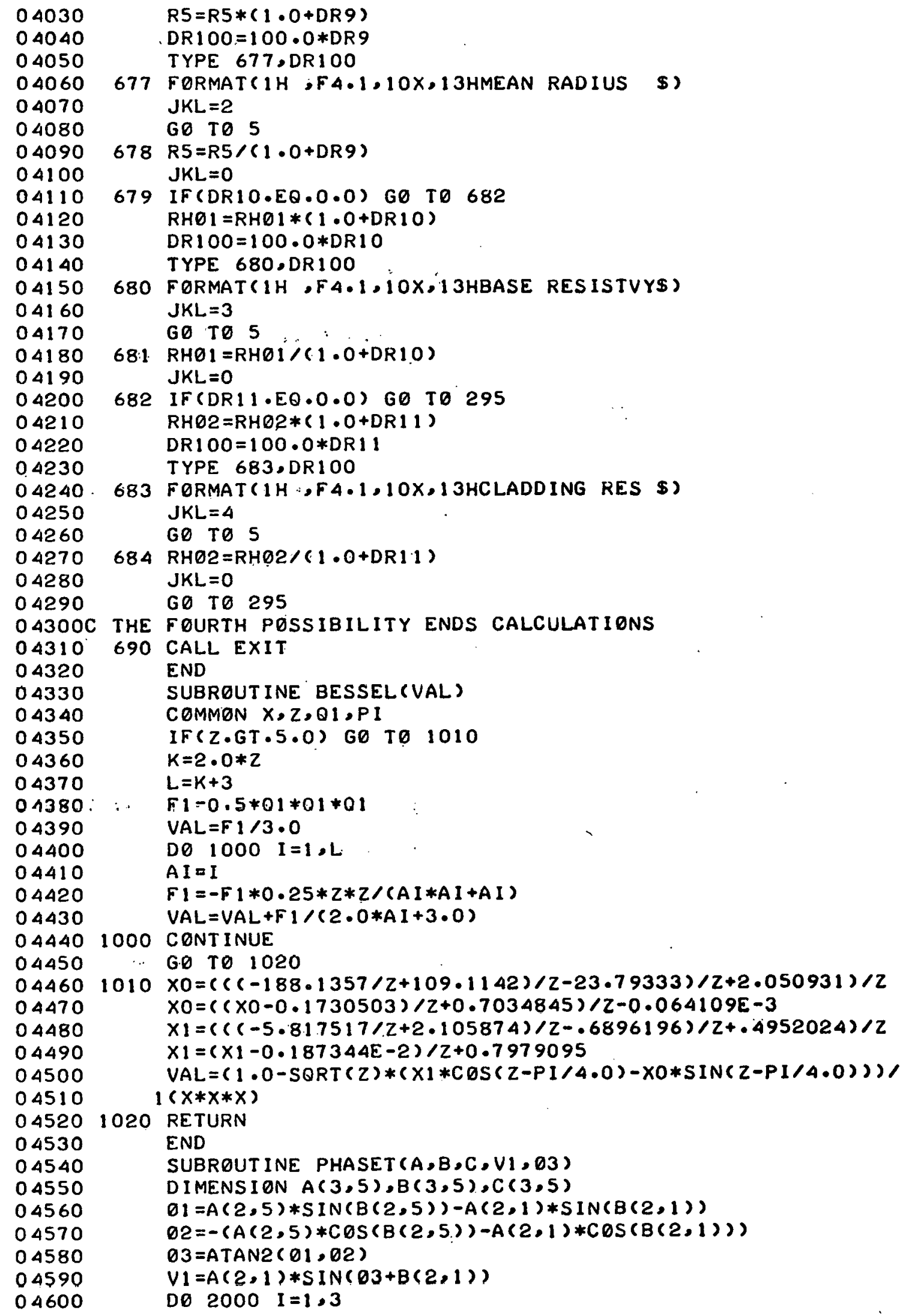




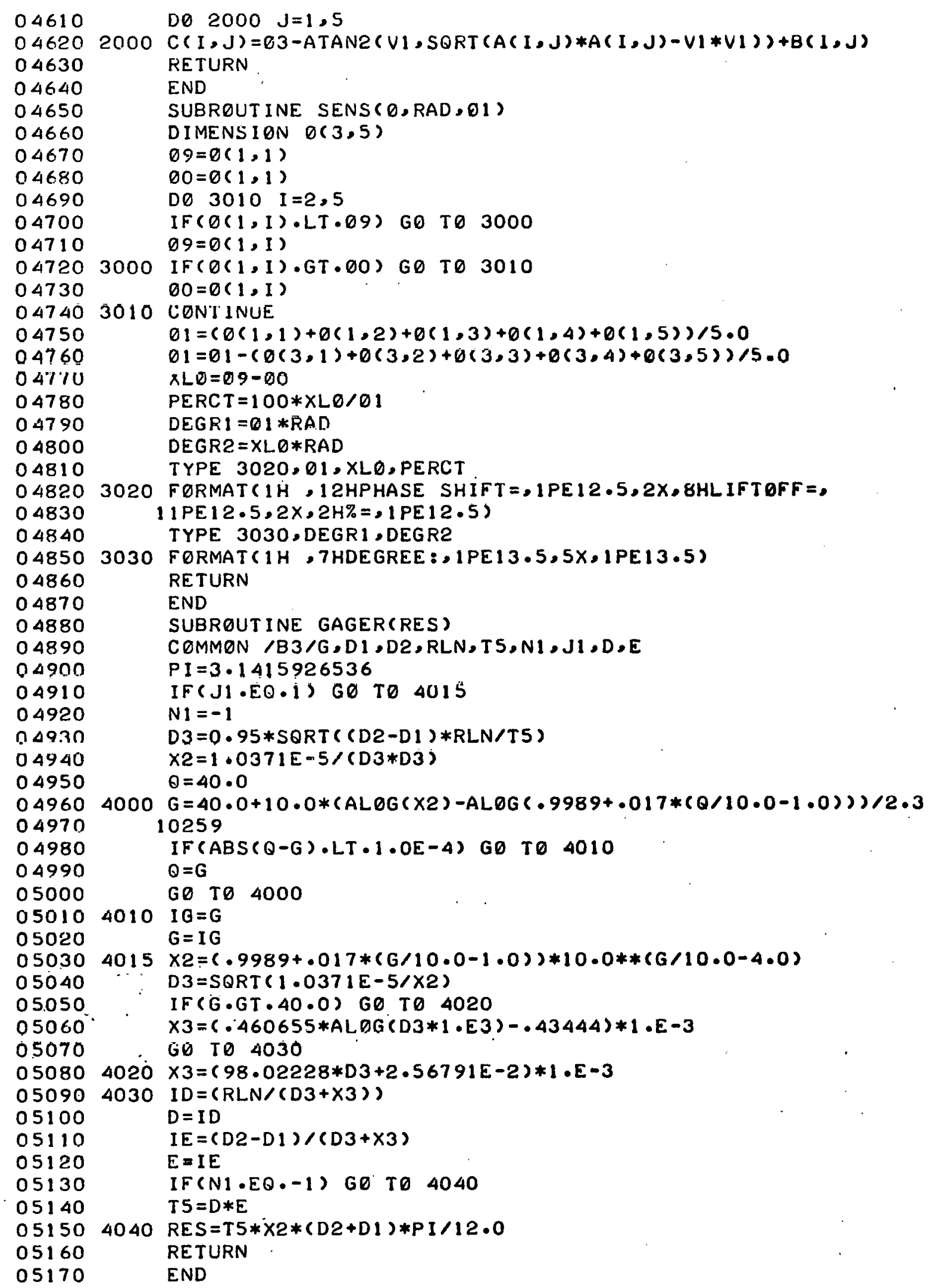




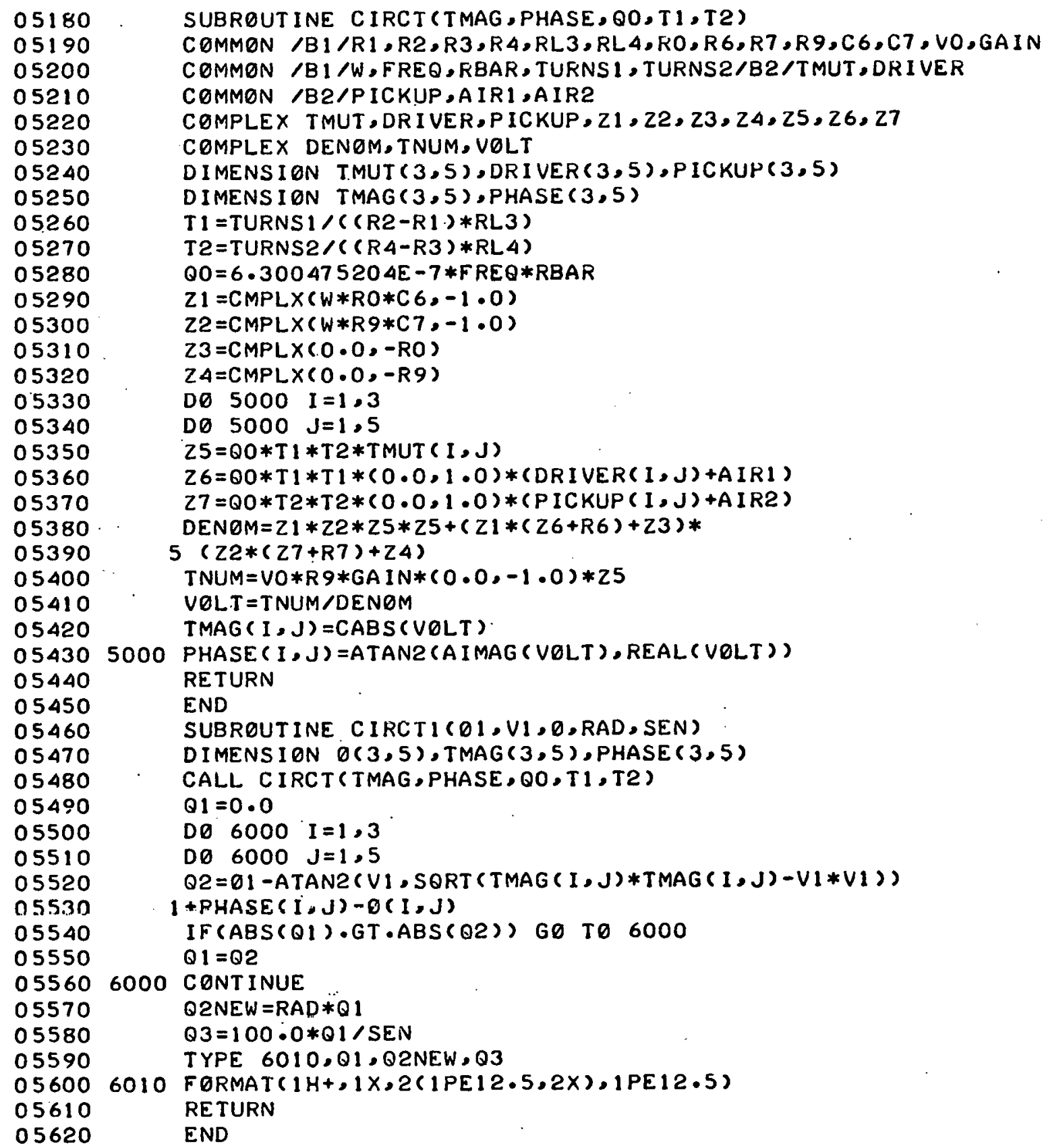


REFLECTION COIL ABOVE MULTIPLE CONDUCTORS, CONDUCTIVITY VARIATION

We shall now consider the case of a reflection coil above multiple conductors, as shown in Fig. 4 (p. 7). This program calculates the magnitude and phase of the voltage that is fed to the phase measuring circuits of the phase sensitive eddy-current instruments and is designed to help analyze eddy-current measurements of conductivity.

The program calculates the magnitude and phase of the induced voltage at 5 diff'erent values uf lift-off for eash of 3 different conductivity values of a specific conductor, maklue a total of 15 oalculations. This allows one to examine the sensitivlly to lift-oft vardations as well as conductivity variations of the specific oonductor. In addition, the program also calculates the phase shift with the discriminator adjusted to give the same phase on the nominal conductivity sample with maximum and minimum lift-off. The phase on the nominal conductivity sample with minimum lift-off is taken as zero, and all other phase shifts are measured relative to it.

The equations which are evaluated are Eq. (8) for the mutual coupling, Eq. (9) f'or the drlver coll 1mpedanos, and Eq. (17) for the pickup coil impedance. The gamma factor for multiple conductors is calculated from Eqs. (24) to (28).

The programs are written in both BASIC and FORTRAN for use on the PDP-10. The BASIC program follows.

To use this program, MULTIC (BASIC), one must first divide all dimensions hy the mean radius of the driver coll. Then the following J.ines must be typed into the program. R.5 = (numerical value of driver coil mean rädus ln luclies)

$200 \mathrm{R} / \mathrm{L}$ - (numerical value of normalized driver coil inner radius)

$270 \quad \mathrm{R} 2=$ (numerical value of normallzed driver coil outer radius)

$280 \mathrm{~L} 3=$ (numerical value of normalized driver coil length)

?9n R3 = (numerical value of normalized pickup coil inner radius)

$300 \mathrm{R} 4=$ (numerical value of normalized pickup coil outer radius)

$310 \quad \mathrm{~L} 4=$ (numerical value of normalized pickup coil length)

$320 \mathrm{~L} 5=$ (numerical value of normalized pickup coil recess from face of driver) 
L6 = (numerical value of normalized driver coil minimum liftoff)

340

R6 = (numerical value of resistance of driver coil in ohms)

350 $R T=$ (numerical value of total resistance of both pickup coils in ohms)

$360 \quad \mathrm{N3}=$ (number of turns on driver coil)

$370 \quad \mathrm{~N} 4=$ (number of turns on each pickup coil)

$380 \quad \mathrm{RO}=$ (output series resistance of driving amplifier in ohms)

390.. R9 = (input shunt resistance of pickup amplifier in ohms)

$400 \quad \mathrm{C} 6=$ (total shunt capacitance in driving circuit in farads)

$410 \mathrm{C7}=$ (total shunt capacitance in pickup circuit in farads)

420 vo = (output voltage of driving amplifier in volts)

$430 \quad G 5=$ (gain of pickup amplifier)

$440 \quad F=$ (operating frequency in Hertz)

$450 \cdot$ L2 $=$ (numerical value of normalized driver coil lift-off increment)

510 N9 $=$ (total number of conductors +1 )

$520 N 8=$ (number of the specific conductor with conductivity variation, refer to Fig. 4)

670 MO $=$ (numerical value of fractional conductivity change of the N8-th layer)

The input data of conductors are typed into the program between the statement numbers 800 and 980 , according to the order of appearance from the luwest conductors [reter to Fig. 4 (p. 7)].

800 DATA $1 E 10, \mathrm{~K}(1), \mathrm{U}(1)$

810 DATA $\mathrm{T}(2), \mathrm{K}(2), \mathrm{U}(2)$

$\vdots \quad \vdots$

- $\quad$ DATA $T(N), K(N), U(N)$

$\vdots \quad \vdots$

- $\quad$ DATA $\mathrm{T}(\mathrm{N} g-\mathrm{l}), \mathrm{K}(\mathrm{N} 9-\mathrm{l}), \mathrm{U}(\mathrm{N} 9-\mathrm{l})$

(980) DATA 1 (arbitrary number), $1 E 10,1$

where 


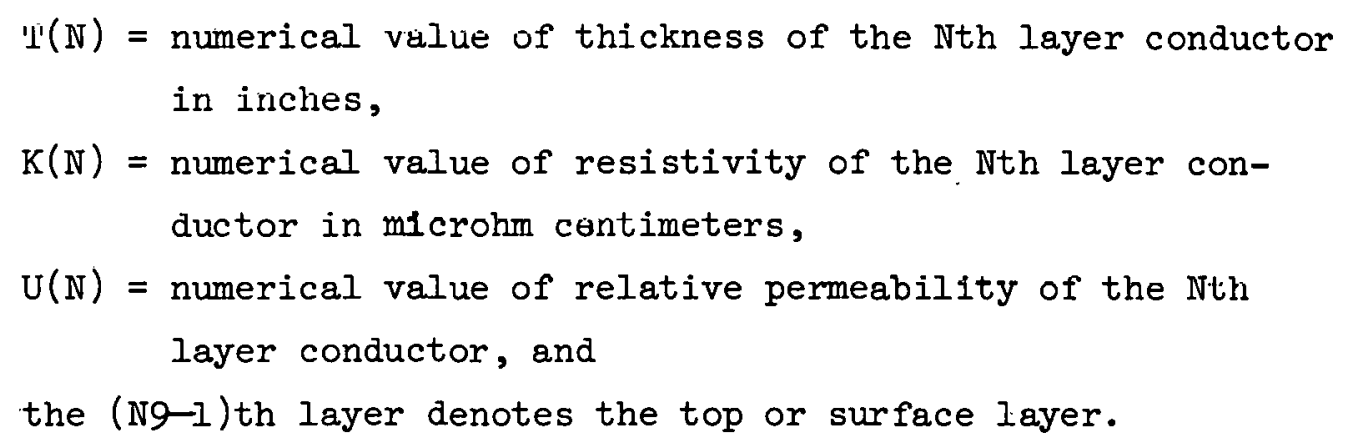

The current version of MULTIC (BASIC) is limited to a maximum of nine conductors." However, this limitation can be removed easily by adding one DIMENSION statement.

60 DIM $T(N 9), R(N 9), U(N 9), S(N 9), X(N 9), Y(N 9)$.

The program may now be run. The print-out by the computer will have the following format.

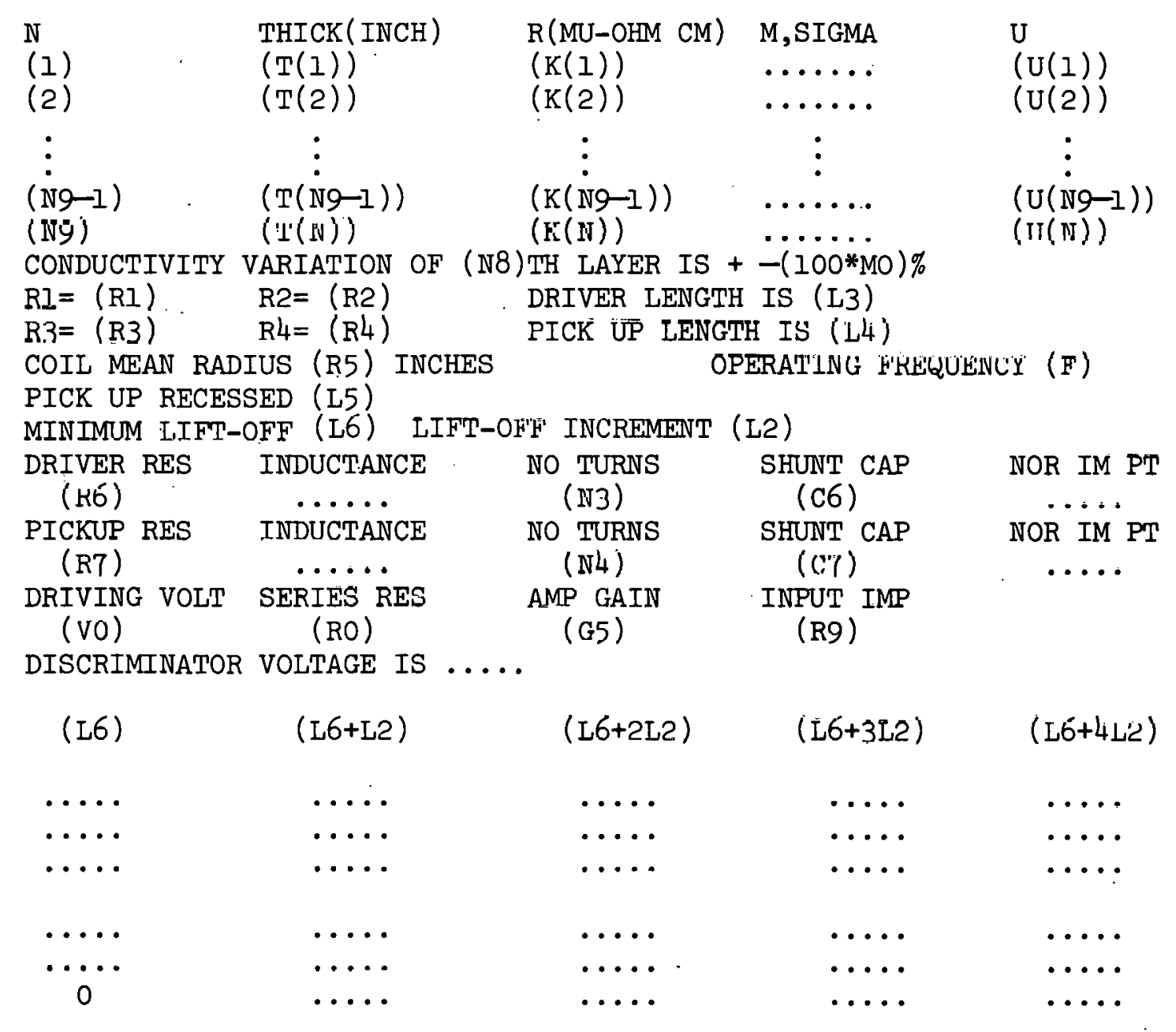




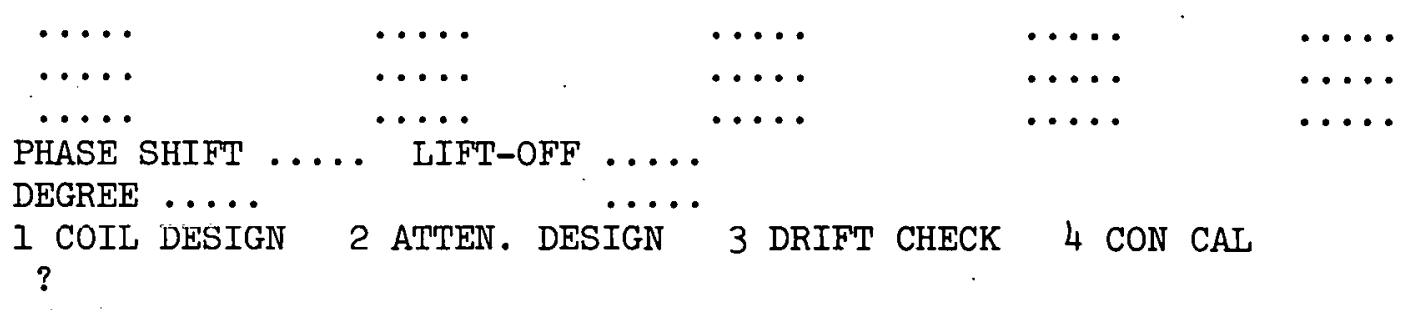

The various symbols enclosed in parentheses are used to indicate that-the numerical value of the symbol will be printed.

There are five columns of data, one under each value of lift-off. Each column is divided into three sections of three lines each. These sections correspond, from top to bottom, to the three values ( $-100 * \mathrm{MO}$, 0 , and $+100 * \mathrm{MO} \%$ variations from nominal) of the conductivity of the N8-th layer. The three lines in each section are, from top to bottom, the magnitude of the voltage out of the pickup amplifier, the phase shift between the voltage out of the pickup amplifier and the driving voltage, and the phase shift between the voltage out of the pickup amplifier with the discriminator set to give the same phase shift with minimum lift-off and maximum. Iift-off on the nominal conductivity. sample. The phase shift in the third line is always measured from the nominal conductivity sample with minimum lift-off. The voltage out of the pickup amplifier will be in volts and be either peak-to-peak or RMS, whichever is used for Vo, the output voltage of the driving amplifier. For each conductor $N$, the value of a dimensionless product $\mathrm{R}_{5}{ }^{2} \omega \mu_{\mathrm{N}} \sigma_{\mathrm{N}}$ is also calculated and printed under the column M,SIGMA. The inductance in henries of the driving coil in air and the normalized imaginary part of the driving coil impedance are also printed, with nominal conductivity and nominal lift-off (L6+2L2). The inductance in henries of both pickup coils in air and the normalized imaginary part of the pickup coils' impedance with nominal conductivity and lift-off is also printed. The total phase shift for the 200*M0\% conductivity variation, the maximum phase shift due to lift-off and the maximum percent of range error in conductivity measurements due to lift-off are given. The phase shifts are given first in radians and then in degrees. 
The program then enters a branching loop that allows the following options, depending on which of $1,2,3$, or 4 is typed as input after the question mark.

1. Coil Design

If a $l$ is typed by the operator after the question mark, the program will enter the Coil Design Loop. This loop will allow the number of turns on the driver and pickup coils to be varied. The loop will allow the wire gage to be given and then calculate the number of turns and coil resistance, or it will allow the number of turns to be entered and calculate the gage and coil resistance, or both turns and gage carl be entered. If zeros are entered for both the gage and turns of either the driver or pickup coils, the present value of these will be retained. The program then starts with the label

\section{DRIVER RES INDUCTANCE NO TURNS SHUNT CAP NOR IM PT,} and the remainder of the program is recalculated and printed, with the "new" coil in the circuit. However, the numerical integrations to calculate $M, Z_{D R}$, and $Z_{P U}$ do not have to be repeated.

2. Attenuator Design

This loop will allow the driver series resistance, RO, the driver shunt capacitance, $\mathrm{C} 6$, the amplifier input impedance, $\mathrm{R} 9$, and the shunt capacitance in the pickup circuit, $\mathrm{C} 7$, to be varied. If a 2 is typed after the question mark, the computer will respond with

DRIVER SERIES RES, SHUNT CAP, PICK-UP SHUNT RES, SHUNT CAP . The resistance is to be given in ohms, and the capacitance in farads. If zero is typed in for any value, the present value in the computer will be retained. After the input data and a carriage return are typed, the computer will calculate the ratio of resonant frequency to operating frequency for the particular $L=C$ circuit, a very rough value of resistance for minimum temperature drift, and the ratio between the resistance and reactance in the circuit for both the ariver and pickup circuits. The program then starts with the label

\section{DRIVER RES INDUCTANCE NO TURNS SHUNT CAP NOR IM PT ,} and the remainder of the program is recalculated and printed with the "new" attenuator in the circuit. Again, the numerical integrations to calculate $\mathrm{M}, \mathrm{Z}_{\mathrm{DR}}$, and $\mathrm{Z}_{\mathrm{P} \cdot \mathrm{U}}$ do not have to be repeated. 
3. Drift Check

This loop calculates the effect of the drift of any of the circuit or sample parameters after the instrument has been calibrated and adjusted. If a 3 is typed as input, the program will respond with the percent variation, the parameter varied, the maximum change in phase (both radians and degrees) of any of the 15 different phases calculated ( 5 lift-off values for each of 3 different conductivity values) and the percent of the range the drift represents. The percent variation of each parameter may be varied independently. The following table gives the parameter, the line number, and the constant to be varied:

\begin{tabular}{lcc}
$\frac{\text { Parameter }}{\text { Dine Number }}$ & Constant \\
\cline { 2 - 3 } Pickup Resistance & 8610 & E1 \\
Driver Shunt Cap. & 8620 & E2 \\
Pickup Shunt Cap. & 8630 & E3 \\
Series Resistance & 8640 & E4 \\
Amp. Input Resistance & 8650 & E7 \\
Applied Voltage & 8660 & E8 \\
Frequency. & 8670 & E9 \\
Mean Radius & 8680 & Al \\
\end{tabular}

For example, to put in a $2 \%$ variation in the driver coil resistance, one would type:

$$
8610 \mathrm{El}=.02
$$

The amount that each parameter is varied must be set before the program is run. All of the variations are 0.01 or $1 \%$ in the current version of the program. Since the phase shift produced by the parameter variation is quite linear over a range of about $10 \%$, a linear interpolation or extrapolation may be used from the $1 \%$ parameter variation. If zero is typed in for any parameter variation, that parameter will not be varied nor will it be typed out in the list of parameter variations. When the calculation is completed and the drifts printed, the program returns to the branch point and repeats the question

1 Coil Design 2 Atten. Design 3 Drift Check 4 Con Cal . 
The first seven drifts do not require that the numerical integrations to calculate $\mathrm{M}, \mathrm{Z}_{\mathrm{DR}}$, and $\mathrm{Z}_{\mathrm{PU}}$ be repeated, but they must be repeated to calculate the drifts due to frequency and mean radius changes. Therefore, the calculation of these last two drifts requires a considerable amount of computer time.

4. Con Cal

This loop is to continue calculations. If a series of calculations is to be made, a loop may be established at this point. However, in the present version of the program, if a 4 is typed as input, the program will end.

\section{Sample Calculation of MULTIC}

Let us suppose we wish to design a reflection-type coili to measure the conductivity variation of a cladding material that has a thickness of $28 \mathrm{mils}$ and a nominal resistivity of $3.632 \mu \Omega-\mathrm{cm}$. Below the surface cladding, the next conductor is $194 \mathrm{mils}$ thick and has a resistivity nf 5.393 u $\Omega-c m$. Finally, there is another layer of cladding material, with a thickness of $28 \mathrm{mils}$ and resistivity of $3.632 \mu \Omega-\mathrm{cm}$. The driver coil has a mean radius of 0.08325 in., inner and outer radii of 0.0625 and $0.104 \mathrm{in.}$, and a length of $0.03 \mathrm{in.}$ The pickup coils have inner and outer radii of 0.03 and $0.058 \mathrm{in.,} \mathrm{a} \mathrm{length} \mathrm{of} 0.008 \mathrm{in}$. and are mounted flush with the ends of the driver coil. The driver coil has 360 turns of No. 46 wire with a resistance of' ' $19.36 \Omega$, and the plukup cuils have 410 turns each of No. 34 wire, with a resistance of $530.5 \Omega$ for bull coils. The driver series and the pickup amplifier input resistances are both chosen to be I M $\Omega$. The shunt capacitances in both circuits are chosen to be $1 \mathrm{pF}$. This corrcoponde to practically infinite source and detector impedances, so that only the mutual coupling, $M$, affects the phases. The minimum lift-off is taken to be $0.0083 \mathrm{in}$. with a lift-off increment of $0.002 \mathrm{in}$. The variation in the conductivity of the surface cladding is $\pm 5 \%$. The relative permeability of all layers is 1. The frequency is $10,000 \mathrm{~Hz}$, the output voltage of the driving amplifier is $10 \mathrm{~V}$, and the gain of the pickup amplifier is unity 
(a unity gain allows the actual gain needed in the amplifier to be calculated by dividing the maximum output voltage with unity gain into 10).

The program MUTIC is assumed to be in the active core, and the following information is typed into the computer. All linear dimensions are normalized by dividing by the coil mean radius, except for the coil mean radius, which is in inches.

$\begin{array}{ll}250 & \text { R5 }=.08325 \\ 260 & \text { R1 }=.15 \\ 270 & \text { R2 }=1.25 \\ 280 & \text { L3 }=.36 \\ 290 & \text { R3 }=.36 \\ 300 & \text { R4 }=.696 \\ 310 & \text { L4 }=.096 \\ 320 & \text { L5 }=0 \\ 330 & \text { L6 }=.1 \\ 340 & \text { R6 }=79.36 \\ 350 & \text { R7 }=530.5 \\ 360 & \text { N3 }=360 \\ 370 & \text { N4 }=410 \\ 380 & \text { RO }=1 E 6 \\ 390 & \text { R9 }=1 E 6 \\ 400 & \text { C6 }=1 E-1.2 \\ 110 & \text { C7 }=1 E-12 \\ 420 & \text { V0 }=10 \\ 430 & \text { G5 }=1 \\ 440 & \text { F }=10000 \\ 450 & \text { L2 }=.025 \\ 510 & \text { N9 }=5 \\ 520 & \text { N8 }=4 \\ 670 & \text { MO }=-.05 \\ 370 \\ 370\end{array}$


800 DATA 1E10, 1E10, 1

810 DATA $.028,3.632,1$

$820 \quad$ DATA $.194,5.393,1$

830 DATA $.028,3.632,1$

840 DATA $1,1 \mathrm{E} 10,1$

The program may now be run with the following results. The data inputed from the terminal by the user are underlined. A carriage return must be typed by the user at the end of each input line. 
MULTIT (BAS IC)

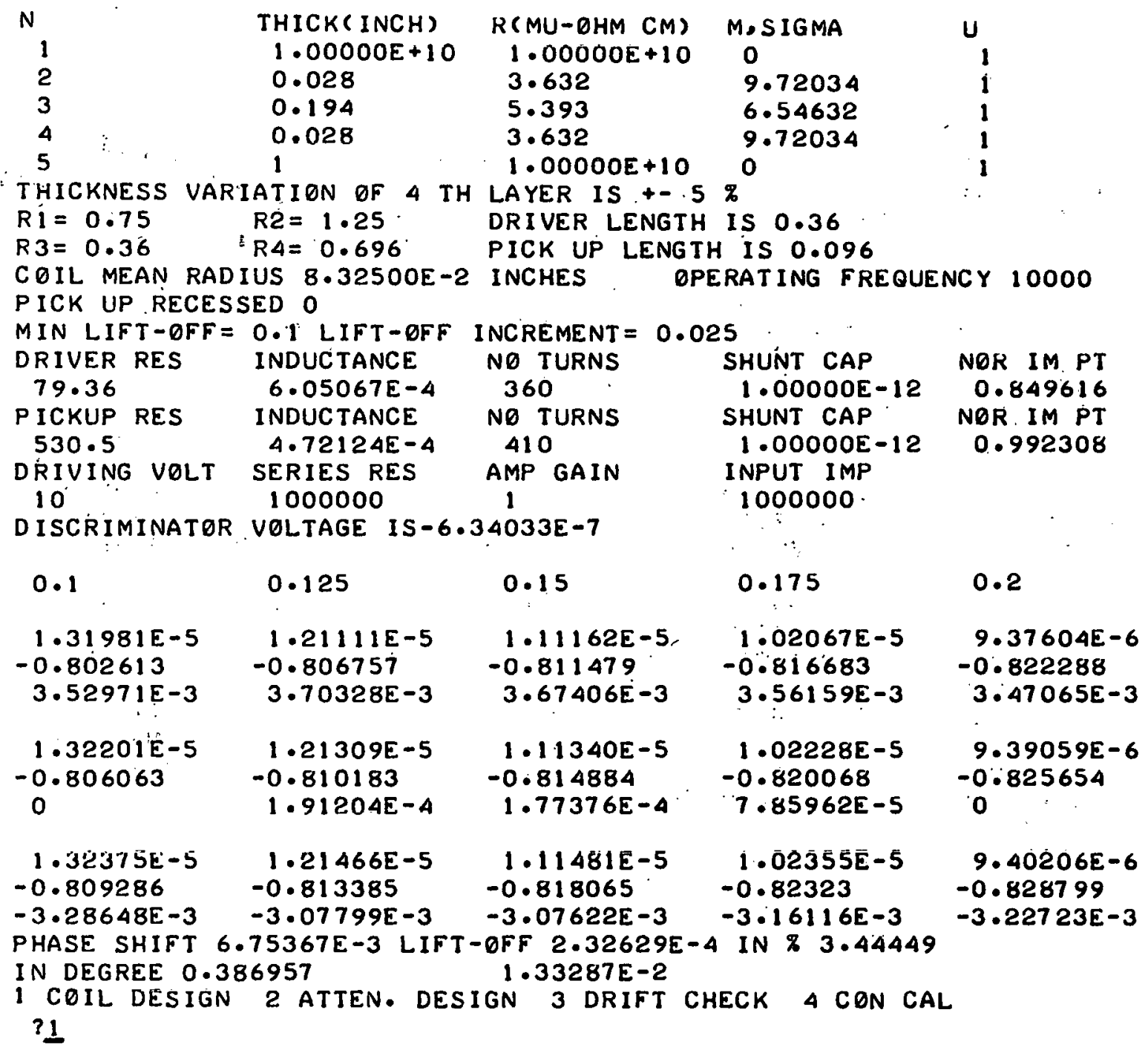


DRIVER WIRE GAGE, TURNS, PICK-UP WIRE GAGE. TURNS $? 46,0,54,0$

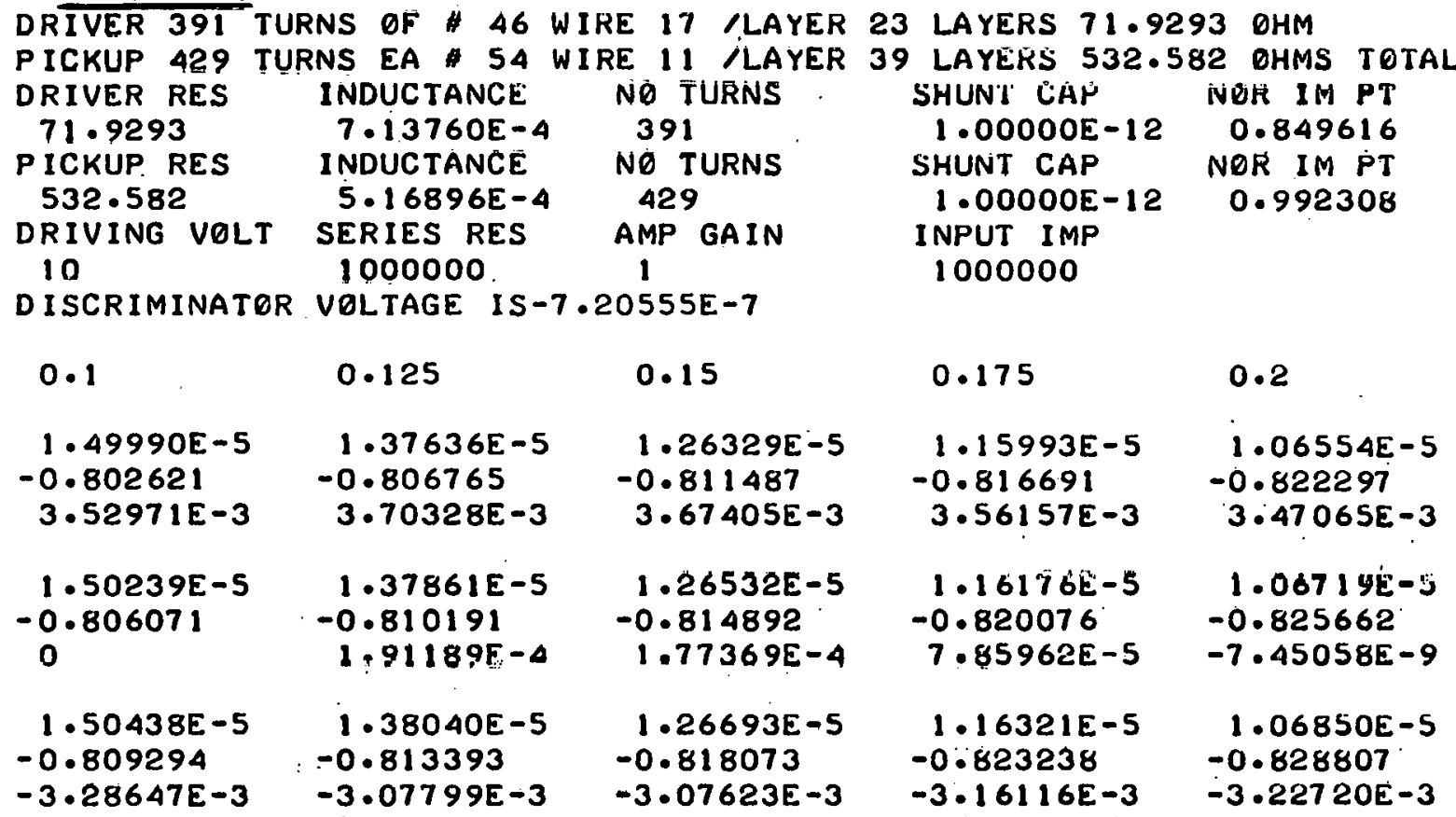

PHASE SHIFT $6.75367 E-3$ LIFT-OFF $2.32629 E-4$ IN $\% 3.44449$

IN: DEGREE 0.386957 1.33287E-2

1 COIL DESIGN 2 ATTEN. DESIGN. 3 DRIFT CHECK 4 CON CAL ?ב․ㅡ. 


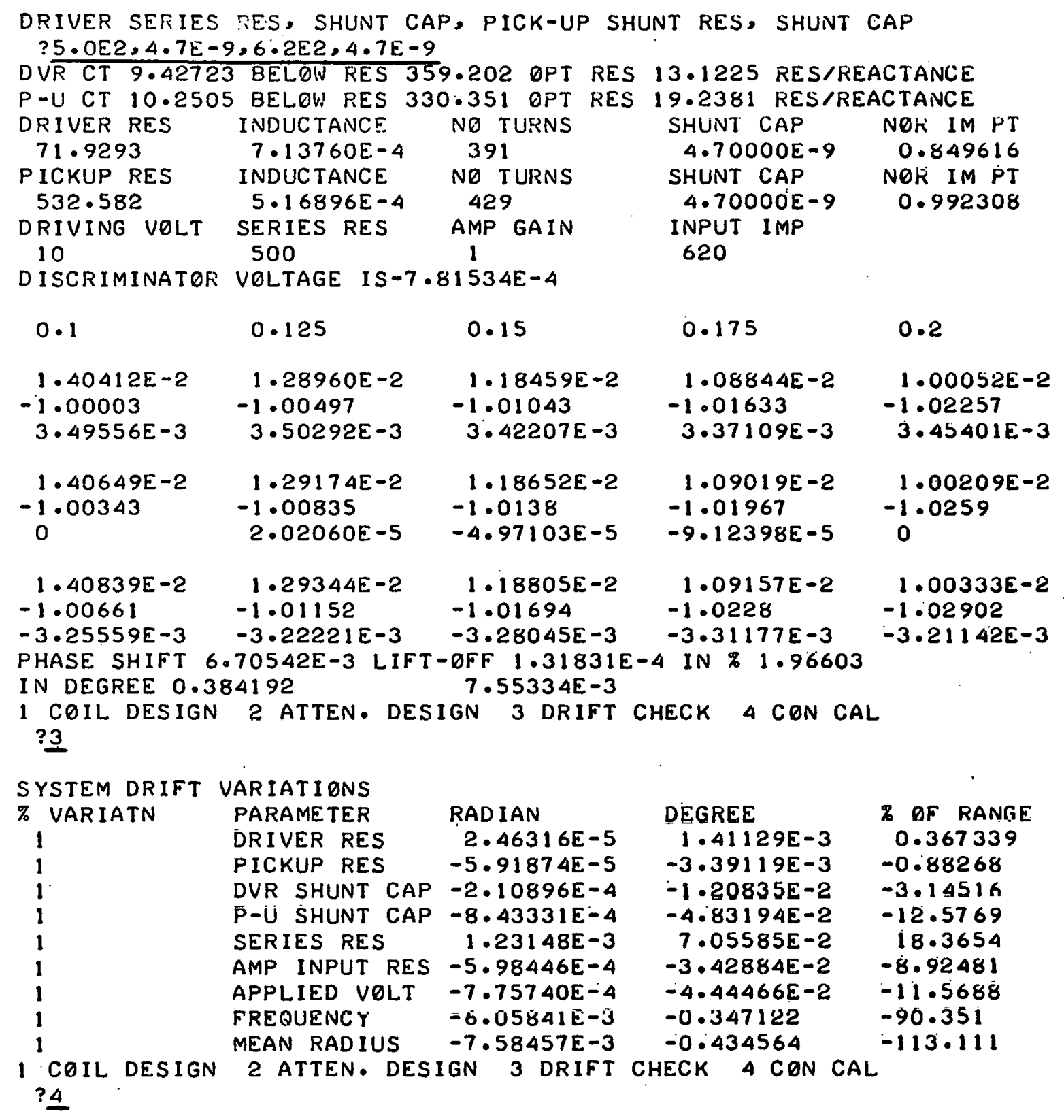

The user has exercised all the design options available, and these options may be repeated, omitted, or taken in any order. The BASIC version of the program MUTIC follows. 


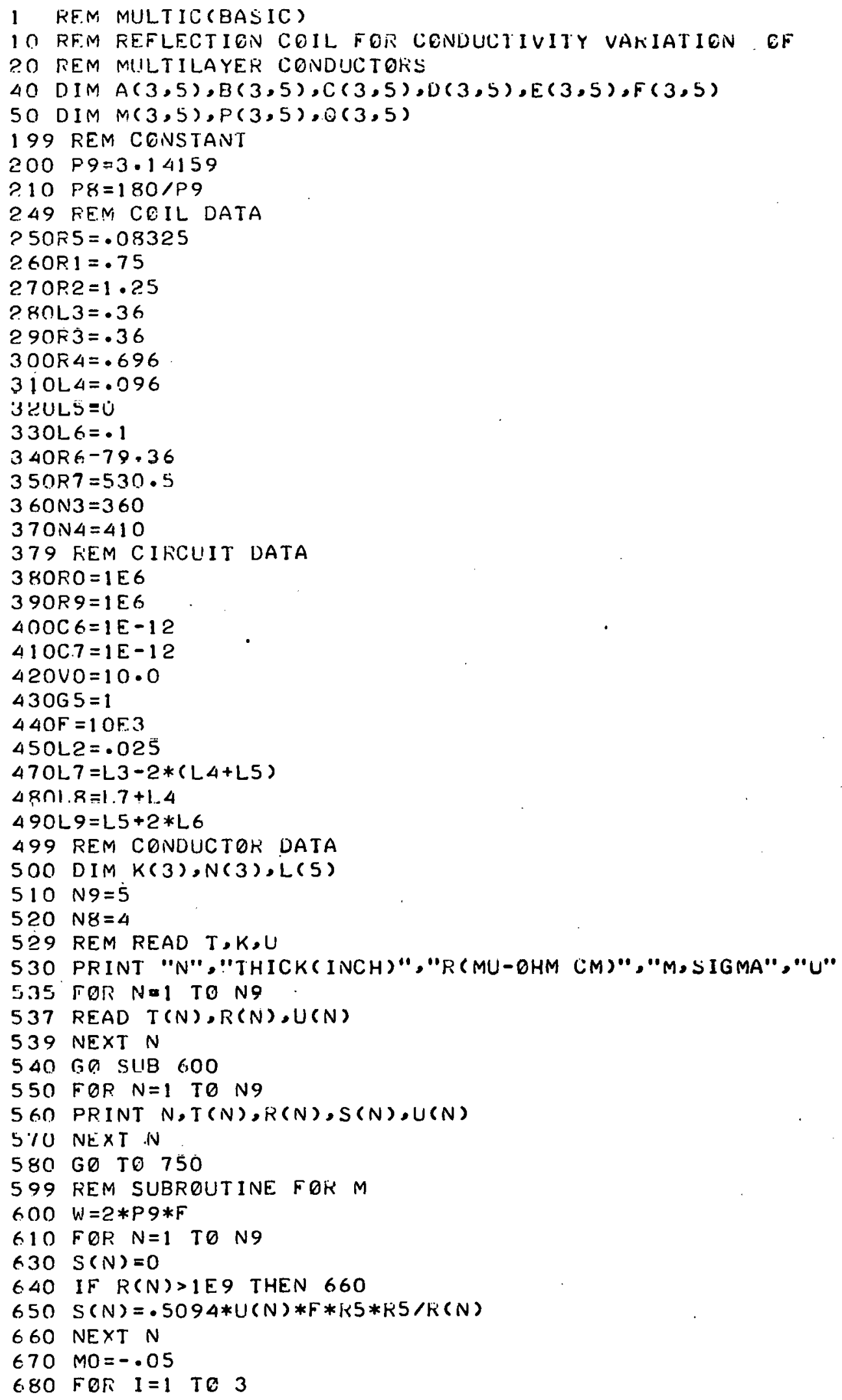




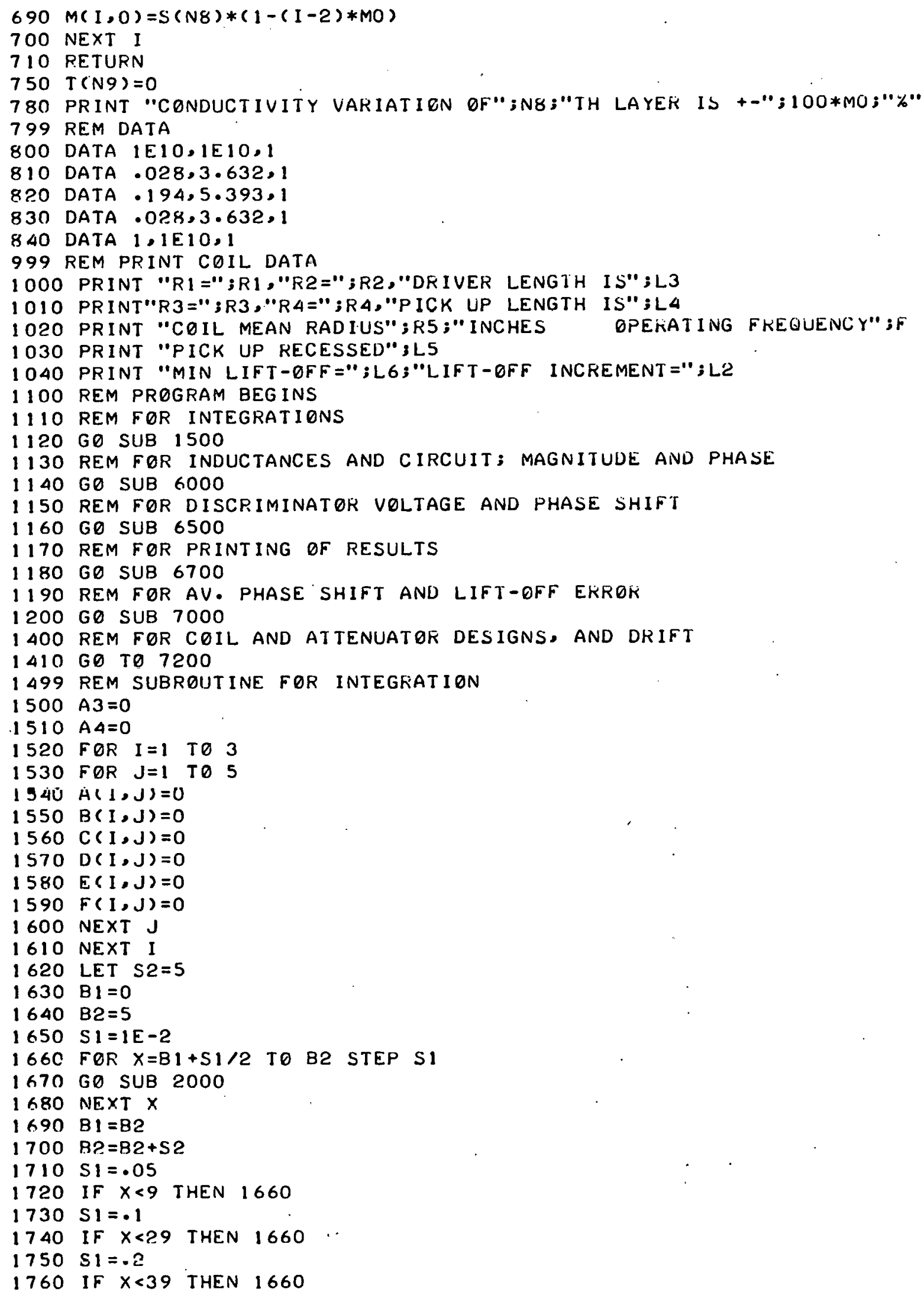




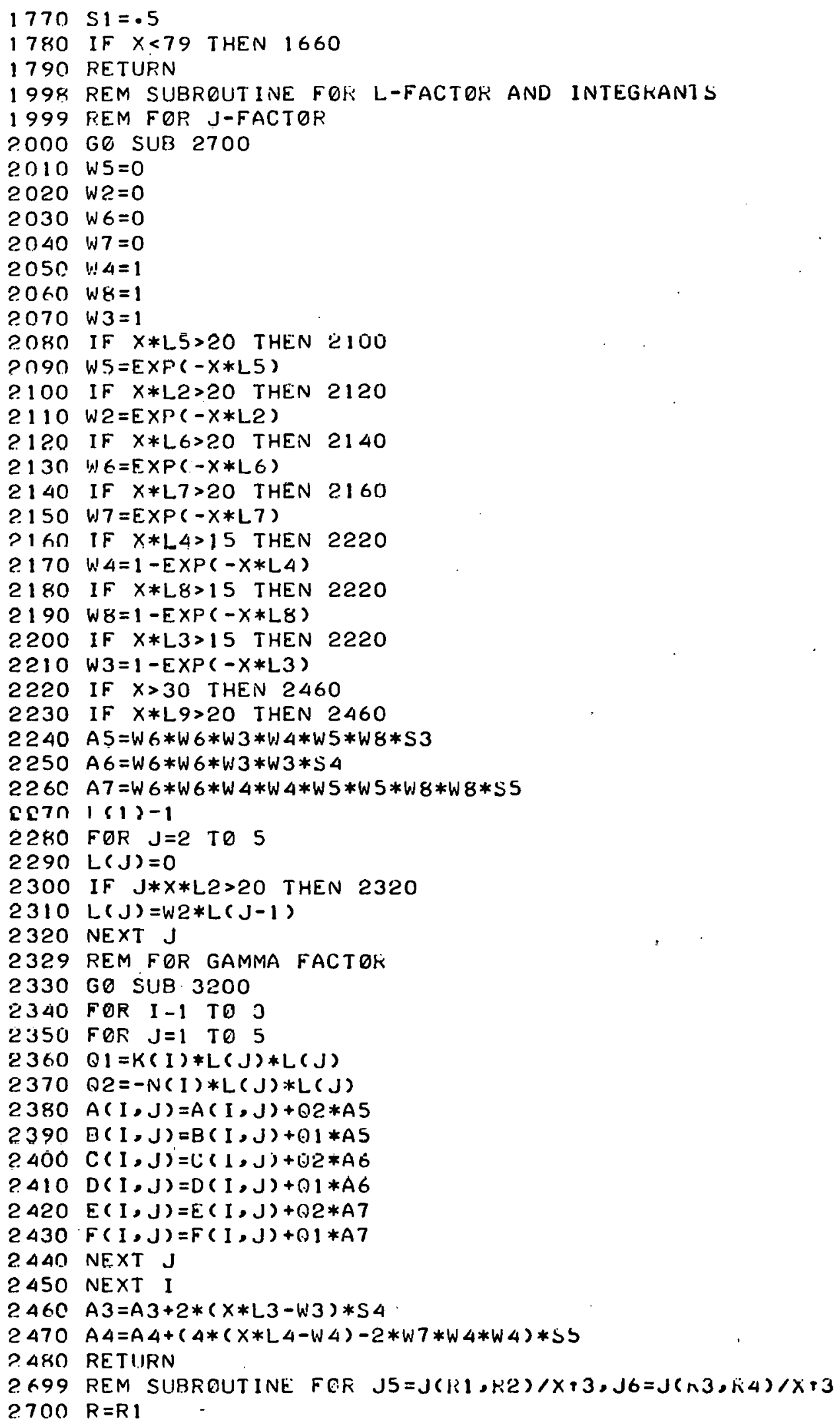




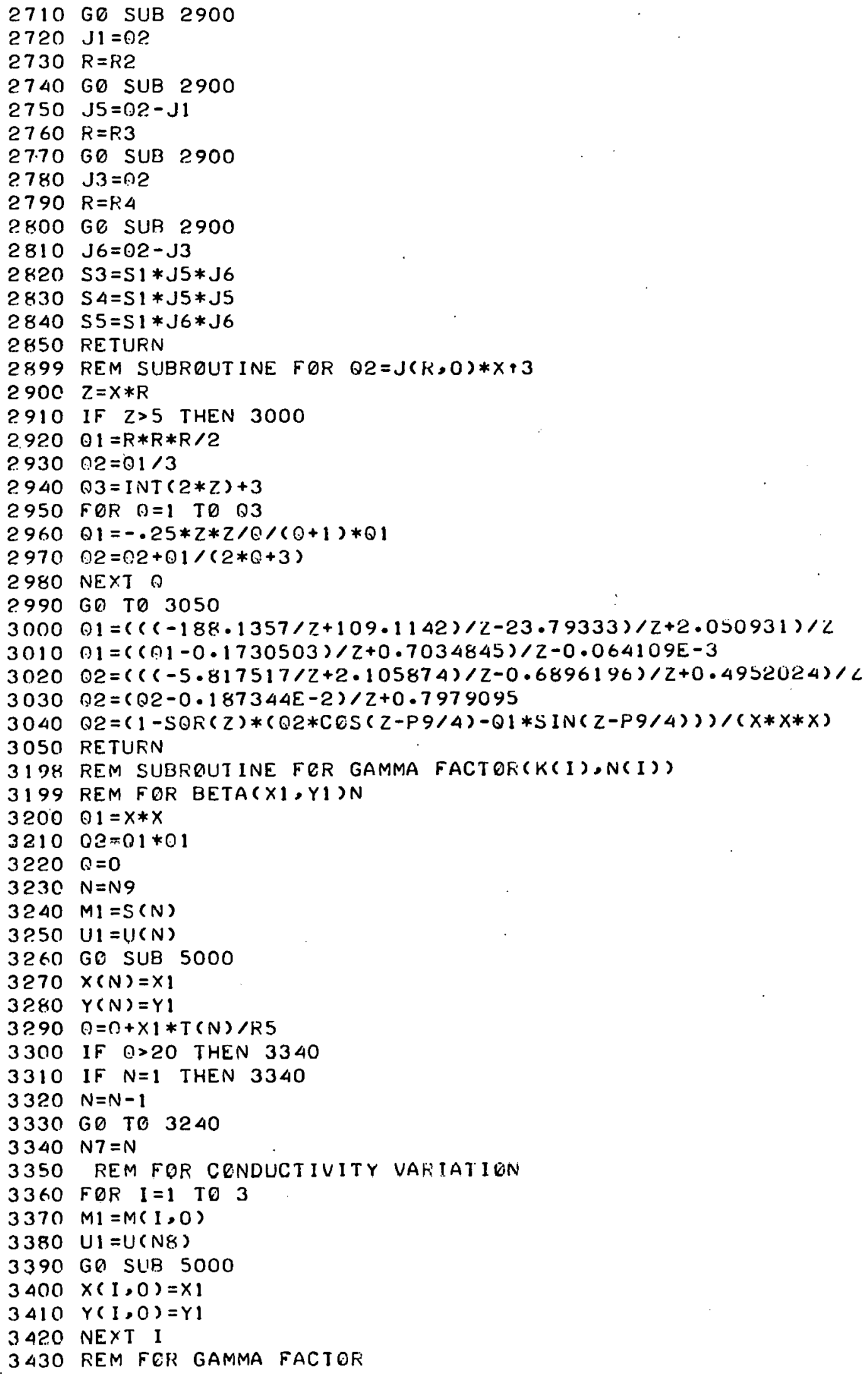




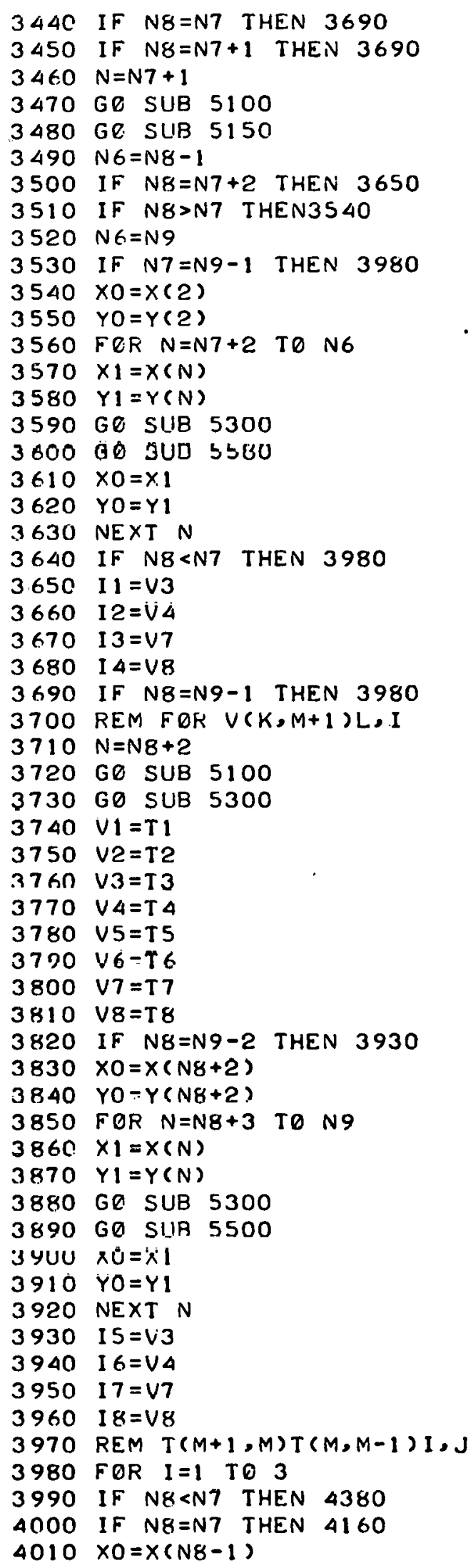




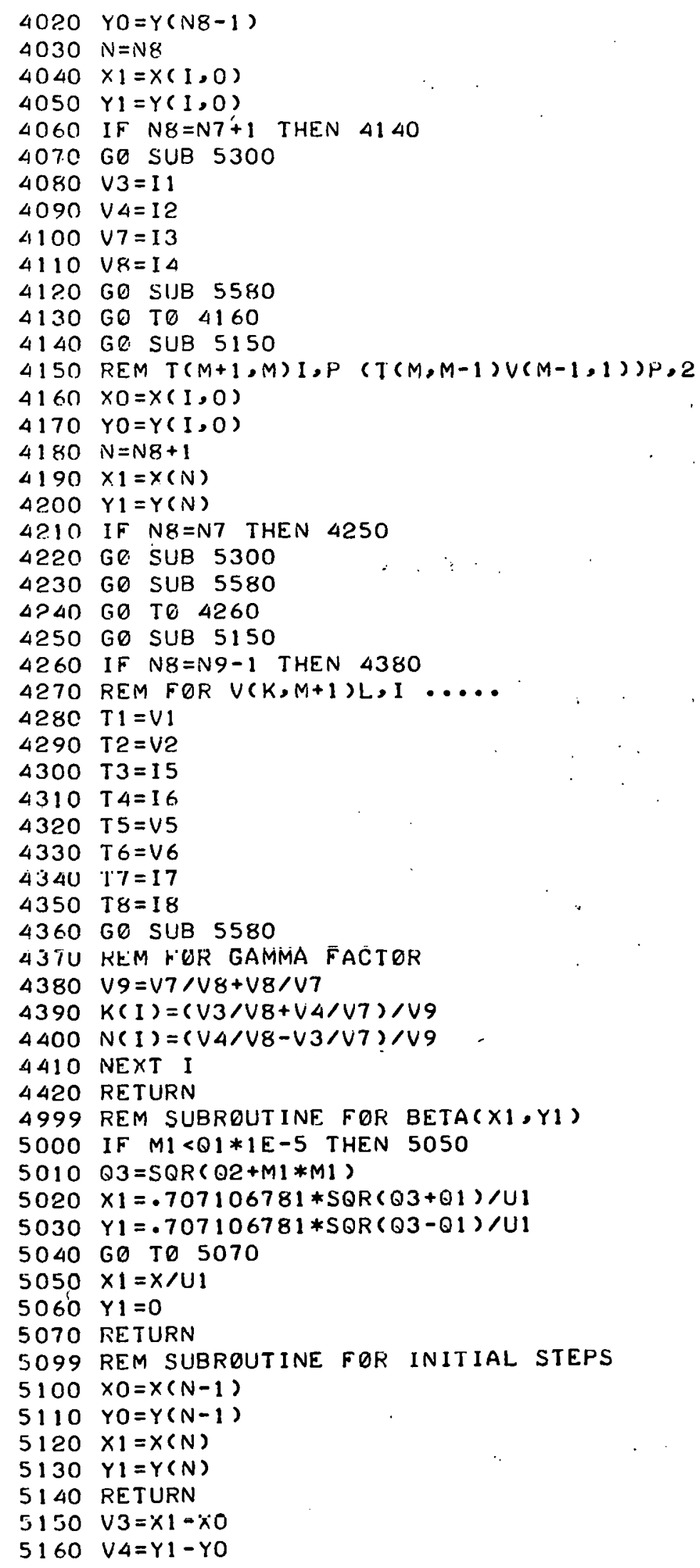




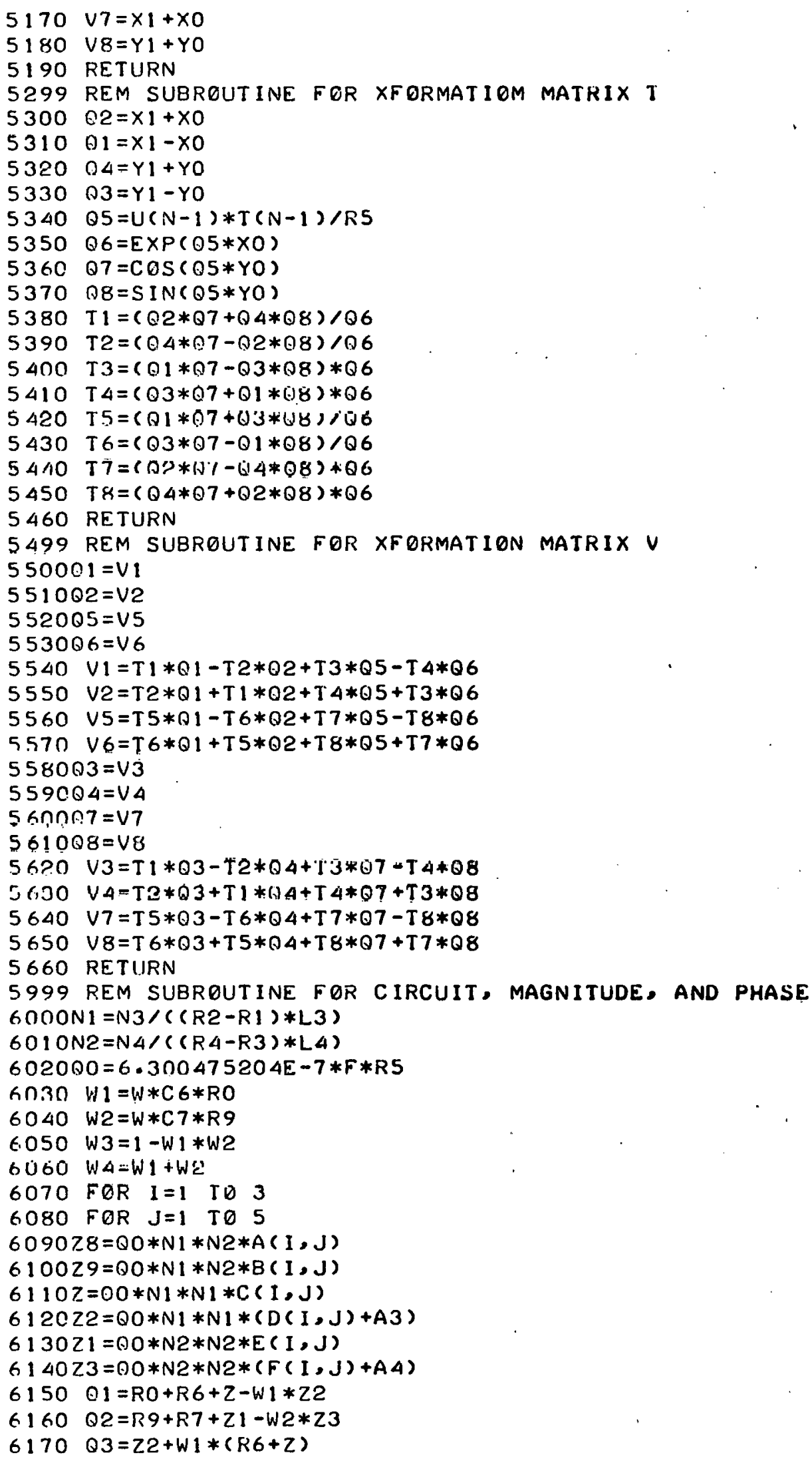




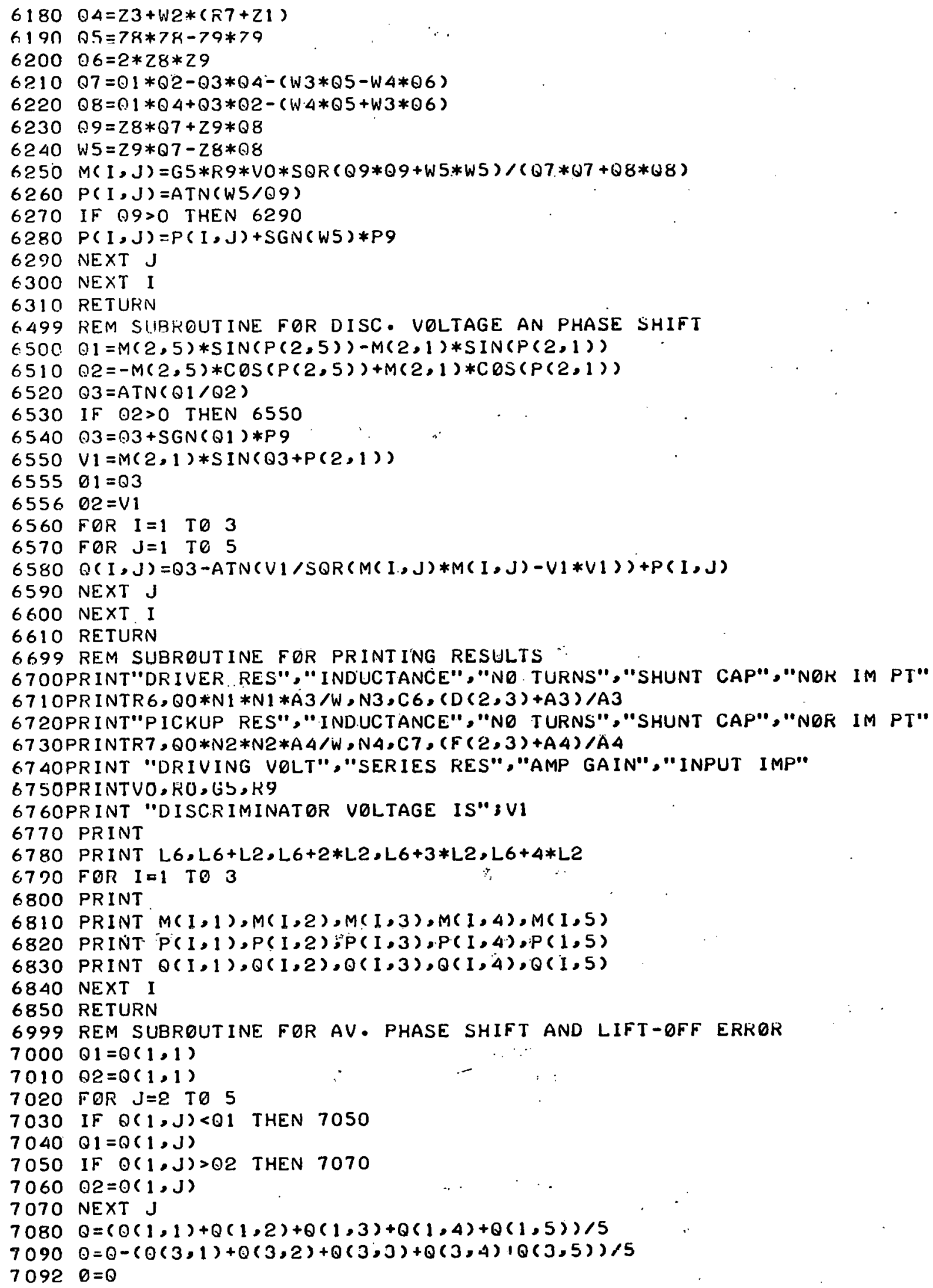


7100 PRINT"PHASE SHIFT"30;"LIFT-OFF" $301-023 "$ IN $2 " 3100 *(0,1-02) / 0$

7110 PRINT"IN DEGREE"; $\theta * P 8,(01-02) * P 8$

7120 RETURN

7199 REM FOR COIL DESIGN, ATTENUATER, DRIFT, AND EXIT

7 2OOPRINT"1 COIL DESIGN 2 ATTEN. DESIGN 3 DKIFT CHECK 4 CON CAL"

7210 INPUT NS

7 22OPRINT

$72300 N$ N5 GO TO $7300,8200,8600,9900$

7299 REM FOR COIL DESIGN

7300 PRINT "DRIVER WIRE GAGE, TURNS, PICK-UP WIKE GAGE, IUKNS"

7310 INPUT $01,02,03,04$

7319 REM FOR DRIVER

$7320 W 1=R 1$

$7330 W 2=R 2$

7340 W $3=L 3$

7350 GD SUB 7510

$7360 \quad N 3=02$

7370 R6 $=09$

7380 PRINT "DRIVER" 3 N33"TURNS OF \#", 36"WIKE";

7390 PRINT 07;"/LAYER" 308 ;"LAYERS" 3R63"OHM"

7399 REM FOR PICKUP

$7400 \quad Q 1=03$

$7410 \quad 82=84$

$7420 W 1=R 3$

7430 W2 $=R 4$

$7440 W 3=L 4$

7450 GO SUB 7510

$7460 \quad N 4=02$

$7470 \quad R 7=2 * Q 9$

7480 PRINT "PICKUP"; N4;"TURNS EA \#", G3"WIKE",

7490 PRINT 07;"/LAYER";08;"LAYERS"3R73"OHMS TOTAL"

7500 GO TO 1140

7509 REM SUBROUTINE FOR GAGE AND TURN NUMBER

$7510 W 1=W 1 * R 5$

7520 ' $W 2=W 2 * R 5$

7530 W $3=W 3 * R 5$

7539 REM FOR GAGE

$7540 \quad G=01$

7550 IF $G>.5$ THEN 7640

$7560 \quad Q 5=.95 * S Q R((W 2-W 1) * W 3 / Q 2)$

$7570 \quad 06=1.0371 E-5 / 05 / 05$

$7580 \mathrm{GO}=40$

$7590 G=40+10 *(\operatorname{LGG}(Q 6)-L \emptyset G(.9989+.017 *(G 0 / 10-1))) / 2.30259$

7600 IF ABS $(G-G 0)<1 E-4$ THEN 7630

$7610 \mathrm{GO}=\mathrm{G}$

$7620 \mathrm{G} \theta \mathrm{T} \emptyset 7590$

$7630 \mathrm{G}=$ INT (O)

7639 REM FOR TURN NUMBER AND R6

$7640 \quad \theta 6=(.9989+.017 *(G / 10-1)) * 10+(G / 10-4)$

$7650 \quad Q 5=\operatorname{SQR}(1.0371 E-5 / 06)$

7660 IF $G>40$ THEN 7690

$7670 \quad Q 5=(.460655 * \operatorname{LOG}(Q 5 * 1 E 3)-.43444) * 1 \mathrm{E}-3+05$

7680 GO TO 7700

$7690 \quad Q S=(98.02228 * Q 5+2.56791 E-2) * 1 E-3+Q 5$

$7700 \quad 07=I N T(W 3 / 05)$

7710 B8 $=I N T((W 2-W 1) / 05)$

7720 IF $Q 2>.5$ THEN 7740

7730 B2 $=07 * 08$ 


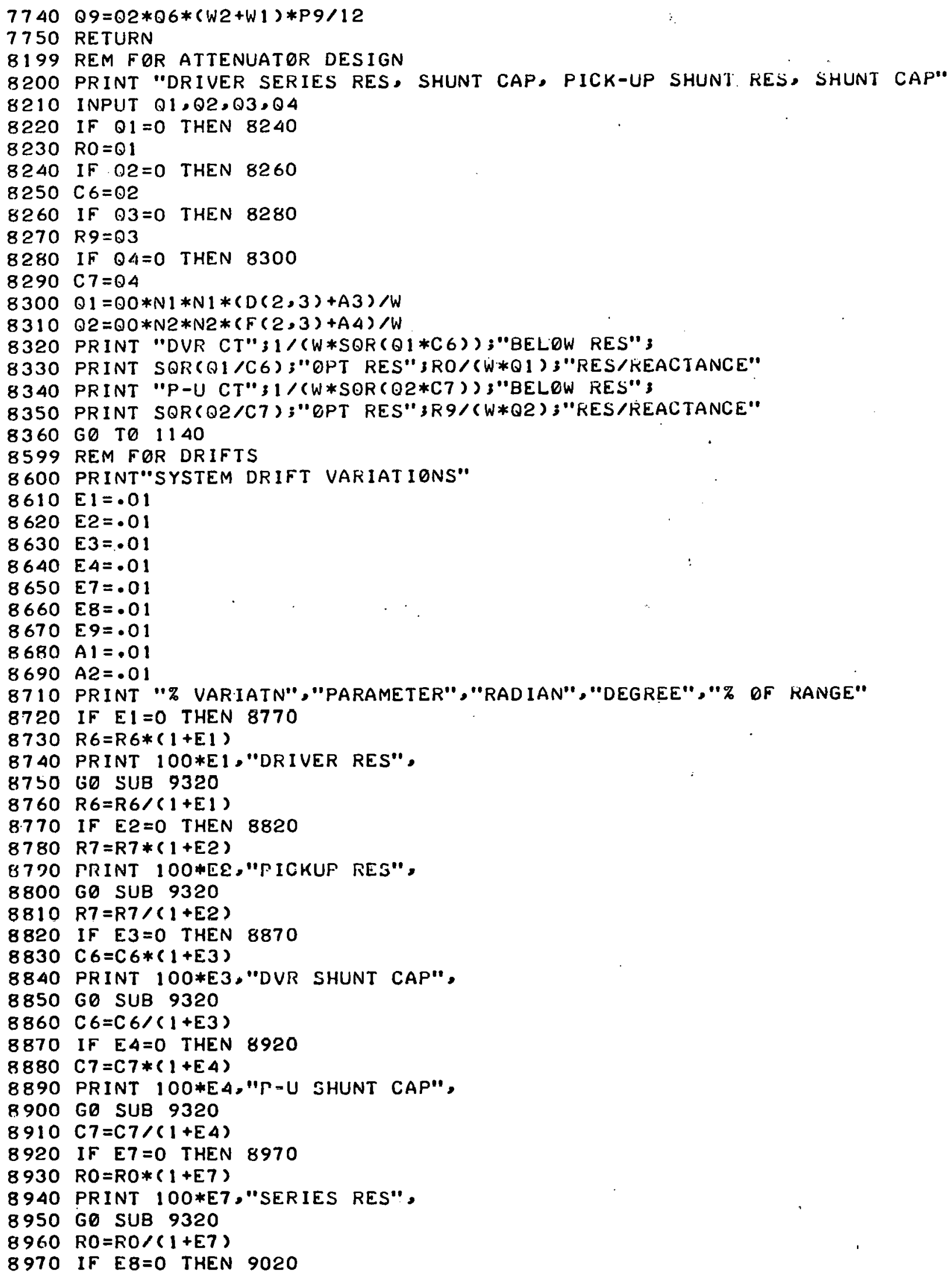




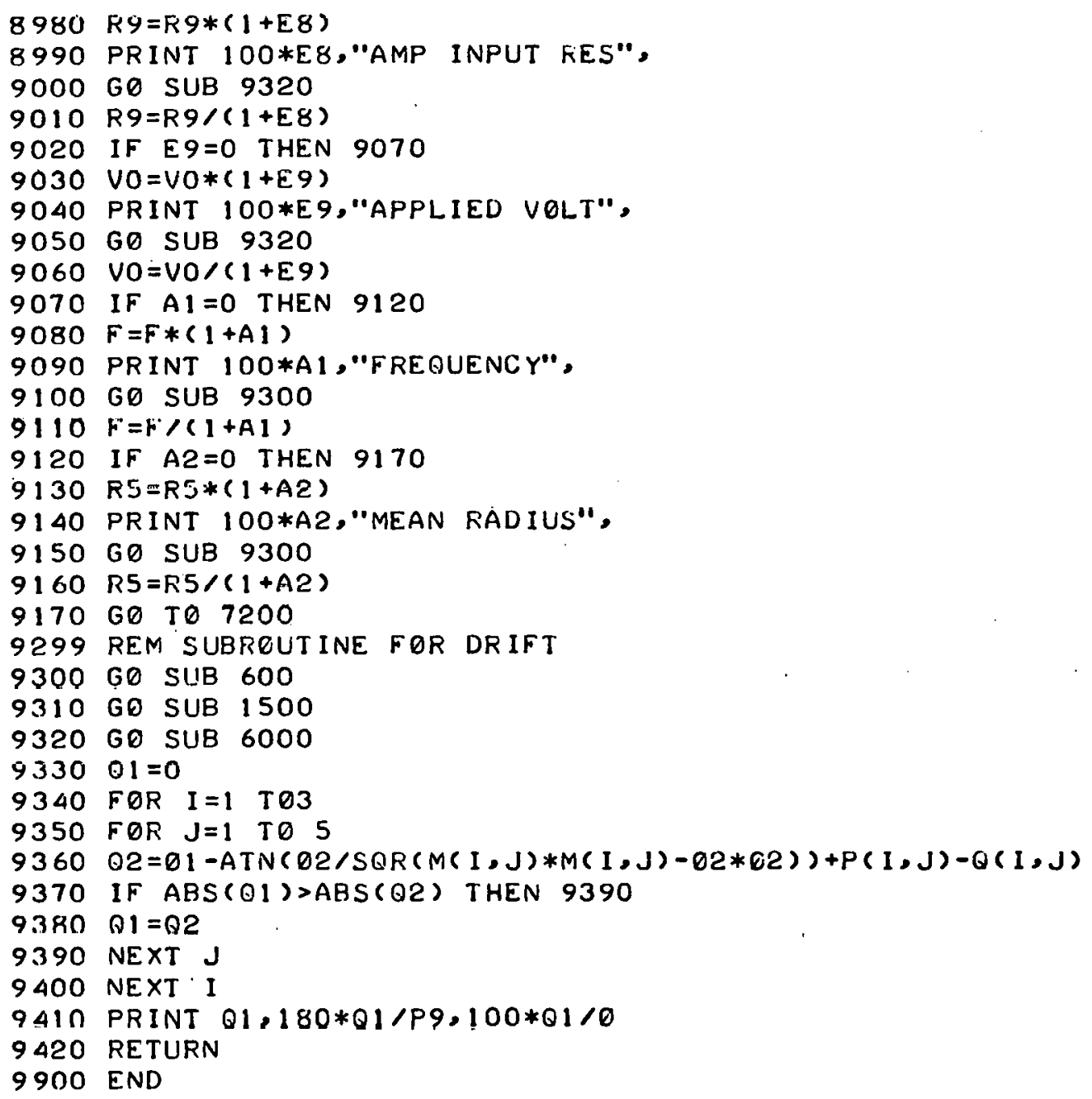




\section{MULTIC, FORTRAN Version}

The FORTRAN version of MULTIC is very similar to the BASIC version. The lịne numbers given are only for identification and editing purposes and have no effect on the actual execution of the FORTRAN program. The data must be typed in the seventh column, or six spaces must first be typed. The data are inputed as follows:

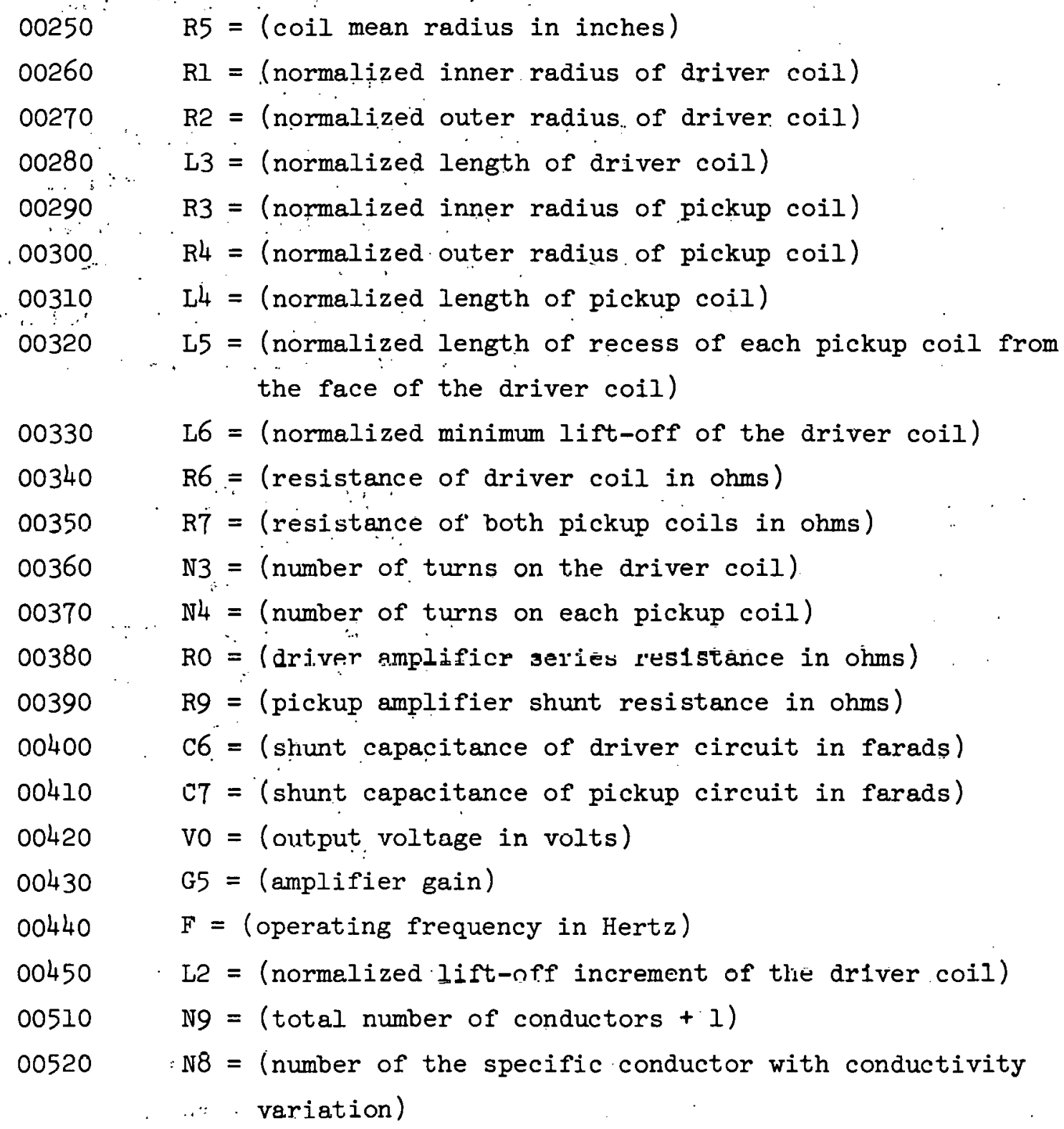


00540 DATA RHO/(resistivities in microhm-cm)/

00550 DATA $U /$ (permeabilities)/

00560 DATA T/(thicknesses in inch)/

00740 MO = (fractional variation of conductivity of the N8-th layer)

The current version of MULTC.F4 is limited to a maximum of nine conductors. However, this limitation can be removed easily by changing one DIMENSION statement.

00110 DIMENSION T(N9), U(N9), RHO(N9), M(N9), Bł̣lA(N9)

The print-out of the FORTRAN version of MULTIC is practically identical to the BASIC version and will not be repeated. The main difference is that the question mark is not priuled out when the program is ready to accept data. The Coil Design, Attenuator Design, Drift Check, and Continue Calculations options are lle same. Tho line numpers, constant names, and parameter varied in the drift calculations are as follows:

\begin{tabular}{|c|c|c|}
\hline T,ine. Number & Constant & Parameter Varied \\
\hline 04380 & DRI & Driver Resistance \\
\hline 04390 & DR? & Pickup Resistance \\
\hline 04400 & DR3 & Driver Shunt Capac1tance \\
\hline 04410 & DR4 & Pickup Shunt Capacitance \\
\hline 04420 & DR5 & Series Reslstance \\
\hline 04430 & DR6 & Amplifier Input Resistance \\
\hline 01.440 & $\overline{\mathrm{DR}} 7$ & Applied Voltage \\
\hline 04450 & UR8 & Froquensy \\
\hline 01460 & DR9 & Mean Radius \\
\hline
\end{tabular}

For example, to vary the driver resistance by. $2 \%$ one would type: $04380 \quad \mathrm{DR} I=0.02$

As in the BASIC version, the last two drifts require that the entire numerical integration be repeated and are relatively long running. If any of the drifts is set equal to zero, it will be omitted from the drift calculations. 


\section{Sample Calculation of MULTIC.F4}

Let us suppose that we wish to design a reflection type coil, identical to the one designed by the BASIC version. We will put the following data in the program (generally by using the EDIT MULTIC.F4 command on the PDP-10 and inserting the statements). All linear dimensions are normalized by dividing by the coil mean radius, except the coil mean radius, which is in inches.

$$
\begin{aligned}
& 00250 \quad \mathrm{R} 5=.08325 \\
& 00260 \quad \mathrm{RI}=0.75 \\
& 00270 \quad \mathrm{R} 2=1.25 \\
& 00280 \quad \mathrm{~L} 3=.36 \\
& 00290 \quad \mathrm{R} 4=.36 \\
& 00300 \quad \mathrm{R} 4=.696 \\
& 00310 \quad \mathrm{~L} 4=.096 \\
& 00320 \quad \mathrm{~L} 5=0.0 \\
& 00330 \quad L 6=0.1 \\
& 00340 \quad \mathrm{R} 6=79.36 \\
& 00350 \mathrm{RT}=530.5 \\
& 00360 \quad N 3=360 \text {. } \\
& 00370 \quad N 4=410 \text {. } \\
& 0,0300 \text { RO - I.EC } \\
& 00390 \quad \mathrm{R} 9=1 . \mathrm{E} 6 \\
& 00400 \quad \mathrm{C} 6=1 . \mathrm{E}-12 \\
& 00410 \quad \text { C7 }=1 . \mathrm{E}-12 \\
& 00420 \quad \mathrm{VO}=10.0 \\
& 00430 \quad \text { G5 }=1.0 \\
& 00440 \quad F=1.0 E 4 \\
& 00450 \text {. L2 }=0.025 \\
& 00510 \text { N9 }=5 \\
& 00520 \quad N 8=4 \\
& 00540 \text { DATA RHO/1.E10, 3.632, 5.393, 3.632, 1.E10, 5*0.1 } \\
& 00550 \text { DATA U/5*1., 5*0./ } \\
& 00560 \text { DATA T/1.El0, 2.8E-2, 1.94E-1, 2.8E-2, 1., 5*0./ } \\
& 00740 \quad \text { MO }=.05
\end{aligned}
$$


The FORTRAN program may now be executed. The print-out will be essentially identical to the BASIC print-out and will not be repeated. The FORTRAN version of MULTIC follows. 


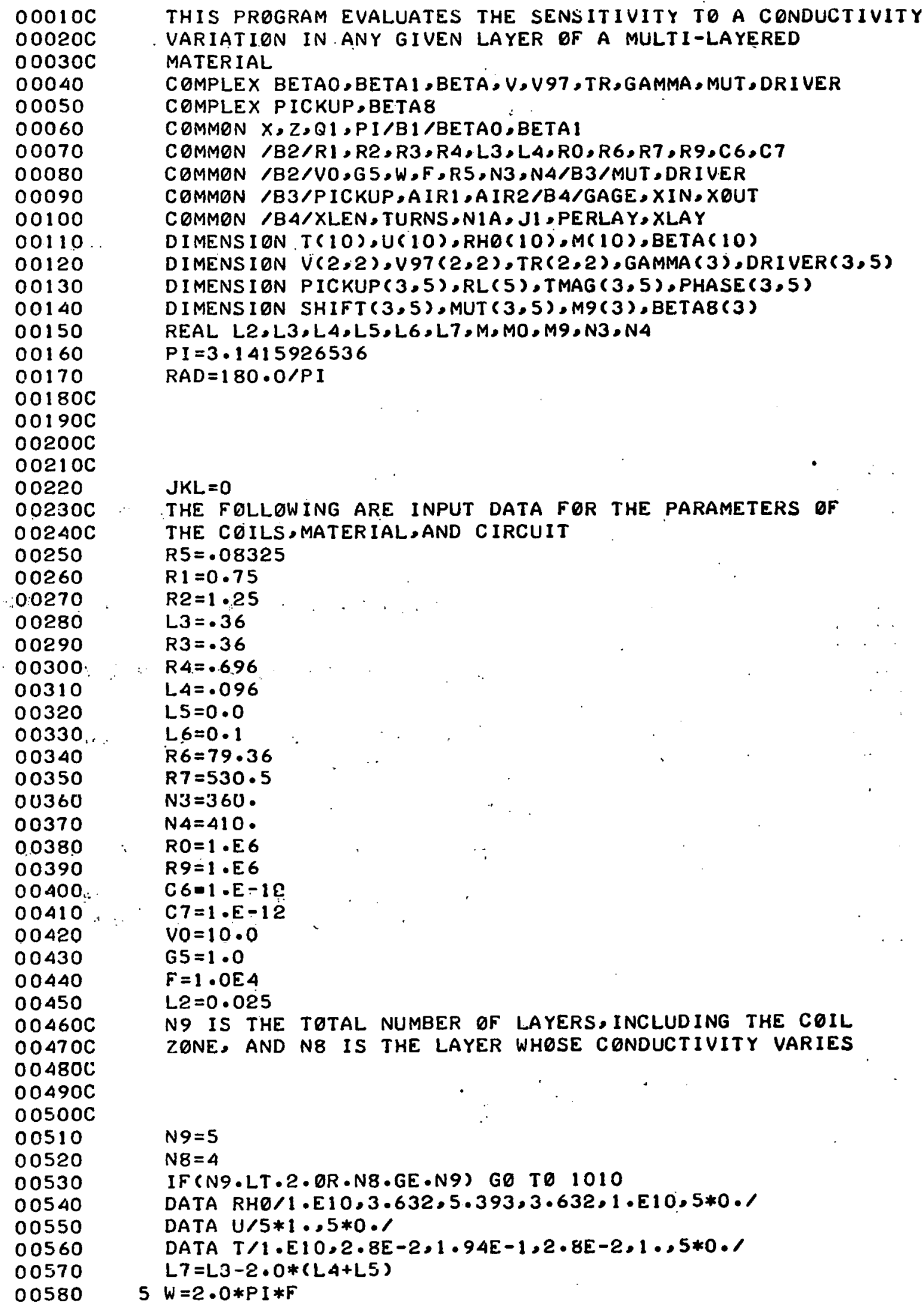


00590

00600

00610

00620

00630

00640

00650

00660

00670

00680

00690

00700

00710

00720

00730

00740

00750

00760

00770

00780

00790

$00800 \mathrm{C}$

00810

00820

00830

00840

00850

00860

00870

00880

00890

00900

00910

00920

00930

00940

00950

00960

00970

00980

$00990 \mathrm{C}$

$01000 \mathrm{C}$

01010

01020

01030

01040

$0105 n$

01060

01070

01080

01090

01100

01110

01120

01130

01140

01150
IF (JKL.NE・O) GO TO 15

TYPE 10

10 FORMAT (1H, 1HN, 13X,10HTHICK.(IN), 4X,11HR(M-OHM CM),

$13 X, 7 H M=S I G M A, 7 X, 1 H U)$

15 DO $50 \quad I=1, N 9$

IF $(R H O(I) \cdot G T \cdot 1 \cdot 0 E 9)$ GO TO 20

$M(I)=0.5094 * U(I) * F * R 5 * R 5 / R H \theta(I)$

GO TO 25

$20 M(1)=0.0$

25 IF (JKL.NE・0) GØ TO 50

30 TYPE $40, I, T(I), R H O(I), M(I), U(I)$

40 FORMAT(1H, I2,12X,1PEI2,5,2X,E12,5,2X,E12,5,2X,OPF6.2)

5O CONT INUE

$T(1)=0.0$

$T(N 9)=0.0$

$M O=.05$

กด โ? $1=1,3$

$A I=I$

$52 M 9(I)=M(N 8) *(1 \cdot 0+(A I-2 \cdot 0) * M 0)$

$I F(J K L \cdot N E \cdot 0) G \theta$ Tø 105

VAR $=100 \cdot 0 * M O$

THE SYSTEM PARAMETERS ARE PRINTED OUT

TYPE $55, N 8, V A R$

55 FORMAT $1 \mathrm{H}, 25 \mathrm{HCONDUCTIVITY} \mathrm{VARIATION} \mathrm{OF,} \mathrm{13,14HTH} \mathrm{LAYER}$

1 IS $+-, F 6 \cdot 2,(\mathrm{HZ})$

TYPE 470

TYPE $60, R 1, R 2, L 3$.

60 FORMAT $(1 \mathrm{H}, 3 \mathrm{HR} 1=, F 8.5,3 \mathrm{X}, 3 \mathrm{HR} 2=, F 8,5,3 \mathrm{X}, 14 \mathrm{HDRIVER}$ LENGTH $=$,

1F8.5)

TYPE $70, R 3, R 4, L 4$

70 FORMAT $(1 H, 3 H R 3=, F 8,5,3 X, 3 H R 4=, F 8,5,3 X, 14 H P$ ICKUP LENGTH=, (F8.5)

TYPE $80, R 5, F$

80 FORMAT $(1 \mathrm{H}, 17 \mathrm{HCOIL}$ MEAN RADIUS $=, 58.5,7 \mathrm{H}$ INCHES, $3 \mathrm{X}$,

12OHOPERAT ING FREQUENCY $=, 1 P E 12.5$ )

TYPE 90, LS

90 FORMAT (1H, 15HPICKUP RECESSED,F8.5)

TYPE 100, L6,L2

100 FORMAT $(1 \mathrm{H}, 13 \mathrm{HMIN}$ LIFT-OFF $=, F 8.5,3 \mathrm{X}, 19 \mathrm{HLIFT-OFF}$ INCREM $1 E N T=, F 8.5)$

THE INTEGRATION BEGINS HERE. THE MUTUAL,DRIVER,AND

PICKUP INDUCTANCES AND THE AIR VALUES ARE CALCULATED

$105 \mathrm{~S} 1=0.01$

$52=5.0$

$\mathrm{B1}=0.0$

$\mathrm{B2}=\mathrm{S2}$

DQ $107 \quad I=1,3$

$D \emptyset 107 \mathrm{~J}=1,5$

$\operatorname{MUT}(I, J)=(0.0,0.0)$

$\operatorname{DRIVER}(I, J)=(0.0,0.0)$

$107 \operatorname{PICKUP}(I, J)=(0.0,0.0)$

$A I R I=0.0$

$A \operatorname{IR2}=0.0$

$110 \quad 11=(B 2-B 1) / S 1$

$X=B 1-S 1 / 2 \cdot 0$

DO 390 ID $X=1, I 1$

$x=x+S 1$ 


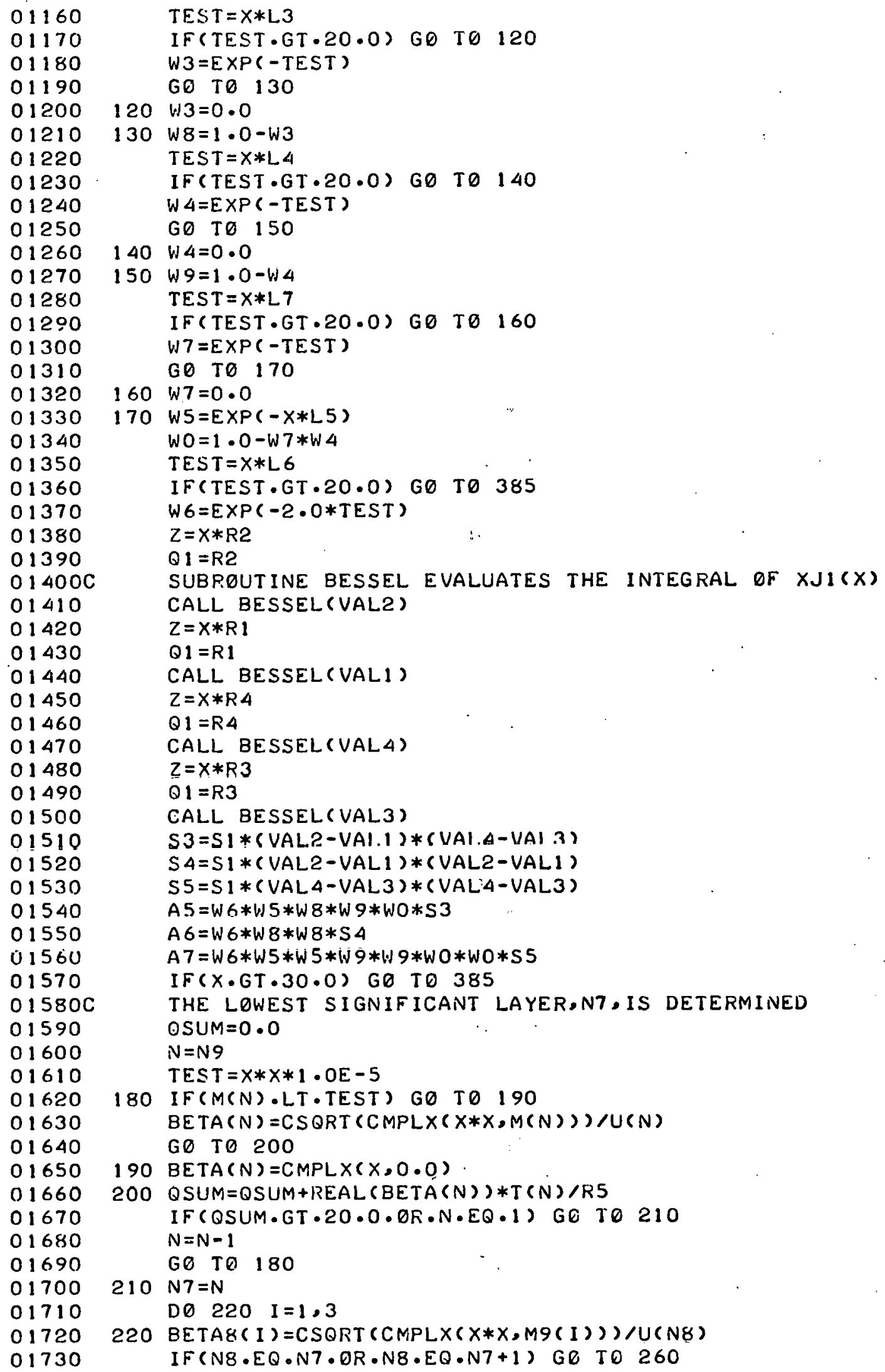

01160

01170

01180

01190

01200

01210

01220

01230

01240

01250

01260

01270

01280

01290

01300

01310

01320

01330

01340

01350

01360

01370

01380

01390

$01400 \mathrm{C}$

01410

01420

01430

01440

01450

01460

01470

01480

01490

01500

01510

01520

01530

01540

01550

U1560

01570

$01580 \mathrm{C}$

01590

01600

01610

01620

01630

01640

01650

01660

01670

01680

01690

01700

01710

01720

01730

TEST $=X *$ L 3

IF(TEST.GT.20.0) GO TO 120

$W 3=E \times P(-T E S T)$

GO TO 130

$120 \omega 3=0.0$

$130 w 8=1 \cdot 0-w 3$

TEST $=X * L 4$

IF (TEST.GT.20.0) GD TO 140

$W 4=E \times P(-T E S T)$

GD Tø 150

$140 W 4=0.0$

$150 w 9=1 \cdot 0-w 4$

TEST $=X * L 7$

IF(TEST.GT.20.0) GO TO 160

$W 7=\operatorname{EXP}(-T E S T)$

GO TO 170

$160 W 7=0.0$

$170 W 5=E X P(-X * L 5)$

$W 0=1 \cdot 0-W 7 * W 4$

TEST $=X *$ L 6

IF(TEST.GT.20.0) GO TO 385

W6 $=E \times P(-2 \cdot 0 * T E S T)$

$Z=X * R 2$

$Q 1=R 2$

SUBROUTINE BESSEL EVALUATES THE INTEGRAL OF XJl(X) CALL BESSEL (VAL2)

$Z=X * R 1$

$Q 1=R 1$

CALL BESSEL (VAL1)

$Z=X * R 4$

$Q 1=R 4$

CALL BESSEL (VAL 4)

$Z=X * R 3$

Q1 $=R 3$

CALL BESSEL (VAL3)

S $3=S 1 *(V A L . ?-V A I .1) *(V A 1 . A-V A I .3)$

$S 4=S 1 *(V A L 2-V A L 1) *(V A L 2-V A L 1)$

$\mathrm{S} 5=\mathrm{S} 1 *(\mathrm{VAL} 4-\mathrm{VAL} 3) *(\mathrm{VAL} 4-\mathrm{VAL} 3)$

$A 5=W 6 * W 5 * W 8 * W 9 * W 0 * S 3$

$A 6=W 6 * W 8 * W 8 * S 4$

$A 7=W 6 * W 5 * W 5 * W 9 * W 9 * W 0 * W 0 * S 5$

IF $(X \cdot G T \cdot 30 \cdot 0)$ GO TO 385

THE LOWEST SIGNIFICANT LAYER, N7, IS DETERMINED

$\odot S U M=0 \cdot 0$

$N=N 9$

TEST $=X * X * 1 \cdot O E-5$

180 IF $(M(N) \cdot L T \cdot T E S T)$ GO TO 190

$\operatorname{BETA}(N)=\operatorname{CSQRT}(\mathrm{CMPLX}(X * X, M(N))) / U(N)$

GO TO 200

$190 \mathrm{BETA}(N)=C M P L X(X: 0.0)$

$200 Q S U M=Q S U M+R E A L(B E T A(N)) * T(N) / R 5$

IF (QSUM.GT $20 \cdot 0 \cdot O R \cdot N \cdot E Q \cdot 1)$ GE TO 210

$\mathrm{N}=\mathrm{N}-1$

$210 N 7=N$

GO TO 180

DO $220 \quad I=1,3$

$220 B E T A 8(I)=\operatorname{CSQRT}(\operatorname{CMPLX}(X * X, M 9(I))) / U(N 8)$

IF (N8 EEQ $\cdot N 7 \cdot 0 R \cdot N 8 \cdot E Q \cdot N 7+1)$ GE TO 260 


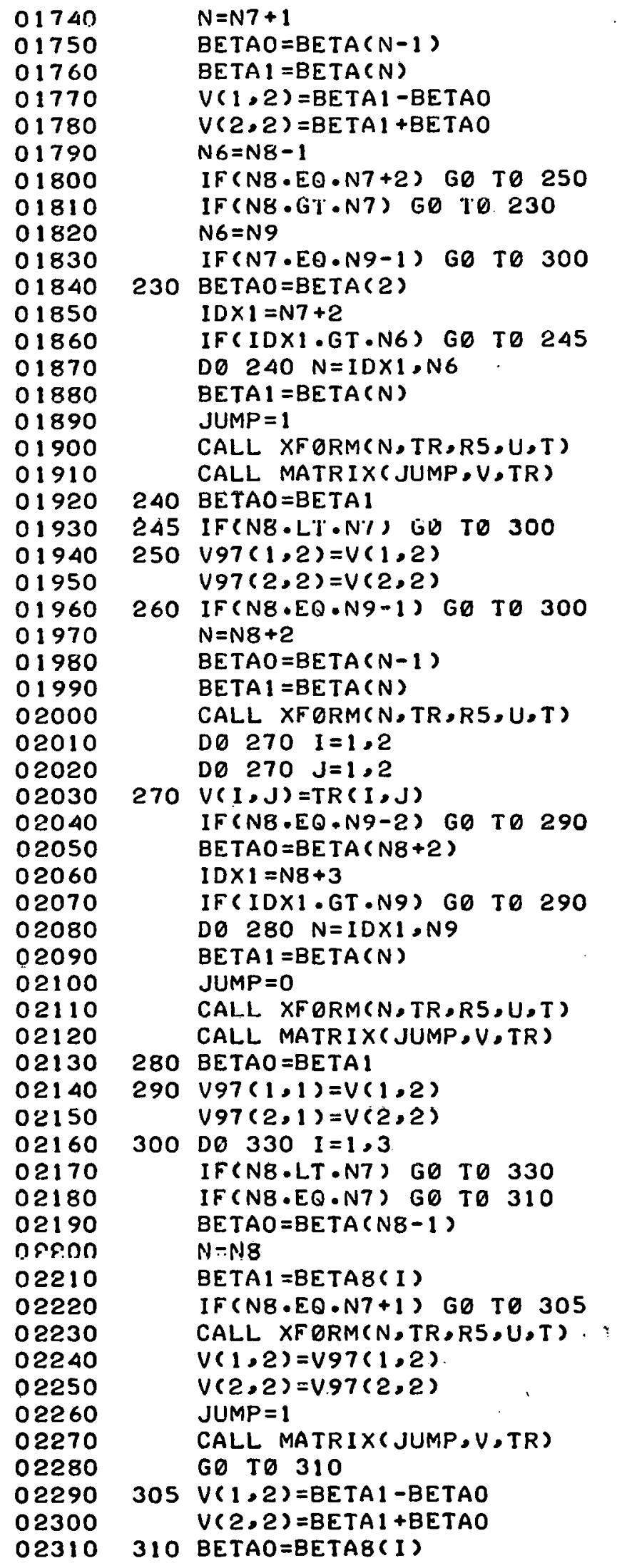




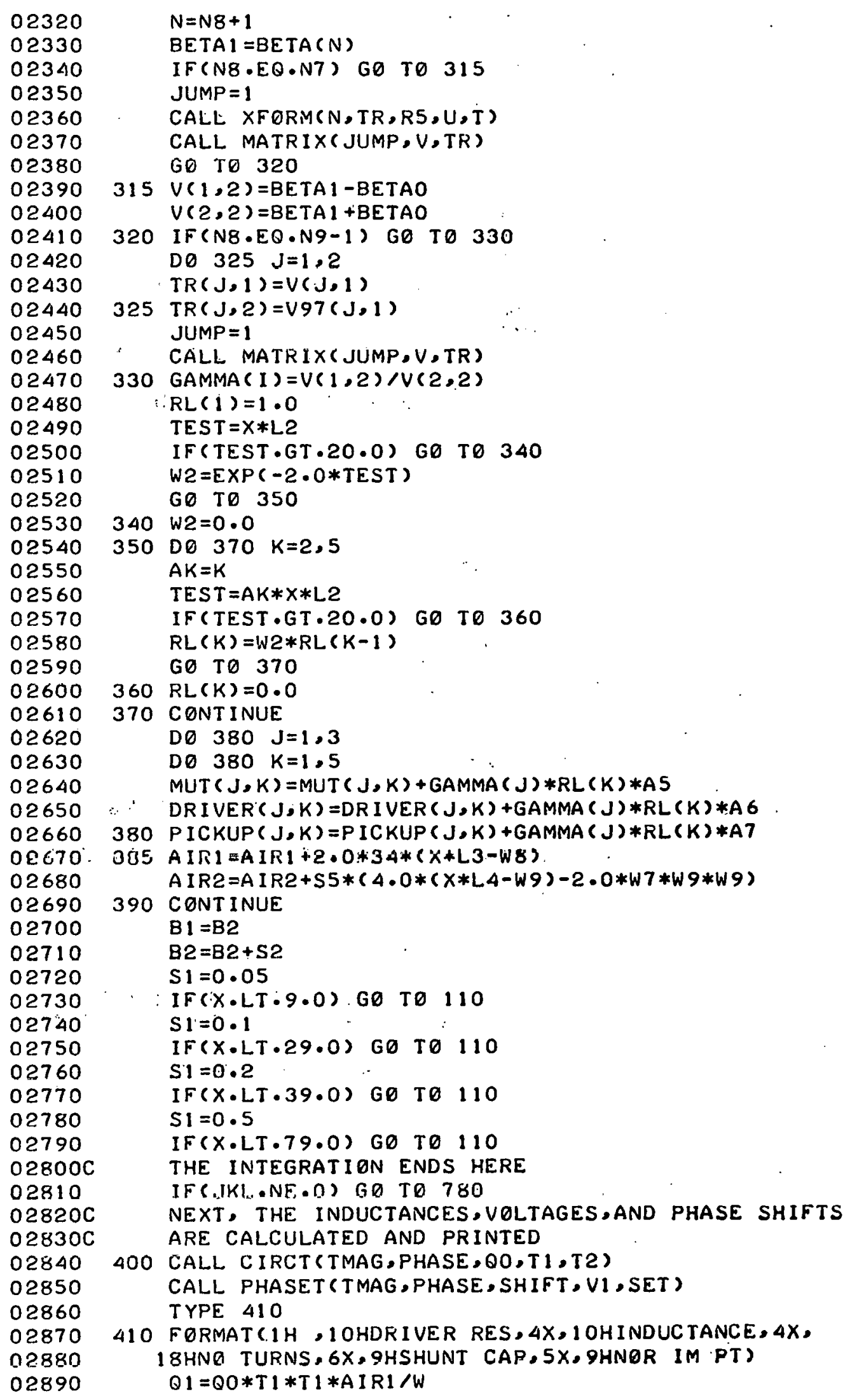




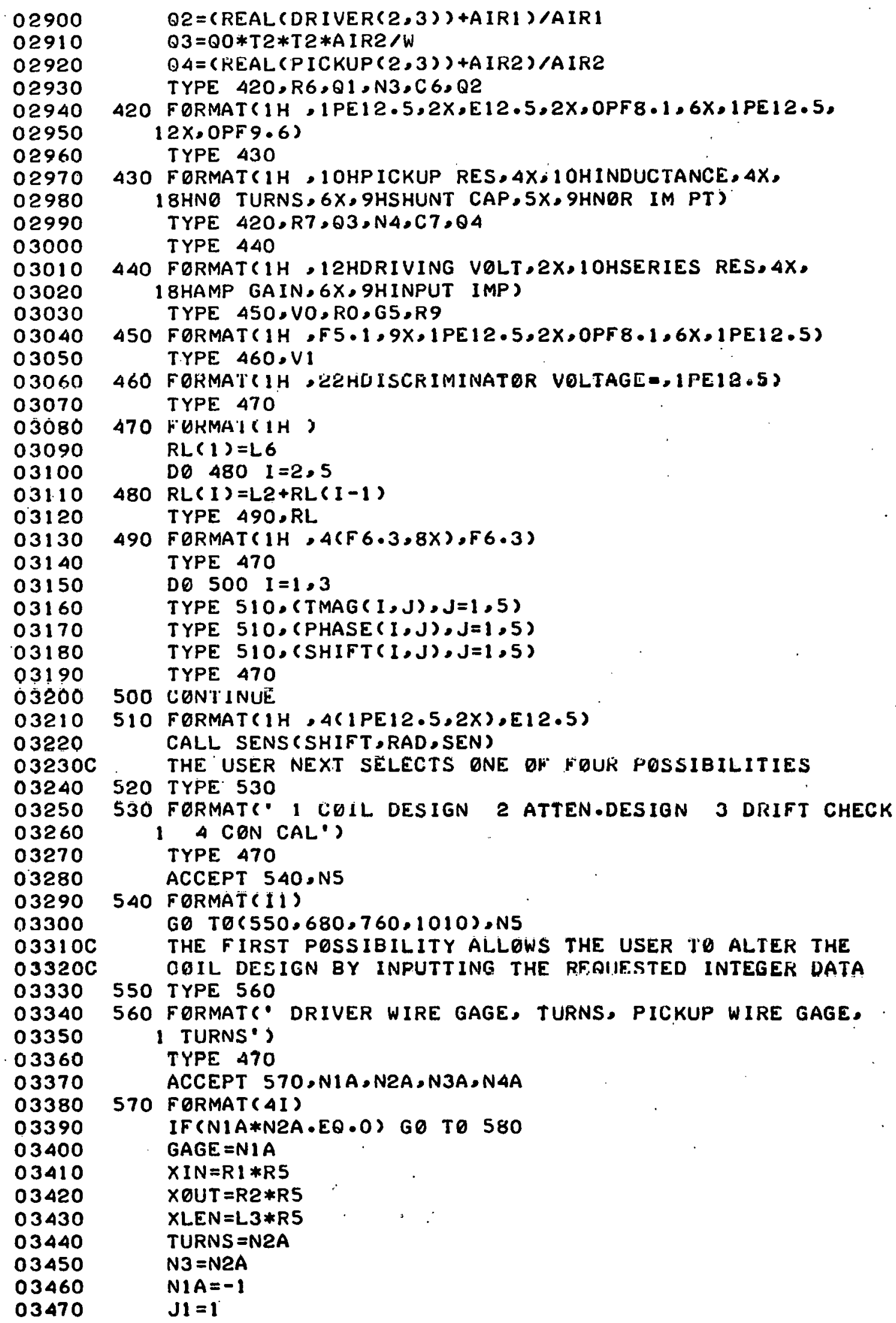




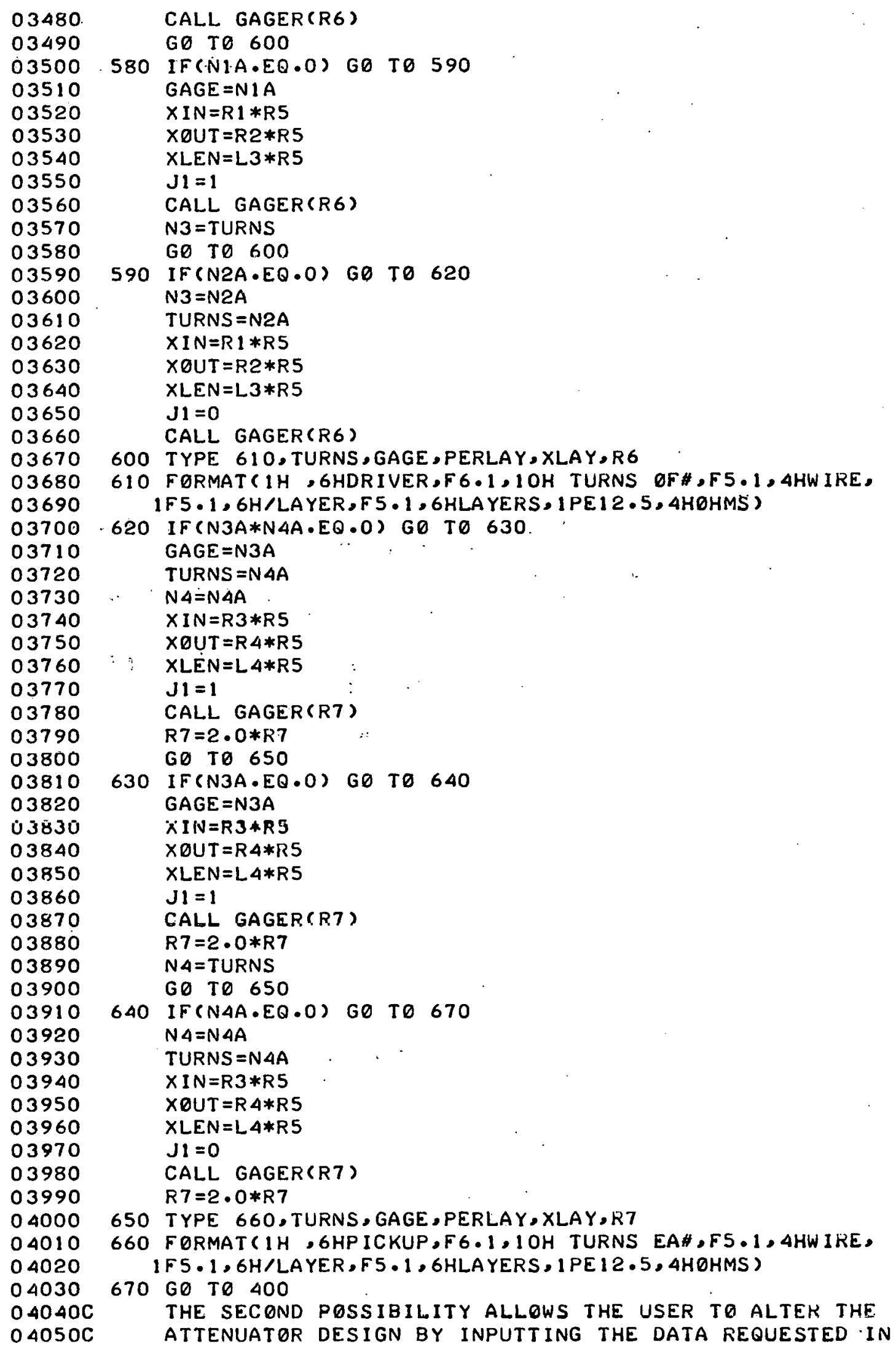

03480

03490

03500

03510

03520

03530

03540

03550

03560

03570

03580

03590

03600

03610

03620

03630

03640

03650

03660

03670

03680

03690

03700

03710

03720

03730

03740

03750

03760

03770

03780

03790

03800

03810

03820

ن 3830

03840

03850

03860

03870

03880

03890

03900

03910

03920

03930

03940

03950

03960

03970

03980

03990

04000

04010

04020

04030

$04040 \mathrm{C}$

$0405 \mathrm{OC}$

CALL GAGER(R6)

GO TO 600

580 IF (NIA.EQ.0) GO TO 590

GAGE $=N \perp A$

$X I N=R 1 * R 5$

$X \otimes U T=R 2 * R 5$

$X L E N=L 3 * R 5$

$J I=1$

CALL GAGER(R6)

N3 $=$ TURNS

GO TO 600

590 IF (N2A.EQ.0) GQ TO 620

N3 $=$ N2A

TURNS $=$ N2A

$X I N=R 1 * R 5$

$X \oslash U T=R 2 * R 5$

$X \mathrm{LEN}=\mathrm{L} 3 * \mathrm{R} 5$

$J 1=0$

CALL GAGER(R6)

600 TYPE 610 , TURNS, GAGE, PERLAY, XLAY, R6

610 FORMAT (1H , 6HDRIVER,F $6.1,10 \mathrm{H}$ TURNS OF\#,F5,1, 4HWIRE, $1 F 5.1,6 \mathrm{H} / L A Y E R, F 5 \cdot 1,6 \mathrm{HLAYYRS}, 1 \mathrm{PE} 12,5,4 \mathrm{HOHMS}$ )

620 IF (N3A*N $4 A \cdot E Q .0)$ GO TO 630

GAGE $=N 3 A$

TURNS $=N 4 A$

$N 4=N A A$

$X I N=R 3 * R 5$

$X \emptyset U T=R 4 * R 5$

$\because \quad X L E N=L 4 * R 5$

$J \mathfrak{l}=1$

CALL GAGER(R7)

$R 7=2 \cdot 0 * R 7$

$G 0$ TO 650

630 IF (N3A.EQ.0) GO TO 640

GAGE $=N 3 A$

$X I N=R 3 * R 5$

$X \emptyset U T=R A * R S$

$X L E N=L 4 * R 5$

$\mathrm{J} !=1$

CALL GAGER(R7)

$R 7=2 \cdot 0 * R 7$

$N 4=$ TURNS

GO TO 650

640 IF (NAA.EQ.O) GO TO 670

$N 4=N 4 A$

TURNS $=N 4 A$

$X I N=R 3 * R 5$

$X \otimes U T=R A * R 5$

$X L E N=L A * R 5$

$J 1=0$

CALL GAGER(R7)

$R 7=2 \cdot 0 * R 7$

650 TYPE 660 , TURNS, GAGE, PERLAY, XLAY,R7

660 FORMAT ( $1 \mathrm{H}, 6 \mathrm{HPICKUP,F6.1,10H}$ TURNS EA\#,F5,1, 4HW IRE,

IF5 .1,6H/LAYER, F5 1, 6HLAYERS, 1PE 12 .5, 4HOHMS )

$670 \mathrm{GO}$ TO 400

THE SECOND POSSIBILITY ALLOWS THE USER TO ALTER THE

ATTENUATOR DESIGN BY INPUTTING THE DATA REQUESTED IN 


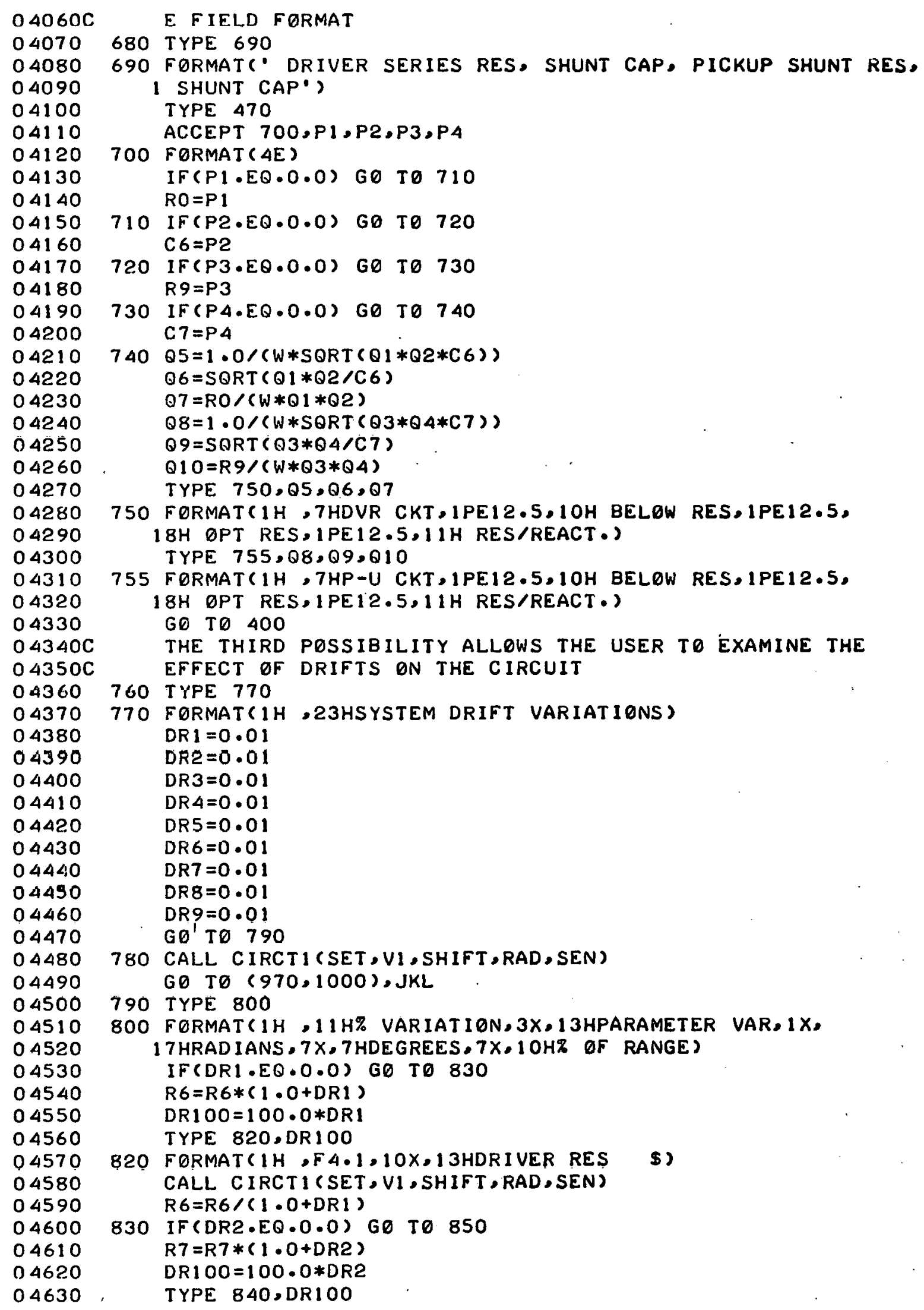


04640

04650

04660

04670

04680

04690

04700

04710

04720

04730

04740

04750

04760

04770

04780

04790

04800

04810

04820

04830

04840

04850

04860

04870

04880

04890

04900

04910

04920

04930

04940

04950

04960

04970

04980

04990

05000

05010

05020

05030

05040

05050

05060

05070

05080

05090

05100

05110

05120

05130

05140

05150

05160

05170

05180

05190

05200

o5210C
840 FORMAT 1 1H,F $4.1,10 X, 13$ HPICKUP RES

CALL CIRCII (SET, VI,SHIFT,RAD,SEN)

$R 7=R 7 /(1 \cdot 0+D R 2)$

850 IF (DR3 EEQ.0.0) GB TO 870

$C 6=C 6 *(1 \cdot 0+D R 3)$

DR $100=100 \cdot 0 * D R 3$

TYPE $860.0 R 100$

860 FORMAT $(1 H, F 4.1,10 X, 13 H D V R$ SHUNT CAP\$)

CALL CIRCTI (SET,VI,SHIFT,RAD, SEN)

$C 6=C 6 /(1 \cdot 0+D R 3)$

870 IF(DRA.EQ.0.0) GD TO 890

$C 7=C 7 *(1 \cdot 0+D R 4)$

DR $100=100 \cdot 0 *$ DR 4

TYPE $880, D R 100$

880 FORMAT $1 \mathrm{H}, F 4.1,10 \mathrm{X}, 13 \mathrm{HP}-\mathrm{U}$ SHUNT CAPS)

CALL CIRCTI (SET,VI,SHIFT, RAD,SEN)

$C 7=C 7 /(1 \cdot 0+D R 4)$

890. IF(DR5 EQ E.0.0) GO TO 910

$R O=R O *(1 \cdot 0+D R 5)$

DR $100=100 \cdot 0 *$ DRS

TYPE 900, DR 100

900 FØRMAT ( $1 \mathrm{H}, \mathrm{F} 4.1,10 \mathrm{X}, 13 \mathrm{HSERIES}$ RES \$)

CALL CIRCTI (SET,VI,SHIFT,RAD,SEN)

$R O=R O /(1 \cdot 0+D R 5)$

910 IF(DR6 E E $0 \cdot 0 \cdot 0)$ GO TO 930

$R 9=R 9 *(1 \cdot 0+D R 6)$

DR1 $00=100 \cdot 0 *$ DR6

TYPE $920, D R 100$

920 FBRMAT ( 1 H,F $4.1,10 X, 13$ HAMP INPUT RES\$)

CALL CIRCTI (SET,VI,SHIFT,RAD,SEN)

$R 9=R 9 /(1 \cdot 0+D R 6)$

930 IF (DR7 E EQ.0.0) G0 TO 950

$V 0=V 0 *(1 \cdot 0+D R 7)$

DR1 $00=100 \cdot 0 * D R 7$

TYPE $940, D R 100$

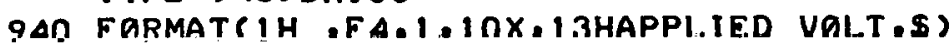

CALL CIRCT I (SET, VI, SHIFT, RAD, SEN)

$\mathrm{VO}=\mathrm{VO} /(1 \cdot 0+\mathrm{DR} 7)$

950 IF (DRB E E 0.0 .0$)$ GO TO 980

$F=F *(1 \cdot 0+D R 8)$

DR $100=100 \cdot 0 * D R 8$

TYPE 960, DR100

960 FORMAT (1H,F4.1,10X,13HFREQUENCY S)

$J K L=1$

GO TO 5

$970 F=F /(1 \cdot 0+D R 8)$

$J K L=0$

980 IF(DR9.EQ.0.0) GO TO 520

$R 5=R 5 *(1 \cdot 0+D R 9)$

$D R 100=100.0 * D R 9$

TYPE $990, D R 100$

990 FORMAT ( $1 \mathrm{H}, F 4.1,10 \mathrm{X}, 13 \mathrm{HMEAN}$ RADIUS \$)

$J K L=2$

GO TO 5

$1000 R 5=R 5 /(1 \cdot 0+D R 9)$

$J K L=0$

GO TO 520 .

THE FOURTH POSSIBILITY ENDS CALCULATIONS 


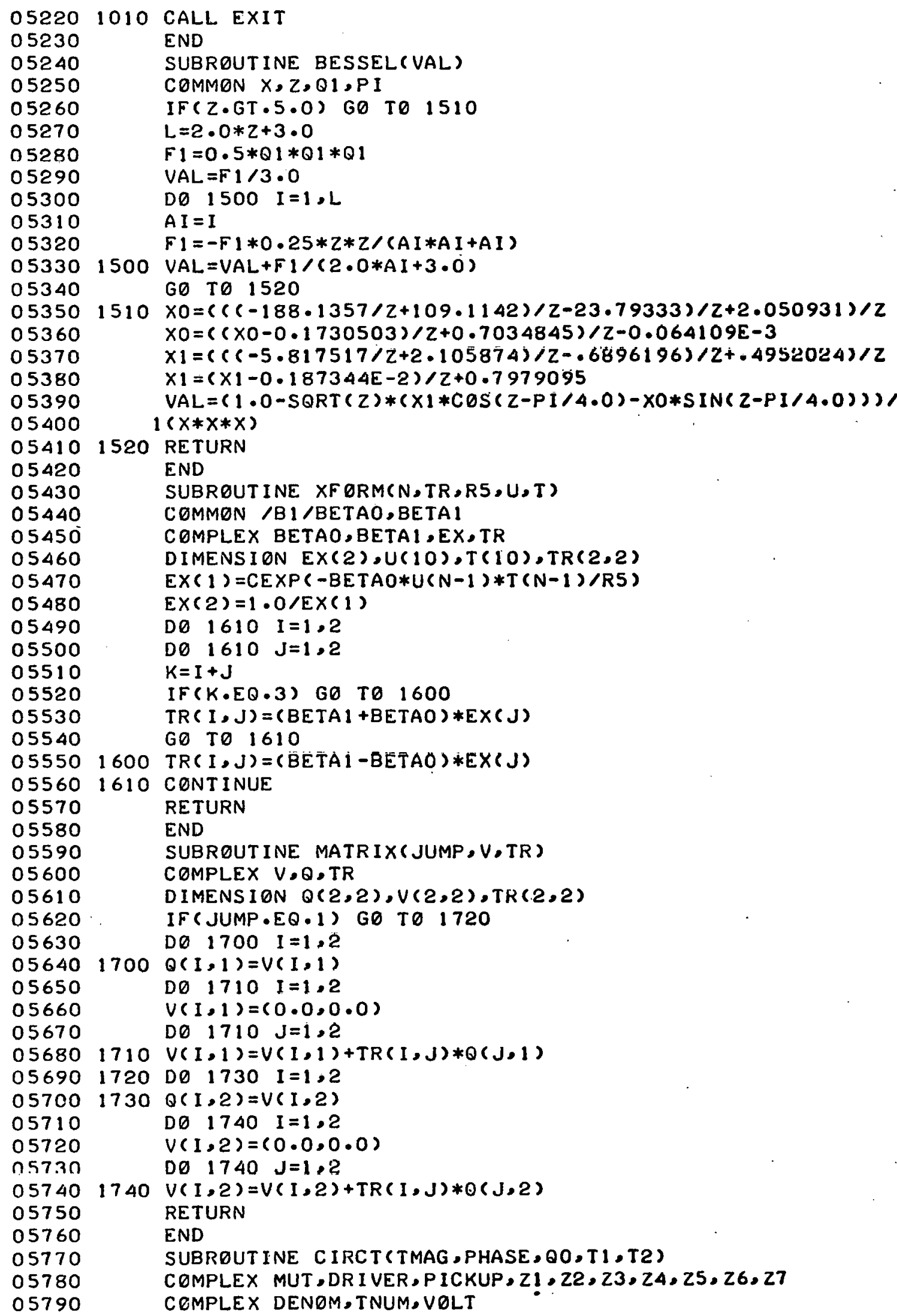




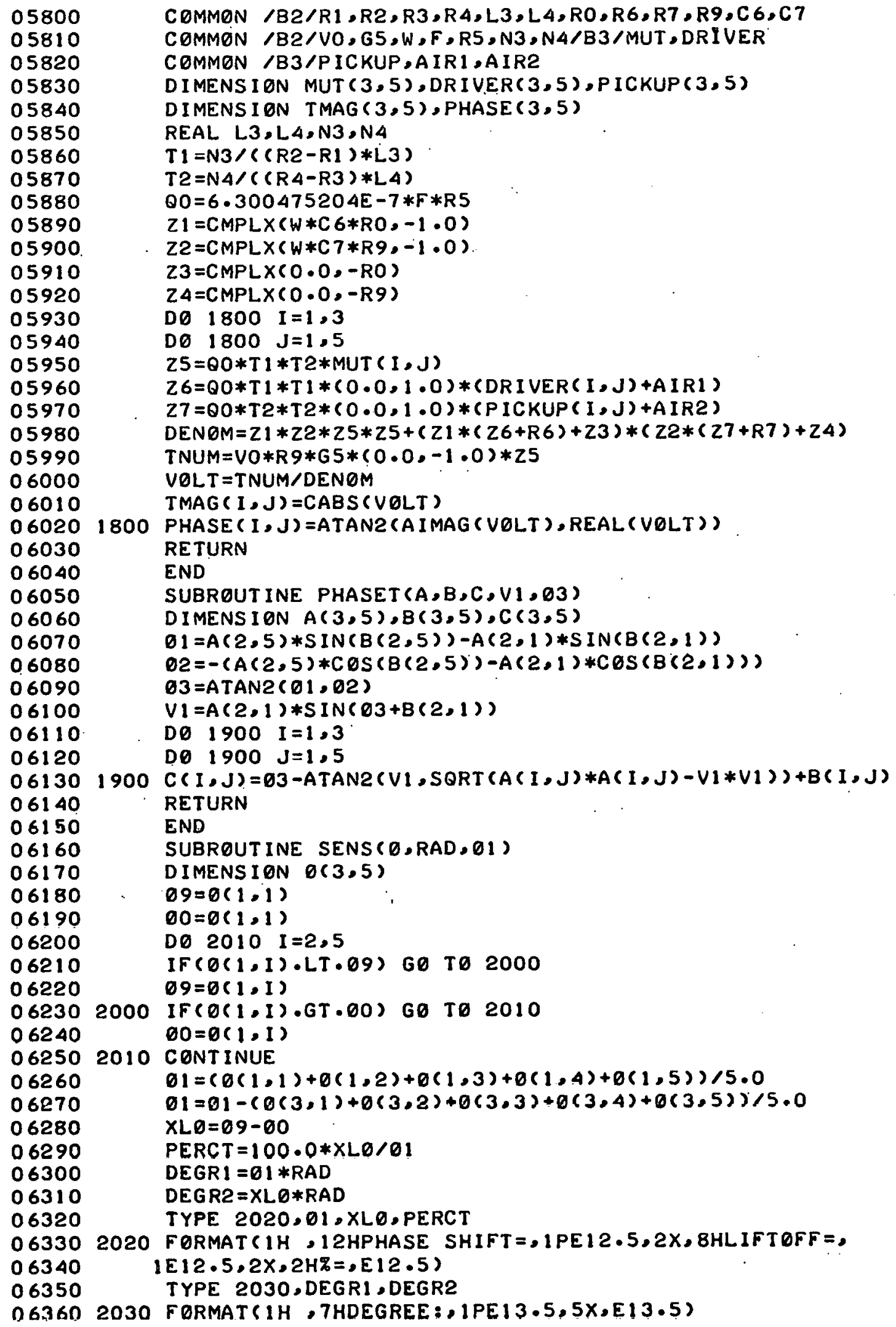




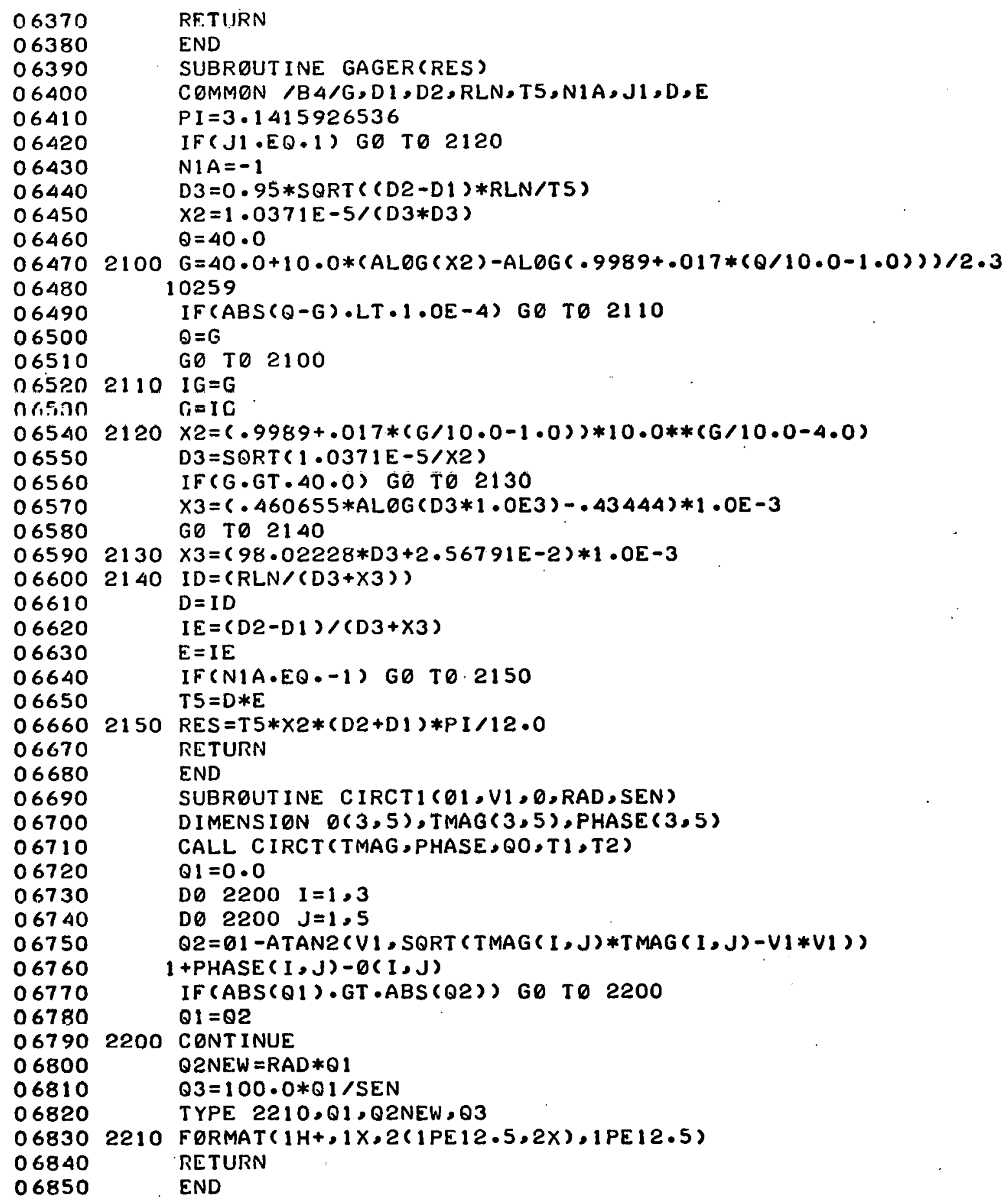


REFLECTION COIL ABOVE MULTIPLE CONDUCTORS, THICKINESS VARIATION

We shall now consider further the case of a reflection coil above multiple conductors, as shown in Fig. 4 (p. 7). This program calculates the magnitude and phase of the voltage that is fed to the phase measuring circuits of the phase-sensitive eddy-current instrument and is designed to help analyze eddy-current measurements of cladding thickness.

The program calculates the magnitude and phase of the induced voltage for five different values of lift-off with each of three different thickness values of a specific conductor, for a total of fifteen calculations. This allows one to examine the sensitivity to lift-off variations as well as cladding thickness variations. In addition, the program also calculates the phase shift with the discriminator adjusted to give the same phase on the nominal cladding thickness sample with maximum and minimum lift-off. The phase on the nominal sample with minimum lift-off is taken as zero, and all other phase shifts are measured relative to it. The equations which are evaluated are Eq. (8) for the mutual coupling, Eq. (9) for the driver coil impedance, and Eq. (17) for the pickup coil impedance. The gamma factor for the clad conductor is calculated from Eqs. (24) to (26). The programs are written in both BASIC and FORTRAN for use on a PDP-10. The BASIC program follows.

To use this program, one must first divide all coil and lift-off dimensions by the mean radius of the driver coil. Then the following lines must be typed into the program:

$250 \mathrm{R} 5=$ (numerical value of driver coil mean radius in inches)

$260 \mathrm{RI}=$ (numerical value of normalized driver coil inner radius)

$270 \mathrm{R} 2=$ (numerical value of normalized driver coil outer radius)

$280 \mathrm{~L} 3=$ (numerical value of normalized driver coil length)

$290 \mathrm{R} 3=$ (numerical value of normalized pickup coil inner radius)

$300 \quad \mathrm{R} 4=$ (numerical value of normalized pickup coil outer radius)

$310 \mathrm{~L} 4=$ (numerical value of normalized pickup coil length)

320 I5 $=$ (numerical vlaue of normalized pickup recess from face of driver) 
L6 = (numerical value of normalized driver coil minimum lift-off)

$340 \quad \mathrm{R} 6=$ (numerical value of resistance of driver coil in ohms)

$350 \mathrm{RT}=$ (numerical value of total resistance of both pickup coils in ohms)

360

N3 = (number of turns on driver coil)

$370 \quad \mathrm{~N} 4=$ (number of turns on each pickup coil)

$380 \quad \mathrm{RO}=$ (output series resistance of driving amplifier in ohms)

$390 \quad \mathrm{R} 9=$ (input shunt resistance of pickup amplifier in ohms)

$400 \quad \mathrm{C6}=$ (total ohunt capacitance of driving circuit in farads)

$410 \mathrm{C7}=$ (total shunt capacitance of pickup circuit in farads)

$420 \quad$ VO = (output voltage of driving amplifier in volts)

$430 \quad G 5=$ (gain of pickup amplifier)

$440 \quad F=$ (operating frequency in Hertz)

$450 \quad \mathrm{~L} 2=$ (numerical value of normalized driver coil lift-off increment)

$510 \quad \mathrm{~N} 9=($ total number of conductors +1$)$.

$520 \quad \mathrm{~N} 8=$ (number of the specific conductor with thickness variation, refer to Fig. 4)

$770 \quad \mathrm{~T} 9=$ (numerical value of fractional thickness change of the N8-th layer)

The input data of conductors are typed into the program between the statement numbers 800 and 980 , according to the order of appearance from the lowest conductors [refer to Fig. 4 (p. 7)].

800 DA'LA IELO, K(1), U(I)

810 DATA $T(2), K(2), U(2)$

$\vdots \quad \vdots$

- DATA $T(N), K(N), U(N)$

$\vdots \quad \vdots$

- $\quad$ DATA T(N9-1), K(N9-1), U(N9-1)

(980) DATA I(arbitrary number), 1El0, I

where 


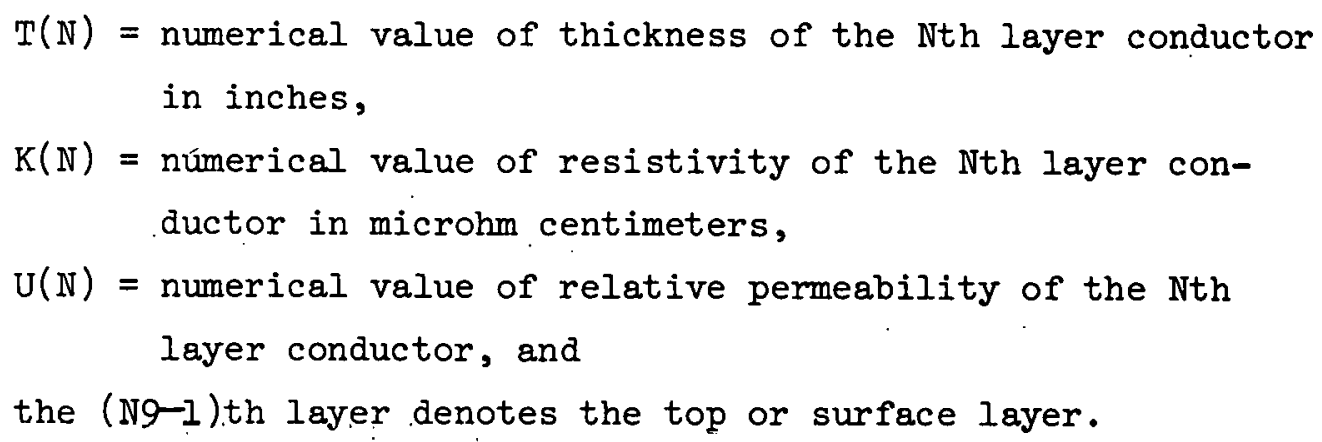

The current version of MULTIT (BASIC) is limited to a maximum of nine conductors: However, this limitation can be removed easily by adding one DIMENSION statement.

$$
60 \text { DIM } \mathrm{T}(\mathrm{N9} 9), \mathrm{R}(\mathrm{N9}), \mathrm{U}(\mathrm{N9}), \mathrm{S}(\mathrm{N9}), \mathrm{X} \text { (N9), } \mathrm{Y} \text { (N9) }
$$

The program may now be run. The print-out by the computer will have the following format.

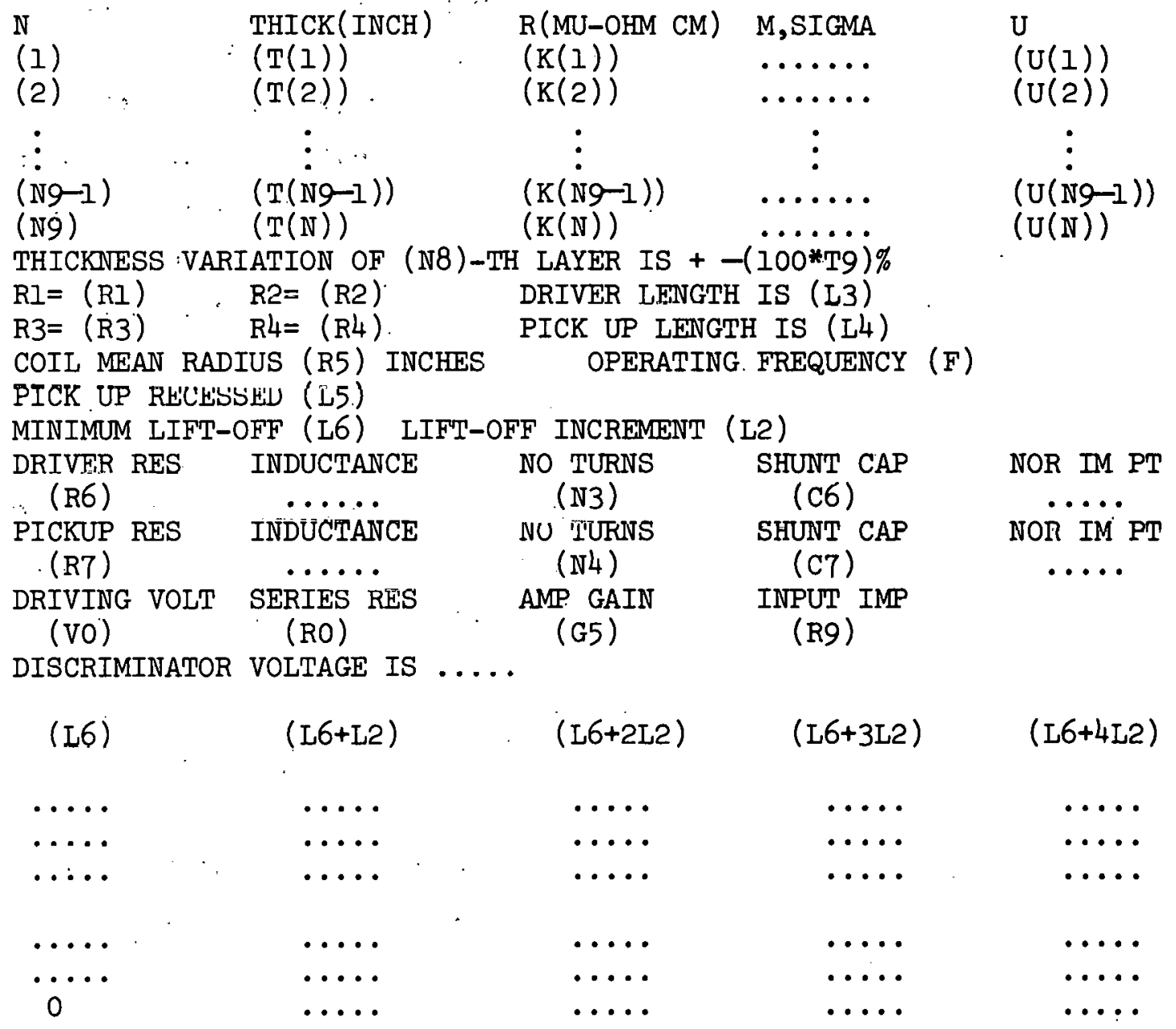




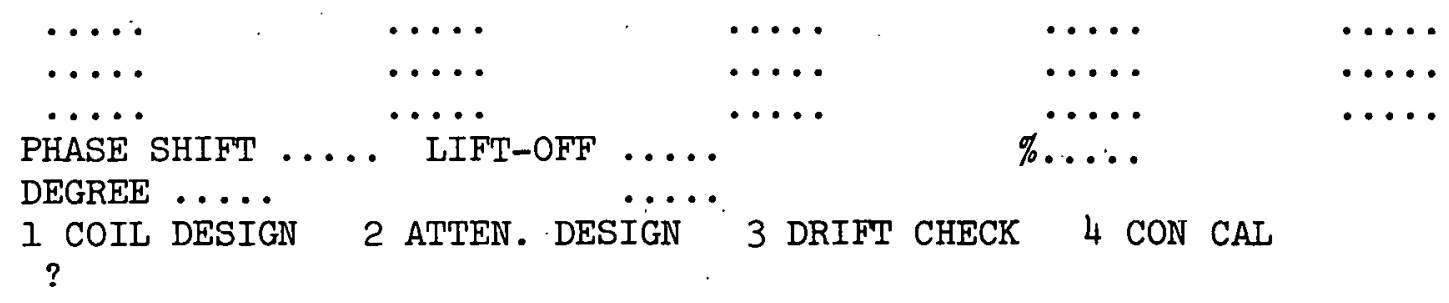

The various symbols enclosed in parentheses are used to indicate that the numerical value of the symbol will be printed.

There are five columns of data, one under each value of lift-off. Each column is divided into three sections of three lines each. These sections correspond, from top to bottom, to the three values of (-1חN*T\%, 0 , and $+100 *$ T9\% variations from nominal) the cladding thickness of the N8-th layer. The three lines in each section are, from top to bottom, the magnitude of the voltage out of the pickup amplifier, the phase shift between the voltage out of the pickup amplifier and the driving voltage, and the phase shift between the voltage out of the pickup amplifier with the discriminator set to give the same phase shift with minimum lift-off and maximum lift-off on the nominal cladding thickness sample. The phase shift in the third line is always measured from the nominal cladjing thickness sample with minimum lift-off. The voltage out of the pickup amplifier will be in volts and be either peak-topeak or RMS, whichever is used for Vo, the output voltage of the driving amplifier. For each conductor, $N$, the value of a dimensionless product $R_{5}{ }^{2} \omega \mu_{N} \sigma_{N}$ is also calculated and printed out under the column M,SIGMA. The inductance in henries of the driving coil in air and the normalized imaginary part of the driving coil impedance, with nominal cladding thickness and nominal lift-off $(L 6+2 L 2)$, is also printed. Likewise, the inductance in henries of both pickup coils in air and the normalized imaginary part of the pickup soils' impedance with nominal cladding thickness and lift-off is also printed. The total phase shift for the 200*T9\% cladding thickness variation, the maximum phase shift due to lift-off, and the maximum percent of range error in cladding thickness measurements due to lift-off are given. The phase shifts are given first in radians and then in degrees. 
The program then enters a branching loop that allows the following options, depending on which of $1,2,3$, or 4 is typed as input after the question mark.

1. Coil Design

If $a 1$ is typed by the operator after the question mark, the program will enter the Coil Design Loop. This loop will allow the number of turns on the driver and pickup coils to be varied. The loop will allow the wire gage to be given and then calculate the number of turns and coil resistance, or it will allow the number of turns to be entered and calculate the gage and coil resistance, or both turns and gage can be entered. If zeros are entered for both the gage and turns of either the driver or pickup coils, the present value of these will be retained. The program then starts with the label

DRIVER RES INDUCTANCE NO TURNS SHUNT CAP NOR IM PT, and the remainder of the program is recalculated and printed, with the "new" coil in the circuit. However, the numerical integrations to calculate $M, Z_{D R}$, and $z_{P U}$ do not have to be repeated.

2. Attenuator Design

This loop will allow the driver series resistance, RO, the driver shunt capacitance, $\mathrm{C} 6$, the amplifier input impedance, $\mathrm{R} 9$, and the shunt capacitance in the pickup circuit, $\mathrm{C} 7$, to be varied. If a 2 is typed after the question mark, the computer will respond with DRIVER SERIES RES, SHUNT CAP, PICK-UP SHUNT RES, SHUNT CAP . The resistance is to be given in ohms, and the capacitance in farads. If zero is typed in for any value, the present value in the computer will be retained. After the input data and a carriage return are typed, the computer will calculate the ratio of resonant frequency to operating frequency for the particular L-C circuit, a very rough value of resistance for minimum temperature drift, and the ratio between the resistance and reactance in the circuit for both the driver and pickup circuits. The program then starts with the label

DRIVER RES INDUCTANCE NO TURNS SHUNT CAP NOR IM PT, and the remainder of the program is recalculated and printed with the 
"new" attenuator in the circuit. Again, the numcrical integrations to calculate $M, Z_{D R}$, and $Z_{P U}$ do not have to be repeated.

3. Drift Check

This loop calculates the effect of the drift of any of the circuit or sample parameters after the instrument has been calibrated and adjusted. If a 3 is typed as input, the program will respond with the percent variation, the parameter varied, the maximum change in phase (both raitians and degrees) of any of the 15 different phases calculated (5 lift-off values for each of 3 different cladding thickness values) and the percent of the rulbe the drift reprcoente. The percent. variation of each parameter may be varied independently. The following. table gives the parameter, the line number, and the constant to be varied:

\begin{tabular}{lcc}
\multicolumn{1}{c}{ Parameter } & Linc Number & Ennstant \\
Driver Resistance & 8610 & E1 \\
Pickup Resistance & 8620 & E2 \\
Drivnr Shunt Fap, & 8630 & E3 \\
Pickup Shunt Cap. & 8640 & E4 \\
Series Resistance & 8650 & E7 \\
Amp. Input Resistance & 8660 & E8 \\
Applied Voltage & 8670 & E9 \\
Frequency & 8680 & Al \\
Mean Radius & 8690 & A2
\end{tabular}

For example, to put in a $2 \%$ variation in the driver soil resistanne. one would type:

$$
8610 \mathrm{El}=.02
$$

The amount that each parameter is varied must be sel vefure the program is run. All of the variations are 0.01 or $1 \%$ in the current version of the program. Since the phase shift produced by the parameter variation is quite linear over a range of about 10\%, a linear interpolation or extrapolation may be used from the $1 \%$ parameter variation. If zero is typed in for any parameter variation, that parameter will not be 
varied nor will it be typed out in the list of parameter variations. When the calculation is completed and the drifts printed, the program returns to the branch point and repeats the question

1 Coil Design 2 Atten. Design 3 Drift Check 4 Con Cal.

The first seven drifts do not require that the numerical integrations to calculate $M, Z_{D R}$, and $z_{P U}$ be repeated, but they must be repeated to calculate the drifts due to frequency, mean radius, and resistivity changes of the base and cladding materials. Therefore, the calculation of these last four drifts requires a considerable amount of computer time.

4. Con Cal

This loop is to continue calculations. If a series of calculations is to be made, a loop may be established at this point, However, in the present version of the program, if a 4 is typed as input, the program will end.

\section{Sample Calculation of MULTIT}

Let us suppose we wish to design a reflection-type coil to measure the thickness variation of an aluminum cladding with a resistivity of $3.632 \mu \Omega-\mathrm{cm}$ and a nominal thickness of $0.028 \mathrm{in}$. Below the cladding, there are two conductors, a $0.194 \mathrm{in}$. layer of aluminum with a resistivity of $5.393 \mu \Omega-\mathrm{cm}$ and a $0.028 \mathrm{in}$. layer of aluminum with a resistivity of $3.632 \mu \Omega-\mathrm{cm}$. The driver coil has a mean radius of $0.08325 \mathrm{in}$., inner and outer radii of 0.0625 and $0.104 \mathrm{in.}$, and a length of $0.030 \mathrm{in}$. The pickup coils have inner and outer radii of 0.030 and 0.058 in., a length of $0.008 \mathrm{in.}$, and are mounted flush with the ends of the driver coil. The driver coil has 360 turns of No. 46 wire with a resistance of $79.36 \Omega$, and the pickup coils have 410 turns each of No. 54 wire, with a resistance of $530.5 \Omega$ for both coils. The driver series and the pickup amplifier input resistances are both chosen to be $1 \mathrm{M} \Omega$. The shunt capacitances in both circuits are chosen to be $1 \mathrm{pF}$. This corresponds to practically infinite source and detector impedances, so that only the mutual coupling, M, affects the phases. The minimum 
lift-off is taken to be 0.0083 in. with a lift-off increment of 0.002 in. The variation from the nominal thickness of the surface cladding is $\pm 5 \%$. The relative permeability of all layers is 1 . The frequency is $10 \mathrm{KHz}$, the output voltage of the driving amplifier is.10 V, and the gain of the pickup amplifier is unity (a unity gain allows the actual gain needed in the amplifier to be calculated by dividing the maximum output voltage with unity gain into 10).

The program MULTT is assumed to be in the active core, and the following information is typed into the computer. All linear dimensions are normalized by dividing by the coil mean radius, except for the coil mean radius, which is in inches.

\begin{tabular}{|c|c|}
\hline 250 & $\mathrm{R} 5=.08325$ \\
\hline 260 & $\mathrm{RI}=.75$ \\
\hline 270 & $\mathrm{R} 2=1.25$ \\
\hline 280 & $\overline{\mathrm{L}} 3=.36$ \\
\hline 290 & $\mathrm{R} 3=.36$ \\
\hline 300 & $\mathrm{R} 4=.696$ \\
\hline 310 & L4 \pm .036 \\
\hline 320 & $\mathrm{~L} 5=0$ \\
\hline 330 & $\mathrm{~L} 6=.1$ \\
\hline 340 & $R 6=79.36$ \\
\hline 350 & $\mathrm{RT}=530 . \dot{5}$ \\
\hline 360 & $N 3=360$ \\
\hline 370 & $\mathrm{~N} 4=410$ \\
\hline 380 & $\mathrm{RO}=1 \mathrm{E} 6$ \\
\hline 390 & $\mathrm{R} 9=1 \mathrm{E} 6$ \\
\hline 400 & $16 \equiv 1 \mathrm{E}-12$ \\
\hline 470 & $\mathrm{C} 7=1 \mathrm{E}-12$ \\
\hline 420 & $\mathrm{Vo}=10$ \\
\hline 430 & $\mathrm{G} 5=1$ \\
\hline 440 & $F=1 E 4$ \\
\hline 450 & $\mathrm{~L} 2=.025$ \\
\hline 510 & N9 $=5$ \\
\hline
\end{tabular}




$\begin{array}{ll}520 & \text { N8 }=4 \\ 770 & \text { T9 }=.05 \\ 800 & \text { DATA } 1 E 10,1 E 10,1 \\ 810 & \text { DATA } .028,3.632,1 \\ 820 & \text { DATA } .194,5.393,1 \\ 830 & \text { DATA } .028,3.632,1 \\ 840 & \text { DATA } 1,1 . \mathrm{FI} 0,1\end{array}$

The program may now be run with the following results. The data inputed from the terminal by the user are underlined. A carriage return must be typed by the user at the end of each input line. 
MULT IC (BAS IC)

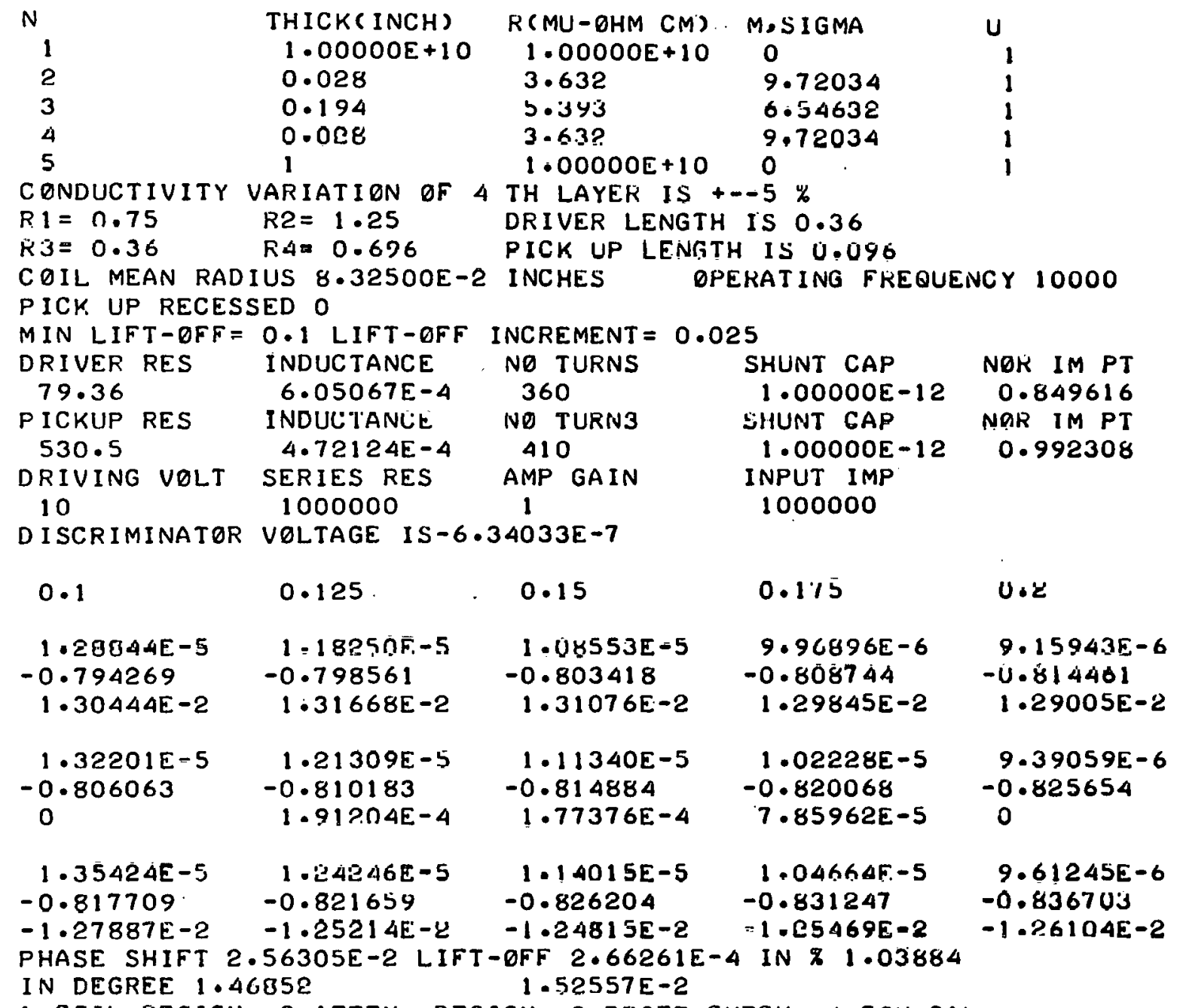

COIL DESIGN 2 ATTEN. DESIGN 3 DRIFT CHECK 4 CON CAL ? 1 
DRIVER WIRE GAGE, TURNS, PICK-UP WIRE GAGE, TURNS

$? 46,0,54,0$

DR'TVER 391 TURNS OF \# 46 WIRE 17 /LAYER 23 LAYERS 71.9293 OHM

PICKUP 429 TURNS EA \# 54 WIRE 11 /LAYER 39 LAYERS 532.582 OHMS TOTAL

DRIVER RES INDUCTANCE NO TURNS

$71.9293 \quad 7.13760 E-4 \quad 391$

PICKUP RES INDUCTANCE

$532 \cdot 582$.

INDUCTANCE NO TURNS 429

DRIVING VOLT SERIES RES AMP GAIN 10. . . . $1000000 \quad 1$

DISCRIMINATOR VOLTAGE IS-7.20555E-7

SHUNT CAP NOR IM PT

1.00000E-12 0.849616

SHUNT CAP NOR IM PT

1.00000E-12 0.992308

INPUT IMP

1000000

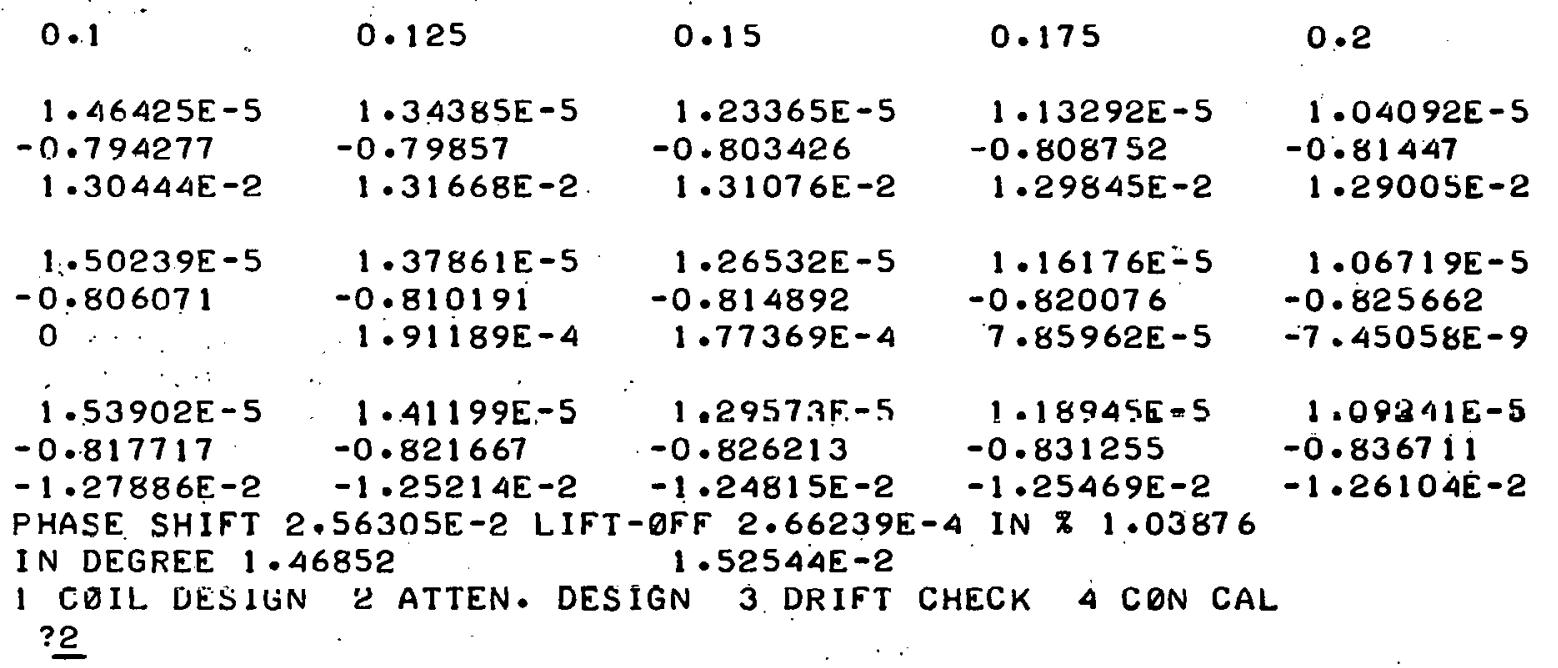


DRIVER SERIES RES, SHUNT CAP, PICK-UP SHUNT RES, SHUNT CAP ?5.OE2, 4.7E-9,6.2E2, 4.7E-9

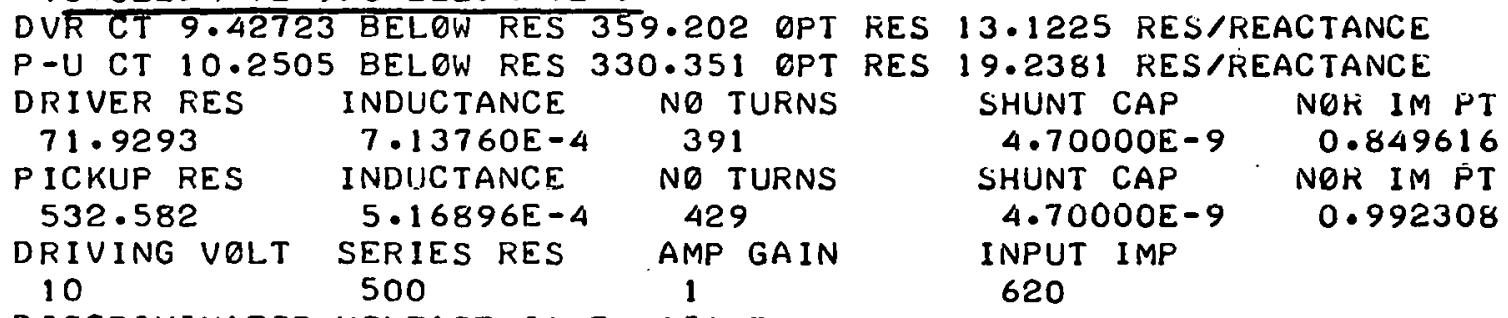

DISCRIMINATOR VOLTAGE IS-7.81534E-4

\begin{tabular}{|c|c|c|c|c|}
\hline 0.1 & 0.125 & 0.15 & 0.175 & 0.2 \\
\hline $\begin{array}{l}1.37094 E-2 \\
-0.992003 \\
1.28689 E-2\end{array}$ & $\begin{array}{l}1.25929 E-2 \\
-0.997071 \\
1.28639 E-2\end{array}$ & $\begin{array}{l}1.15692 E-2 \\
-1.00265 \\
1.27909 E-\varepsilon\end{array}$ & $\begin{array}{r}1.06320 \mathrm{E}-2 \\
-1.00864 \\
1.07662 \mathrm{E}=?\end{array}$ & $\begin{array}{r}9.77466 \mathrm{E} \\
-1.01498 \\
1.28924 \mathrm{E}\end{array}$ \\
\hline $\begin{aligned} & 1.40649 E-2 \\
- & 1.00343 \\
& 0\end{aligned}$ & $\begin{array}{l}1.29174 E-2 \\
-1.00835 \\
2.02060 E-5\end{array}$ & $\begin{aligned} & 1.18652 E-2 \\
- & 1.0138 \\
- & 4.97103 E-5 .\end{aligned}$ & $\begin{array}{l}1.09019 E-2 \\
-1.01967 \\
-9.12398 E-5\end{array}$ & $\begin{array}{l}1.00209 E \\
-1.0259 \\
0\end{array}$ \\
\hline $\begin{array}{l}1.44064 E-2 \\
-1.01472 \\
-1.26074 E-2 \\
\text { PHASE SHIFT } 2 \\
\text { IN DEGREE } 1.4 \\
1 \text { COIL DESIGN } \\
\text { ? } 3\end{array}$ & $\begin{array}{l}1.32290 E-2 \\
-1.0195 \\
-1.25529 E-2 \\
.54395 E-2 \text { LIFT } \\
5758 \\
2 \text { ATTEN. DES }\end{array}$ & $\begin{array}{r}1.21494 \mathrm{E}-2 \\
-1.02481 \\
-1.26095 \mathrm{E}-2 \\
- \text {-OFF } 1.26258 \mathrm{E} \\
7.23403 \mathrm{E}-3 \\
\mathrm{IGN} 3 \text { DRIFT }\end{array}$ & $\begin{array}{c}1.11610 E-2 \\
-1.03057 \\
-1.26568 E-2 \\
=-4 \text { IN } \% 0.496305\end{array}$ & $\begin{array}{l}1.02571 \mathrm{E} \\
-1.03669 \\
-1.25888 \mathrm{E}\end{array}$ \\
\hline $\begin{array}{l}\text { S YSTEM DRIFT } \\
\% \text { VARIATN } \\
1 \\
1 \\
1 \\
1 \\
1 \\
1 \\
1 \\
1 \\
1\end{array}$ & $\begin{array}{l}\text { VARIATI INS } \\
\text { PARAMETER } \\
\text { DRIVER RES } \\
\text { PICKUP RES } \\
\text { DVR SHUNT CAP } \\
\text { P-U SHUNT CAP } \\
\text { SERIES RES } \\
\text { AMP INPUT RES } \\
\text { APPLIED VOLT } \\
\text { FREQUENCY } \\
\text { MEAN RADIUS }\end{array}$ & $\begin{array}{l}\text { RADIAN } \\
2.72989 E-5 \\
-6.31032 E=5 \\
-2.10963 E-4 \\
-8.43406 E-4 \\
1.24957 E-3 \\
-6.06865 E-4 \\
-7.94128 E-4 \\
-6.05208 E-3 \\
-7.63857 E-3\end{array}$ & $\begin{array}{l}\text { DEGREE } \\
1.56411 E-3 \\
-3.73014 E-3 \\
-1.20873 E-2 \\
-4.83236 E-2 \\
7.15950 E-2 \\
-3.47708 E-2 \\
-4.55002 E-2 \\
-0.346759 \\
-0.437658\end{array}$ & $\begin{array}{l}2 \text { OF RANGE } \\
0.107309 \\
-0.25591 .3 \\
-0.829273 \\
-3.31534 \\
4.91191 \\
-2.38552 \\
-3.12163 \\
-23.7901 \\
-30.0264\end{array}$ \\
\hline
\end{tabular}

1 COIL DESIGN 2 ATTEN. DESIGN 3 DRIFT CHECK 4 CÉN CAL ?4

The user has exercised all the design options avallable, ull these options may be repeated, omitted, or taken in any order. The BASIC version of the program MULTIT follows. 


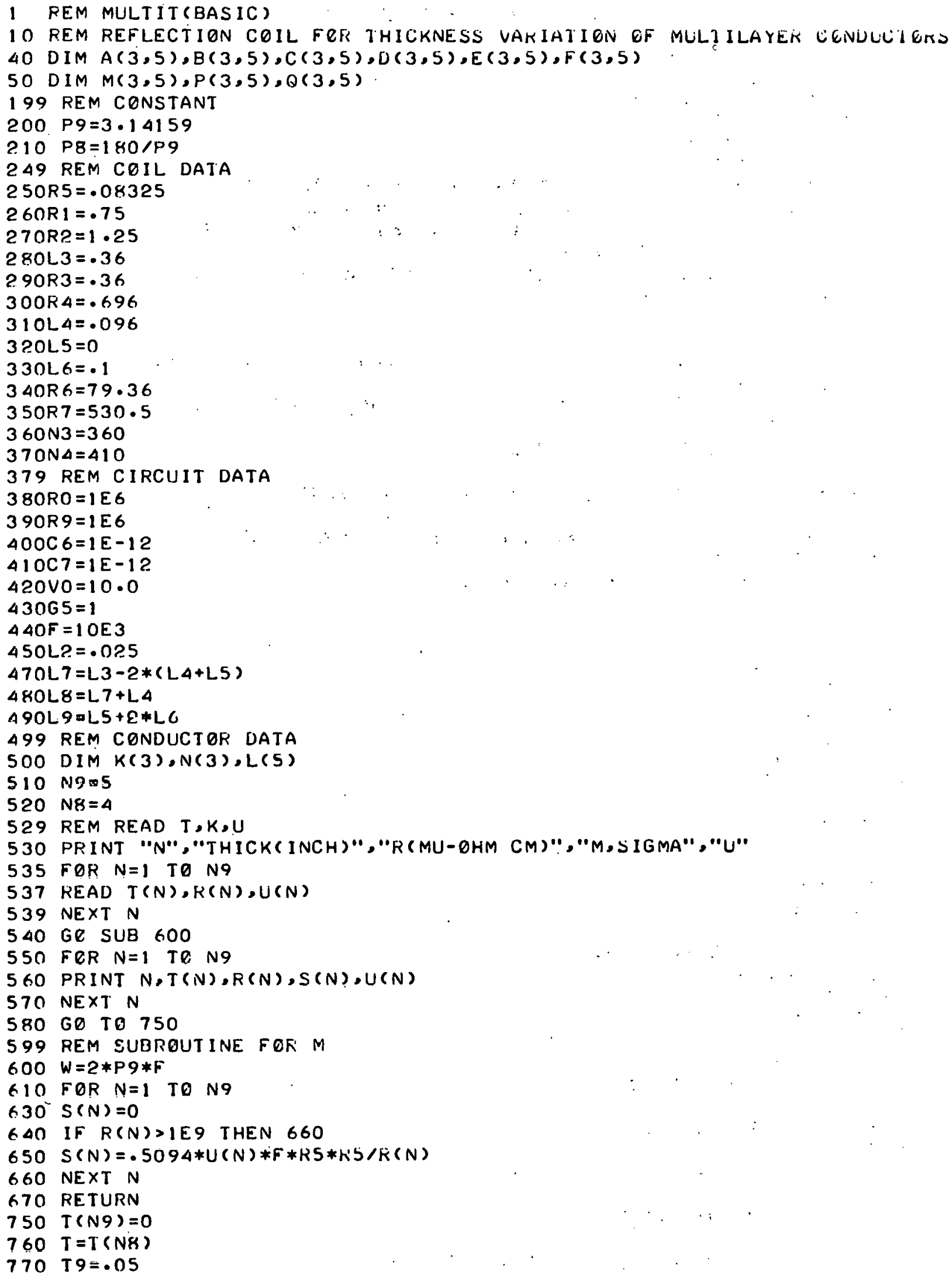


780 PRINT "THICKNESS VARIATION OF" 3N83"TH LAYER IS +-"3100*I9;"\%"

799 REM DATA

800 DATA 1 E10,1E10,1

810 DATA $\cdot 028,3 \cdot 632,1$

820 DATA $194,5 \cdot 393,1$

830 DATA $.028,3.632,1$

840 DATA $1.1 \mathrm{E} 10.1$

999 REM PRINT COIL DATA

1000 PRINT "R1 =" 3R1, "R2=" 3R2, "DRIVER LENGTH IS" 3 L3

1010 PRINT"R3=";R3,"R4=" \$R4,"PICK UP LENGTH IS" 34

1020 PRINT "COIL MEAN RADIUS" "R53"INCHES OPERATING FKEOUENCY";F

1030 PRINT "PICK UP RECESSED" 3 L5

1.040 PRINT "MIN LIFT-OFF $=" 3$ L63"LIFT-OFF INCKEMENI =" 3 L2

1100 KEM PROGRAM BEGINS

1110 REM FOR INTEGRATIONS

1120 GO SUB 1500

1130 REM FOR INDUCTANCES ANU CIRCUIT; MAGNITUDE AND PHASE

$1140 \mathrm{GO}$ SUB 6000

1150 REM FOR DISCRIMINATOR VOLTAGE AND PHASE SHIFT

$1160 \mathrm{GO}$ SUB 6500

1170 REM FOR PRINTING OF RESULTS

$1180 \mathrm{GO}$ SUB 6700

1190 REM FOR AV. PHASE SHIFT AND LIFT-OFF EKROR

$1200 \mathrm{GQ}$ SUB 7000

1400 REM FOR COIL AND ATTENUATOK DESIGNS, ANO DKIFT

1410 GO TO 7200

1499 REM SUBROUTINE FOK INTEGRATION

$1500 A 3=0$

$1510 A 4=0$

1 5Pก FOR I=1 TO 3

1530 FOR $J=1$ TO 5

$1540 A(I, J)=0$

1550 B $(1 \cdot .1)=0$

$1560 C(I, J)=0$

$1570 D(I, J)=0$

$1580 E(I, J)=0$

$1590 F(I, J)=0$

1600 NEXT J

1610 NEXT I

1620 LET S2 $=5$

$16.30 \mathrm{B1}=0$

$164082=5$

$1650 \quad 31 \div 1 E-\varepsilon$

1660 FQR $X=B 1+S 1 / 2$ TO B2 STEP S1

1670 GO SUB 2000

1680 NEXT $X$

$1690 \mathrm{~B} 1=\mathrm{B2}$

$1700 \mathrm{B2}=\mathrm{B2}+\mathrm{S2}$

$1710 \mathrm{S1}=.05$

1720 IF $x<9$ THEN 1660

$1730 \mathrm{S1}=.1$

1740 IF $x<29$ THEN 1660

$1750 \mathrm{S1}=.2$

1760 IF $x<39$ THEN 1660

1770 S1 $=.5$

1780 IF $x<79$ THEN 1660

1790 RETURN

1998 REM SUBROUTINE FOR L-FACTOR AND INIEGKANTS 


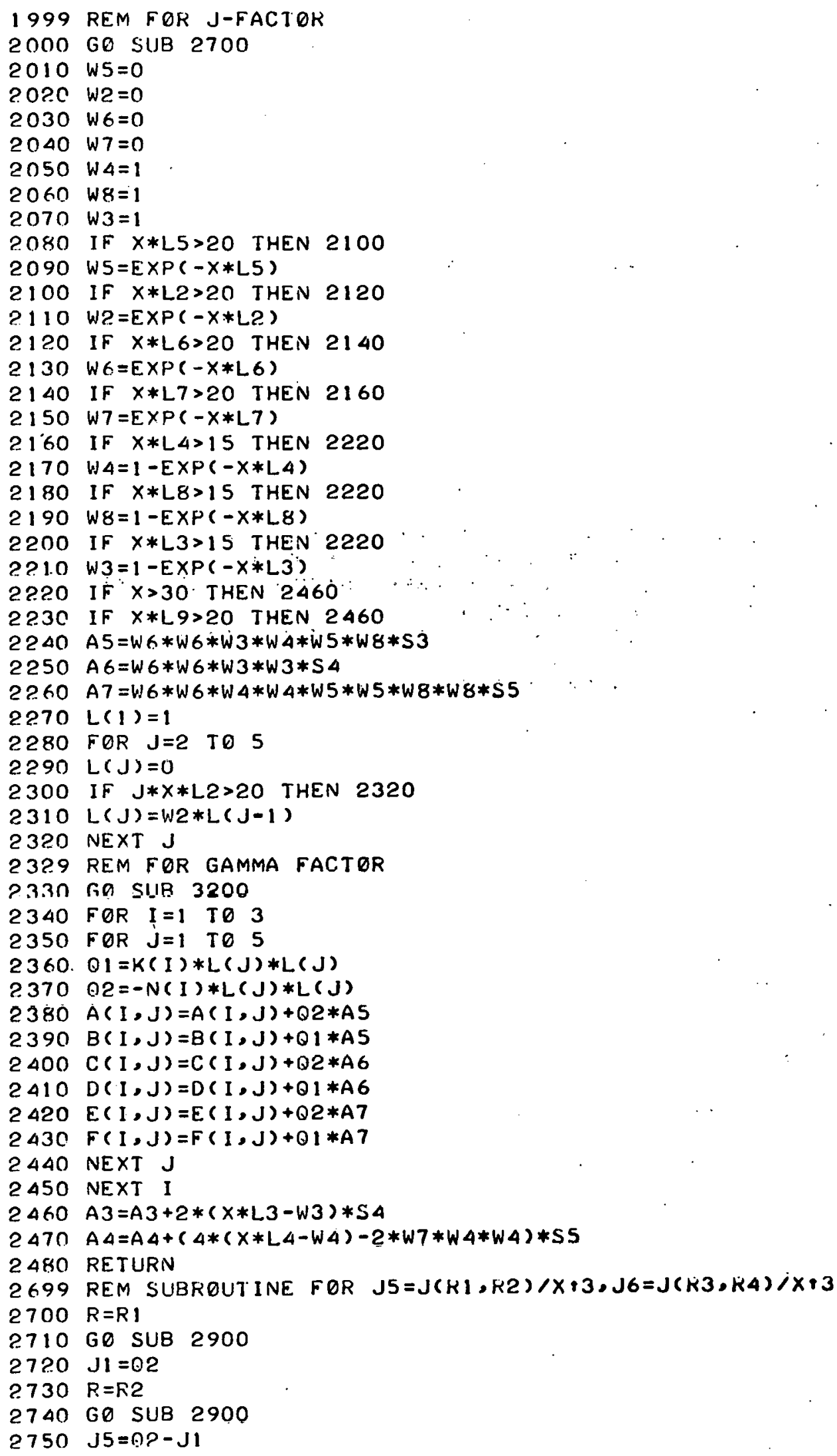




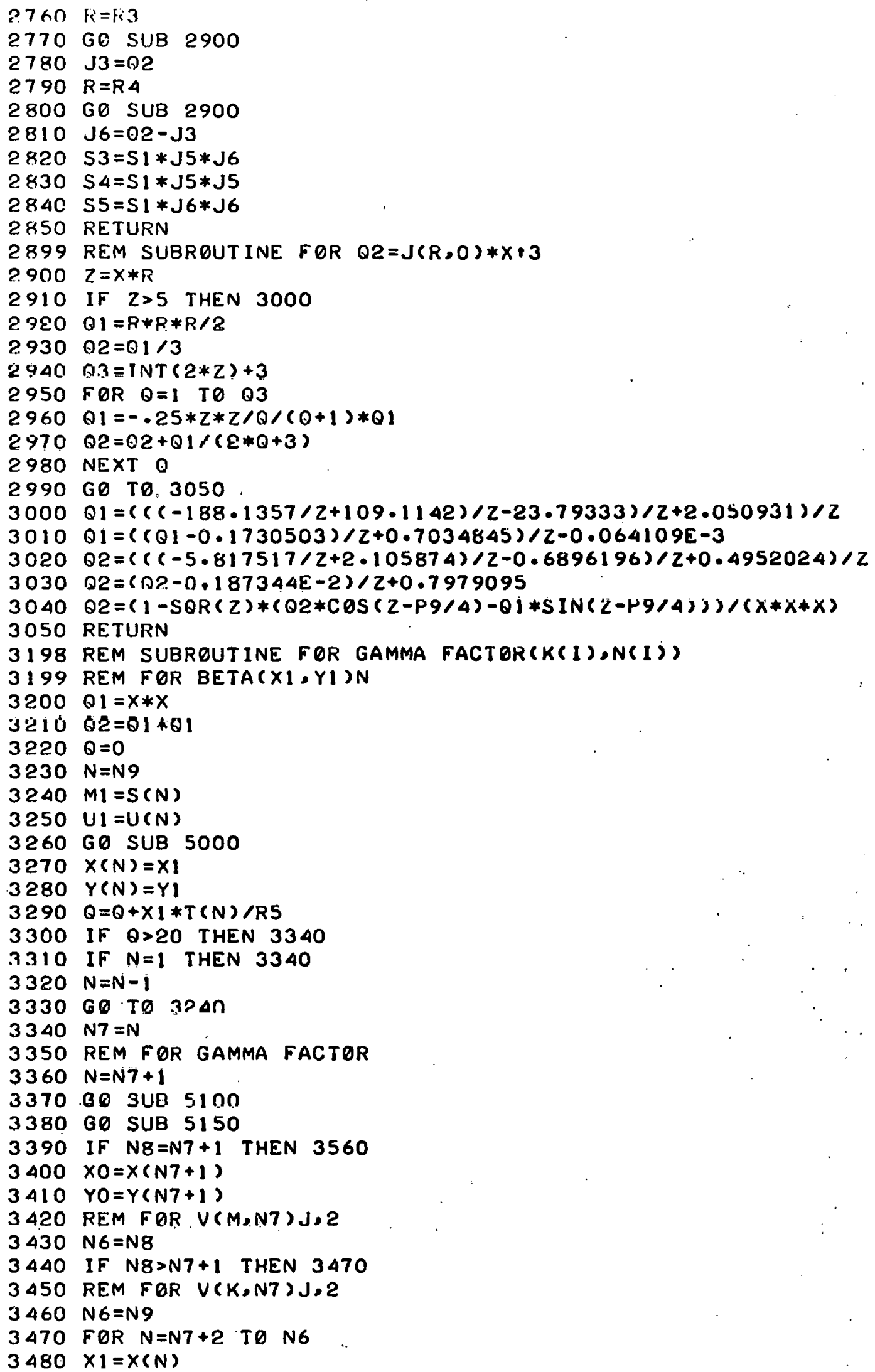




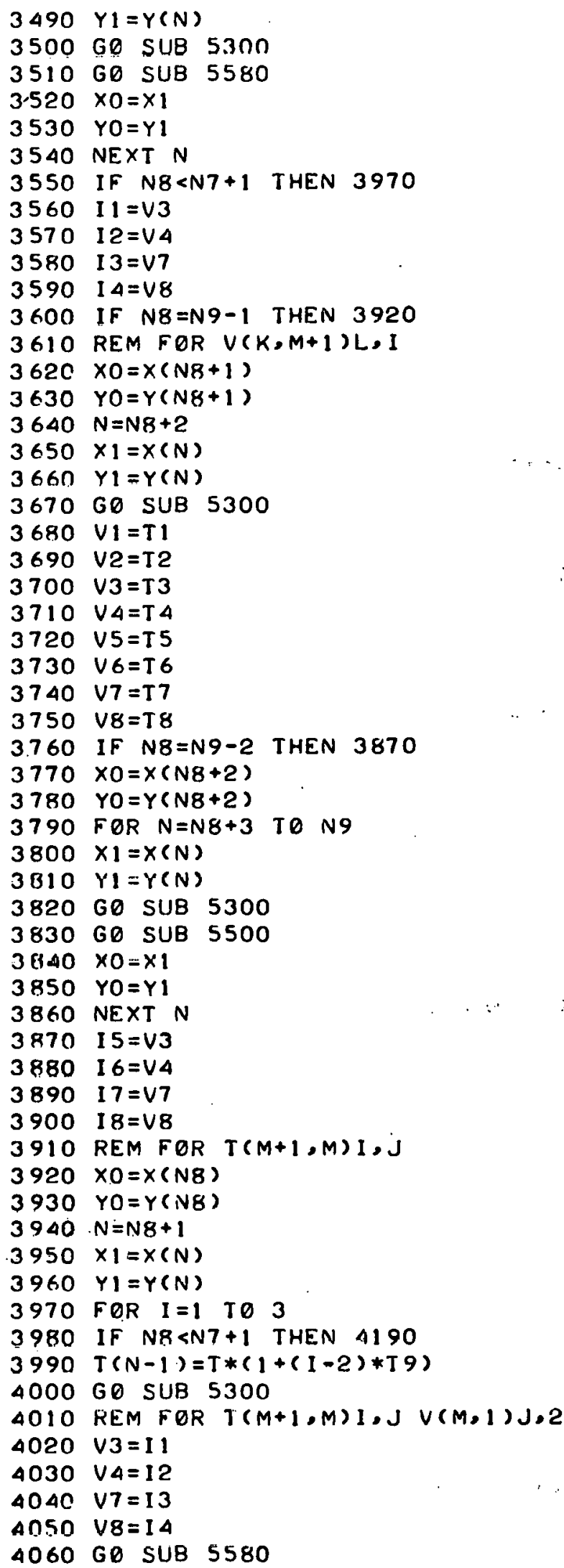


144

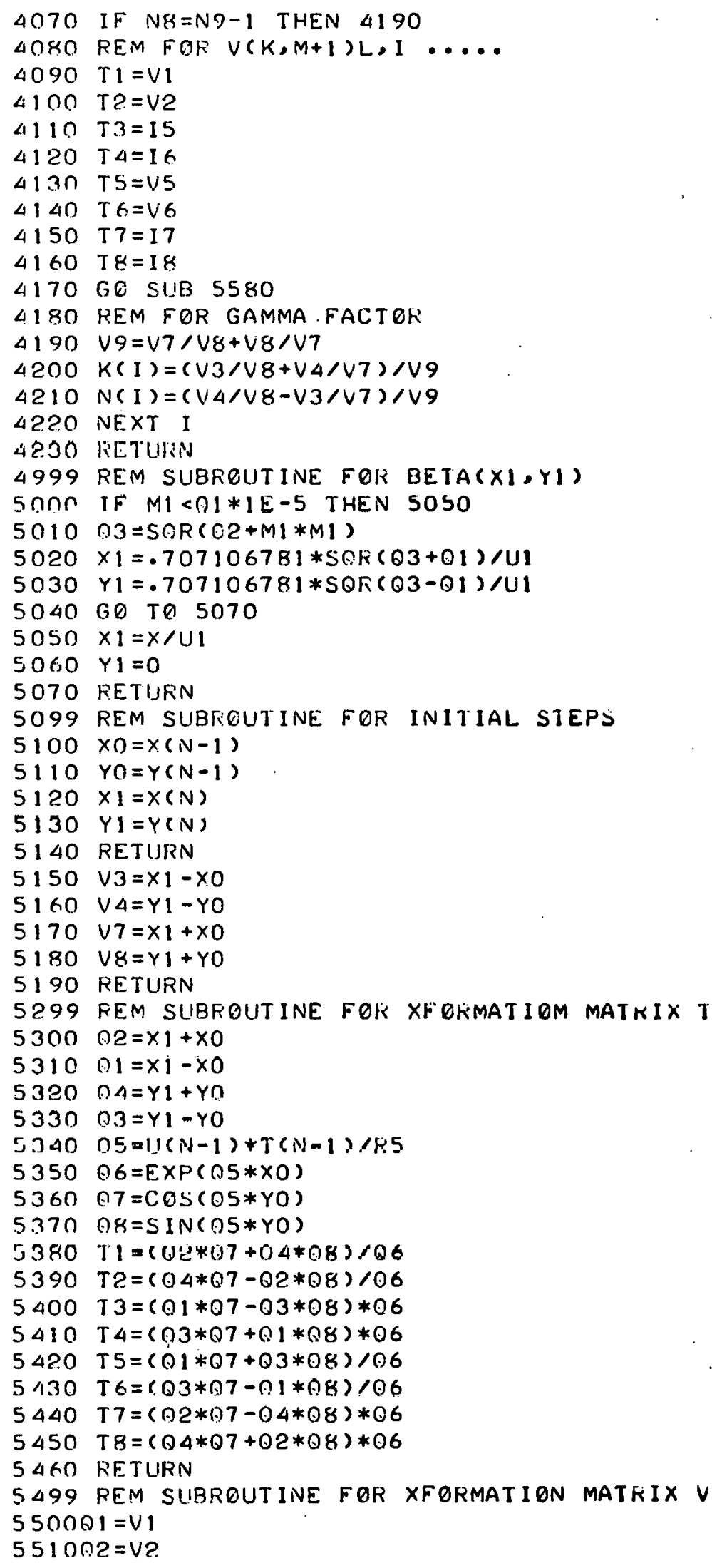




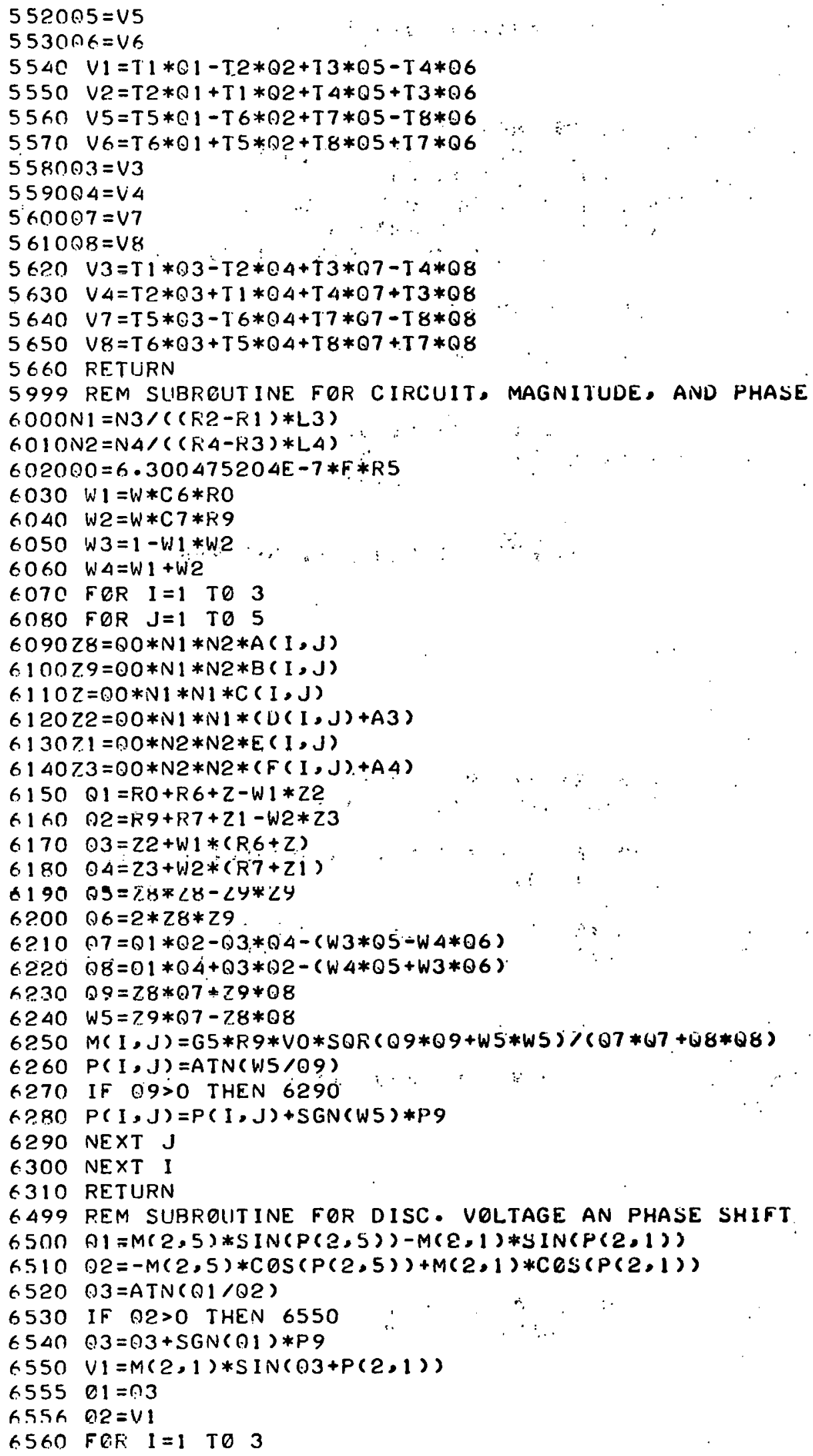




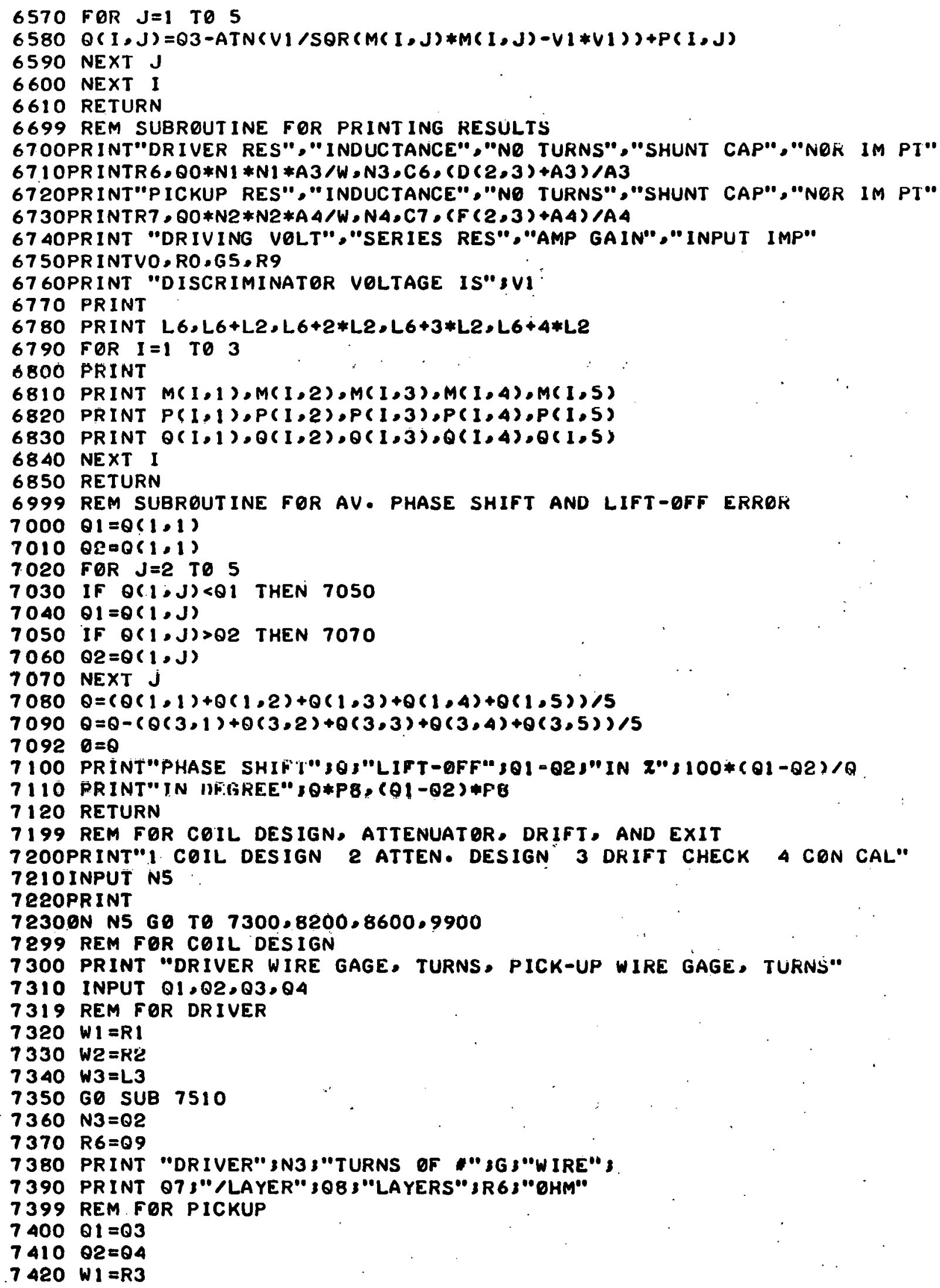




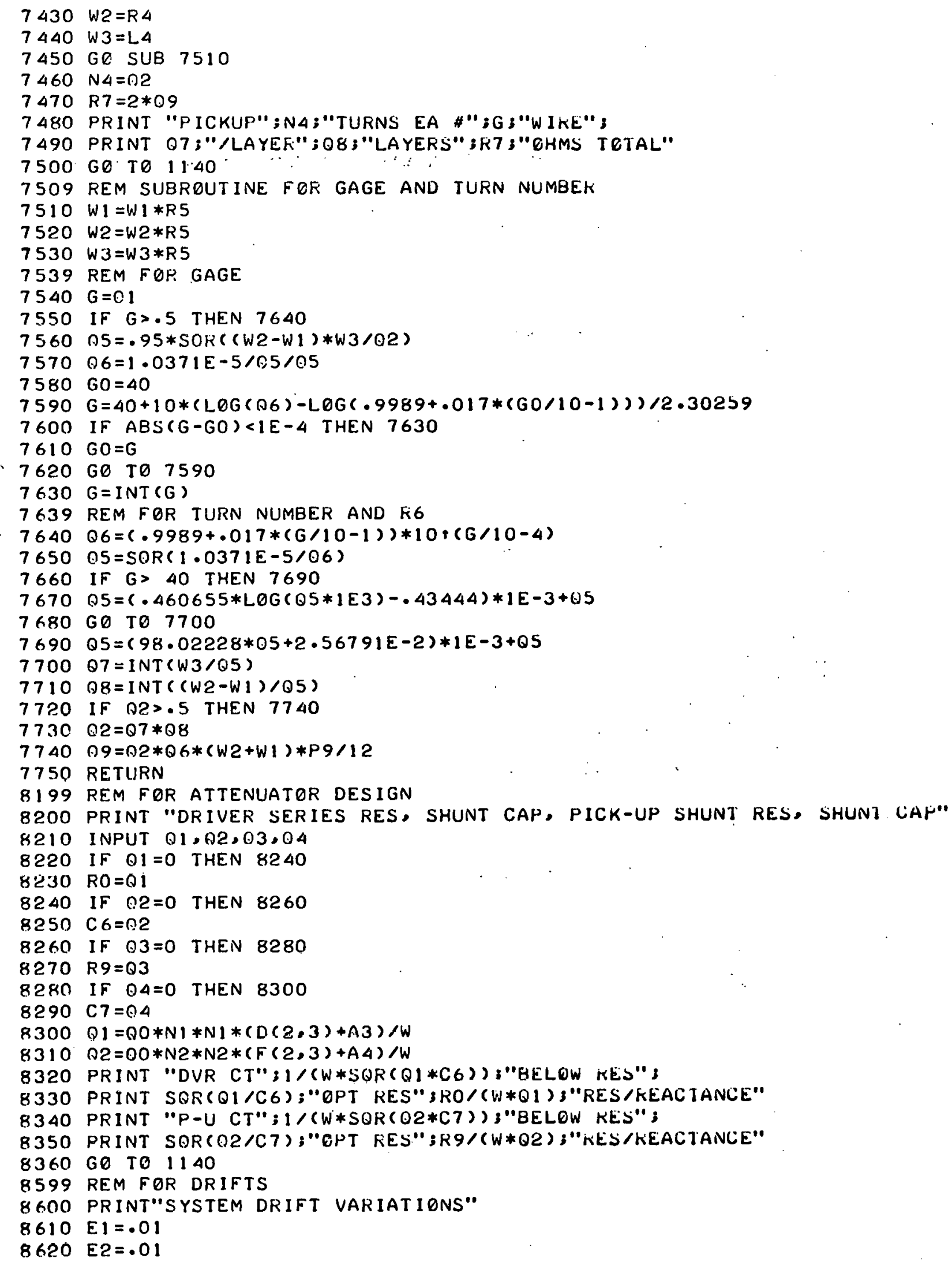




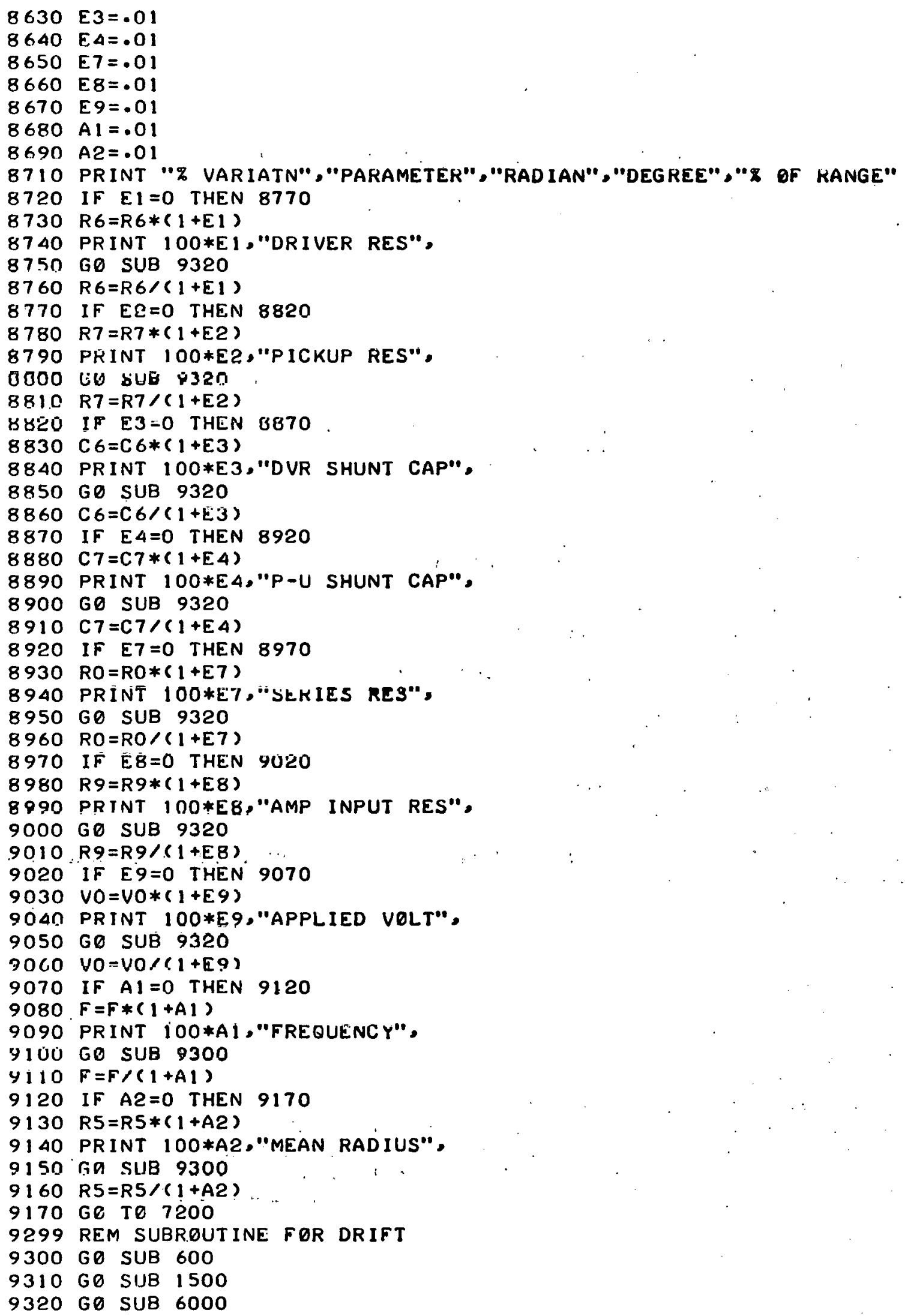




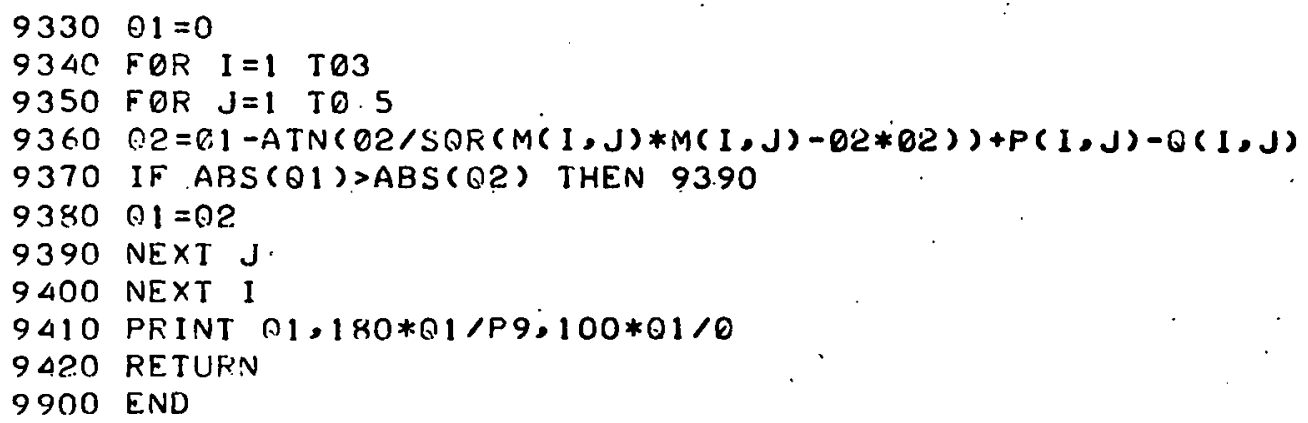


MUTIT, FORTRAN Version

The FORTRAN version of MULTIT is very similar to the BASIC version. The line numbers given are only for identification and editing purposes and have no effect on the actual execution of the FORTRAN program. The data must be typed in the seventh column, or six spaces must first be typed. The data are inputed as follows:

$00250 \cdot \mathrm{R} 5=$ (coil mean radius in inches)

$00260 \quad \mathrm{RI}=$ (normalized inner radius of driver coil)

$00270 \quad R P=$ (normalized outer radius of driver coil)

$00280 \quad$ L3 $=$ (normalized length of driver coil)

$00290 \mathrm{R} 3=$ (normalized inner radius of plckup coil)

$00300 \quad \mathrm{R} 4=$ (normalized outer radius of pickup coil)

$00310 \quad L 4=$ (normalized length of pickup coil)

$00320 \quad$ L5 $=$ (normalized length of recess of each pickup coil from the face of the driver coil)

$00330 \quad$ L6 = (normalized minimum lift-off of the driver coil)

$00340 \quad R 6=$ (resistance of driver coil in ohms)

$00350 \quad R 7=$ (resistance of both pickup coils in ohms)

n.36n N3 = (number of turns on the driver coil)

$00370 \quad \bar{N} 4=$ (number of turns on eqch pickup coil)

$00380 \quad \mathrm{RO}=$ (driver amplifier series resistance in ohms)

$00390 \quad \mathrm{R} 9=$ (pickup amplifier shunt resistance in ohms)

$00400 \quad \mathrm{C} 6=$ (shunt capacitance of driver circuit in farads)

$00410 \quad \mathrm{C} 7=$ (shunt capacitance of plckup elreult in farads)

$00420 \quad V U=$ (output vollage is vilts)

$00430 \quad$ G5 $=$ (amplifier gain)

$00440 \quad F=$ (operating frequency in Hertz)

$00450 \quad$ L2 $=$ (normalized lift-off increment of the driver coil)

$00510 \quad N 9=$ (total number of conductors +1 )

$00520 \quad N 8=$ (number of the specific conductor with conductivity variation) 
00540 DATA RHO/(resistivities in microhm-cm)/

00550 DATA U/(permeabilities)/

$00560 \quad$ DATA $\mathrm{T} /$ (thicknesses in inches)/

00740 T9 = (fractional variation of thickness of the N8-th layer)

The current version of MULTIT.F4 is limited to a maximum of nine conductors. However, this limitation can be removed easily by changing one DIMENSION statement.

00110 DIMENSION T(N9), U(N9), RHO(N9), M(N9), BETA(N9) .

The print-out of the FORTRAN version of MULTIT is practically identical to the BASIC version and will not be repeated. The main difference is that the question mark is not printed out when the program is ready to accept data. The Coil Design, Attenuator Design, Drift Check, and Continue Calculations options are the same. The line numbers constant names, and parameter varied in the drift calculations are as follows:

\begin{tabular}{|c|c|c|}
\hline Line Number & Constant & Parameter Varied \\
\hline 04230 & DRI & Driver Resistance. \\
\hline 04240 & DR2 & Pickup Resistance \\
\hline 04250 & DR3 & Driver Shunt Capacitance \\
\hline 04260 & DR4 & Pịckup Shunt Capocitance \\
\hline 04270 & DR5 & Series Resistance \\
\hline 04280 & DR6 & Amplifier Input Resistance \\
\hline 04290 & DR7 & Applied Voltage \\
\hline 04300 & DR8 & Frequency \\
\hline 04310 & DR9 & Mean Radius \\
\hline
\end{tabular}

For example, to vary the driver resistance by $2 \%$ one would type: $04230 \quad$ DRI $=0.02$

As in the BASIC version, the last two drifts require that the entire numerical integration be repeated and are relatively long running. If any of the drifts is set equal to zero, it will be omitted from the drift calculations. 


\section{Sample Calculation of MULTIT.F4}

Let us suppose that we wish to design a reflection type coil, identical to the one designed by the BASIC version. We will put the following data in the program (generally by using the EDIT MULTIC.F4 command on the PDP-10 and inserting the statements). All linear dimensions are normalized by dividing by the coil mean radius, except the coil mean radius, which is in inches.

$\begin{array}{ll}00250 & \text { R5 }=.08325 \\ 00260 & \text { RI }=0.75 \\ 00270 & \text { R2 }=1.25 \\ 00280 & \text { L3 }=.36 \\ 00290 & \text { R3 }=.36 \\ 00300 & \text { R4 }=.696 \\ 00310 & \text { L4 }=.096 \\ 00320 & \text { L5 }=0.0 \\ 00330 & \text { L6 }=0.1 \\ 00340 & \text { R6 }=79.36 \\ 00350 & \text { R7 }=530.5 \\ 00360 & \text { N3 }=360 . \\ 00370 & \text { N4 }=410 . \\ 00380 & \text { R0 }=1 . E 6 \\ 00390 & \text { R9 }=1 . E 6 \\ 00400 & \text { C6 }=1 . \mathrm{E}-12 \\ 00410 & \text { CT }=1 . E-12 \\ 00420 & \text { V0 }=10.0 \\ 00430 & \text { G5 }=1.0 \\ 00440 & \text { F }=1.0 E 4 \\ 00450 & \text { L2 }=0.025 \\ 00510 & \text { N9 }=5 \\ 00520 & \text { N8 }=4 \\ 000 & \end{array}$


00540 DATA RHO/1.E10, 3.632, 5.393, 3.632, 1.E10, 5*0./

00550 DATA U/5*I., 5*0./

00560 DATA T/1.EIO, 2.8E-2, I. $94 \mathrm{E}-1,2.8 \mathrm{E}-2,1 ., 5 * 0.1$

$00740 \quad$ T9 $=0.05$

The FORTRAN program may now be executed. 'The print-out will be essentially identical to the BASIC print-out and will not be repeated. The FORTRAN version of MULTIT follows. 


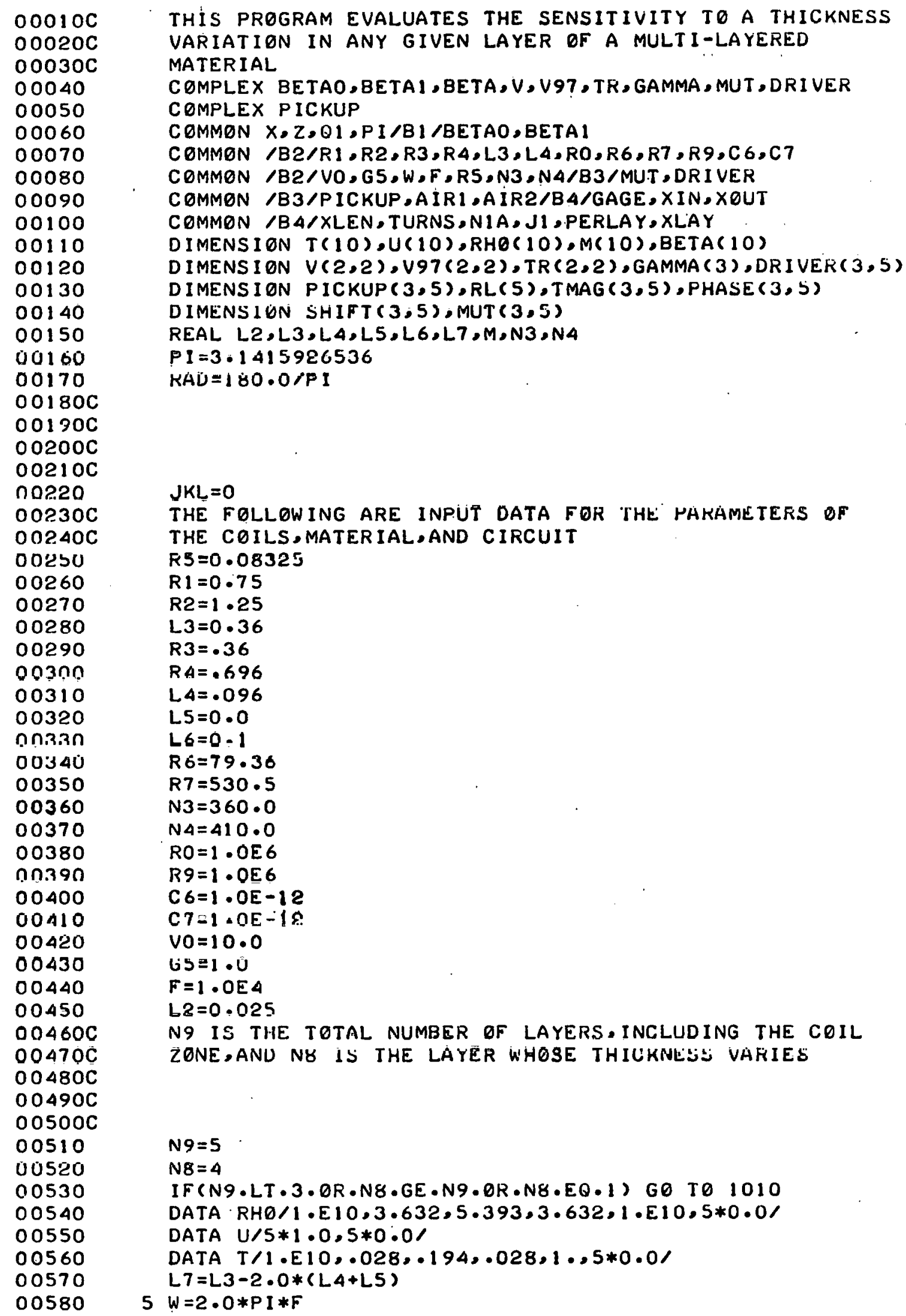


00590

00600

00610

00620

00630

00640

00650

00660

00670

00680

00690

00700

00710

00720

00730

00740

00750

00760

$00770 \mathrm{C}$

00780

00790

00800

00810

00820

00830

00840

00850

00860

00870

00880

00890

00900

00910

00920

00930

00940

00950

$00960 \mathrm{C}$

$00970 \mathrm{C}$

00980

00990

01000

01010

01020

01030

01040

01050

01060

01070

01080

01090

01100

01110

01120

01130

01140

01150
IF (JKL.NE • O) GO TO 15

TYPE 10

10 FORMAT (1H, 1HN, 13X,10HTHICK.(IN), 4X,11HR(M-OHM CM), $13 X, 7 \mathrm{HM}, \mathrm{S}$ I GMA, $7 \mathrm{X}, 1 \mathrm{HU})$

15 DO $50 \quad I=1$, N9

IF (RHO(I).GT ・ 1.0E9) GO TO 20

$M(I)=0.5094 * U(I) * F * R 5 * R 5 / R H \theta(I)$

GO TO 25

$20 M(I)=0.0$

25 IF (JKL.NE.O) GO TO 50

30 TYPE $40, I, T(I), R H O(I), M(I), U(I)$

40 FORMAT $(1 H, 12,12 X, 1 P E 12,5,2 X, E 12.5,2 X, E 12,5,2 X, O P F 6,2)$

SO CONTINUE

$T(N 9)=0.0$

$T 0=T(N 8)$

$T 9=0.05$

IF (JKL.NE.O) GO T.O 105

TVAR $=100.0 *$ T 9

THE SYSTEM PARAMETERS ARE PRINTED OUT

TYPE 55,N8, TVAR

55 FORMAT(1H, 22HTHICKNESS VARIATION OF, 13,14HTH LAYER

1 IS,$+- F 6.2 ; 1 \mathrm{~Hz})$

TYPE 470

TYPE $60, R 1, R 2, L 3$

60 FORMAT $(1 \mathrm{H}, 3 \mathrm{HR} 1=, F 8,5,3 \mathrm{X}, 3 \mathrm{HR2}=, F 8 \cdot 5,3 \mathrm{X}, 1$ 4HDRIVER LENGTH=, (F8.5)

TYPE $70, R 3, R 4, L 4$

70 FDRMAT $(1 H, 3 H R 3=, F 8.5,3 X, 3 H R 4=, F 8.5,3 X, 14 H P I C K U P$ LENGTH=, (F8.5)

TYPE $80, R 5, F$

80 FORMAT $(1 \mathrm{H}, 17 \mathrm{HCOIL}$ MEAN RADIUS $=, 58,5,7 \mathrm{H}$ INCHES, $3 X$, 12OHOPERATING FREQUENCY $=, 1$ PE 12.5)

TYPE 90.45

90 FORMAT ( $1 H, 15$ HPICKUP :RECESSED,F8.5)

TYPE 100, L 6, L2

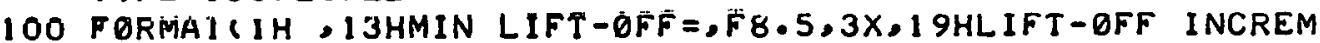
IENT $=, F 8 \cdot 5$ )

THE INTEGRATION BEGINS HERE: THE MUTUAL,DR IVER,AND PICKUP INDUCTANCES AND THE AIR VALUES ARE CALCULATED

$105 S 1=0.01$

$S 2=5 \cdot 0$

$B 1=0.0$

$\mathrm{B} 2=\mathrm{S} 2$

D0 $107 \quad I=1,3$

DO $107 \mathrm{~J}=1,5$

$\operatorname{MUT}(I, J)=(0.0,0.0)$

DRIVER $(I, J)=(0.0,0.0)$

$107 \operatorname{PICKUP}(I, J)=(0.0 ; 0,0)$

$A I R 1=0.0$

$A I R 2=0.0$

$110 \quad I 1=(B 2-B 1) / S 1$

$X=B 1-S 1 / 2 \cdot 0$

$D 0 \cdot 390$ IDX $=1,11$

$\mathrm{X}=\mathrm{X}+\mathrm{S} 1$

TEST $=X *$ L 3

IF (TEST.GT .20.0) G0 TO 120

W3 $=\operatorname{EXF}(=$ TEST $)$ 


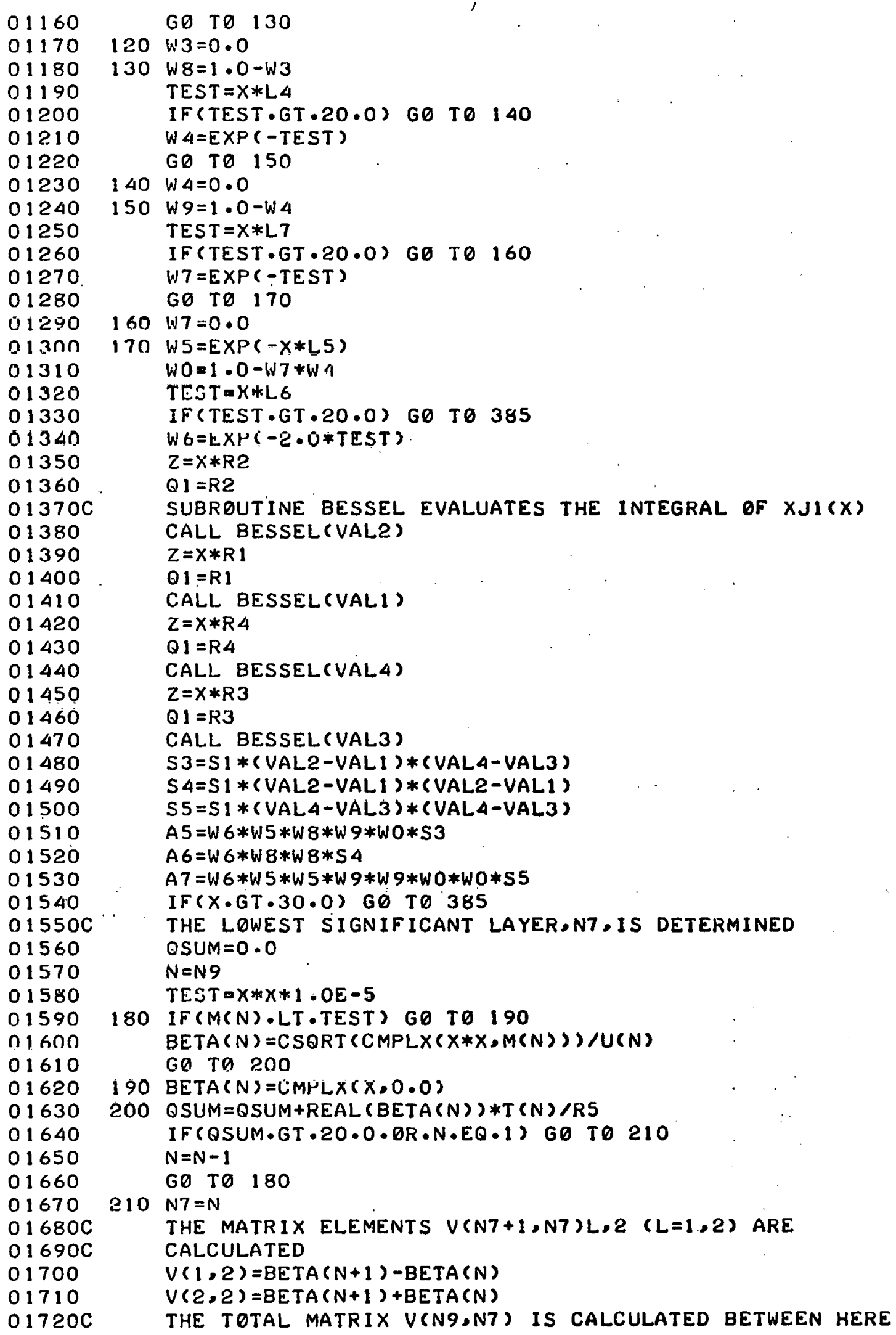




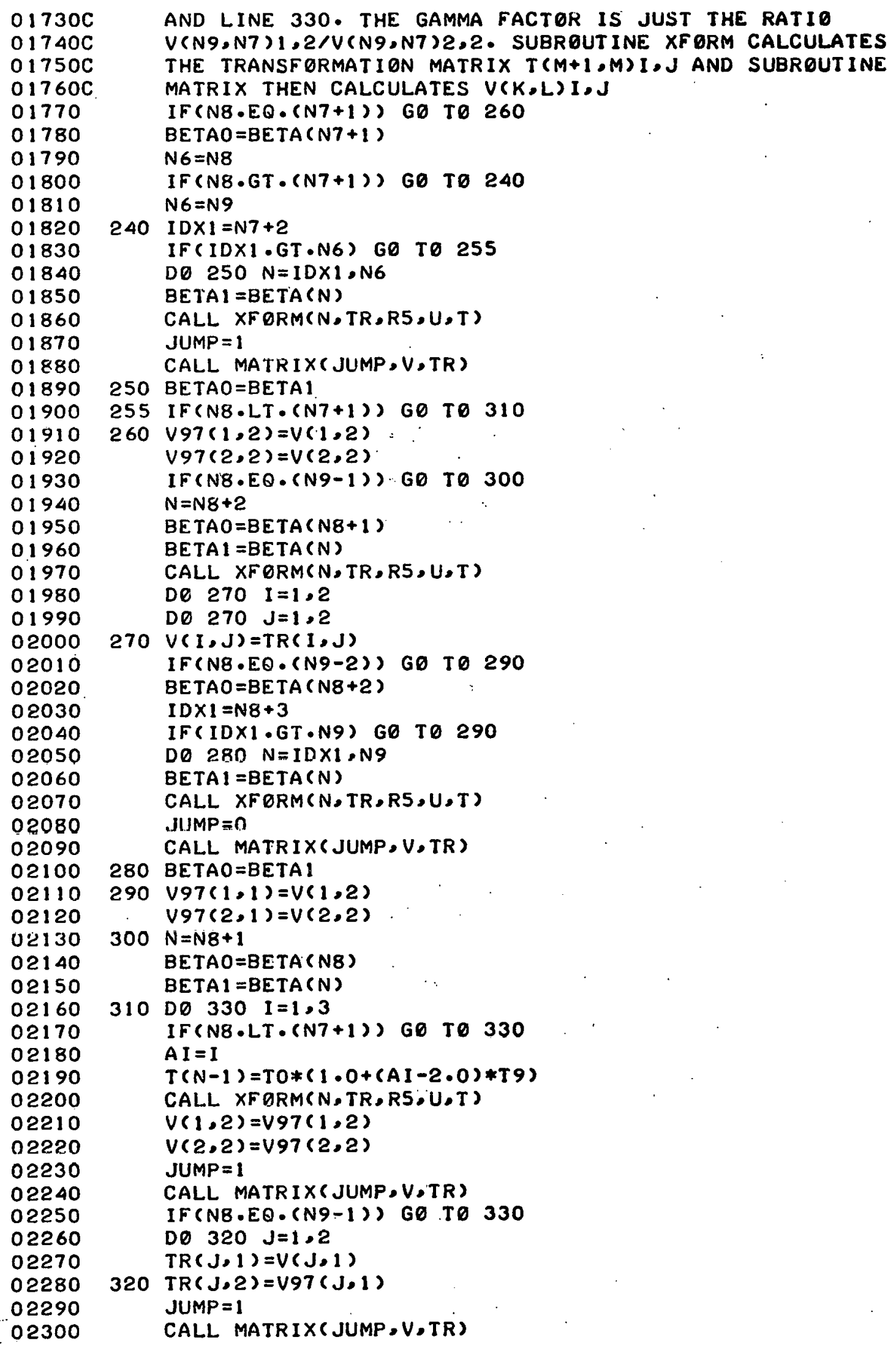




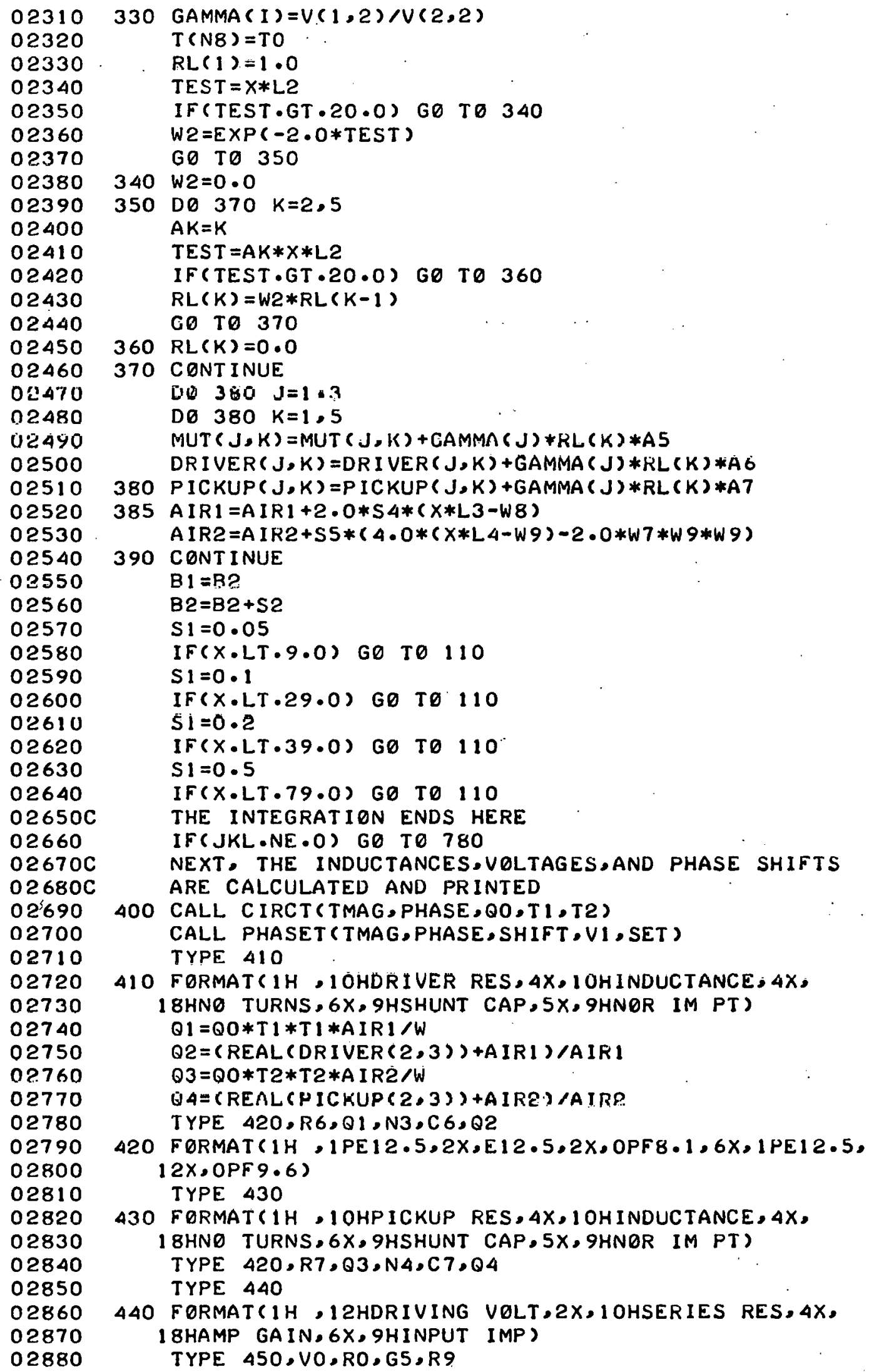




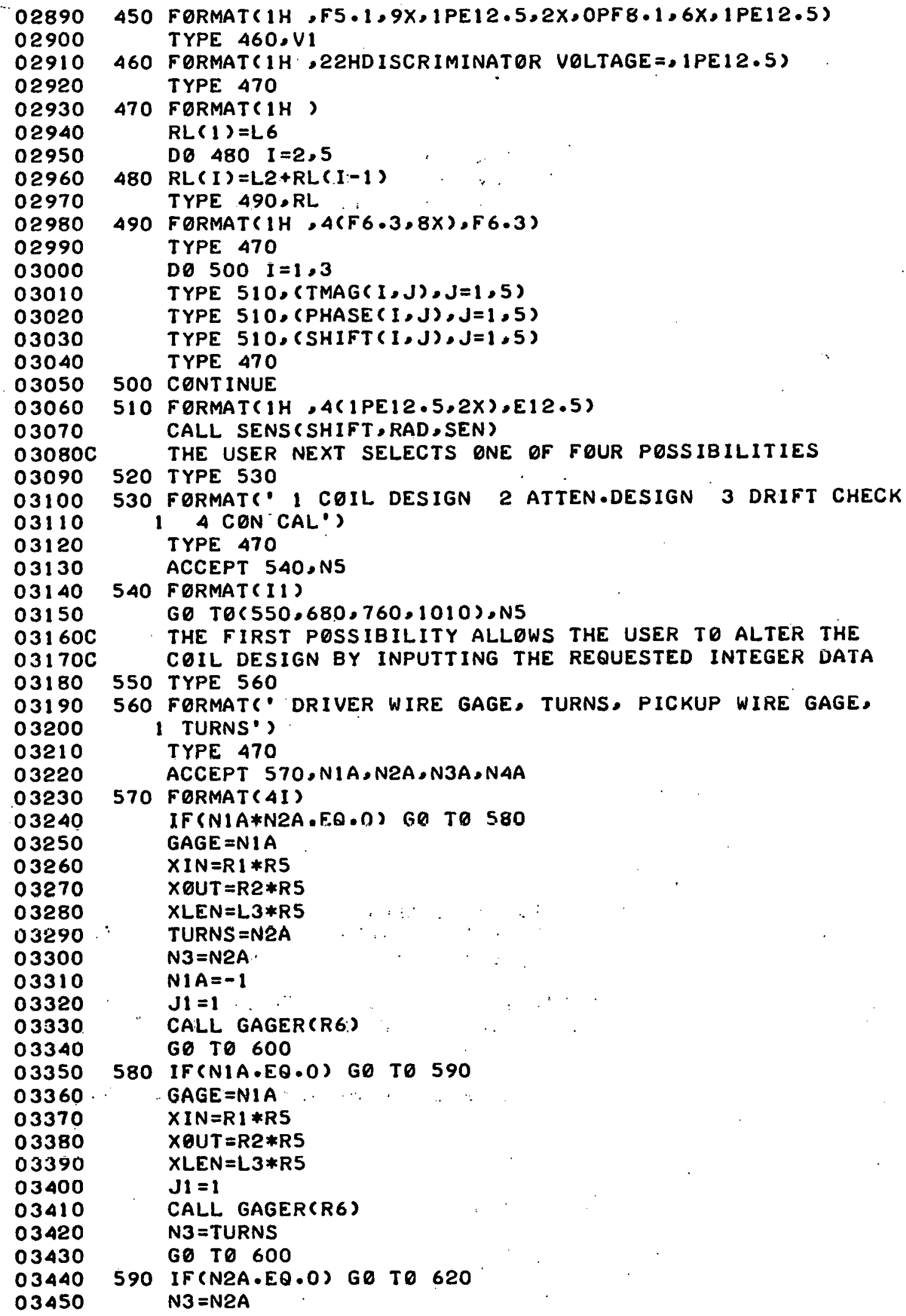




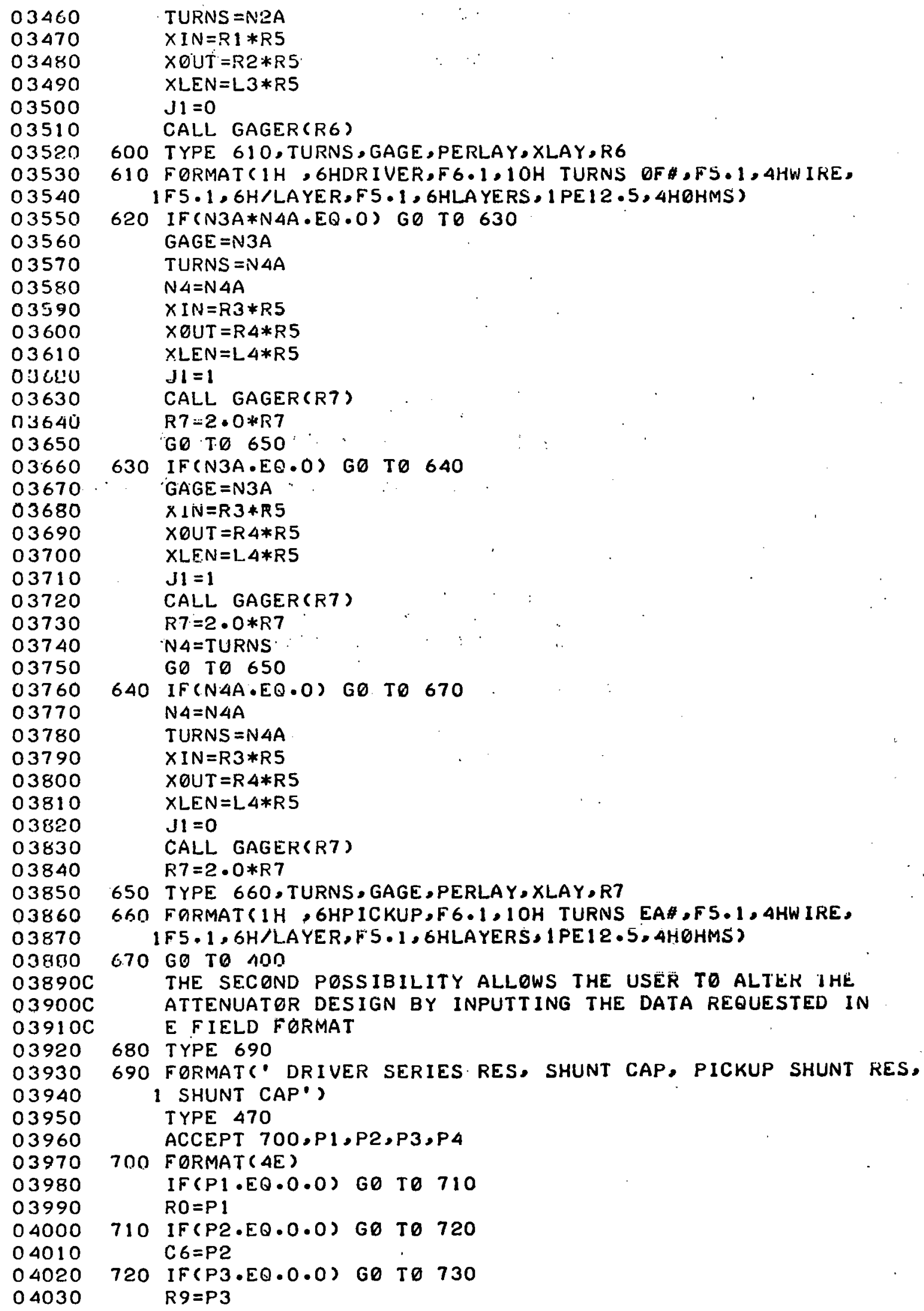




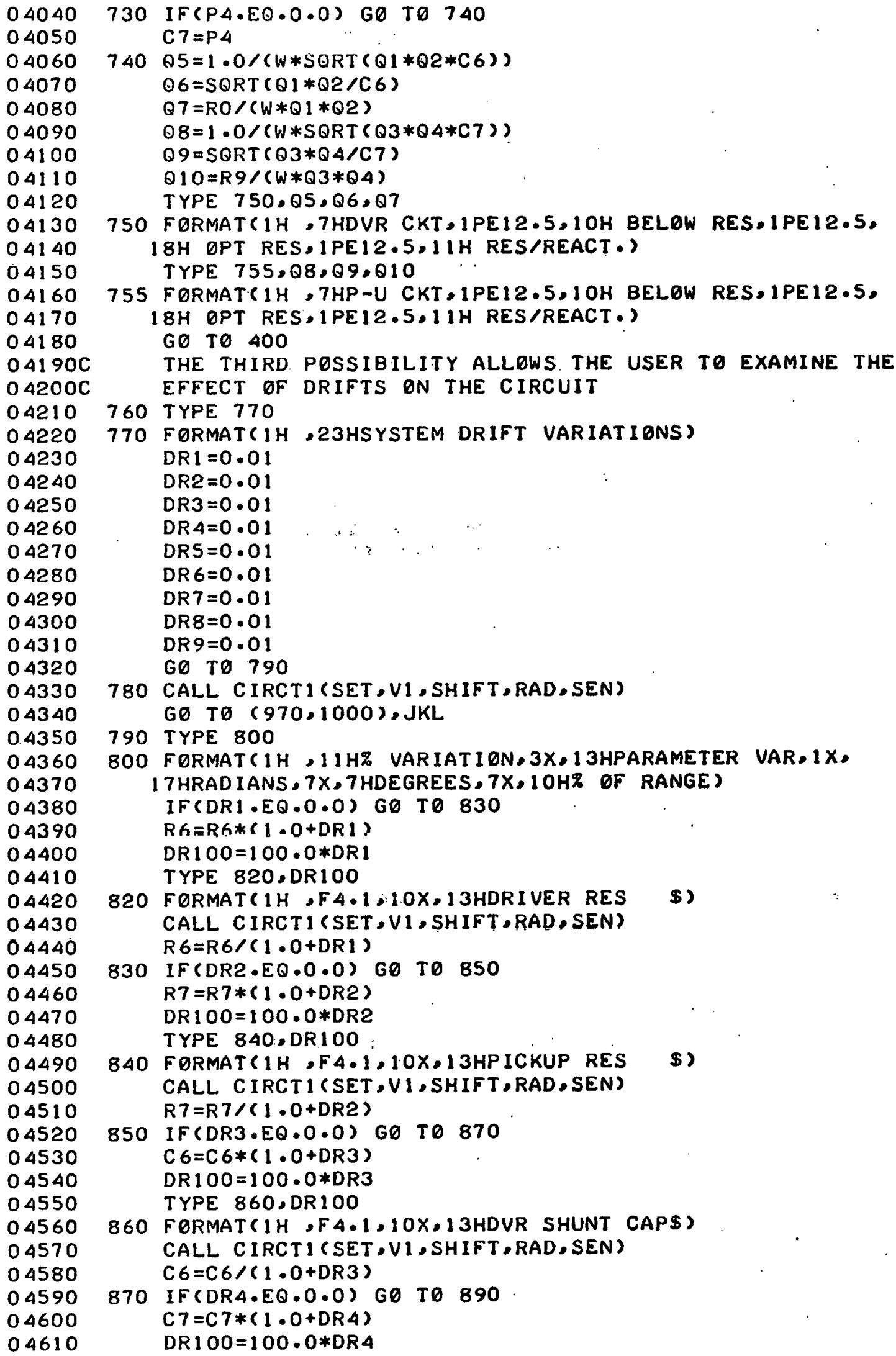

04040

04050

04060

04070

04080

04090

04100

04110

04120

04130

04140

04150

04160

04170

04180

$04190 \mathrm{C}$

$04200 \mathrm{C}$

04210

04220

04230

04240

04250

04260

04270

04280

04290

04300

04310

04320

04330

04340

0.4350

04360

04370

04380

04390

04400

04410

04420

04430

04440

04450

04460

04470

04480

04490

04500

04510

04520

04530

04540

04550

04560

04570

04580

04590

04600

04610

730 IF (PA.EQ.0.0) GO TO 740

$\mathrm{C} 7=\mathrm{P} 4$

740 Q $5=1 \cdot 0 /(W * S Q R T(Q 1 * Q 2 * C 6))$

$06=S Q R T(Q 1 * Q 2 / C 6)$

$Q 7=R 0 /(W * Q 1 * Q 2)$

$08=1 \cdot 0 /(W * S Q R T(Q 3 * Q 4 * C 7))$

$Q 9=\operatorname{SQRT}(Q 3 * Q 4 / C 7)$

$010=R 9 /(W * Q 3 * 04)$

TYPE $750,05, Q 6,07$

750 FORMAT 1 1H,7HDVR CKT,1PE12.5,10H BELOW RES,1PE12.5,

$18 \mathrm{H}$ DPT RES,1PE12.5,11H RES/REACT •)

TYPE $755,88,09,010$

755 FORMATC1H,7HP-U CKT,1PE12.5,10H BELOW RES, IPE12.5,

$18 \mathrm{H}$ OPT RES,1PE 12.5.11H RES/REACT •)

GD TO 400

THE THIRD POSSIBILITY ALLOWS. THE USER TO EXAMINE THE EFFECT OF DRIFTS ON THE CIRCUIT

760 TYPE 770

770 FORMAT (IH, 23HSYSTEM DRIFT VARIATIONS)

DR $1=0.01$

$\mathrm{DR2}=0.01$

$D R 3=0.01$

DR $4=0.01$

$\mathrm{DRS}=0.01$

DR $6=0.01$

DR7 $=0.01$

DR8 $=0.01$

DR9 $=0.01$

GO TO 790

780 CALL CIRCTI (SET,VI,SHIFT,RAD,SEN)

GO TO $(970,1000), \mathrm{JKL}$

790 TYPE 800

800 FORMAT ( $1 \mathrm{H}, 11 \mathrm{H} \%$ VARIATION,3X, 13 3PARAMETER VAR, $1 \mathrm{X}$, 17 HRAD IANS, 7X,7HDEGREES, 7X, 10H\% OF RANGE ?

IF (DR 1.EQ.0.0) GO TO 830

$R G=R G *(1 \cdot 0+D R 1)$

DR $100=100 \cdot 0 * D R 1$

TYPE $820, D R 100$

820 FORMAT ( $1 \mathrm{H}, \mathrm{F} 4.1 ; 10 \mathrm{X}, 13$ HDRIVER RES

\$)

CALL CIRCTI (SET,VI, SHIFT,RAD, SEN)

$R 6=R 6 /(1 \cdot 0+D R 1)$

830 IF (DR2 EQ.0.0) GO TO 850

$R 7=R 7 *(1 \cdot 0+D R 2)$

DR $100=100 \cdot 0 * D R 2$

TYPE 840:DR 100

840 FORMAT $1 \mathrm{H}, F 4.1,10 \mathrm{X}, 13 \mathrm{HPICKUP}$ RES

\$)

CALL CIRCTI (SET,VI,SHIFT,RAD, SEN)

$R 7=R 7 /(1 \cdot 0+D R 2)$

850 IF (DR3.EQ.0.0) G0 TO 870

C $6=C 6 *(1 \cdot 0+D R 3)$

DR $100=100 \cdot 0 *$ DR3

TYPE 860, DR 100

860 FORMAT(1H,F 4.1.10X,13HDVR SHUNT CAPS)

CALL CIRCTI (SET,VI,SHIFT,RAD, SEN)

$\mathrm{C} 6=\mathrm{C} 6 /(1.0+\mathrm{DR} 3)$

870 IF (DRA.EQ.0.0) GO TO 890

$C 7=C 7 *(1 \cdot 0+D R 4)$

DR $100=100 \cdot 0 *$ DR 4 


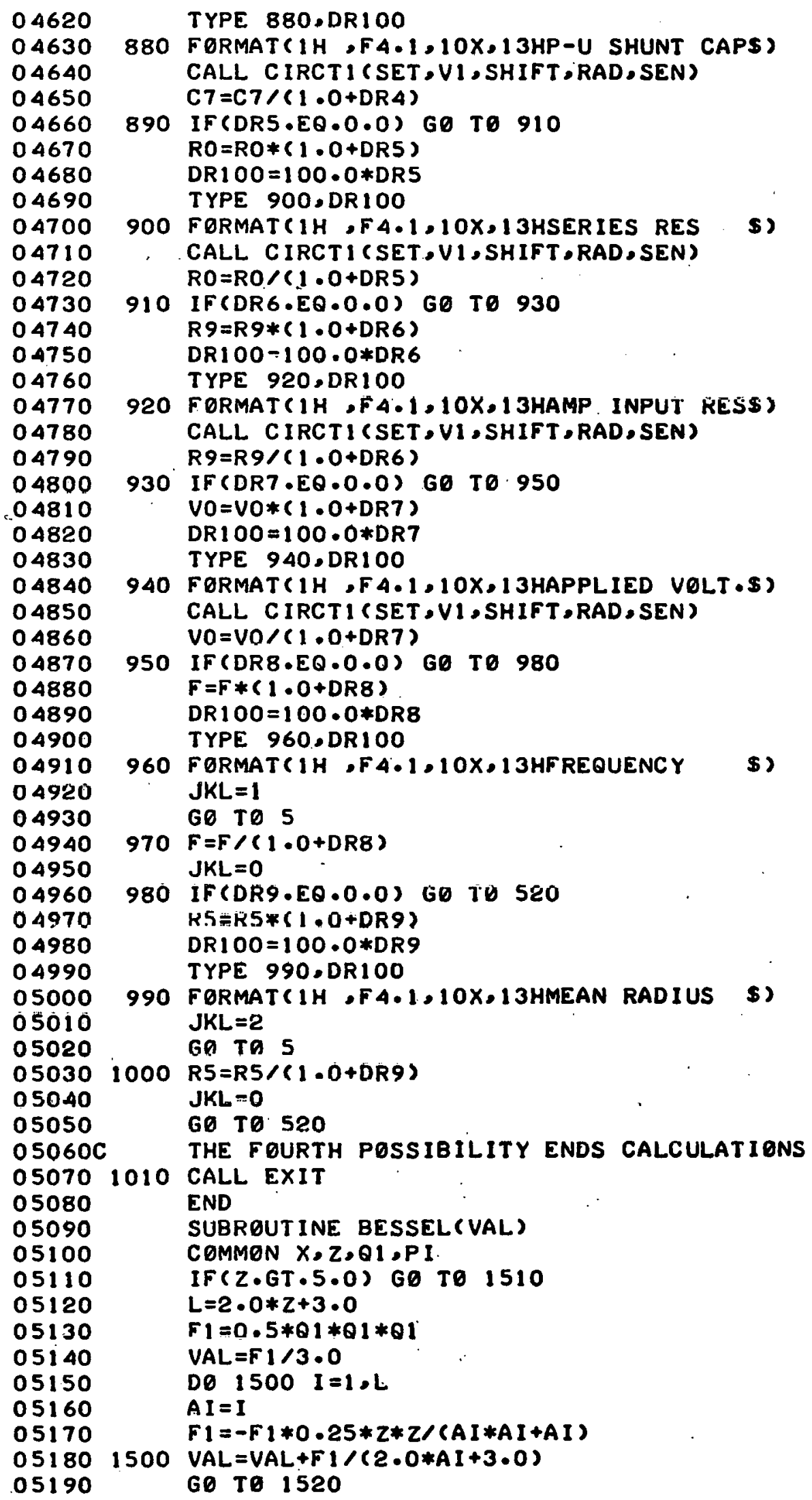




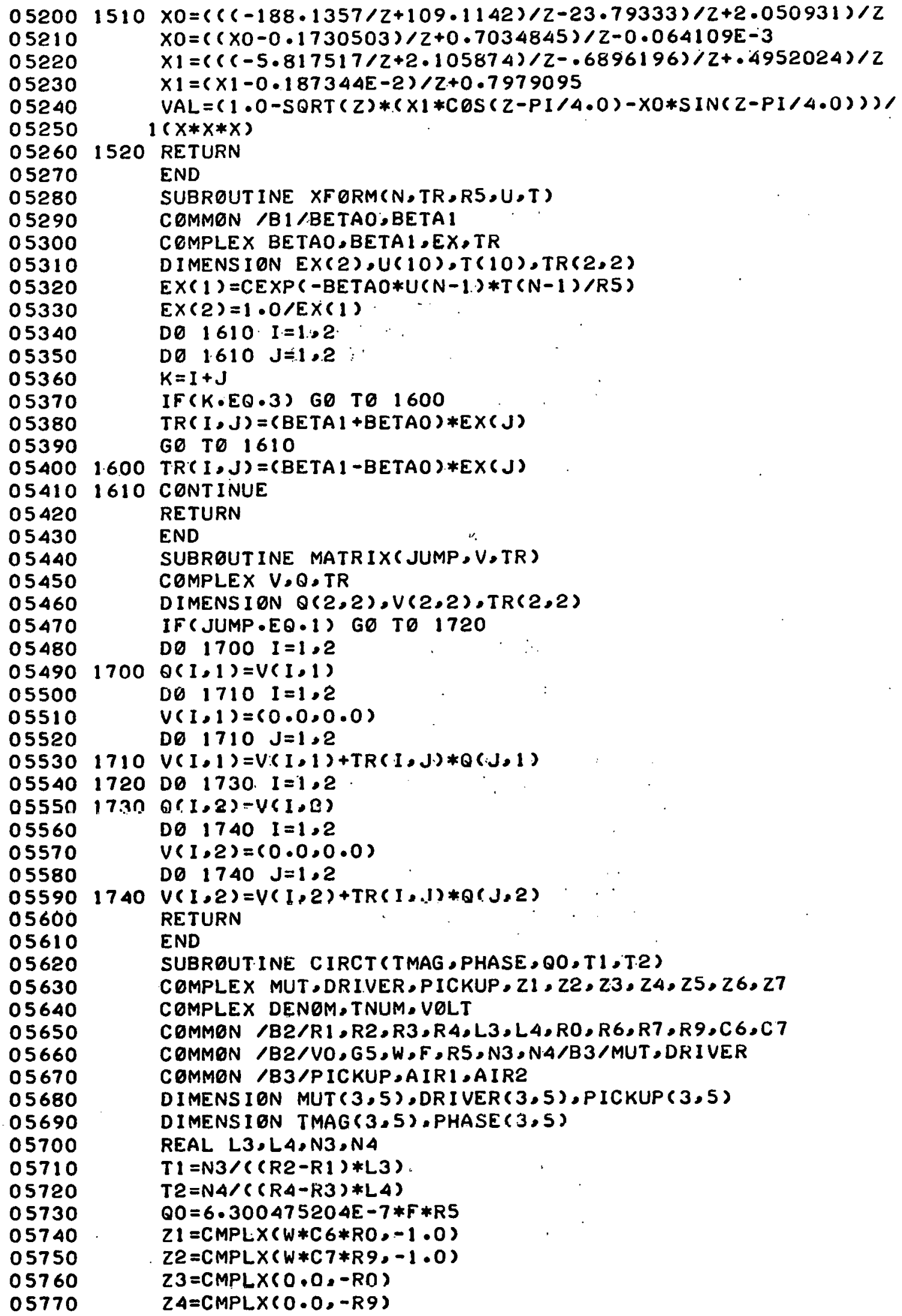




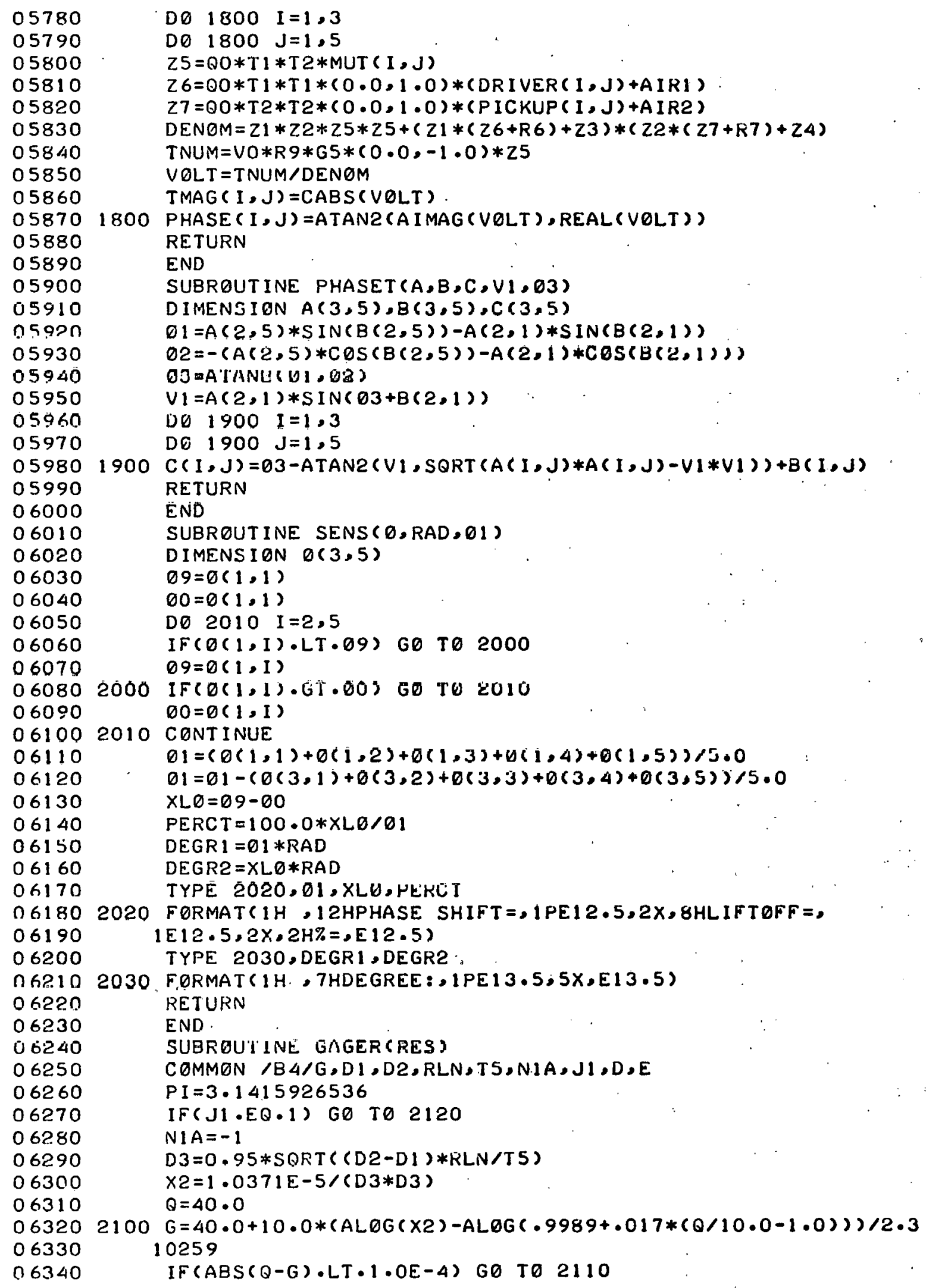




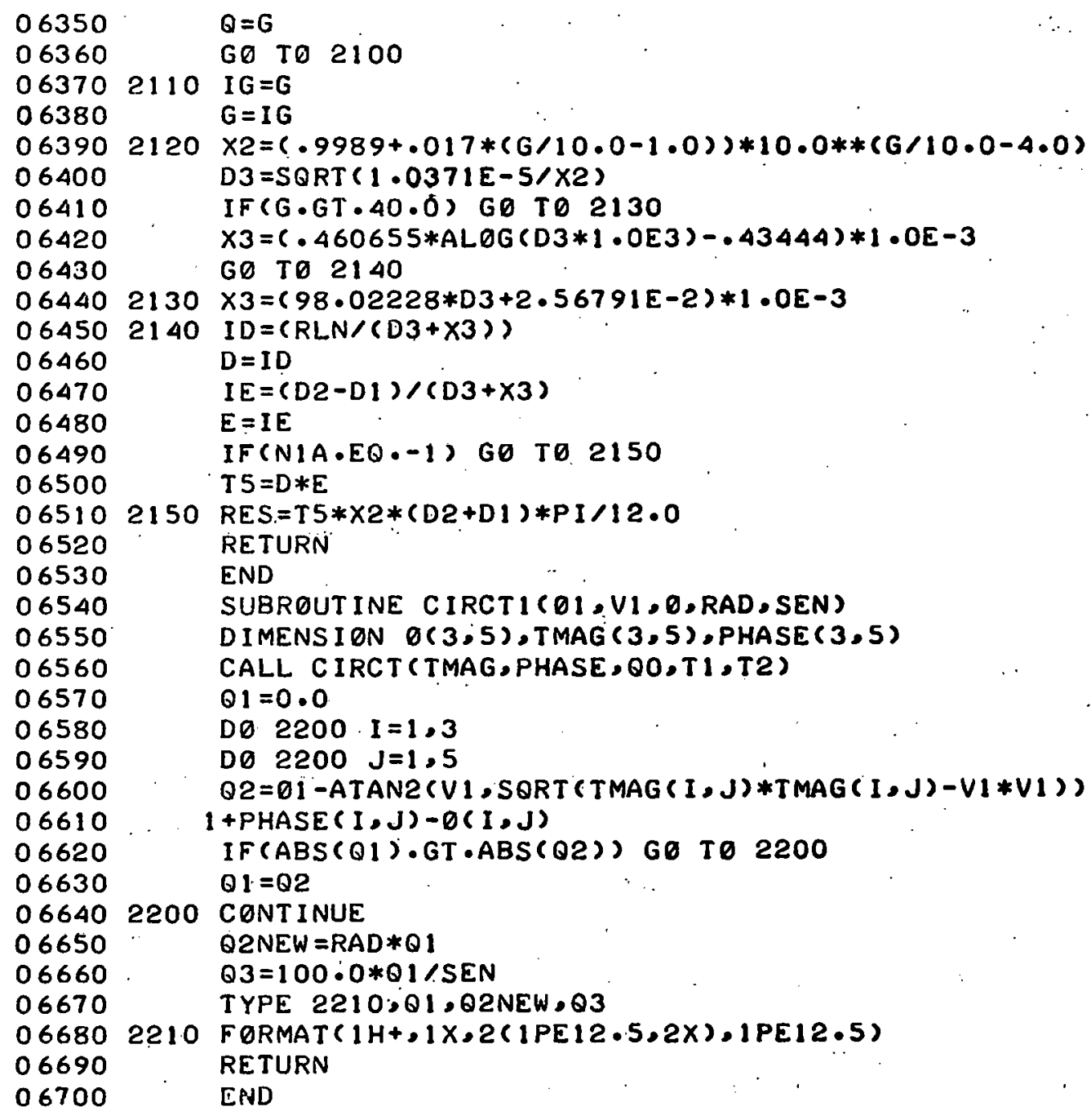


REFLECTION COIL ABOVE MULTIPLE CONDUCTORS, DEFECT

We shall now continue to consider the case of a reflection coil above multiple conductors, as shown in Fig. 4 (p. 7). This program calculates the magnitude and phase of the voltage that is fed to the phase measuring circuits of the phase sensitive eddy-current instruments and is designed to help analyze eddy-current measurements of defects.

The program calculates the magnitude and phase of the induced voltage at five different values of lift-off for two conditions, a nominal condition without defects in any conductor and a varied condition with a defect in a specific conductor, making a total of ten calculations. This allows one to examine the sensitivity to lift-off variations as well as defect variations in a specific conductor. In addition, the program also calculates the phase shift with the discriminator adjusted to give the same phase in the nominal condition with maximum and minimum lift-off. The phase in the nominal condition with minimum lift-off is. taken as zero, and all other phase shifts are measured relative to it.

The equations that are evaluated are Eq. (8) for the mutual coupling, Eq. (9) for the driver coil impedance, and Eq. (17) for the pickup coil impedance. The gamma factor for multiple conductors is calculated from Eqs. (24) to (28). Due to the presence of the defect, the self and the mutual impedances are changed and can be calculated from Eq. (21).

The programs are written in both BASIC and FORTRAN for use on the PDP-10. The BASIC program follows.

To use this program, one must first divide all dimensions by the mean radius of the driver coil. Then the following lines must be typed into the program.

$250 \mathrm{R} 5=$ (numerical value of driver coll mean radius in inches)

$260 \mathrm{RI}=$ (numerical value of normalized ariver coil inner radius)

$270 \mathrm{R} 2$ = (numerical value of normalized driver coil outer radius)

$280 \mathrm{~L} 3=$ (numerical value of normalized driver coil length)

$290 \mathrm{R} 3=$ (numerical value of normalized pickup coil inner radius)

$300 \mathrm{R} 4=$ (numerical value of normalized pickup coil outer radius) 
$310 \quad$ L4 $=$ (numerical value of normalized pickup coil length).

$320 \mathrm{~L} 5=$ (numerical value of normalized pickup coil recess from face of driver)

330 L6 = (numerical value of normalized driver coil minimum liftoff)

$340 \mathrm{R} 6=$ (numerical value of resistance of driver coil in ohms)

$350 \mathrm{R} 7=$ (numerical value of total resistance of both pickup coils in ohms)

$360 \quad \mathrm{~N} 3=$ (number of turns on driver coil)

$370 \mathrm{~N} 4=$ (number of turns on each pickup coil)

$380 \mathrm{RO}=$ (output series resistance of driving amplifier in ohms)

390 R9. = (input shunt resistance of pickup amplifier in ohms)

$400 \quad \mathrm{C6}=$ (total shunt capacitance in driving circuit in farads)

$410 \mathrm{C} 7=$ (total shunt capacitance in pickup circuit in farads)

$420 \quad \mathrm{VO}=$ (output voltage of driving amplifier in volts)

$430 \quad G 5=$ (gain of pickup amplifier)

$440 \quad F=$ (operating frequency in Hertz)

450 L2 $=$ (numerical value of normalized driver coil lift-off increment)

510 N9 $=$ (total number of conductors +1 )

$520 \quad N 8=$ (number of the specific conductor with a defect, refer to Fig. 4)

$760 \cdot R 8=$ (numerical value of normalized defect distance from coil axis)

$770 \quad 27=$ (numerical value of defect distance below the surface of the N8-th layer in inches)

$780 \quad \mathrm{~V} 5=$ (numerical value of normalized defect volume)

$790 \quad A O=$ (numerical value of shape and orientation factor of defect)

The input data of conductors are typed into the program between the statement numbers 800 and 980 ; according to the order of appearance from the lowest conductors [refer to Fig. 4 (p. 7)]. 


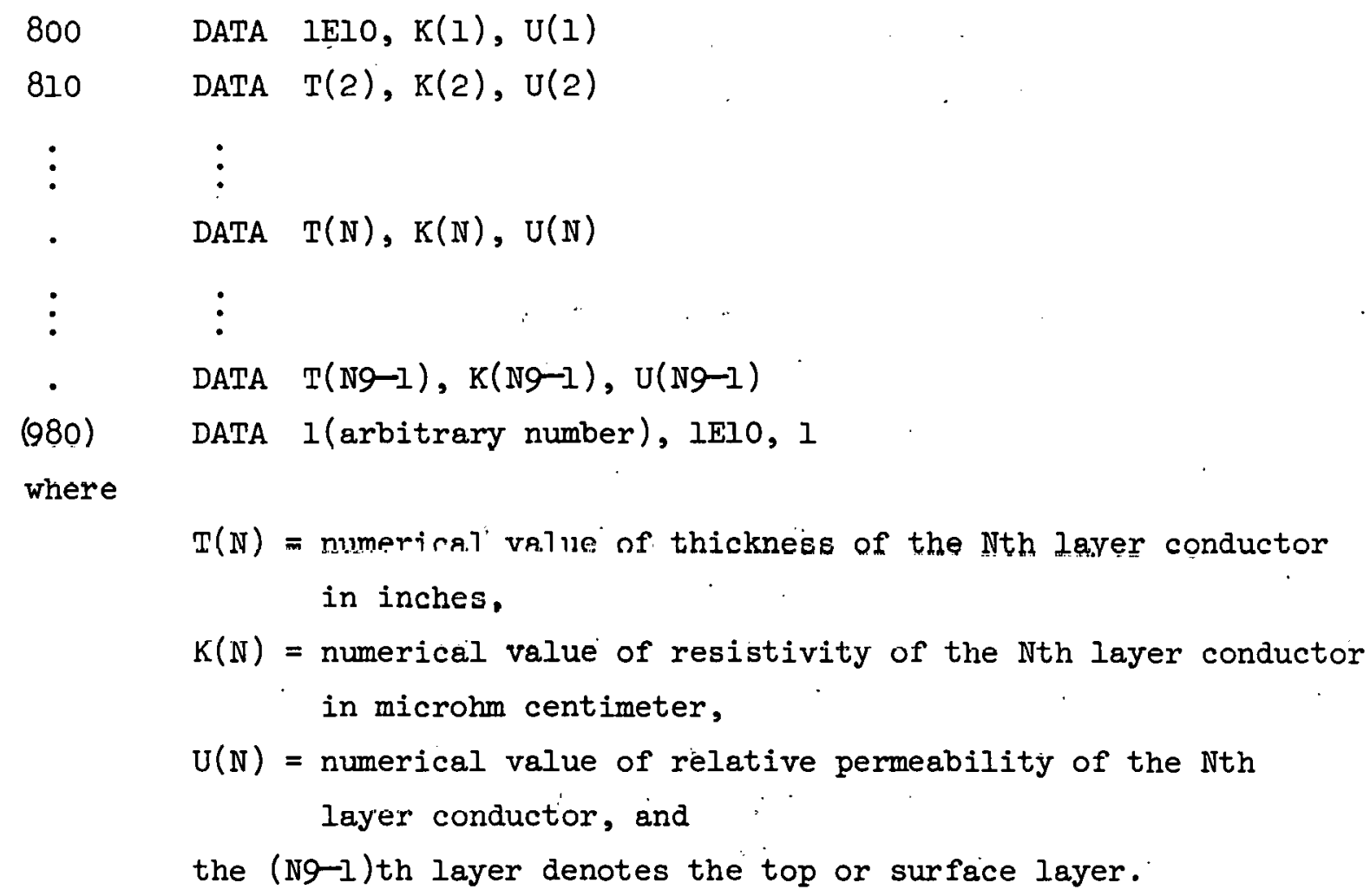

The current version of MULTID (BASIC) is limited to a maximum of nine conductors. However, this limitation can be removed easily by adding one DIMENSION statement:

$$
60 \text { DIM } T(N 9), R(N 9), U(N 9), S(N 9), X(N 9), Y(N 9) \text {. }
$$

The program may now be run. The print-out by the computer will have the following format.

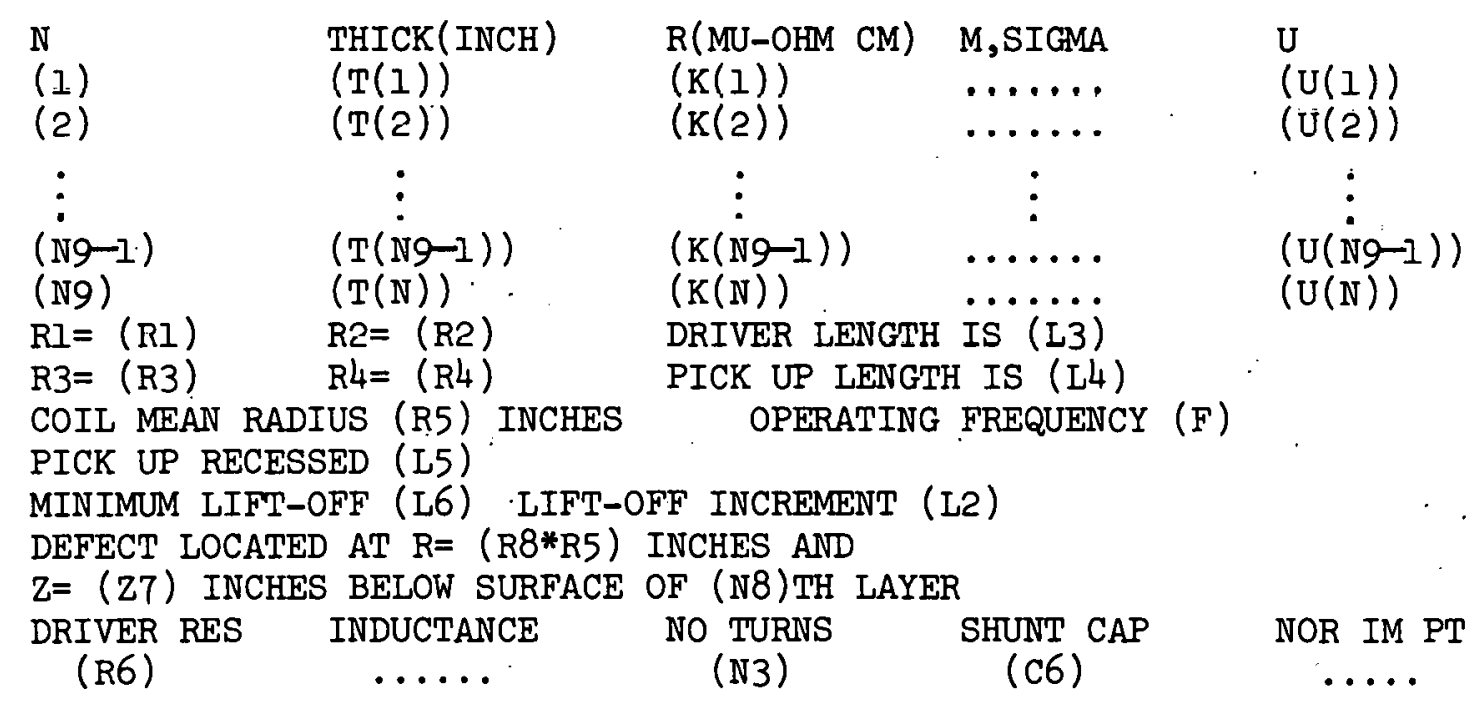




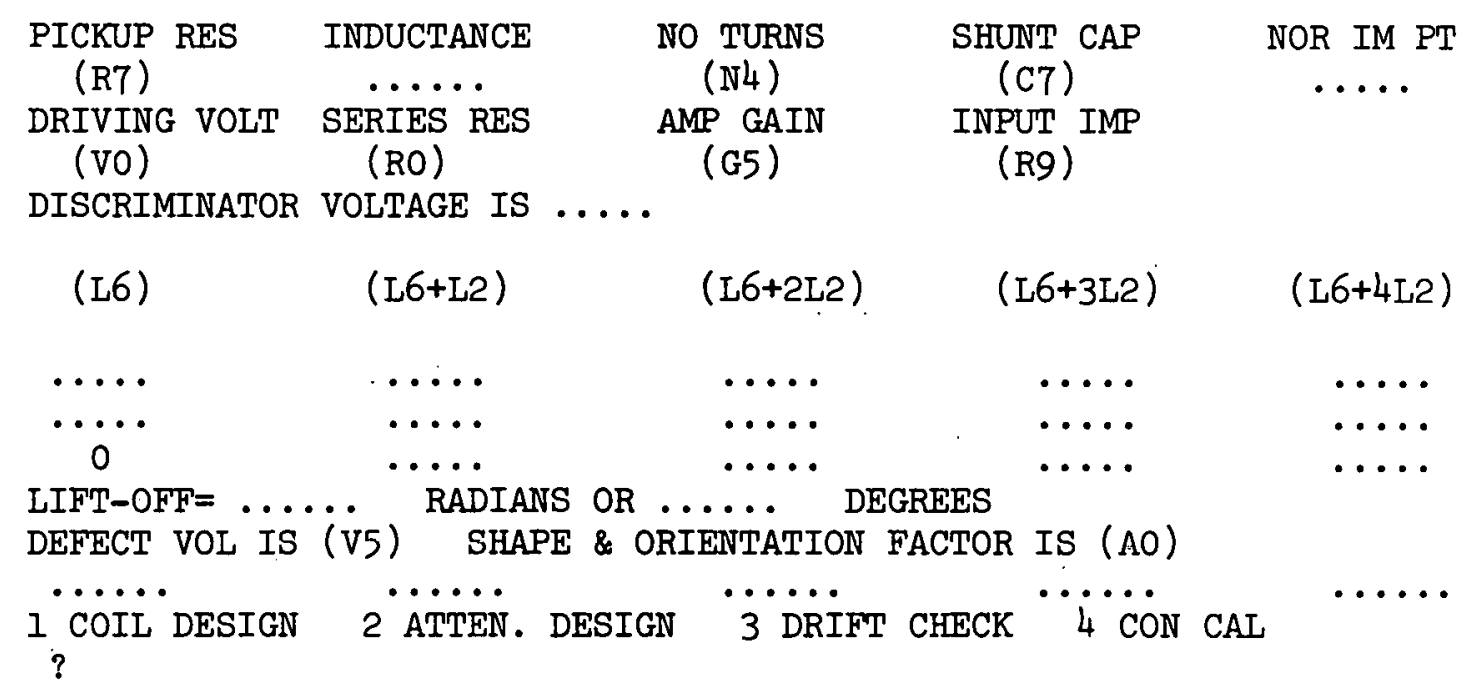

The various symbols enclosed in parentheses are used to indicate that the numerical value of the symbol will be printed.

There are five columns of data, one under each value of lift-off. There are three lines in each column. From top to bottom they are: the magnitude of the voltage out of the pickup amplifier, the phase shift between the voltage out of the pickup amplifier and the driving voltage, and the phase shift between the voltage out of the pickup amplifier with the discriminator set to give the same phase shift with minimum lift-off and maximum lift-off. This set of print-outs is for" the nominal condition of no defects. The voltage out of the pickup amplifier will be in volts and be either peak-to-peak or RMS, whichever is used for Vo, the output voltage of the driving amplifier. For each condurtior $N$, the value of a dimensionless product $R_{5}{ }^{2} \omega \mu_{N} \sigma_{N}$ is also calculated and printed out under the column M,SIGMA. The inductance in henries of the driving coil in air and the normalized imaginary part of the driving coil impedance, with no defect and nominal lift-off $(L 6+2 L 2)$, is also printed. Likewise the inductance in henries of both pickup coils in air and the normalized imaginary part of the pickup coils' impedance with no defect and nominal lift-off is also printed. The maximum phase shift due to lift-off for the nominal condition is given. The location, volume, and shape and orientation factor of the defect are printed. Then, the phase shifts due to the defect are given for five lift-off values. The phase shifts are measured from the nominal condition with no defects and are given in degrees. 
The program then enters a branching loop that allows the following options, depending on which of $1,2,3$, or 4 is typed as input after the question mark.

\section{Coil Design}

If a 1 is typed by the operator after the question mark, the program will enter the Coil Design Loop. This loop will allow the number of turns on the driver and pickup coils to be varied. The loop will allow the wire gage to be given and then calculate the number of turns and coil resistance, or it will allow the number of turns ton he entered and calculate the gage and coil resistance, or hoth turns and gago oan be entered. If zeros are entered for both the gage and turns of either the driver or pickup coils, the present value of these will, be retained. The program then starts with the label

\section{DRIVER RES INDUCTANCE NO TURNS SHUNT CAP NOR IM PT,}

and the remainder of the program is recalculated and printed, with the "new" coil in the circuit. However, the numerical integrations to calculate $M, Z_{D R}$, and $Z_{P U}$ do not have to be repeated.

\section{Ntitinnuntior Design}

This loop will allow the driver series resistance, RO, the driver shunt capacitance, $\mathrm{C} 6$, the amplifier input impedance, $\mathrm{R} 9$, and the shunt capacitance in the pickup circuit, $\mathrm{C7}$, to be varied. If a ? is typer after the question mark the computer will respond with DRIVER SERIES RES, SHUNT CAP, PICK-UP SHUNT RES, SHUNT CAP . The resistance is to be given in ohms, and the capacitance in farads. If zero is typed in for any value, the present value in the computer will be retained. After the input data and a carriage return are typed, the computer will calculate the ratio of resonant frequency to operatine frequency tor the particular I-C circuit, a very rough value of reoiotance for minimum temperature drift, and the ratio between the resistance and reactance in the circuit for both the driver and pickup circuits. The program then starts with the label

\section{DRIVER RES INDUCTANCE NO TURNS SHUNT CAP NOR IM PT,} and the remainder of the program is recalculated and printed with the "new" attenuator in the circuit. Again, the numerical integrations to calculate $M, Z_{D R}$, and $Z_{P U}$ do not have to be repeated. 
3. Drift Check

This loop calculates the effect of the drift of any of the circuit or sample parameters after the instrument has been calibrated and adjusted. If a 3 is typed as input, the program will respond with the precent variation, the parameter varied, the maximum change in phase (both radians and degrees) of any of the five different phases calculated (five lift-off values with the presence of the defect) and the percent of the range the drift represents. The percent variation of each parameter may be varied independently. The following table gives the parameter, the line number, and the constant to be varied:

\begin{tabular}{|c|c|c|}
\hline Parameter & Line Number & Constant \\
\hline Driver Resistance & 8610 & El \\
\hline Pickup Resistance & 8620 & E2 \\
\hline Driver Shunt Cap. & 8630 & E3 \\
\hline Pickup Shunt Cap. & 8640 & E4 \\
\hline Series Resistance & 8650 & E7 \\
\hline Amplifier Input Resistance & 8660 & E8 \\
\hline Applied Voltage & 8670 & E9 \\
\hline Frequency & .8680 & AI \\
\hline Mean Radius & 8690 & A2 \\
\hline
\end{tabular}

For example, to put in a $2 \%$ variation in the driver coil resistance, one would type:

$$
8610 \mathrm{E} 1=.02
$$

The amount that each parameter is varied must be set before the program is run. All of the variations are 0.01 or $1 \%$ in the current version of the program. Since the phase shift produced by the parameter variation is quite linear over a range of about 10\%, a linear interpolation or extrapolation may be used from the $1 \%$ parameter variation. If zero is typed in for any parameter variation, that parameter will not be varied nor will it be typed out in the list of parameter variations. When the calculation is completed and the drifts printed, the program returns to the branch point and repeats the question

1 Coil Design 2 Atten. Design 3 Drift Check 4 Con Cal. 
The first seven drifts do not require that the numerical integrations to calculate $\mathrm{M}, \mathrm{Z}_{\mathrm{DR}}$, and $\mathrm{Z}_{\mathrm{PU}}$ be repeated, but they must be repeated to calculate the drifts due to frequency and mean radius changes. Therefore, the calculation of these last two drifts requires a considerable amount of computer time.

4. Con Cal

This loop is to continue calculations. If a series of calculations is to be made, a loop may be established at this point. However, in the present version of the program, if a 4 is typed as input, the program will end.

\section{Sample Calculation of MULTID}

Let us suppose we wish to design a reflection-type coil to measure a defect in a sodium layer that has a thickness of $10 \mathrm{mils}$ and a resistivity of $4.99 \mu \Omega-\mathrm{cm}$. Above the sodium layer, there is a conductor 15 mils thick with a resistivity of $75 \mu \Omega-\mathrm{cm}$. Below the sodium layer, there is a very thick material with a resistivity of $130 \mu \Omega-\mathrm{cm}$. The driver coil has a mean radius of $0.06^{\circ}$ in., inner and oules rauts of 0.045 and $0.075 \mathrm{in.}$, and a length of $0.018 \mathrm{in.}$ The pickup coils have inner and outer radii of 0.021 and 0.04 ' in., a length of $0.006 \mathrm{in.}$, and are mounted flush with the ends of the driver coil. The driver coil has 252 turns of No. 48 wire with a resistance of $59.06 \Omega$, and the pickup coils have 450 turns each of No. 58 wire with a resistance of $1067.4 \Omega$ for both coils. The driver series and the pickup amplifier input resistances are both chosen to be $1 \mathrm{M} \Omega$. The shunt capacitances in both circuits are chosen to be $1 \mathrm{pF}$. This corresponds to practically infinite source and detector impedances, so that only the mutual coupling, $M$, affects the phases. The minimum lift-off is taken to be 0.003 in. with lift-off increments of 0.00075 in. The defect is located 5 mils below the surface of the sodium layer and $60 \mathrm{mils}$ from the axis of the coil. The defect is a spherical defect with a radius of 2.5 mils. 
Thus, the shape and orientation factor is equal to one. Other shape and orientation factors are given elsewhere. 11

The frequency is $100 \mathrm{KHz}$, the output voltage of the driving amplifier is $10 \mathrm{~V}$, and the gain of the pickup amplifier is unity (a unity gain allows the actual gain needed in the amplifier to be calculated by dividing the maximum output voltage with unity gain into 10).

The program MULTID is assumed to be in the active core, and the following information is typed into the computer. All linear dimensions are normalized by dividing by the coil mean radius, except for the coil mean radius, which is in inches.

$\begin{array}{ll}250 & \mathrm{R} 5=.06 \\ 260 & \mathrm{R} 1=.75 \\ 270 & \mathrm{R} 2=1.25 \\ 280 & \mathrm{~L} 3=.3 \\ 290 & \mathrm{R} 3=.35 \\ 300 & \mathrm{R} 4=.7 \\ 310 & \mathrm{~L} 4=.1 \\ 320 & \mathrm{~L} 5=0 \\ 330 & \mathrm{~L} 6=.05 \\ 340 & \mathrm{R} 6=59.06 \\ 350 & \mathrm{R} 7=1067.4 \\ 360 & \mathrm{~N} 3=252 \\ 370 & \mathrm{~N} 4=450 \\ 380 & \mathrm{R} 0=1 . \mathrm{F} 6 \\ 390 & \mathrm{R} 9=1 \mathrm{E} 6 \\ 400 & \mathrm{C} 6=1 \mathrm{E}-12 \\ 410 & \mathrm{C} 7=1 \mathrm{E}-12 \\ 420 & \mathrm{VO}=10 \\ 430 & \mathrm{G} 5=1 \\ 440 & \mathrm{~F}=100 \mathrm{E} 3 \\ 450 & \mathrm{~L} 2=.0125\end{array}$

${ }^{11}$ C. V. Dodd, W. E. Deeds, J. W. Luquire, and W. G. Spoeri, Some Eddy-Current Problems and Their Integral Solutions, ORNL-4.384 (April 1969). 


$\begin{array}{ll}760 & \text { R8 }=1 \\ 770 & \text { Z7 }=.005 \\ 780 & \text { V5 }=3.030811 E-4 \\ 790 & \text { AO }=1 \\ 800 & \text { DATA } 1 E 10,130,1 \\ 810 & \text { DATA } .01,4.99,1 \\ 820 & \text { DATA } .015,75,1 \\ 830 & \text { DATA } 1,1 \mathrm{E} 10,1\end{array}$

The program may now be run with the following results. The data inputed from the terminal by the user are underlined. A carriage return must be typed by the user at the end of each input line. 
MULT ID (BASIC)

$\begin{array}{ccccc}N & \text { THICK(INCH) } & \text { R(MU-OHM CM) } & \text { M.SIGMA } & \text { U } \\ 1 & 1.00000 E+10 & 130 & 1.41065 & 1 \\ 2 & 0.01 & 4.99 & 36.7503 & 1 \\ 3 & 0.015 & 75 & 2.44512 & 1 \\ 4 & 1 & 1.00000 E+10 & 0 & 1 \\ R 1=0.75 & R 2=1.25 & \text { DRIVER LENGTH IS } 0.3 & \\ R 3=0.35 & R 4=0.7 & \text { PICK UP LENGTH IS } 0.1 & \\ \text { COIL MEAN RADIUS } 0.06 \text { INCHES } & \text { OPERATING FREQUENCY } 100000\end{array}$

PICK UP RECESSED 0

MIN LIFT-OFF $=0.05$ LIFT- DFF INCREMENT $=0.0125$

DEFECT LOCATED AT $R=0.06$ INCHES AND

$z=0.005$ INCHES BELOW SURFACE OF 2 TH LAYER

$\begin{array}{lcccc}\text { DRIVER RES } & \text { INDUCTANCE } & \text { NO TURNS } & \text { SHUNT CAP } & \text { NOR IM PT } \\ \text { 59.06 } & 2.22053 E-4 & 252 & 1.00000 E-12 & 0.827304 \\ \text { PICKUP RES } & \text { INDUCTANCE } & \text { NO TURNS } & \text { SHUNT CAP } & \text { NOR IMPT } \\ 1067.4 & 3.20001 E-4 & 450 & 1.00000 E-12 & 0.991584 \\ \text { DRIVING VELT } & \text { SERIES RES } & \text { AMP GAIN } & \text { INPUT IMP } & \\ 10 & 1000000 & 1 & 1000000 & \end{array}$

DISCRIMINATER VELTAGE IS- $1.86118 E-6$

$\begin{array}{lllll}0.05 & 0.0625 & 0.075 & 0.0875 & 0.1 \\ 5.66040 E-5 & 5.41995 E-5 & 5.19010 E-5 & 4.97043 E-5 & 4.76056 E-5 \\ -0.994593 & -0.995917 & -0.997404 & -0.99 .9041 & -1.00081 \\ 0 & 1.36040 E-4 & 1.70328 E-4 & 1.19887 E-4 & 1.49012 E-8\end{array}$

LIFT-OFF = $1.70328 E-4$ RADIANS OR 9.75907E-3 DEGREES

DEFECT VOL IS $3.03081 E-4$ SHAPE \& ORIENTATION FACTOR IS 1

$-9.42610 E-3 \quad-9.44360 E-3 \quad-9.45769 E-3 \quad-9.46964 E-3 \quad-9.47690 E-3$

1 COIL DESIGN 2 ATTEN. DESIGN 3 DRIFT CHECK 4 CON CAL ?

DRIVER WIRE GAGE, TURNS, PICK-UP WIRE GAGE, TURNS

$748,0,58,0$

DRIVER 252 TURNS OF 48 WIRE 12 /LAYER 21 LAYERS 53.1236 OHM

PICKUP 598 TURNS EA 58 WIRE 13 /LAYER 46 LAYERS 1344.82 OHMS TOTAL

DRIVER RES INDUCTANCE NO TURNS SHUNT CAP NOK IM PT

2.22053E-4 252

PICKUP RES INDUCTANCE NO TURNS SHUNT CAP NOR IM PT

$\begin{array}{llllll}1344.82 & 5.65105 E-4 & 598 & 1.00000 E-12 & 0.991584\end{array}$

DRIVING VỌLT SERIES RES AMP GAIN INPUT IMP

$10 \quad 1000000 \quad 11000000$

DISCRIMINATOR VOLTAGE IS $-2 \cdot 47288 E-6$

$\begin{array}{lllll}0.05 & 0.0625 & 0.075 & 0.0875 & 0.1 \\ 7.52070 E-5 & 7.20124 E-5 & 6.89584 E-5 & 6.60399 E-5 & 6.32514 E-5 \\ -0.994917 & -0.996241 & -0.997728 & -0.999364 & -1.00114 \\ 0 & 1.36048 E-4 & 1.70335 E-4 & 1.19887 E-4 & 1.49012 E-8\end{array}$

LIFT-OFF $=1.70335 E-4$ RADIANS BR 9.75949E-3 DEGREES

DEFECT VOL IS 3.0308IE-4 SHAPE \& ORIENTATION FACTOR IS 1

$-9.42524 E-3 \quad-9.44360 E-3 \quad-9.45854 E-3 \quad-9.46836 E-3 \quad-9.47604 E-3$

1 COIL DESIGN 2 ATTEN. DESIGN 3 DRIFT CHECK 4 CON CAL $3 \underline{2}$ 
DRIVER SERIES RES, SHUNT CAP, PICK-UP SHUNT RES, SHUNT CAP

?8.OE2,1.3E-10,3.3E3,7.9E-11

DUR CT 10.2988 BELOW RES 1188.75 EPT KES 6.93088 RES/REACTANCE

P-U CT 7.56445 BELOW RES 2663.27 OPT RES 9.37293 KES/KEACTANCE

DRIVER RES INDUCTANCE NO TURNS

$53.1236 \quad 2.22053 E-4 \quad 252$

$\begin{array}{ccc}P I C K U P \text { RES } & \text { INDUCTANCE } & \text { ND TURNS } \\ 1344.82 & 5.65105 E-4 & 598\end{array}$

DRIVING VOLT SERIES RES . AMP GAIN

10

800

1

SHUNT CAP NOR IM PT

$1.30000 E-10 \quad 0.827304$

SHUNT CAP NOK IM PT

7.90000E-11 0.991584

D ISCRIMINATER VELTAGE IS $-3 \cdot 37434 E-3$

INPUT IMP

3300

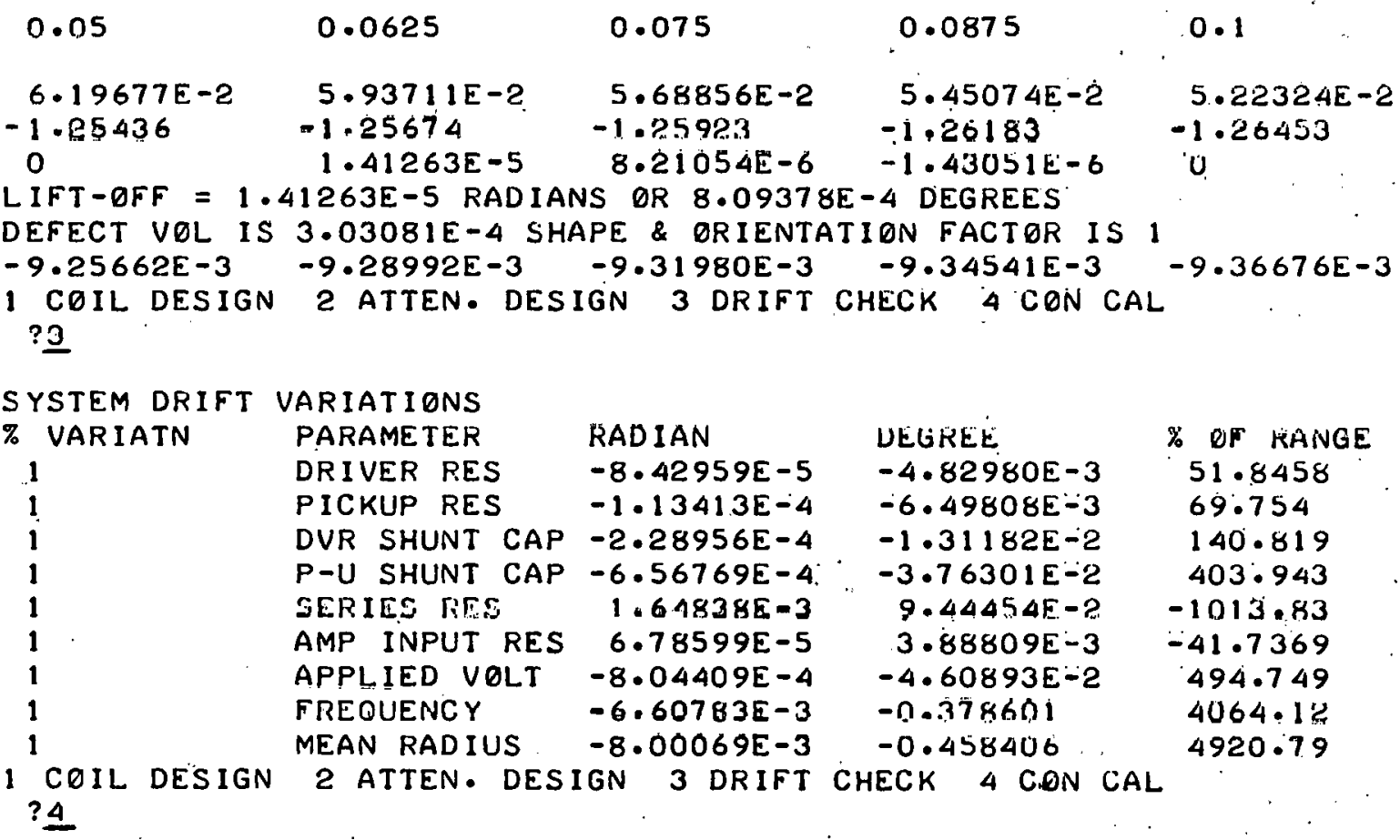

The user has exercised all the design options available, and these options may be repeated, omitted, or taken in any order. The BASIC version of the program MULTID follows. 


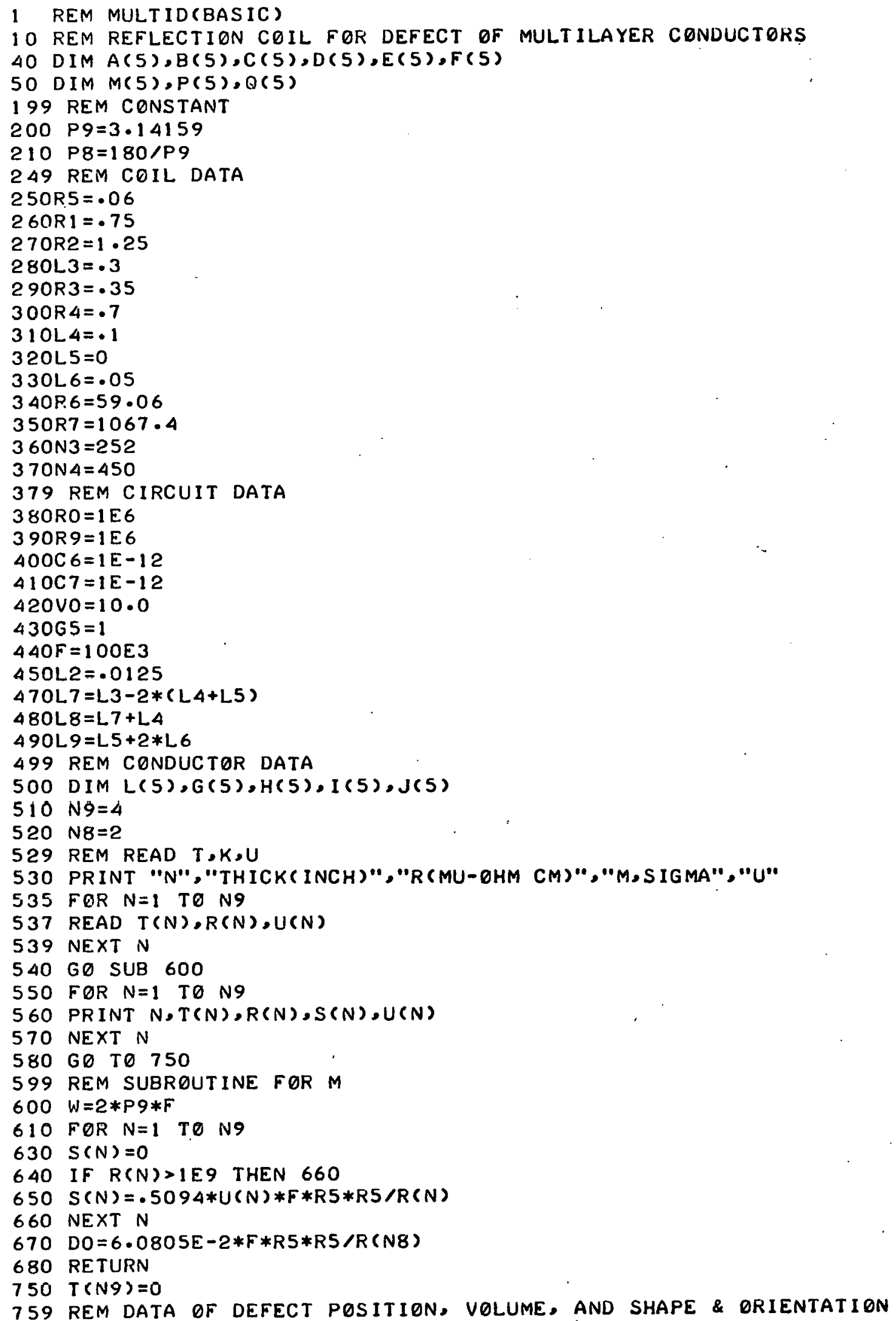




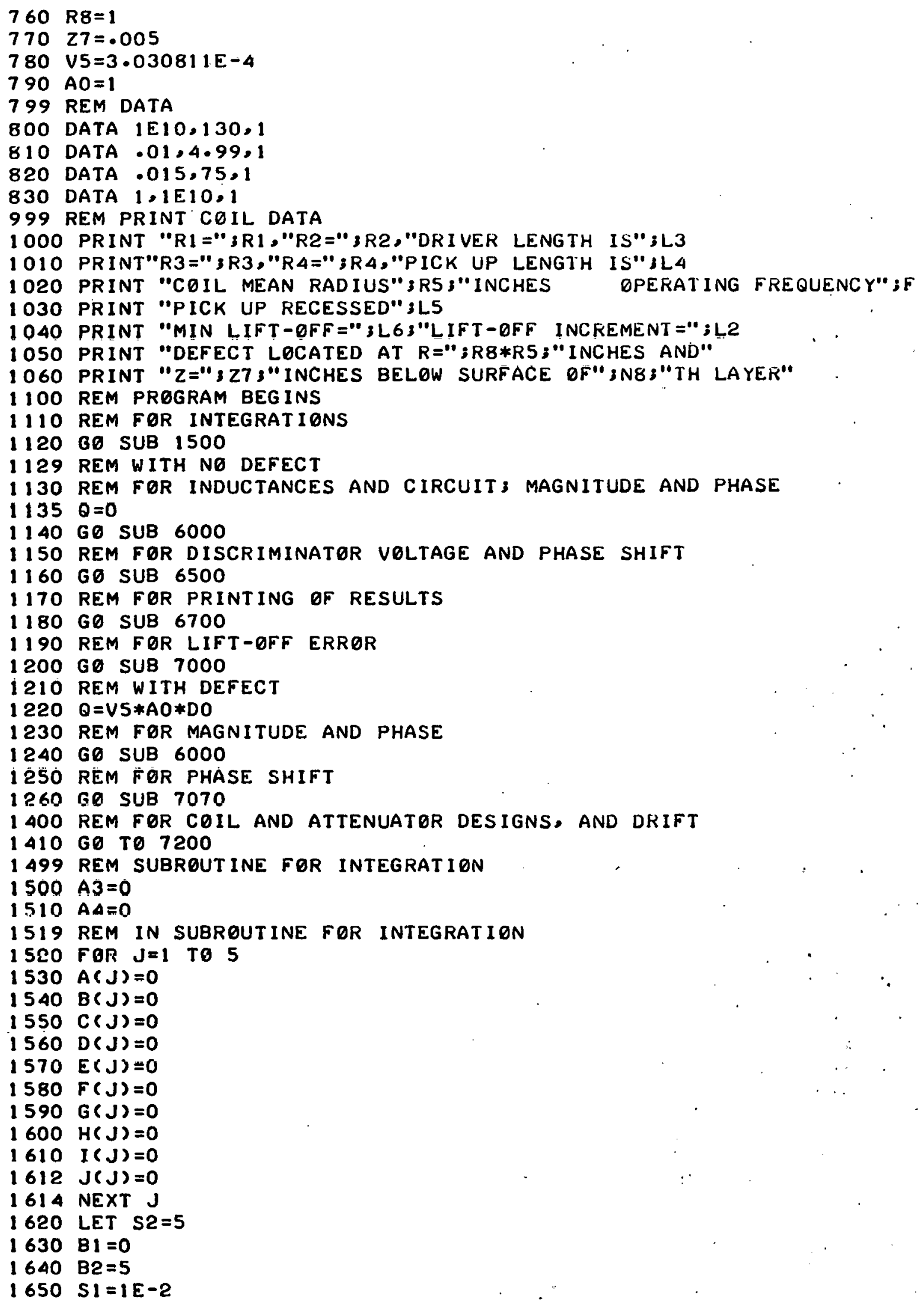




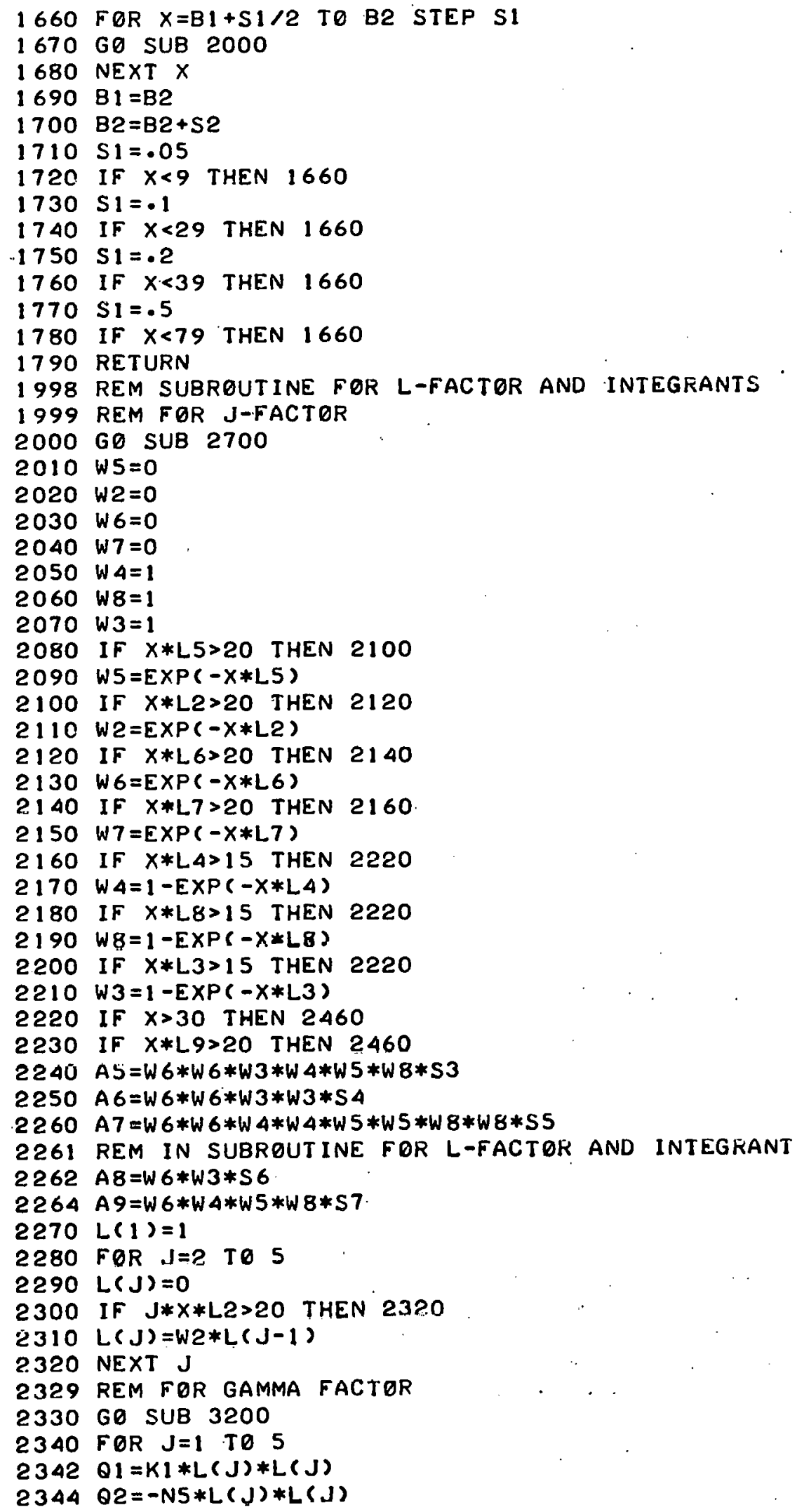




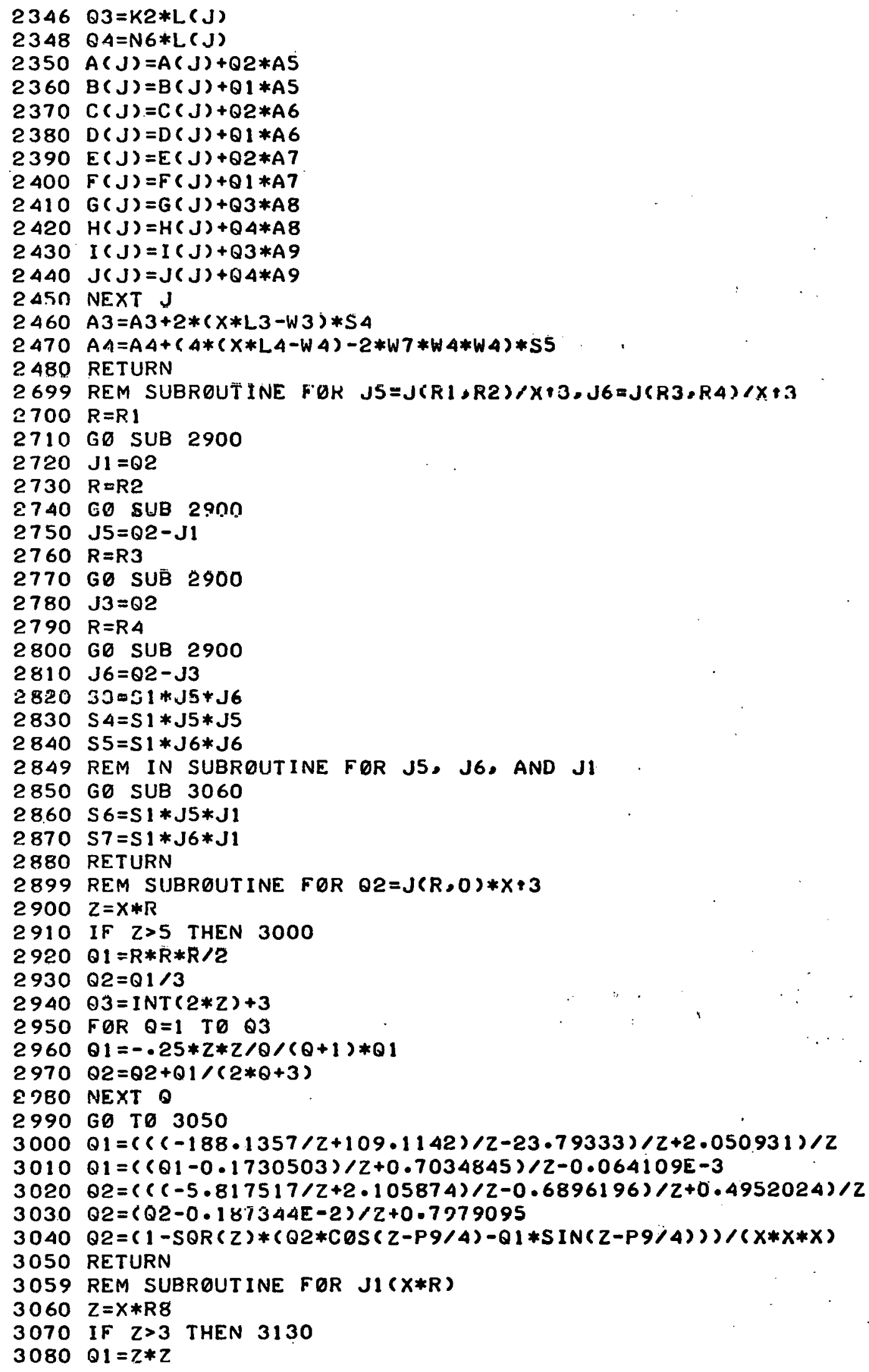









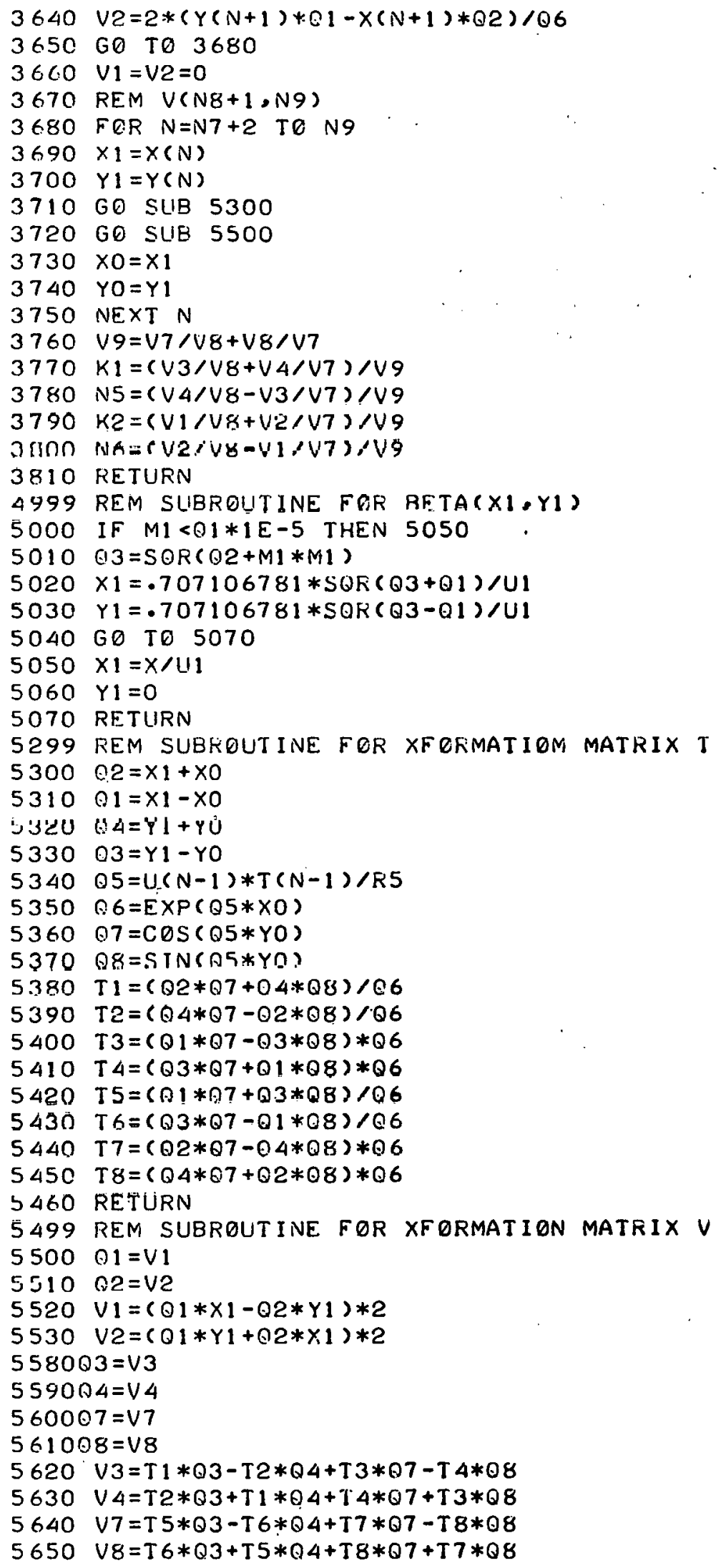




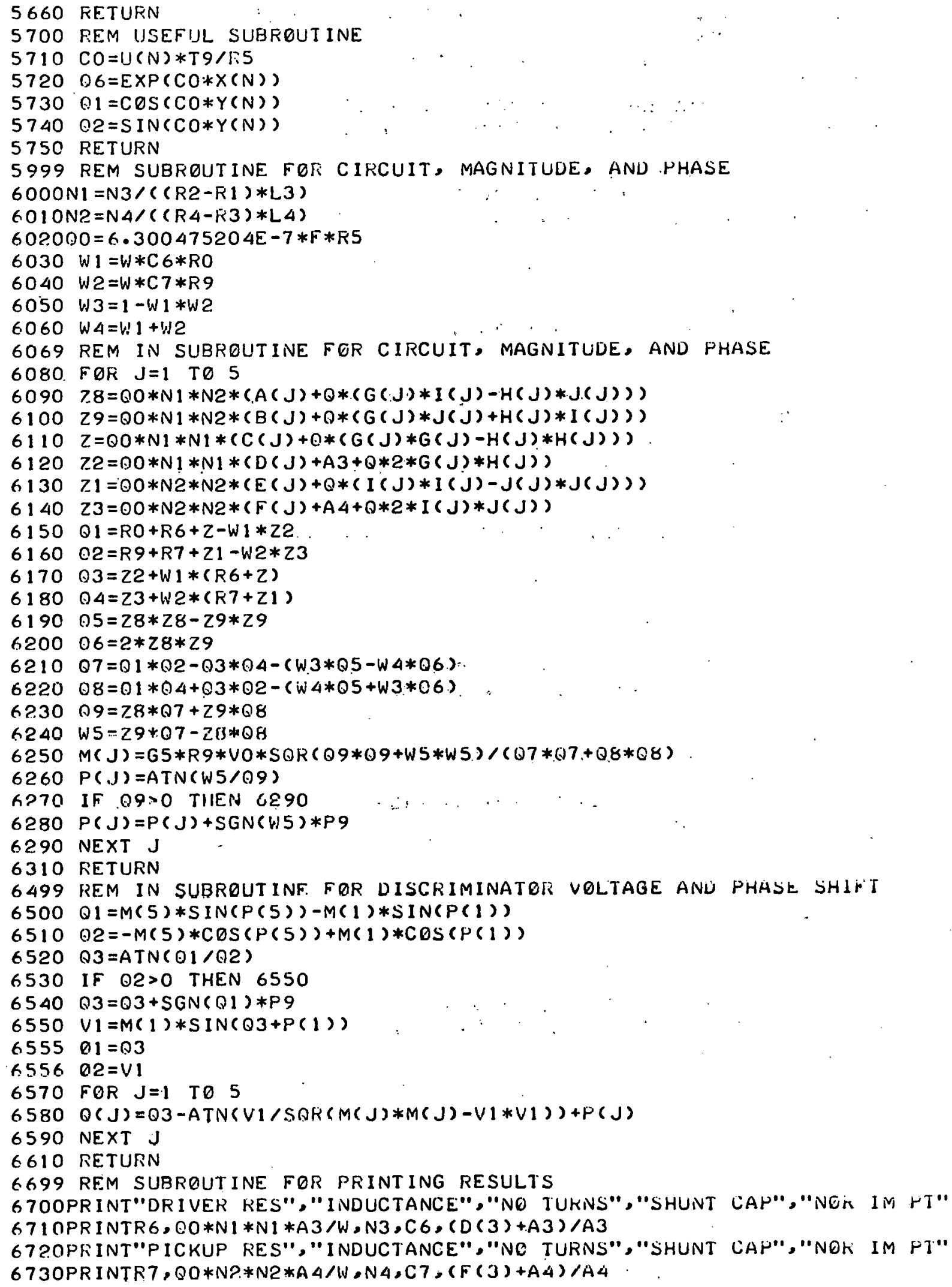


$6740 P R I N T$ "DRIVING VØLT","SERIES RES","AMF GAIN","INPUT IMP" 675OPRINTVO, RO, G5, R9

676OPRINT "DISCRIMINATOR VOLTAGE IS";VI

6770 PRINT

6780 PRINT L $6, L 6+L 2, L 6+2 * L 2, L 6+3 * L 2, L 6+4 * L 2$

6789 REM IN SUBRØUTINE FOR PRINTING RESULTS

6800 PRINT

6810 PRINT $M(1), M(2), M(3), M(4), M(5)$

6820 PRINT $P(1), P(2), P(3), P(4), P(5)$

6830 PRINT $Q(1), O(2), \theta(3), 0(4), Q(5)$

6850 RETURN

6999 REM SUBRøUTINE FER LIFT-OFF

$7000 \quad 01=0(1)$

$7010 \mathrm{~F} \emptyset \mathrm{R} \mathrm{J}=2 \mathrm{TO} 5$

7020 IF $A B S\left(Q_{1}\right)>A B S(\theta(J))$ THEN 7040

$7030 \quad Q 1=Q(. J)$

7040 NEXT J

7050 PRINT "LIFT-OFF =";01;"RADIANS OR" $301 * P 8 ; " D E G R E E S "$

7060 RETURN

7069 REM SUBROUTINE FOR PHASE SHIFT

7070 PRINT"DEFECT VOL IS";V5;"SHAPE \& ORIENTATIEN FACIGR IS" "3AO

$7080 \quad 03 \div 0$

7090 FØR $J=1$ TØ 5

$7100 \quad Q 1=01-A T N\left(V_{1} / S Q R(M(J) * M(J)-V 1 * V 1)\right)+P(J)-Q(J)$

$7110 \quad Q 2=Q 2+Q 1$

7120 PRINT $01 * P 8$,

7130 NEXT J

$7140 \quad 0=02 / 5$

7150 RETURN

7199 REM FGR COIL DESIGN, ATTENUATOR; DRIFT, AND EXIT

$7200 P R I N T " 1$ COIL DESIGN 2 ATTEN. DESIGN 3 UKIFI CHECK 4 CON CAL" 7210 INPUT NS

7 ER:OTRINT

$73300 N$ NG FI TO 7300,8200,8600,9900

72.99 REM FOR COIL DESIGN

7300 PRINT "DRIVEK WIRE GAGE, TURNS, PICK-UP WIRE GAGE, TURNS"

7310 INPUT $Q 1,02,03,04$

7319 REM FOR DRIVER

$7320 \quad W 1=R 1$

$7330 \quad W 2=R 2$

7340 W $3=L 3$

7350 GO SUB 7510

7360 N3 $=02$

$7370 R 6=09$

7380 PRINT "DRIVER"; N33"TUKNS OF \#" 3 G "WIKE",

7390 PRINT D7;"/LAYER"; Q8;"LAYERS" 356;"OHM"

7399 REM FOR PICKUP

$7400 \quad Q 1=03$

$7410 \quad 02=04$

$7420 W 1=R 3$

7430 W2 $=R 4$

7440 W $3=L 4$

7450 GO SUB 7510

$7460 \mathrm{~N} 4=\mathrm{Q} 2$

$7470 \quad R 7=2 * Q 9$

7480 PRINT "PICKUP"' ;N4;"TURNS EA \#";G3"WIRE";

7490 PRINT 67;"/LAYEF";08;"LAYERS"3R73"OHMS TOTAL"

7500 GO TO 1135 
7509 REM SUBREIIT INE. FOR GAGE AND TURN NUMBER

$7510 \quad 41=: 1 * 1 * 15$

$7520 \quad W 2=1: 2 * R 5$

7530 ! $3=\div 3 * R 5$

7539 REM FOR GAGE

$7540 \quad G=01$

7550 IF G>.5 THEN 7640

$7560 \quad 05=.95 * \operatorname{seri}((W 2-W 1) * 13 / 02)$

$7570 \quad 06=1.0371 \mathrm{E}-5 / 05 / 05$

$7580 \quad G 0=40$

$7590 G=40+10 *(\operatorname{LOG}(06)-\operatorname{LOG}(.9989+.017 *(G 0 / 10-1))) / 2.30259$

7600 IF $A B S(G-G 0)<1 E-4$ THEN 7630

$7610 \quad 60=G$

7620 GO TO 7590

$7630 \mathrm{G}=1 \mathrm{NT}(\mathrm{G})$

7639 REM FOR TURN NIJMBER AND $R 6$

$7640 \quad \theta 6=(.9989+.017 *(G / 10-1)) * 10+(G / 10-4)$

$765 C \quad 05=\operatorname{S} Q R(1.0371 E-5 / 06)$

7660 IF G> 40 THEN 7690

7670 QS $=(.460655 * \operatorname{LQG}(\theta 5 * 1 E 3)-.43444) * 1 E-3+Q S$

7680 GO TO 7700

$7690 \quad \triangle 5=(98 \cdot 02228 * 85+2 \cdot 56791 \mathrm{E}-2) * 1 \mathrm{E}-3+Q 5$

$7700 \quad \theta 7=I N T(W 3 / 05)$

$7710 \quad 08=\operatorname{INT}((W 2-W 1) / 05)$

7720 IF $Q 2>.5$ THEN 7740

$7730 \quad 02=\Omega 7 * \Omega 8$

$7740 \quad 89=02 * 06 *(W 2+W 1) * \mathrm{~F} 9 / 12$

7750 RETURN

8199 REM FOR ATTENUATOR DESIGN

8200 PRINT "DRIVER SERIES RES, SHUNT CAP, PICK-UP SHUNT RES, SHUNT CAP"

8210 INPUT $Q 1,02, Q 3,04$

8220 IF $O 1=0$ THEN 8240

$8230 \mathrm{RO}=01$

8240 IF $O 2=0$ THEN 8260

$8250 \mathrm{C} 6=02$

8200 IF $03=0$ THEN 8280

$8270 R 9=03$

8280 IF $Q 4=0$ THEN 8300

$8290 \quad \mathrm{C} 7=04$

$8300 \quad Q 1=Q 0 * N 1 * N 1 *(D(3)+A 3) / W !$

$8310 \quad 02=00 * N 2 * N 2 *(F(3)+A 4) / W$

8320 PRINT "DVR CT";1/(W*SOR(Q1*C6)),3"BELOW RES";

8330 PRINT SOR $(01 / C 6) 3 " O P T$ RES";RO/(W*Q1) 3"RES/REACTANCE".

8340 PRINT "P-U CT"; $1 /(W * S Q R(Q 2 * C 7))$;"BELOW RES";

8350 PRINT SOR(O2/C7);"OPT RES";R9/(W*Q2);"RES/REACTANCE"

$8360 \dot{G O} \mathrm{TO} 1135$

8599 REM FOR DKIFTS

8600 PRINT"SYSTEM DRIFT VARIATIONS"

$8610 E 1=.01$

$8620 E 2=.01$

$8630 E 3=.01$

$8640 E 4=.01$

$8650 \quad E 7=.01$

$8660 E 8=.01$

8670 E9 $=.01$

$8680 A 1=.01$

8690 A2 $=.01$

8710 PRINT "\% VARIATN", "PARAMETER","RADIAN", "DEGREE","\% GF KANGE"

8720 IF $E 1=0$ THEN 8770 


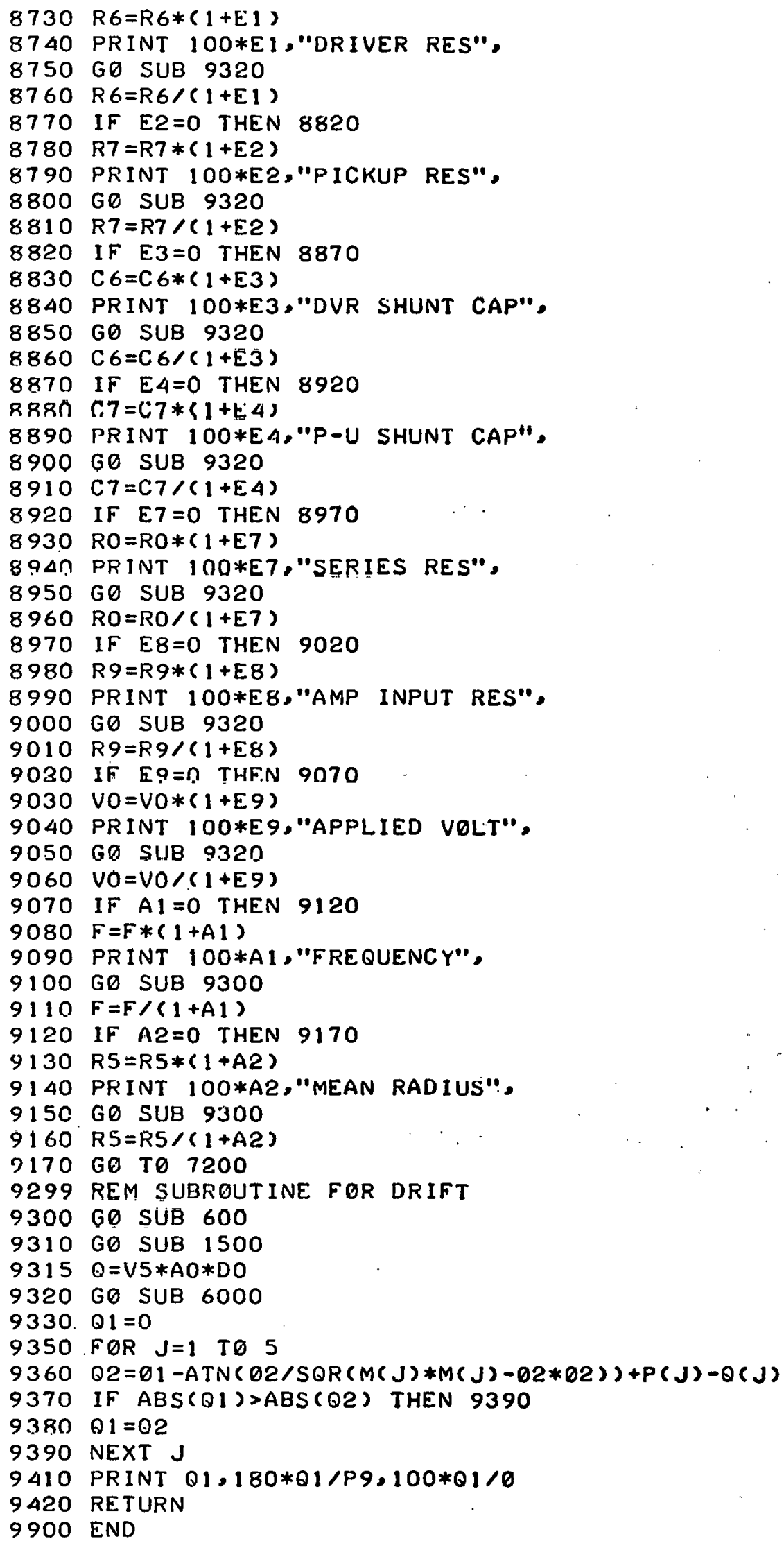


MULTID; FORTRAN Version

The FORTRAN version of MULTID is very similar to the BASIC version. The line numbers given are only for identification and editing purposes and have no effect on the actual execution of the FORTRAN program. The data must be typed in the seventh column, or six spaces must first be typed. The data are input as follows:

\begin{tabular}{|c|c|}
\hline 00250 & $\mathrm{R} 5=($ coil mean radius in inches $)$ \\
\hline 00260 & $\mathrm{Rl}=$ (normalized inner radius of driver coil) \\
\hline 00270 & $\mathrm{R} 2=$ (normalized outer radius of driver coil) \\
\hline 00280 & L3 $=$ (normalized length of driver coil) \\
\hline 00290 & $\mathrm{R} 3 \mathrm{C}=$ (normalized inner radius of pickup coil) \\
\hline 00300 & $\mathrm{R} 4=$ (normalized outer radius of pickup coil) \\
\hline 00310 & L4 = (normalized length of pickup coil) \\
\hline 00320 & $\begin{aligned} \mathrm{L} 5= & \text { (normalized length of recess of each pickup coil from } \\
& \text { the face of the driver coil) }\end{aligned}$ \\
\hline 00330 & L6 = (normalized minimum lift-off of the driver coil) \\
\hline 00340 & $\mathrm{R} 6=$ (resistance of driver coil in ohms) \\
\hline 00350 & $\mathrm{RT}=$ (resistance of both pickup coils in ohms) \\
\hline 00360 & N3 = (number of turns on the driver coil) \\
\hline 00370 & N4 = (number of turns on each pickup coil) \\
\hline 00380 & RO = (driver amplifier series resistance in ohms) \\
\hline 00390 & $\mathrm{R} 9=$ (pickup amplifier shunt resistance in ohms) \\
\hline 001,00 & $66=$ (ohunt capaeitance of ariver clrcult in farads) \\
\hline 00410 & $\mathrm{C7}=$ (shunt capacitance of pickup circuit in farads) \\
\hline 00420 & vo $=$ (output voltage in volts) \\
\hline 00430 & G5 = (amplifier gain) \\
\hline 00440 & $F=$ (operating frequency in Hertz) \\
\hline 00450 & L2 = (normalized lift-off increment of the driver coil) \\
\hline 00510 & N9 = (total number of conductors +1$)$ \\
\hline 00520 & $N 8=$ (number of the specific conductor with a defect) \\
\hline 00540 & DATA RHO/(resistivities in micṛohm-cm)/ \\
\hline 00550 & DATA U/(permeabilities)/ \\
\hline & DATA $T /($ thicknesses in inches $) /$ \\
\hline
\end{tabular}


$00580 \quad \mathrm{R} 8=$ (normalized defect distance from coil axis)

$00590 \mathrm{Z7}=$ (defect distance below the surface of the N8-th layer in inches)

$00600 \quad$ V5 $=$ (normalized defect volume)

$00610 \quad \mathrm{Al}=$ (shape and orientation factor of defect)

The current version of MULTID.F4 is limited to a maximum of nine conductors. However, this limitation can be removed easily by changing one DIMENSION statement:

OOIIO DIMENSION T(N9), U(N9), RHO(N9), M(N9), BETA(N9) .

The print-out of the FORI'RAN version of MULTID is practicaliy identical to the BASIC version and will not be repeuted. The main diffcr ence is that the question mark is not printed out when the program is ready to accept data. The Coil Design, Attenuator Design, Drift Check, and Continue Calculations options are the same. The line numbers, constant names, and parameter varied in the drift calculations are as follows:

\begin{tabular}{|c|c|c|}
\hline Line Number & Cunstänt & Purumbtoi: Variod \\
\hline 04380 & $\mathrm{DRI}$ & Driver Resistance \\
\hline 04390 & DR2 & Pickup Resistance \\
\hline 04400 & DR3 & Driver Shunt Capacitance \\
\hline 04410 & DR4 & Pickup Shunt Capacitance \\
\hline nLLan & DR5 & Series Resistance \\
\hline 011130 & DR6 & Amplifier Input Resistance \\
\hline 04440 & DR7 & Applied Voitage \\
\hline 011150 & nRR & Frequency \\
\hline 04460 & DR9 & Mean Radius \\
\hline
\end{tabular}

For example, to vary the driver resistance by $2 \%$ one would type: $04380 \quad D R I=0.02$

As in the BASIC version, the last two drifts require that the entire numerical integration be repeated and are relatively long running. If any of the drifts is set equal to zero, it will be omitted from the drift calculations. 


\section{Sample Calculation of MULTID.F4}

Let us suppose that we wish to design a reflection-type coil, identical to the one designed by the BASIC version. We put the following data in the program (generally by using the EDIT MULTID.F4 command on the PDP-10 and inserting the statements). All linear dimensions are normalized by dividing by the coil mean radius, except the coil mean radius, which is in inches:

$\begin{array}{ll}00250 & \text { R5 }=.06 \\ 00260 & \text { R1 }=.75 \\ 00270 & \text { R2 }=1.25 \\ 00280 & \text { L3 }=.3 \\ 00290 & \text { R3 }=.35 \\ 00300 & \text { R4 }=.7 \\ 00310 & \text { L4 }=.1 \\ 00320 & \text { L5 }=0.0 \\ 00330 & \text { L6 }=.05 \\ 00340 & \text { R6 }=59.06 \\ 00350 & \text { R7 }=1067.4 \\ 00360 & \text { N3 }=252.0 \\ 00370 & \text { N4 }=450.0 \\ 00380 & \text { RO }=1.0 \mathrm{E} 6 \\ 00390 & \text { R9 }=1.0 \mathrm{E} 6 \\ 00400 & \text { C6 }=1.0 \mathrm{E}-12 \\ 00410 & \text { C7 }=1.0 \mathrm{E}-12 \\ 00420 & \text { V0 }=10.0 \\ 00430 & \text { G5 }=1.0 \\ 00440 & \text { F }=1.0 \mathrm{E} 5 \\ 00450 & \text { L2 }=.0125 \\ 00510 & \text { N9 }=4 \\ 00520 & \text { N8 }=2 \\ 0010\end{array}$




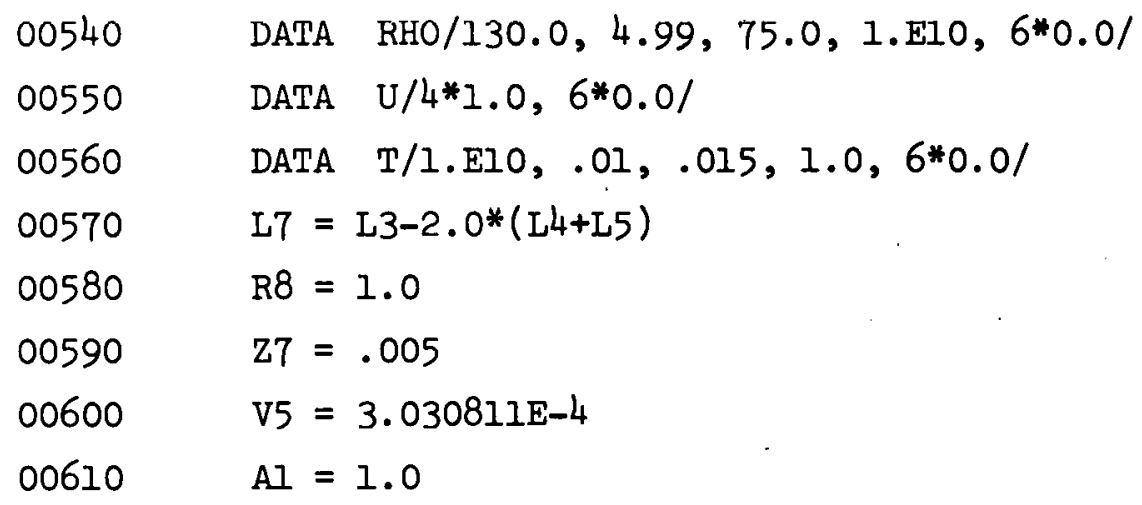

The FORTRAN program may now be executed. The print-out will be essentially identical to the BASIC print-out and will not be repeated. The FORTRAN version of MULTID follows. 
OOOIOC THIS PROGRAM EVALUATES THE SENSITIVITY TO A DEFECT

OOO2OC LOCATED IN ANY GIVEN LAYER OF A MULTI-LAYERED MATERIAL 00030

00040

00050

00060

00070

00080

00090

00100

00110

00120

00130

00140

00150

00160

00170

$00180 \mathrm{C}$

$00190 \mathrm{C}$

$00200 \mathrm{C}$

$00210 \mathrm{C}$

00220

$00230 \mathrm{C}$

$.00240 \mathrm{C}$

00250

00260

00270

00280

00290

00300

00310

00320

00330

00340

00350

00360

00370

00380

00390

0.040 n

00410

00420

00430

00440

00450

$00460 \mathrm{C}$

$00470 \mathrm{C}$

$00490 \mathrm{C}$

$00500 \mathrm{C}$

00510

00520

00530

00540

00550

00560

00570

00580

COMPLEX BETAO,BETA1, BETA, V,TR,GAMMA 1, GAMMA 2 , MUT

COMPLEX DRIVER, PICKUP, GH, IJ,EX

COMMON $X, Z, Q 1, P I / B 1 / B E T A O, B E T A 1$

$C O M M \emptyset N / B 2 / R 1, R 2, R 3, R 4, L 3, L 4, R O, R 6, R 7, R 9, C 6, C 7$

COMMØN /B2/VO,G5,W,F,R5,N3,N4/B3/MUT, DRIVEK

COMMON /B3/PICKUP,AIR1, AIRZ/B4/GAGE, XIN, XOUT

COMMON /B 4/XLEN, TURNS, NIA, J1, PERLAY, XLAY

COMMON /B3/GH,IJ/BS/VS,AI,DO

DIMENSION $T(10), U(10), R H E(10), M(10), B E T A(1,0)$

DIMENSION $V(2,2), T R(2,2), D R I V E R(5)$

DIMENSION PICKUP (5), RL (5), TMAG (5), PHASE ( 5 )

DIMENSION SHIFT (5), MUT (5), GH(5), IJ(5)

REAL L2,L3,L4,LS,L6,L7,M,N3,N4

$P I=3 \cdot 1415926536$

$R A D=180 \cdot 0 / P I$

$J K L=0$

THE FOLLOWING ARE INPUT DATA FOR THE PARAMETERS OF THE COIL, MATERIALS, AND. CIRCUIT

$$
\begin{aligned}
& R 5=.06 \\
& R 1=.75 \\
& R 2=1.25 \\
& L 3=.3 \\
& R 3=.35 \\
& R 4=.7 \\
& L 4=.1 \\
& L 5=0.0 \\
& L G=.05 \\
& R 6=59.06 \\
& R 7=1067.4 \\
& N J=252.0 \\
& N 4=450.0 \\
& R O=1.0 E 6 \\
& R 9=1.0 E 6 \\
& C 6=1.0 E-12 \\
& C 7=1.0 E-12 \\
& V 0=10.0 \\
& G 5=1.0 \\
& F=1.0 E 5 \\
& L 2=.0125
\end{aligned}
$$

N9 IS THE TOTAL NUMBER OF LAYERS, INCLUDING THE CEIL

ZONE, AND N\& IS THE LAYER IN WHICH THE DEFECT IS LECALED

$N 9=4$

$N 8=2$

IF (N9.LT.2.0R・N8.GE・N9) GO TO 1010

DATA RHO/130.0,4.99,75.0,1.E10,6*0.0/

DATA U/4*1.0.6*0.0/

DATA $T / 1 . E 10, .01,0015,1.0,6 * 0.0 /$

$L 7 \equiv L, 3-2.0 *(L 4+L 5)$

$R E=1 \cdot 0$ 


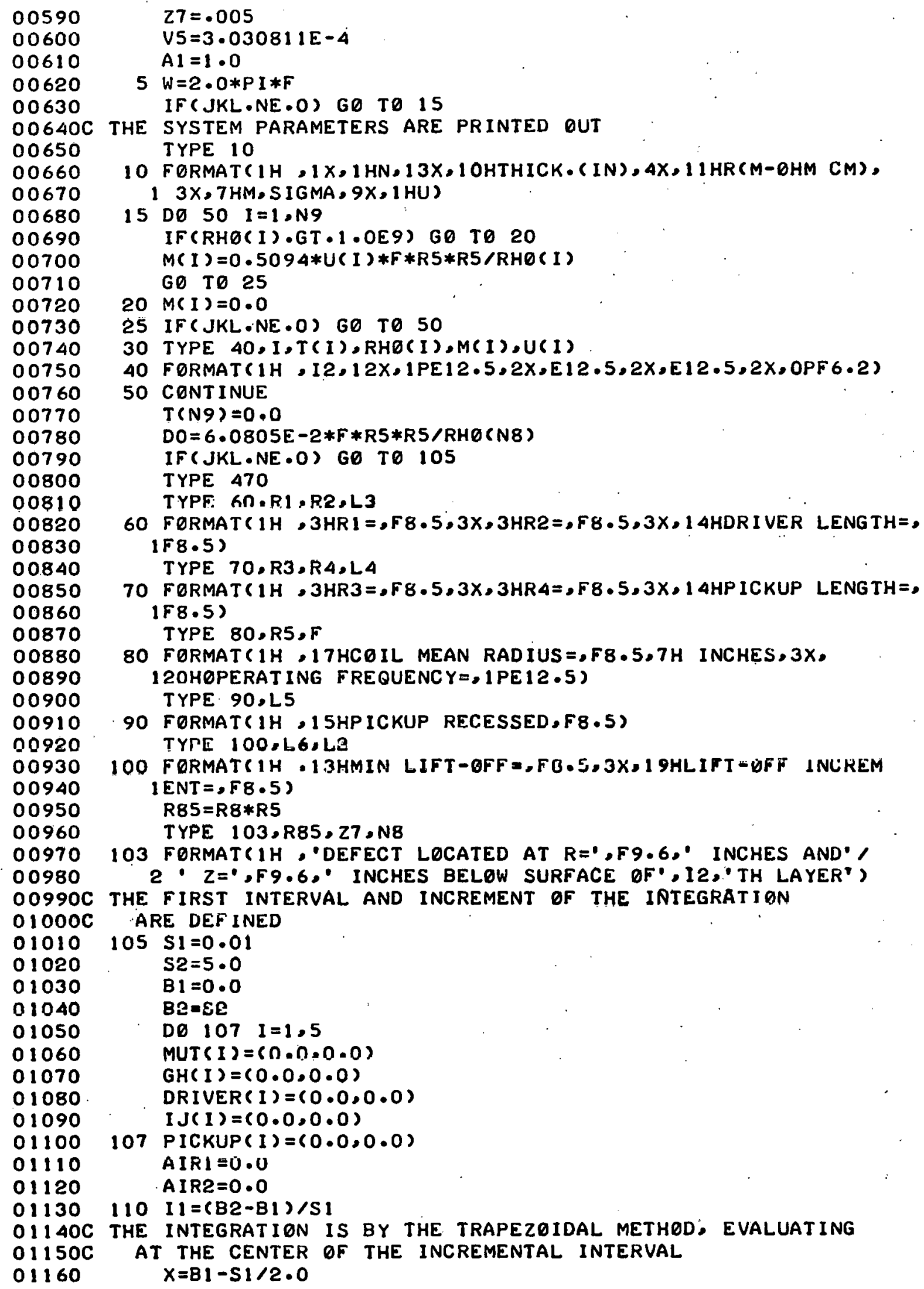


O $1170 \mathrm{C}$ THE INTEGRATION BEGINS HERE

01180

01190

01200

01210

01220

01230

01240

01250

01260

01270

01280

01290

01300

01310

01320

01330

01340

01350

01360

01370

01380

01390

01400

01410

01420

01430

01440

01450

01460

01470

01480

01490

01500

01510

01520

01530

$01540 C$

01550

01560

01570

01580

01590

01600

01610

01620

01630

01640

01650

01660

01670

01680

01690

01700

01710

01720

01730

01740

DQ 390 IDX $=1$, II

$X=X+S 1$

TEST $=X * L 3$

IF (TEST.GT.20.0) GO TO 120

W $3=\operatorname{EXP}(-T E S T)$

GD TO 130

$120 \quad W 3=0.0$

$130 W 8=1 \cdot 0-W 3$

TEST $=X * L 4$

IF(TEST.GT.20.0) GO TO 140

$W 4=\operatorname{EXP}(-T E S T)$

GO TO 150

$140 W 4=0.0$

150 W $9=1 \cdot 0-W 4$

TEST $=X * L 7$

IF(TEST.GT.20.0) GO TO 160

$W 7=\operatorname{EXP}(-\mathrm{TEST})$

GO TO 170

$160 W 7=0.0$

$170 W 5=\operatorname{EXP}(-X * L 5)$

$W O=1 \cdot 0-W 7 * W 4$

TEST $=X *$ L 6

IF(TEST.GT .20.0) GD TO 385

W $6=\operatorname{EXP}(-\mathrm{TEST})$

$\mathrm{Z}=\mathrm{X} * \mathrm{R} 2$

$Q 1=R 2$

CALL BESSEL (VAL2)

$Z=X * R 1$

$\theta 1=R 1$

CALL BESSEL (VALI)

$Z=X * R 4$

Q $1=R 4$

CALL BESSEL (VAL 4)

$\mathrm{Z}=\mathrm{X} * \mathrm{R} 3$

$Q 1=R 3$

CALL BESSEL (VAL3)

$R J 1=J 1(X * R)$ IS CALCULATED

$\mathrm{ZS}=\mathrm{X} * \mathrm{R} 8$

$I F(Z S \cdot G T \cdot 3 \cdot 0)$ GO TO 173

$Q 1 S=Z S * Z S$

$Q 2 S=((2 \cdot 1 E-11 * Q 1 S-5 \cdot 38 E-9) * 01 S+6 \cdot 757 E-7) * Q 1 S$

$3-5.42443 E-5$

$Q 2 S=((Q 2 S * Q 1 S+2 \cdot 60415 E-3) * Q 1 S-6 \cdot 25 E-2) * Q 1 S+0.5$

$\mathrm{RJ} 1=\mathrm{ZS} * Q 2 \mathrm{~S}$

GO TO 176

$173 \quad 03 S=(((-.14604057 / Z S+.27617679) / 2 S-.20210391)$

$4 / Z S+4.61835 E-3) / Z S$

$\theta 3 S=((Q 3 S+.14937) / Z S+4.68 E-6) / 2 S+.79788456$

$Q \Delta S=((s-.21262014 / 2 S+.19397232) / 2 S$

$5+6.022188 E-2) / 2 S-1.7222733 E-1) / 2 S$

$Q 4 S=((Q 4 S+5 \cdot 085 E-4) / 2 S+.37498836) / Z S-2 \cdot 35619449+Z S$

RJ $1=03 S * \operatorname{COS}(04 S) / S Q R T(Z S)$

$176 \mathrm{~S} 3=\mathrm{S} 1 *(\mathrm{VAL} 2-V A L 1) *(V A L 4-V A L 3)$

S $4=S 1 *(V A L 2-V A L 1) *(V A L 2-V A L 1)$

S5 $=S 1 *(V A L 4-V A L 3) *(V A L 4-V A L 3)$

$\mathrm{S} 6=\mathrm{S} 1 *(\mathrm{VAL2}-\mathrm{VAL} 1) * \mathrm{RJ} 1$

$\mathrm{S} 7=\mathrm{S} 1 *(\mathrm{VAL} 4-\mathrm{VAL} 3) * \mathrm{RJ} 1$ 


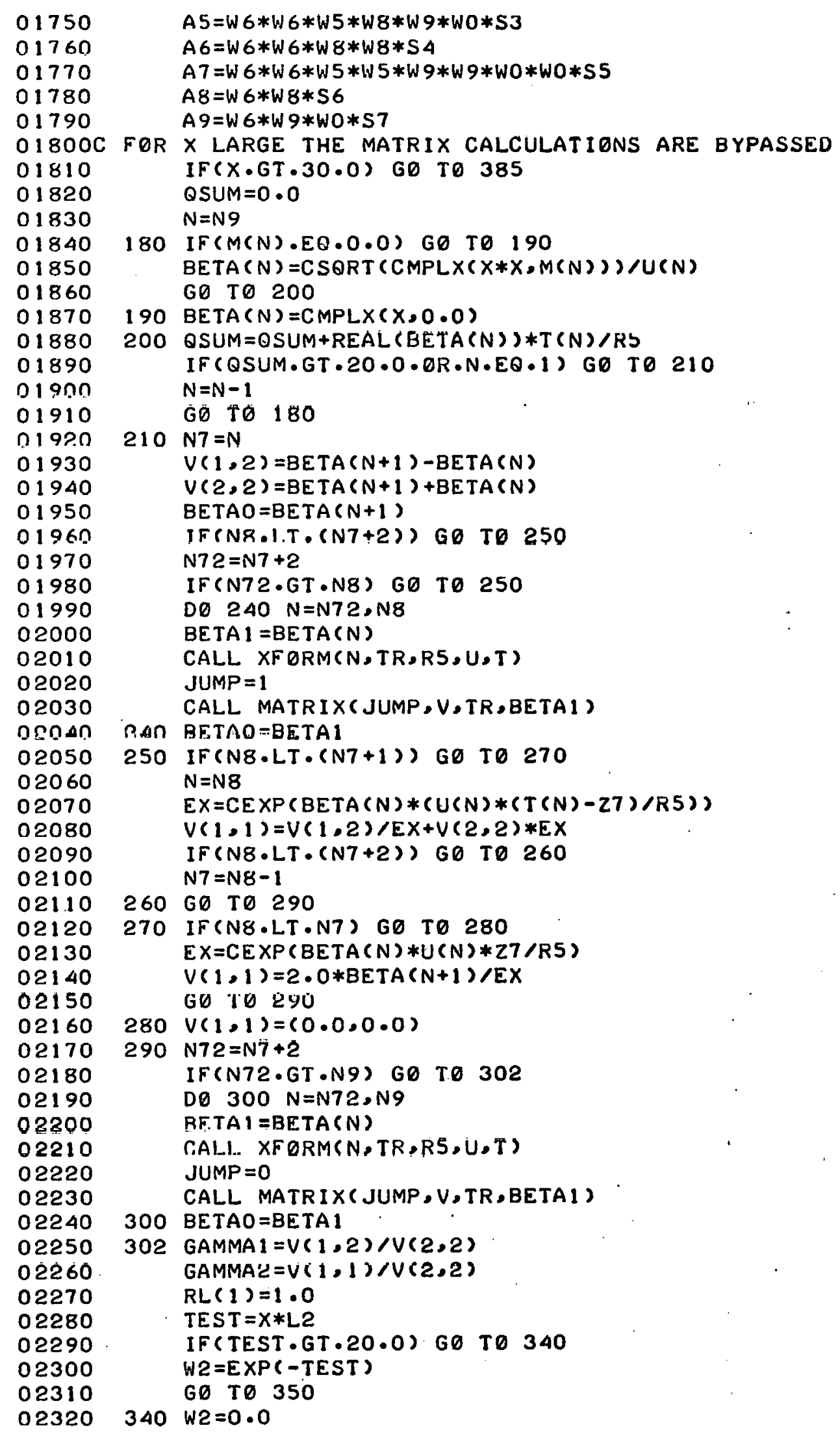




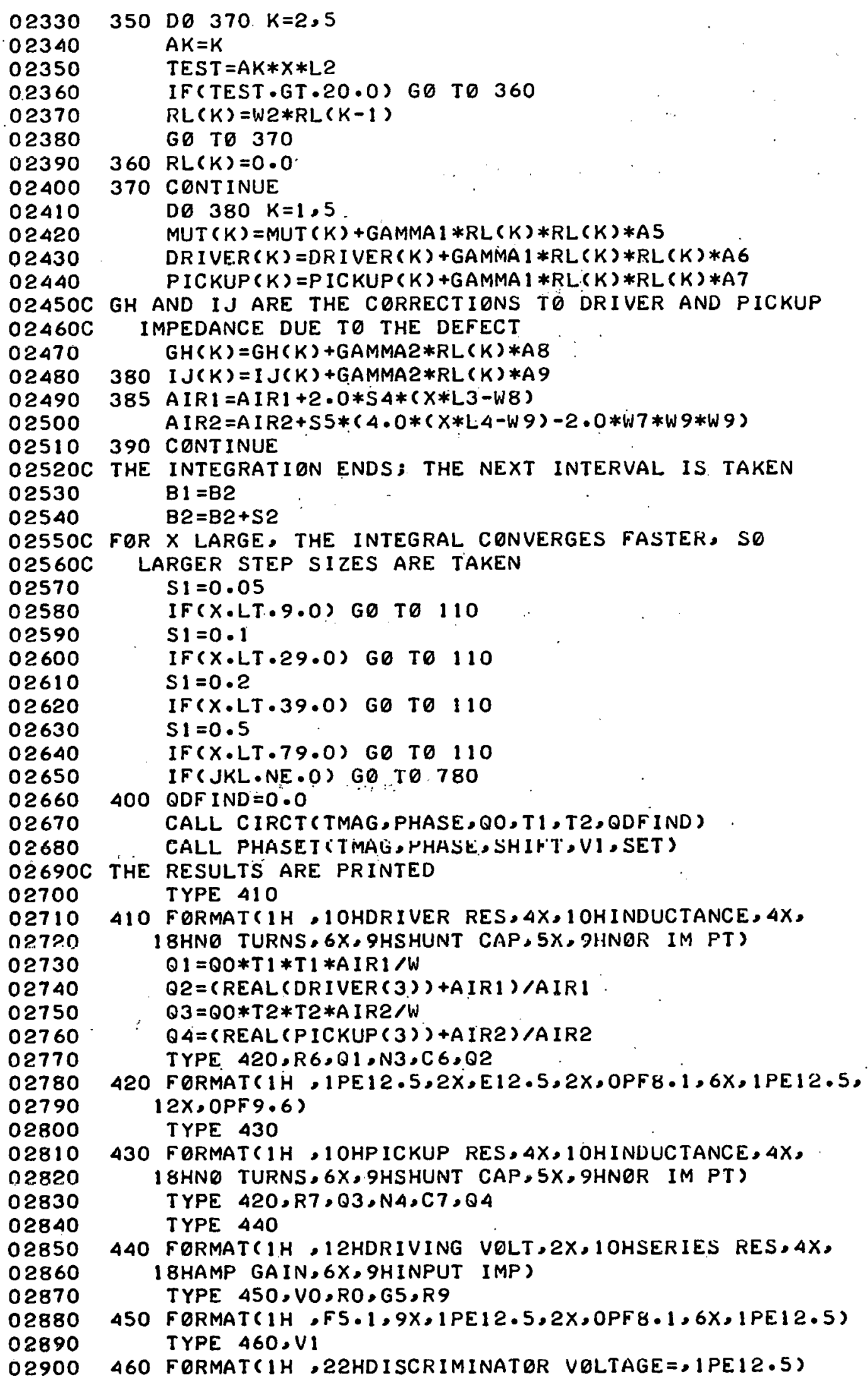

02330

02340

02350

0.2360

02370

02380

02390

02400

02410

02420

02430

02440

$02450 \mathrm{C}$

$02460 \mathrm{C}$

02470

02480

02490

02500

02510

$02520 \mathrm{C}$

02530

02540

$02550 \mathrm{C}$

$02560 \mathrm{C}$

02570

02580

02590

02600

02610

02620

02630

02640

02650

02660

02670

02680

$02690 \mathrm{C}$

02700

02710

ก27?

02730

02740

02750

02760

02770

02780

02790

02800

02810

02820

02830

02840

02850

02860

02870

02880

02890

02900

$350 \mathrm{DO} 370 . \mathrm{K}=2,5$

$A K=K$

TEST $=A K * X *$ L2

IF (TEST.GT.20.0) G0 TO 360

$R L(K)=W 2 * R L(K-1)$

GO TO 370

$360 R L(K)=0.0$.

370 CONTINUE

DO $380 K=1,5$.

$\operatorname{MUT}(K)=\operatorname{MUT}(K)+$ GAMMA $1 * R L(K) * R L(K) * A 5$

DR IVER $(K)=D R I V E R(K)+\operatorname{GAMMA} 1 * R L(K) * R L(K) * A 6$ $P I C K U P(K)=P I C K U P(K)+G A M M A I * R L(K) * R L(K) * A 7$

GH AND IJ ARE THE CORRECTIONS TO DRIVER AND PICKUP

IMPEDANCE DUE TO THE DEFECT

$\mathrm{GH}(K)=\mathrm{GH}(K)+\mathrm{GAMMA} 2 * \mathrm{RL}(K) * A 8$

$380 \quad I J(K)=I J(K)+G A M M A 2 * R L(K) * A 9$

385 AIRI $=A I R 1+2 \cdot 0 * S 4 *(X * L 3-W 8)$

A IR2 $=A$ I R2 $+S 5 *(4.0 *(X * L-4-W 9)-2.0 * W 7 * W 9 * W 9)$

390 CENTINUE

THE INTEGRATION ENDS; THE NEXT INTERVAL IS. TAKEN

$\mathrm{B} 1=\mathrm{B} 2$

$\mathrm{B2}=\mathrm{B} 2+\mathrm{S} 2$

FOR X LARGE, THE INTEGRAL CONVERGES FASTER, SO

LARGER STEP SIZES ARE TAKEN

$S I=0.05$

IF(X.LT.9.0) GO TO 110

$S I=0.1$

IF $(X \cdot L T \cdot 29.0)$ GO TO 110

$S 1=0.2$

IF (X.LT.39.0) GO TO 110

$S I=0.5$

IF $(X \cdot L T \cdot 79.0)$ GO TO 110

IF (JKL.NE・O) GO TO 780

400 ODF IND $=0.0$

CALL CIRCT(TMAG,PHASE,QO,T1,T2,QDFIND)

CALL PHASET (TMAG, PHASE, SHIHT, VI,SET)

THE RESULTS ARE PRINTED

TYPE 410

410 FORMAT ( $1 \mathrm{H}, 1$ OHDRIVER RES, $4 \mathrm{X}, 1$ OHINDUCTANCE, $4 \mathrm{X}$,

18 HNO TURNS, $6 \mathrm{X}, 9 \mathrm{HSHUNT}$ CAP, 5X, 9HNOR IM PT)

$Q 1=00 * T 1 * T 1 * A I R 1 / W$

$Q 2=(R E A L(D R I V E R(3))+A I R 1) / A I R I$

$03=00 * T 2 * T 2 * A I R 2 / W$

$Q 4=(R E A L(P I C K U P(3))+A I R 2) / A I R 2$

TYPE $420, R 6, Q 1, N 3, C 6,02$

420 FORMAT 1 H , 1PE $12.5,2 X, E 12.5,2 X, 0 P F 8,1,6 X, 1 P E 12.5$,

12X,OPF9.6)

TYPE 430

430 FORMAT $(1 \mathrm{H}, 1$ OHP ICKUP RES, $4 \mathrm{X}, 1$ OHINDUCTANCE, $4 \mathrm{X}$,

18 HNO TURNS, $6 X, 9 H S H U N T$ CAP, $5 X, 9 H N O R$ IM PT)

TYPE $420, \mathrm{R7}, \mathrm{Q3}, \mathrm{NA}, \mathrm{C7}, \mathrm{Q4}$

TYPE 440

440 FORMAT $1 \mathrm{H}, 12 \mathrm{LDR}$ IVING VOLT, $2 \mathrm{X}, 1$ OHSERIES RES, $4 \mathrm{X}$,

(8HAMP GAIN, 6X,9HINPUT IMP)

TYPE $450, V O, R O, G 5, R 9$

450 FORMAT (1H,F5.1,9X,1PE12.5,2X,OPF $8.1,6 \mathrm{X}, 1 \mathrm{PE} 12.5)$ TYPE $460, \mathrm{~V} 1$

460 FORMAT (1H, 22HDISCRIMINATBR VOLTAGE=, 1PE12.5) 


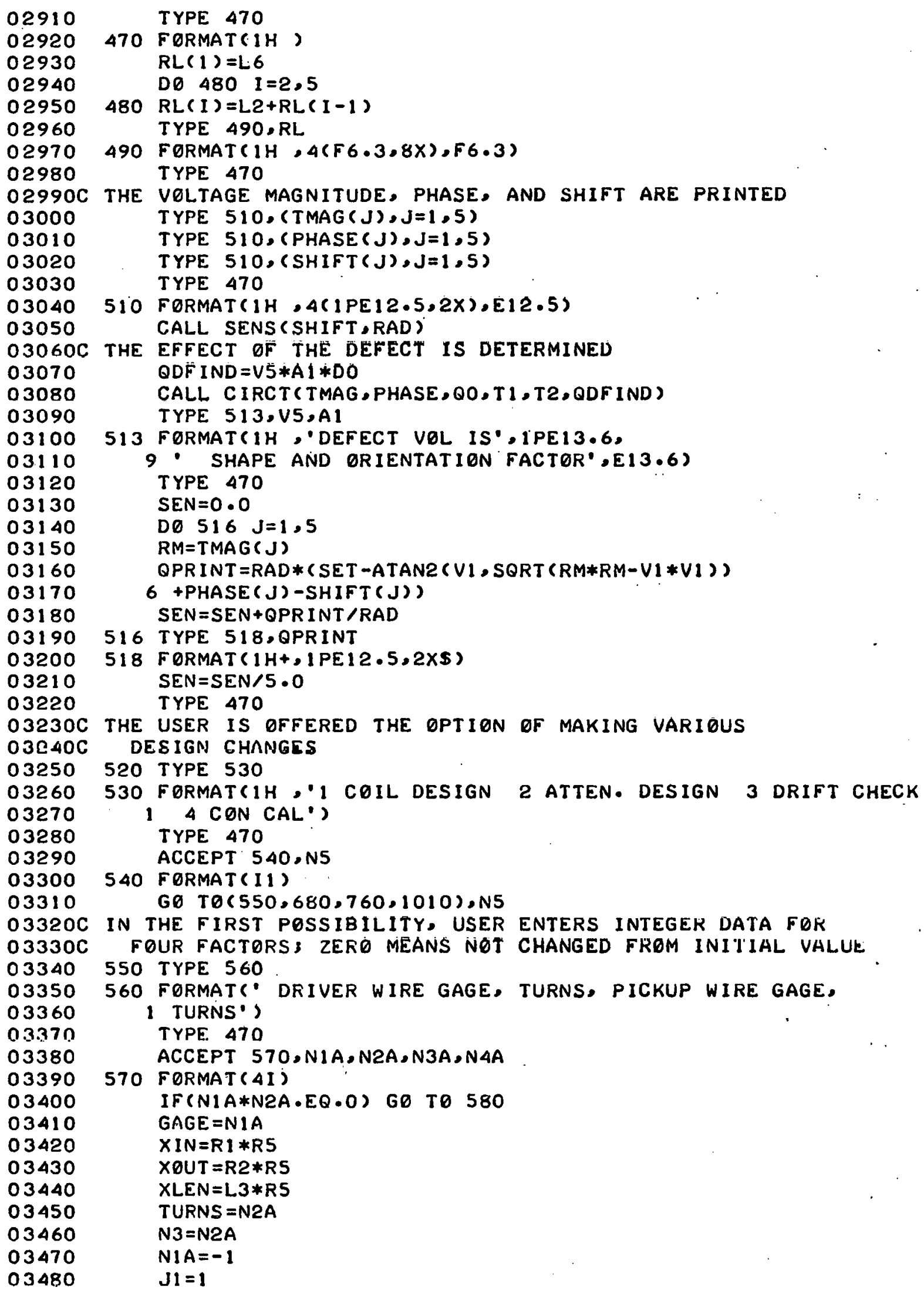




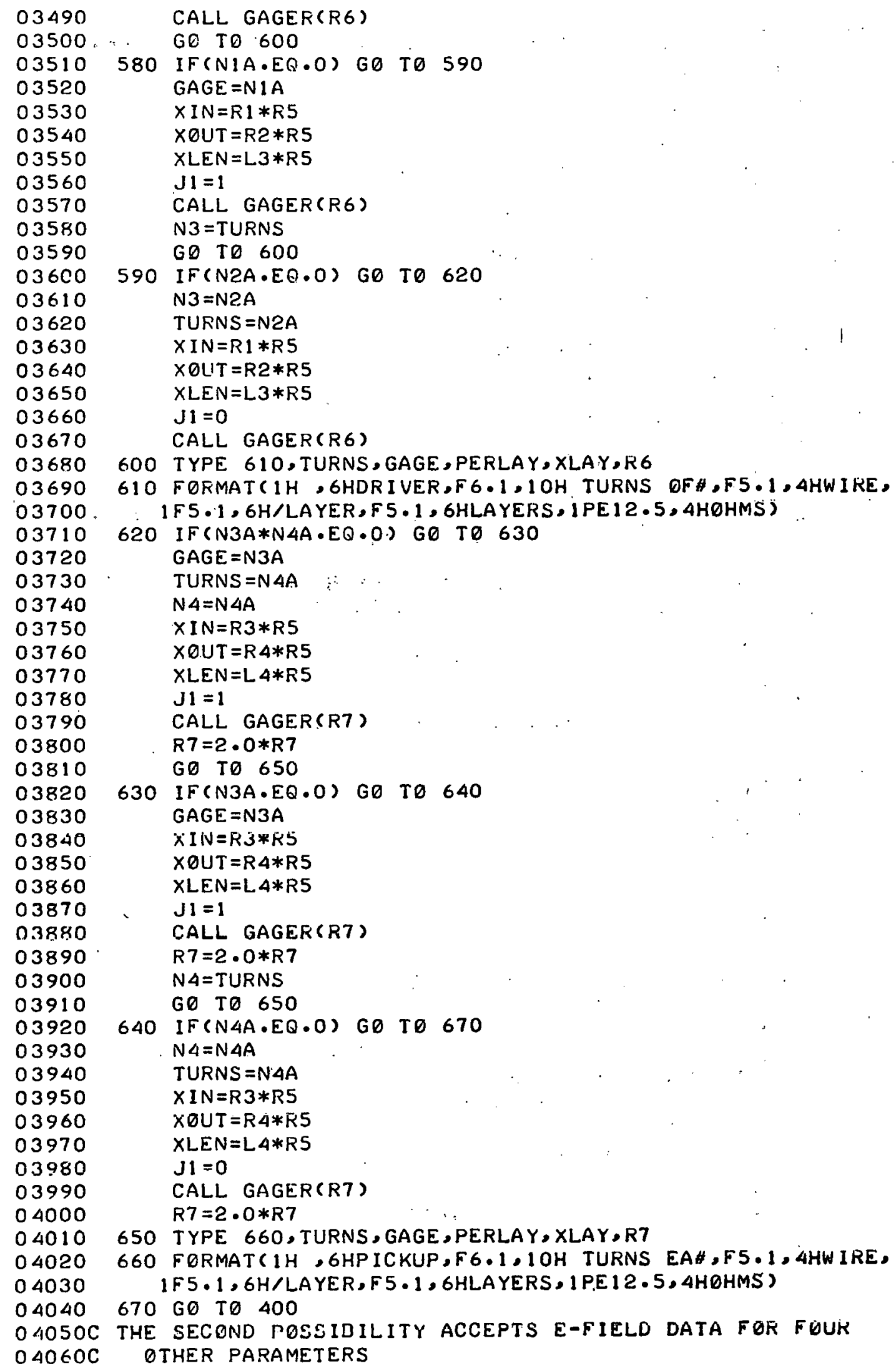




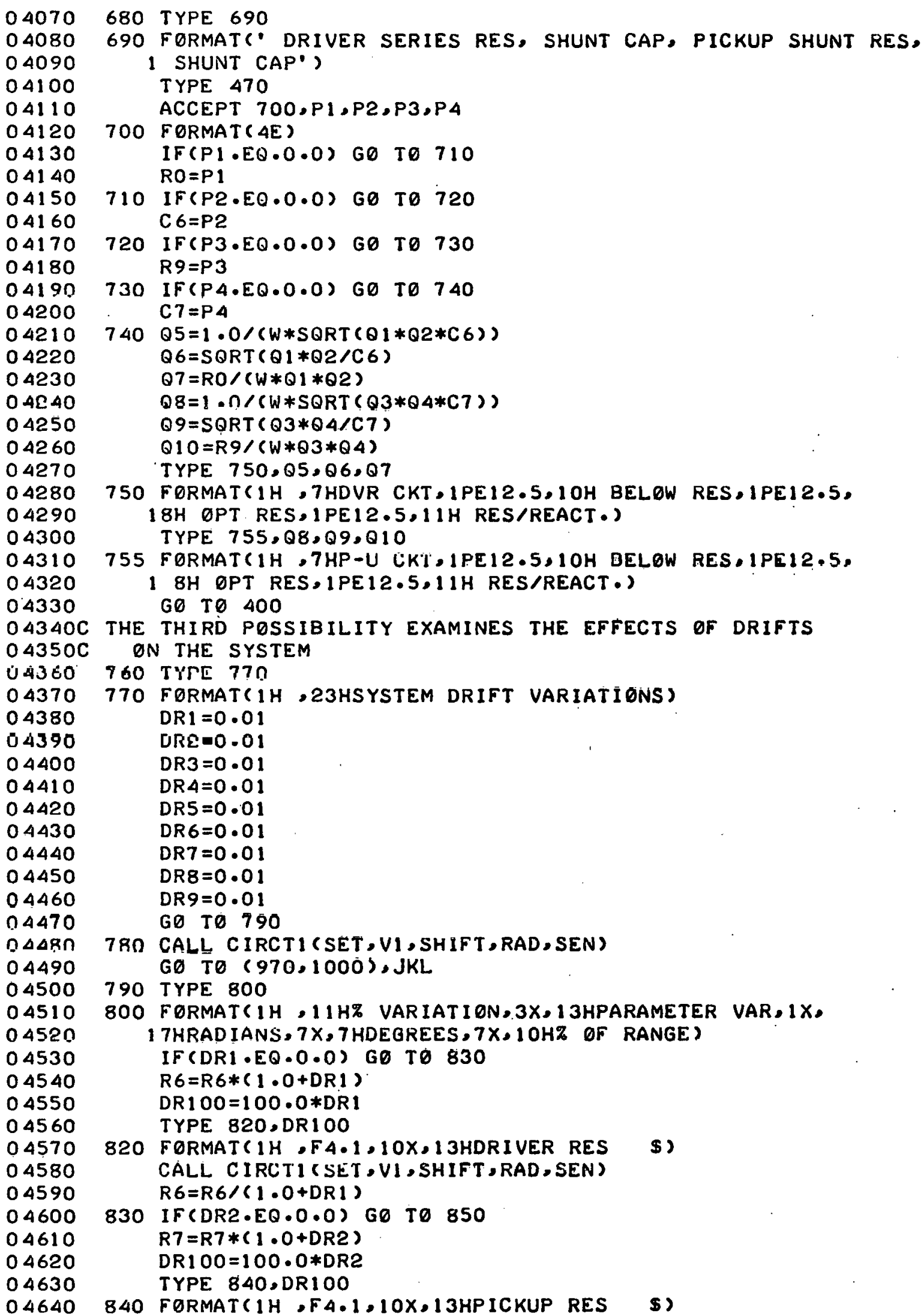




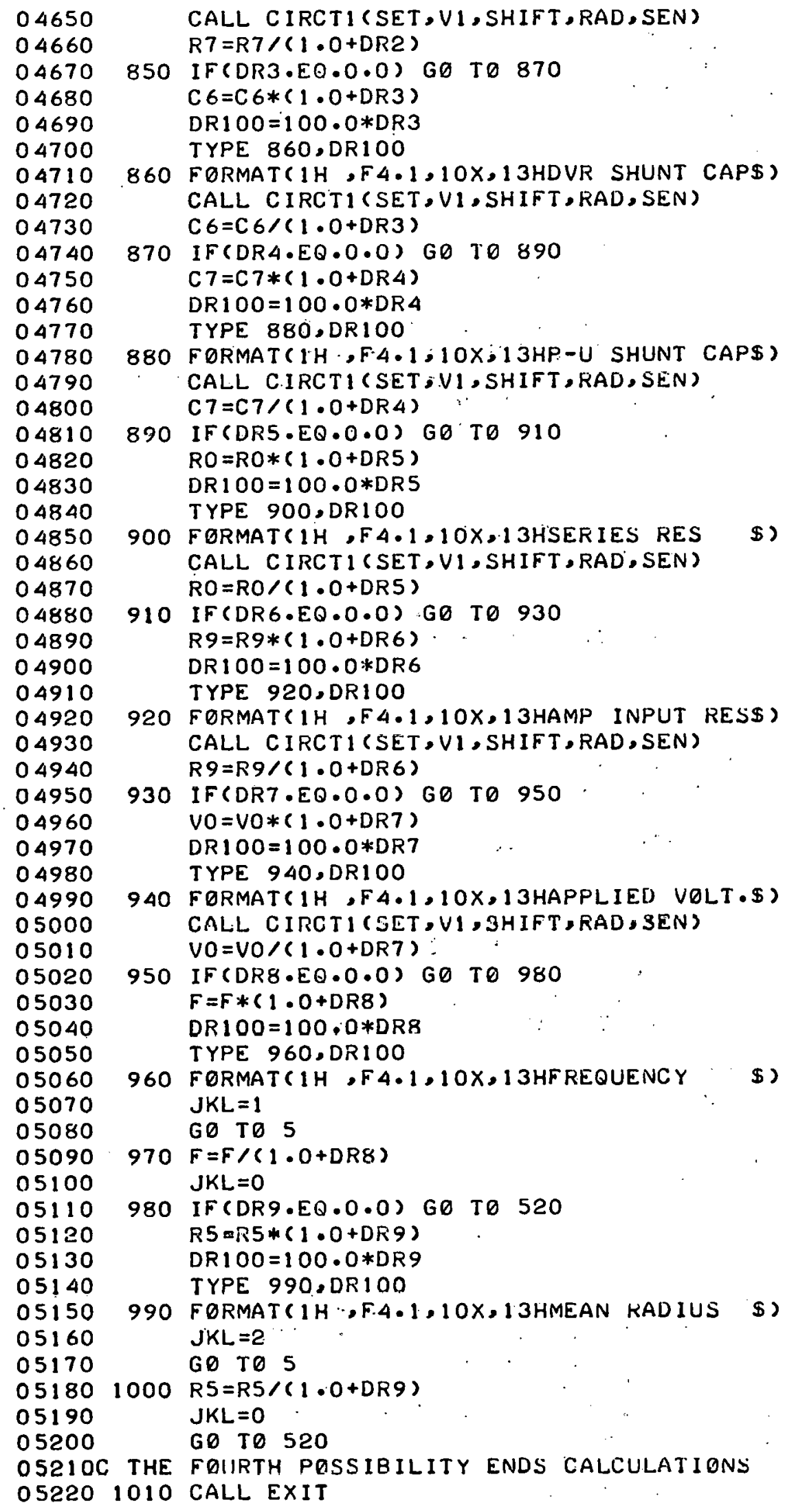




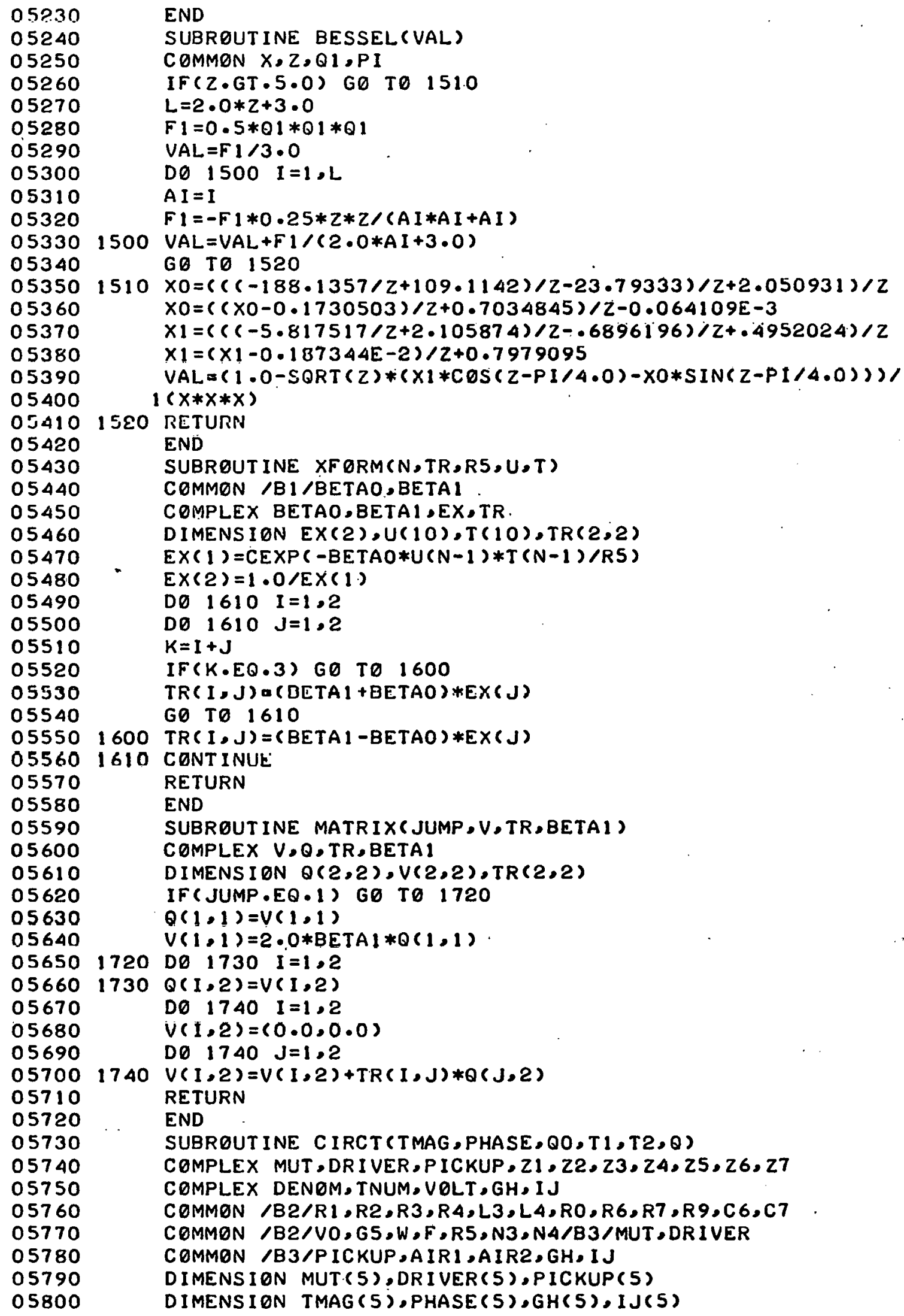




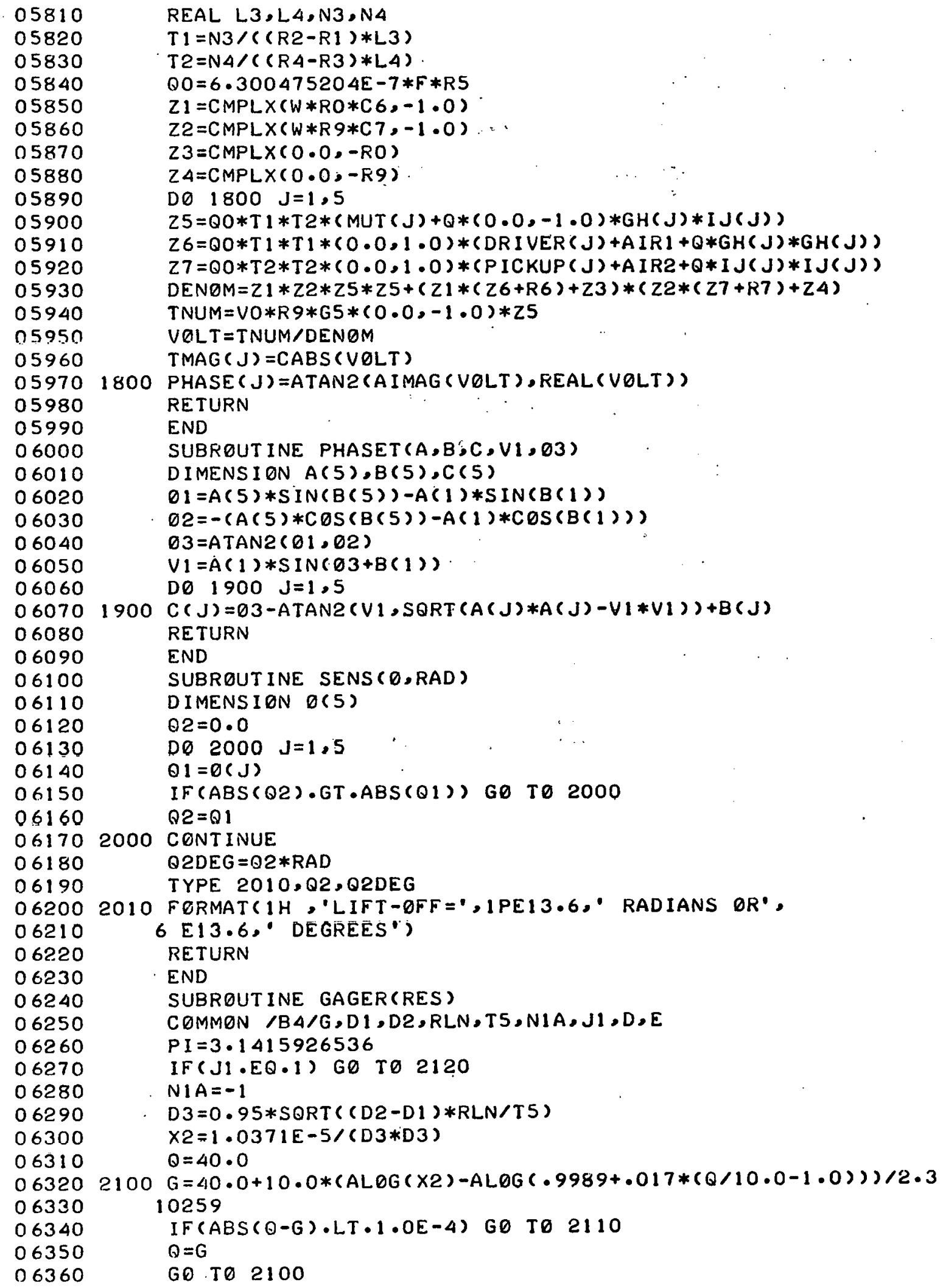




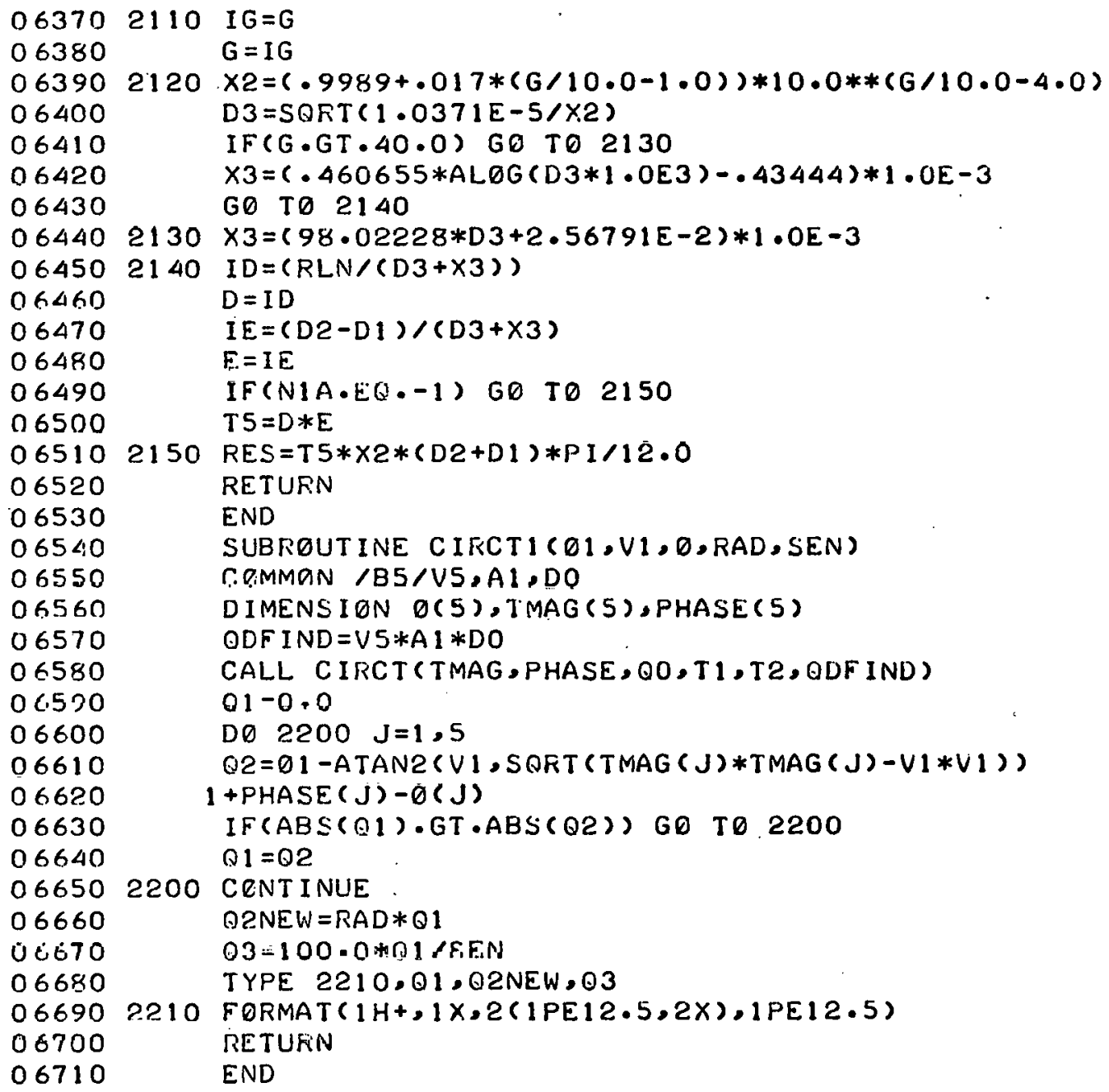


The theoretical analysis and computer programs to study eddycurrent problems using reflection type coils are given in this report. The results of these analyses will agree quite well with experimental results, with errors on the order of $1 \%$ when the coils are large enough to be accurately fabricated. In general, the conductivity and thickness calculations are more accurate than the defect calculations. These programs allow highly accurate, complete, and rapid design of optimum solution to eddy-current problems without the necessity of fabricating standards or making experimental measurements and avoid expensive trial-and-error approaches that have less than optimum results.

\section{ACKNOWLEDGMENTS}

The authors would like to express their appreciation to W. E. Deeds, R. B. Hofstra, and R. W. McClung for their assistance in editing this report and Brenda Jeffers for preparing the final manuscript. 
THIS PAGE

\section{WAS INTENTIONALLY LEFT BLANK}




\title{
INTERNAL DISTRIBUTION
}

(140 copies)

\author{
(3) Central Research Library \\ ORNL - Y-12 Technical Library: \\ Document Reference Section \\ (10) Laboratory Records Department \\ Laboratory Records, ORNL. RC \\ ORNL Patent Office \\ G. M. Adamson, Jr. \\ G. W. Clark \\ J. E. Coulter $(Y-12)$ \\ F. L. Culler \\ J. E. Cunningham \\ C. V. Dodd \\ (100) \\ J. H Frye, Jr. \\ J. W. Garber $(Y-12)$ \\ W. H. Hall (K-25)
}

(3) M. R. Hill

P. J. Long (Y-12)

D. L. Mason (Y-12)

R. W. McClung

F. D. Mundt $(Y-12)$

P. Patriarca

W. D. Ross $(Y-12)$

H. C. Schweinler

W. A. Simpson

G. M. Slaughter

J. H. Smith $(\mathrm{K}-25)$

D. B. Trauger

J. R. Weir, Jr.

EXTERNAL DISTRIBUTION

(51 copies)

AEC, DIVISION OF REACTOR DEVELOPMENT AND TECHNOLOGY, Washington, DC 20545

J. M. Simmons

AEC, SITE REPRESENTATIVES, Oak Ridge National Laboratory, P. O. Box X, Oak Ridge, TN 37830

D. F. Cope

C. L. Matthews

AEROJET NUCLEAR CORP., P. O. BOx 1845, Idaho Falls, ID 83401

F. L. Ciéslridge, AKA-3

AIR FORCE KELLY AIR FORCE BASE,' Kelly Air Force Base, TX 78241

Bernard Boisvert, SAAMA/MMEW

AIR FORCE KIRTLAND AIR FORCE BASE, Kirtland Air Force Base; NM: 87117

C. E. Baum

AIR FORCE MATERIALS IAABORATORY, Wright-Patterson Air Force Base, OH 45433

R. R. Rowland

AIR FORCE ROBBINS AIR FORCE BASE, Robbins Air Force Base, GA 31093

R. W. Bailey, Jr., WRAMA/MMETM 
ARGONNE NATIONAL LABORATORY, 9700 Cass Avenue, Argonne, IL 60439

Harold Berger

C. J. Renken

ARMY EDGEWOOD ARSENAL, Edgewood Arsenal, MD 21010

Ronald Frailer, Physical Laboratory Branch, Inspection Operations Division

ARMY MATERIALS AND MECHANICS RESEARCH CENTER, Watertown, MA 02172

R. C. Grubinskas

C. P. Merhib, Nondestructive Information Analysis Center

ARMY REDSTONE ARSENAL, Redstone Arsenal, AL 35809

W. B. Treplett, AMSMI-QLC, BIdg. 4500

ATOMIC ENERGY OF CANADA, LTD., Chalk RIver, Ontario, Canada

J. W. Hilborn

BATTELLE MEMORIAL INSTITUTE, $505 \mathrm{King}$ Avenue, Columbus, OH 43201

J. H. Flora

BMI-PACIFIC NORTHWEST LABORATORY, P. O. BOX 999, Richland, WA 99352

D. L. Lessor

H. I. LLUty

DOW C.HFMICAI COMPANY, P. O. Box 888, Golden, co 80401

Dave Chamberlain, Nondestructive Testing Depurtment

f. D. Lassahn

E. I. DU PONT DE NEMOURS COMPANY, Savannah River Laboratory, Aiken, SC 298ิดา.

Dan Clayton

GENERAL ELECTRIC, 175 Cortner Ave., San Jose, CA 95125

D. L. Fischer, M/C 164

GENERAi ELL'C'IIIC, Ruite T-75, Maildrop E-45, Evendale, OH 45̋215.

R. F. Feldman

HANFORD ENGINEERING DEVELOPMENT LABORATORY, P. 0. BOX 1970, Richland, WA 99352

R. L. Brown, Jr.

C. B. Shaw 
INSTITUTE OF NUCLEAR ENERGY RESEARCH, P. O. Box 3, Lung-Tan, Taiwan, ... Republic of China

Chwen Fu Huang

KNOLLS ATOMIC POWER LABORATORY, P. O. BOX 1072, Schenectady, NY 12301 Don Gavin

LAWRENCE LIVERMORE LABORATORY, P: O. BOX 808, Livermore, CA 94550

J. W. Sully

LOCKHEED MISSILES AND SPACE COMPANY, P. 0. Box 504, Sunnyvale, CA 94088

A. J. Glispin, Department 84-35

LOS ALAMOS SCIENTIFIC LABORATORY, P. O. Box 1663, Los Alamos, NM 87544

D. Elliott

G. C. MARSHALL SPACE FLIGHT CENTER, Marshall Center, AL 35812

L. H. Burdette, MSFC-S\&E-QUAL-QT

M. C. McIlwain, R-QUAL-ARA

F. M. Saxton, S\&E-ASTR-IR

NASA-LEWIS RESEARCH CENTER, 21000 Brookpark Road, Cleveland, OH 44135

Alex Vary

NAVAL AIR DEVELOPMENT CENTER, Johnsville, Warminster, PA 18974

John Carlyle, MAMM-14

NAVAT, SHIP ENGINEERING CENTER, Hyattsville, MD 20782

John Gleim

SANDIA CORPORATION, Division 7361, P. O. Box 5800, Albuquerque, NM 87115

R. A. Baker

D. W. Ballard

SANDIA CORPORATION, P. O. Box 969, Livermore, CA 94550

Dennis Rathbun

SOUTHWEST RESEARCH INSTITUTE, P. O. Drawer 28510, San Antonio, TX 78228

B. R. Wilson

UNITED KINGDOM ATOMIC ENERGY RESEARCH ESTABLISHMENT, Didcot, Berkshire, England

R. S. Sharpe 
UNIVERSITY OF MICHIGAN, 2317 East Engineering Bldg., Ann Arbor, MI 48104

J. R. Frederick, Department of Electrical Engineering

UNIVERSITY OF MISSOURI, Columbia, MO 65201

D. I. Waidelich, Department of Electrical Engineering

UNIVERSITY OF TENNESSEE, KnOxville, TN 37916

C. C. Cheng, Department of Physics

W. E. Deeds, Department of Physics

J. F. Pierce, Department of Electrical Engineering

J. O. Thompson, Department of Physics

WESTINGHOUSE RESEARCH AND DEVELOPMENT, Beulah Road, Pittsburgh, PA 15235

J. K. Whitie

AEC OPERATIONS OFFICE, P. O. Box E, Oak Ridge, TN 37830

Research and Technical Support Division

AEC TECHNICAL INFORMATION CENTER, OFFICE OF INFORMATION, $P$. O. BOX 62 , Oak Ridge, TN 37830

(2) Manager 